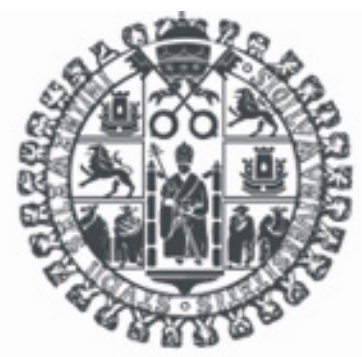 \\ VNiVERSIDAD \\ D SALAMANCA \\ FACVLTAD $\mathrm{B}$ MEDICINA
}

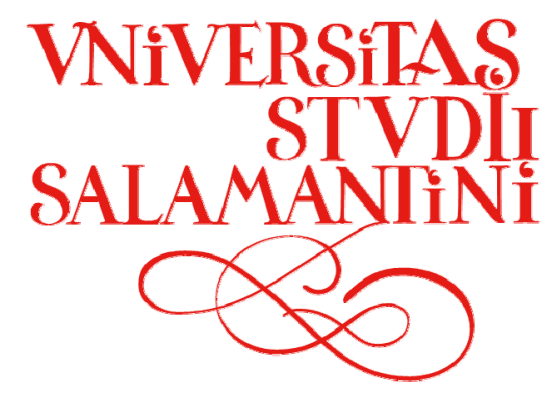




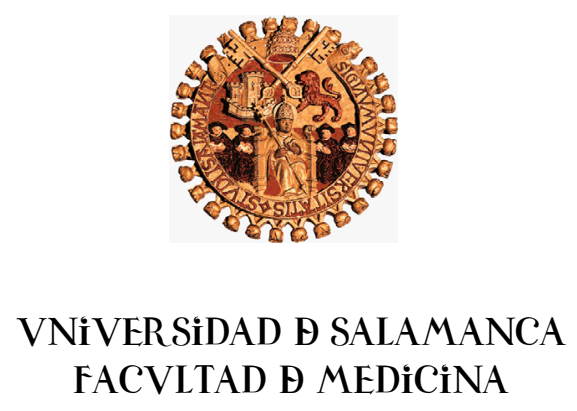

\section{SINTOMATOLOGÍA ANSIOSO - DEPRESIVA Y SU RELACIÓN CON LA TEMPORALIDAD}

\section{TESİS DOCT@RAL}

Salamanca, 2009 
BPARTAMENT@ Đ PSíQVİATRía Y PSiCOLOGía MÉDiCA, MEDiCiNA LEGAL E HiSTOR IA B LA CiENCIA.

$$
\text { ÁREA Đ PSiQVíATRÍA }
$$

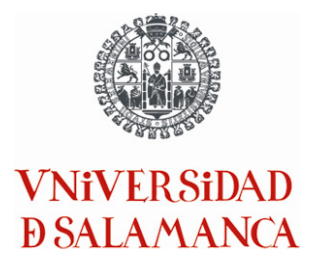

\section{SINTOMATOLOGÍA ANSIOSO DEPRESIVA Y SU RELACIÓN CON LA TEMPORALIDAD.}


GINÉS LLORCA RAMÓN, CATEDRÁTICO DE PSIQUIATRÍA, Ma ÁNGELES DÍEZ SÁNCHEZ, PROFESORA TITULAR DE PSICOLOGÍA MÉDICA, PROFESORES DEL ÁREA DE PSIQUIATRÍA DEL DEPARTAMENTO DE PSIQUIATRÍA Y PSICOLOGÍA MÉDICA, MEDICINA LEGAL E HISTORIA DE LA CIENCIA, Y Ma DEL MAR GONZÁLEZ-TABLAS SASTRE， PROFESORA TITULAR DE ESTADÍSTICA INFERENCIAL APLICADA A LA PSICOLOGÍA, DEL ÁREA DE METODOLOGÍA DEL DEPARTAMENTO DE PSICOLOGÍA BÁSICA, PSICOBIOLOGÍA Y METODOLOGÍA DE LAS CIENCIAS DEL COMPORTAMIENTO DE LA UNIVERSIDAD DE SALAMANCA,

\section{CERTIFICAN:}

Que el presente trabajo de Tesis Doctoral titulado: SINTOMATOLOGÍA ANSIOSO-DEPRESIVA Y SU RELACIÓN CON LA TEMPORALIDAD, ha sido realizado bajo nuestra dirección por D. David Jesús González Gutiérrez, licenciado en Psicología, reuniendo, a nuestro criterio, las condiciones metodológicas y de originalidad requeridas para poder optar al grado de Doctor.

Y para que conste a todos los efectos oportunos, firmamos el presente certificado en Salamanca a 15 de octubre de 2009.

Fdo:

Ginés Llorca Ramón
Fdo:

Ma Ángeles Díez Sánchez
Fdo:

Ma del Mar González-Tablas Sastre 
A mis padres

A Raquel 
Él dijo que, cuando saliese de la cárcel, iría a Porto, al mercado de Belhão, a comprarle un saquito de habas de colores de esas que llaman maravillas.

Ella dijo que le regalaría un saquito con horas, que sabía de un feriante de Valença que vendia horas de tiempo perdido.

Manuel Rivas, El Lápiz del Carpintero. 
Corría el mes de septiembre del año 1996 cuando empecé mis estudios de psicología. La segunda persona (del personal docente) con la que hablé en la facultad fue la Doctora Dña. Ma Ángeles Díez Sánchez. Nunca nadie me ha influido tanto como ella.

Es difícil imaginar un grado tan alto de admiración, respeto y cariño y, por supuesto, es mucho más difícil describirlo. Su capacidad de entrega en lo que ella cree, su profesionalidad, sus profundos conocimientos sobre psicología y sobre psicología clínica. Su amor por la docencia, su sentido de la responsabilidad, su capacidad para exigir y motivar, siempre desde el profundo respeto, la convierten en un ejemplo a seguir. Sin duda esta forma de ser es lo que he pretendido aprender durante estos años juntos y, esta tesis doctoral, es sólo una consecuencia de ello.

Si este trabajo ve la luz, sin duda es debido al constante apoyo y estimulo recibido por el Profesor Doctor D. Ginés Llorca. Fue él quien despertó en mí el interés por la temporalidad. Pasar tiempo junto a su sabiduría es una experiencia llena de recompensas, de retos intelectuales, de búsqueda permanente de respuestas a preguntas planteadas. Me siento afortunado por semejante privilegio.

La Doctora Dña. Ma Mar González-Tablas, también fue profesora durante mi licenciatura, muchos años. Por fin aprendí a amar una parte de sus conocimientos. Aprendí de su apego por la vida, comprendí por qué me exigía y ahora sólo siento gratitud. Todos hemos oído alguna vez que los números cantan, solo una mente como la de Marola, interpreta sinfonías.

A mis amigos: su humor, su compañía, su consejo, sus cenas...han conseguido paliar la soledad del investigador y los momentos cercanos a la zozobra. Zaida, Alberto, Paloma, Diego, Violeta, Pilar...gracias por permitirme cada día compartir experiencias y tiempo con vosotros. 
Es curioso cómo los sentimientos también alteran nuestra percepción del paso del tiempo y de la distancia: Raquel, poder estar a 10 centímetros de ti, me coloca a 10 años luz del mañana. Gracias por el sacrificio, por el cariño, por el apoyo, por creer en mí, por tu paciencia conmigo, por la cantidad de kilómetros recorridos buscando alargar los fines de semana...

Por supuesto, si mis padres no me hubieran marcado el camino a seguir yo no habría llegado aquí. Los principios y los valores marcaron el rumbo. Su naturaleza me dice quién soy.

A mi hermana Patricia, que nunca ha permitido que la distancia nos separe. Gracias por escucharme, por comprenderme, por admirarme. Yo también te admiro. Tu constancia, tu entrega y fidelidad y tu profesionalidad a lo largo de estos años son un gran ejemplo a seguir.

Por último, pero no menos importante, agradezco a todos los pacientes que voluntariamente participaron en este estudio, y agradezco a todas las personas del grupo de control que me ayudaron con el muestreo.

Julio, me hubiera gustado que vieras esto.

Compartir tiempo con todos y cada uno de vosotros me ha convertido en lo que soy y en quién soy. Gracias. 
Si de verdad quieres crecer y no envejecer nunca vayas deprisa ni tampoco lento. $\mathcal{E}$ [ secreto es ir a la inversa del tiempo pero nunca deprisa ni tampoco lento Sólo hay que ir a la velocidad del tiempo para así comenzar a crecer y no envejecer. Canción popular. 


\section{ÍNDICE}

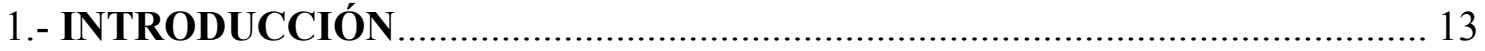

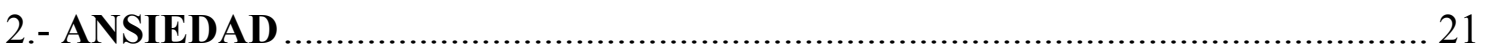

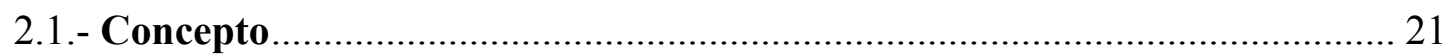

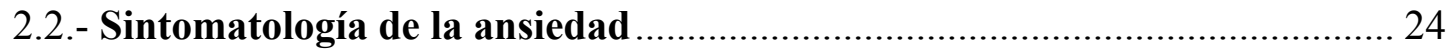

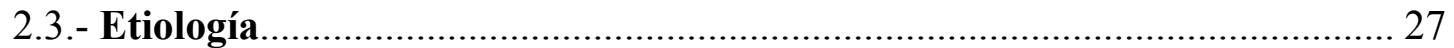

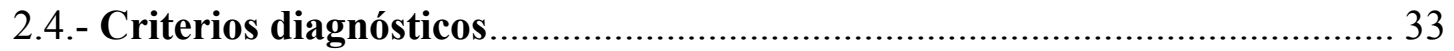

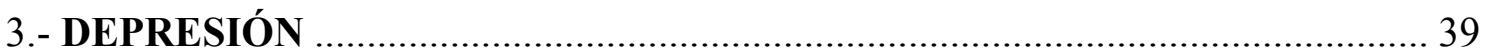

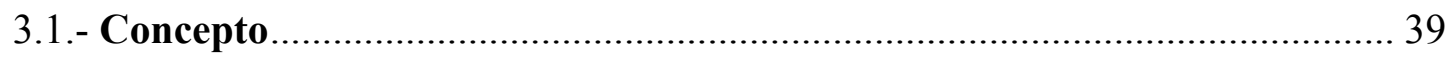

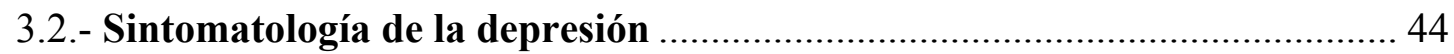

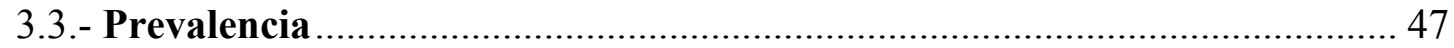

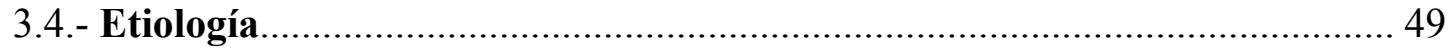

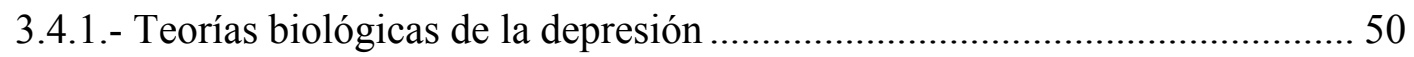

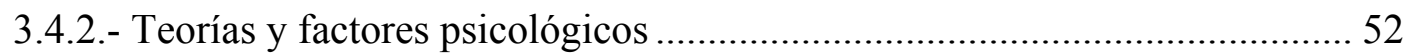

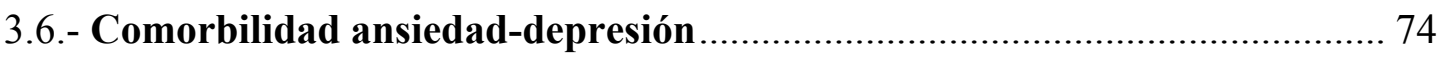

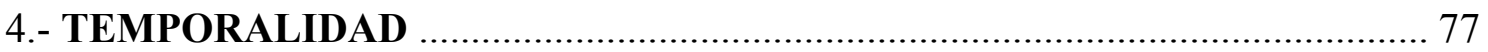

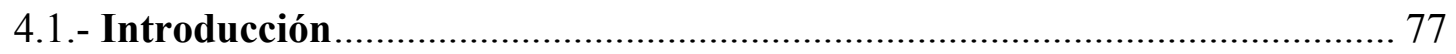

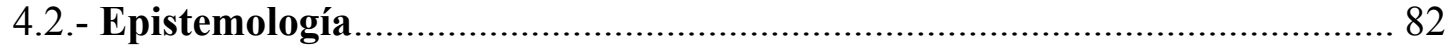

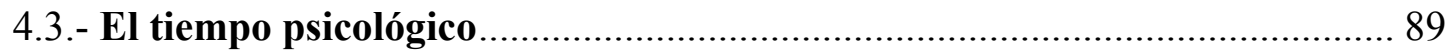

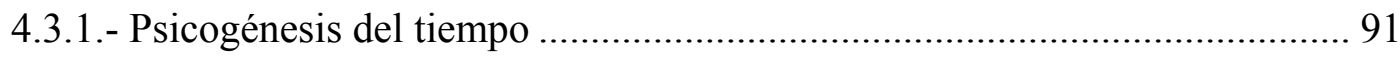

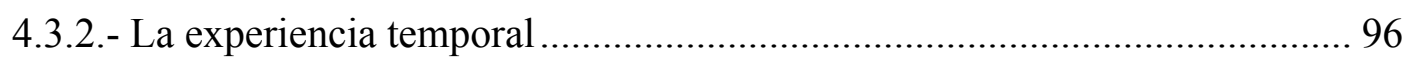

4.3.2.1.- La experiencia de la simultaneidad y de sucesión ............................... 96

4.3.2.2.- La experiencia de intervalos muy breves (el presente) ...................... 97

4.3.2.3.- La experiencia de intervalos más largos ............................................. 98

4.3.2.4.- La experiencia de perspectiva temporal u orientación temporal........ 100

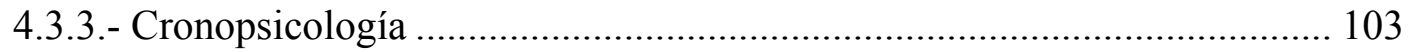

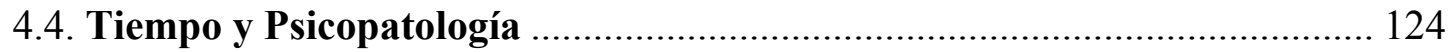




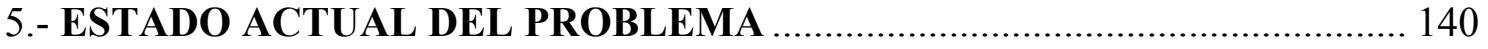

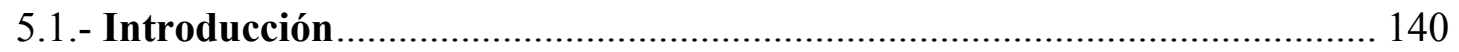

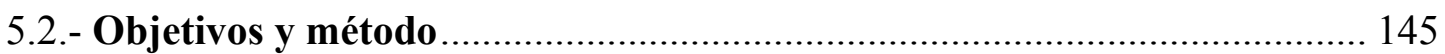

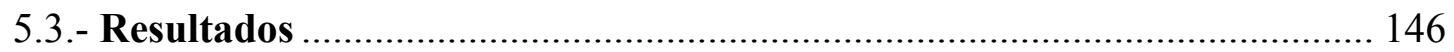

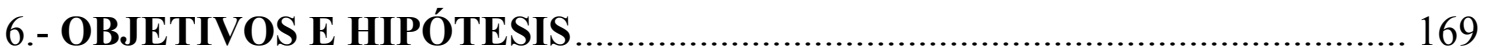

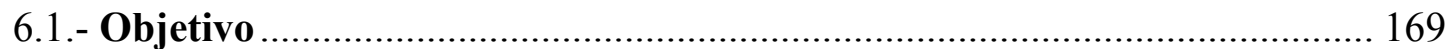

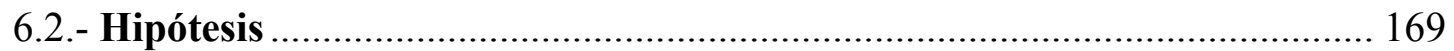

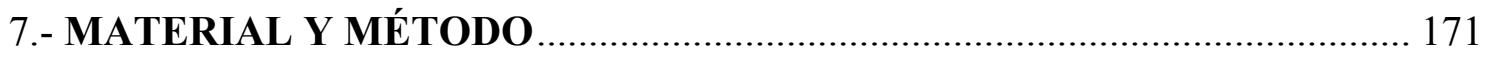

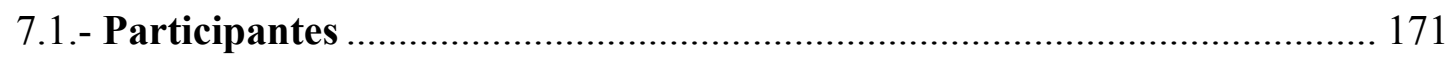

7.1.1. Criterios de inclusión del grupo de estudio ........................................... 171

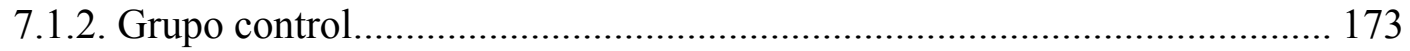

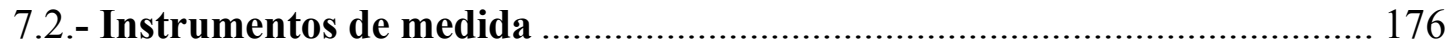

7.2.1. Descripción de los instrumentos de medida ........................................... 176

7.2.2. Pruebas de evaluación de la estimación del paso del tiempo ..................... 181

7.2.3. Descriptivos de los instrumentos ................................................................ 188

7.3. Diseño

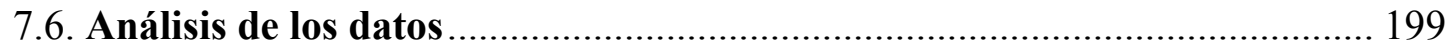

8.- RESULTADOS Y DISCUSIÓN.................................................................. 202

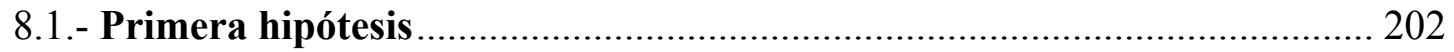

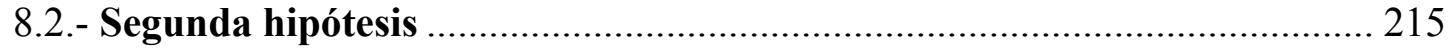

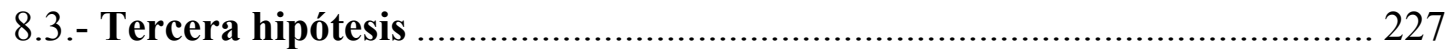

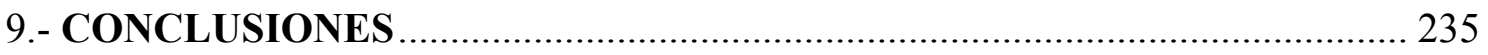

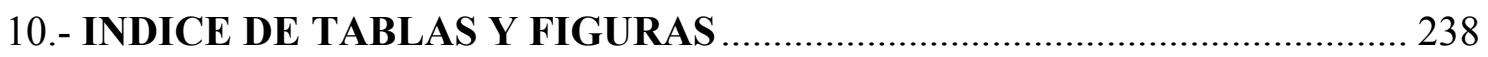

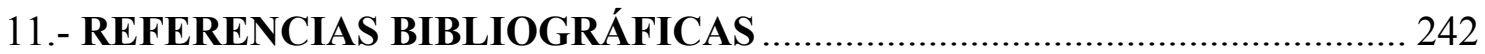


Entre el día y la noche hay un territorio inexplorado.

No es sol ni es sombra; es tiempo.

Octavio Paz 


\section{1.- INTRODUCCIÓN}

Desde muy antiguo, el tema del tiempo ha estado presente en las investigaciones y las preocupaciones de filósofos y científicos. El tiempo es una de las experiencias más universales y continuas de nuestras vidas, todas nuestras experiencias perceptivas, intelectuales y emocionales están relacionadas con el tiempo. Le sentimos pasar continuamente, pero no sabemos de dónde viene. Lo experimentamos continuamente, pero no sabemos cómo es, no podemos tocarlo, ni verlo, ni oírlo (Sánchez, 1999). La formación y el desarrollo de la personalidad ocurren en un espacio temporal, las características y regularidades que distinguen al ser humano en cada periodo de su vida están determinadas por las circunstancias socioculturales e históricas concretas en las que transcurre su existencia. El desarrollo psíquico ocurre como un proceso espontáneo, continuo en el tiempo, que implica el paso a nuevas formas de pensar, sentir y actuar. Es un proceso de cambio que conduce a que en cada periodo temporal se asimilen aspectos nuevos y se reestructuren actualizándose constantemente (Roca, 2004). Es decir, en cada persona hay mecanismos psicológicos y conductas idiosincrásicas que configuran su identidad, aunque lo del "genio y figura hasta la sepultura" no se sostiene, pues es sabido que la persona cambia a lo largo del tiempo hasta extremos imposibles de prever por las teorías psicológicas (McClelland, 1981; Heatherton \& Weinberger, 1994). En palabras de Pelechano (2000), "cuando se habla de cambio y permanencia, la referencia de estos dos conceptos debe hacerse de manera relativa y no absoluta. Esto es, algo cambia y no todo; y algo permanece, y no todo." (p. 667) 
Cuando el estudio del comportamiento humano se convirtió en ciencia de la experiencia consciente, el tiempo fue inevitablemente una de las primeras experiencias que se investigaron (Ornstein, 1977).

Escribía Mach en 1886: "Mucho más dificil que el de la sensación del espacio es el estudio de la sensación del tiempo. Algunas sensaciones aparecen unidas unas a otras sin sensación de espacio perceptible. Pero la sensación del tiempo acompaña a toda otra sensación y no puede ser completamente separada de ninguna”. (Mach véase Mach 1987, p. 217). Contrariamente al espacio, que al menos se deja abarcar mediante la manipulación, no es posible coger el tiempo y no se deja abordar más que por intermediarios, entre ellos el espacio (el desplazamiento de la aguja de un reloj, por ejemplo).

La sensibilidad de las personas al tiempo y a la duración de los acontecimientos ha sido de interés a los largo de la historia de la psicología y se ha investigado en muchos contextos diferentes. La revisión histórica que llevó a cabo Fraisse (1963) permitió la construcción de nuevos análisis sobre la experiencia temporal. Frankanhauser (1959), llevó a cabo un análisis de los determinantes cognitivos del tiempo. La obra de Fischer (1967) contiene discusiones sobre distintas concepciones del tiempo en la literatura, la biología, la religión, la psicología y la física, y sobre su medida. Los trabajos de Michon (1967) y Triesman (1963), permitieron una nueva experimentación psicológica en el análisis de la experiencia de intervalos de tiempo breve. Todo esto proporcionó a Ornstein (1969) la posibilidad de poder ordenar los diversos datos sobre la psicología del tiempo, integrar éstos en un nivel general y elaborar hipótesis sobre el mecanismo que subyace a la experiencia del tiempo, 
particularmente a su duración, integrándolo dentro de la investigación de la psicología cognitiva y del procesamiento de información. El aspecto fundamental que se investiga es, por tanto, la duración. Y se estudia por una razón fundamental: hay discrepancias entre el tiempo medido y el tiempo estimado.

Desde finales de los años 50 del siglo pasado, la medida del tiempo de percepción se utiliza como medio para apreciar la complejidad de las operaciones mentales en el tratamiento de la información que intervienen en ellas. Estas investigaciones, permiten demostrar que la estimación de la duración puede depender en gran medida de otros criterios distintos al de la velocidad, tales como, del espacio recorrido, de la cantidad de cambios producidos, de los esfuerzos realizados..., etc.

El trabajo de Fraisse sobre el tiempo se inscribe en la investigación de lo que él mismo denomina "conductas temporales," es decir, los diversos modos con los que el ser humano se adapta a las condiciones temporales de su existencia. Dentro de estas conductas temporales, distingue tres niveles de adaptación del organismo al tiempo:

1.- Condicionamiento al cambio. En este nivel estamos tratando con el "tiempo fisiológico", es decir, el basado en procesos biológicos comunes a animales y al ser humano. Es la interiorización de los ritmos externos, la que da lugar a reacciones de adaptación periódicas, tanto fisiológicas como comportamentales.

2.- Percepción del cambio. Este nivel está unido a la percepción de los caracteres fundamentales de los cambios, que son fundamentalmente dos, el orden de los estímulos y el intervalo que los separa. Es en este nivel desde donde el sujeto puede entender los fenómenos de “duración” y “sucesión." 
3.- Conocimiento (o dominio) de los cambios. Es el último nivel de adaptación que le permite al ser humano ir más allá de su experiencia inmediata, puesto que es capaz de "representarse los cambios", el sujeto adquiere un horizonte temporal, un pasado, un futuro, que relaciona con un presente, que adquiere así pleno significado (Fraisse, 1957/1982).

Desde la perspectiva del estudio del comportamiento humano, el estudio del tiempo se caracteriza por su dimensión interdisciplinar, ya que los campos de estudio son variados. La investigación sobre tiempo psicológico puede dividirse en dos grandes categorías:

A) La psicogénesis del tiempo, teniendo como referente principal a Piaget (1896 - 1980), quien lo enmarca dentro de su Modelo General de Desarrollo Cognitivo.

B) Percepción del tiempo. Refiriéndose aquí a la estimación del tiempo que hace el sujeto y que, a su vez, se orienta en dos campos específicos:

- Discrepancias entre el tiempo medido y el estimado (Fraisse, 1963).

- Dimensión temporal (pasado, presente o futuro) que es predominante en los sujetos.

El comportamiento humano depende en gran parte de los ritmos biológicos y la alteración de los mismos acarrea graves consecuencias sobre nuestro equilibrio psicológico. En los trastornos del estado de ánimo y en los trastornos de ansiedad, los ritmos biológicos (sobre todo el circadiano) suelen estar alterados y, además, las discrepancias entre el tiempo medido y el estimado tienden a acentuarse (Sánchez, 1999). 
Por otra parte, determinadas características de personalidad, como la procastination o "el dejar para mañana" intervienen en el modo de enfermar de los ansiosos y los depresivos, y en su organización temporal, tanto de sus ritmos biológicos, como de sus diferentes percepciones sobre el tiempo transcurrido (Flett, Blankstein \& Martin, 1995).

Los trastornos psíquicos suelen determinar primeramente la desestructuración del tiempo y la disolución de las referencias temporales. En su desarrollo, la noción del tiempo es más abstracta que la del espacio y se desarrolla más tarde en el niño pequeño. Por todo ello, el tiempo tiene más importancia psicopatológica que el espacio (Alonso, 1978).

Desde la experiencia clínica, Dörr Zegers (citado por López e Higueras, 1996, p. 199) afirma que la dimensión más fundamental de lo humano es la temporalidad; el tiempo cronológico es sólo un derivado, una abstracción del tiempo existencial. Por otra parte, Minkowski (1973) recordaba a un enfermo que, afecto de esquizofrenia, disparaba tiros de revólver contra su reloj para matar, simbólicamente al menos, al tiempo al que consideraba su peor enemigo. Así mismo, Henry Ey (1963), dice que “el maníaco salta en la eternidad de lo posible, mientras que el melancólico está congelado en la eternidad de lo imposible." López e Higueras, en su Compendio de Psicopatología de 1996, comentan el caso de una paciente, muy sensible a los cambios estacionales en su afectación ansioso-depresiva, que les decía "Todo este verano he tomado pastillas porque han estado los días más lentos...". Además se considera que una de las características de los débiles mentales es la incapacidad de abarcar una perspectiva de 
más de veinte días en cada una de las direcciones del tiempo; el pasado o el futuro (Greeff, 1927, citado por Ellenberger, 1970/1976).

Hablamos del tiempo objetivo (cronológico) y, también, de la vivencia subjetiva del tiempo, que no es una apreciación particular, sino una conciencia total del mismo (Jaspers, 1973). Alteraciones de la vivencia subjetiva del transcurrir del tiempo serían los fenómenos que llamamos precipitación, lentificación y detención.

Como Precipitación del tiempo podemos referir los casos descritos por Jaspers, en que la conciencia de su transcurso se traduce en un sentimiento de que pasa rápidamente (como la percepción de hablar, oír hablar, ver, moverse..., todo se percibe más apresuradamente) o, por el contrario, se entiende por Lentificación el iimprimir lentitud a las operaciones o procesos. La estimación del paso del tiempo es más lenta en niños, más rápida en adultos; el maníaco lo percibe demasiado rápido y al melancólico le ocurre lo contrario, pasa con enorme lentitud (Alonso, 1978).

La vivencia de la detención del tiempo (vivencia de eternidad) aparece en algunos esquizofrénicos y en los estados de éxtasis (Alonso, 1978). Dice un esquizofrénico que cita Jaspers: “Un dolor espantoso me cruzó por la cabeza, y el tiempo quedó inmóvil. Simultáneamente se presentó a mi alma de una manera casi sobrehumana la importancia vital de ese momento. Luego fluyó el tiempo otra vez como antes...”

Minkowski (1922, véase 1973), tuvo la oportunidad de convivir durante dos meses con un paciente de 66 años, afecto de un trastorno psicótico. La detenida y profunda observación e interpretación de su patología se convirtió, un año después, en uno de los casos más famosos del análisis existencial. La oscilación continuada de los elementos depresivos y delirantes se afianzaba en el convencimiento del paciente de ser 
ejecutado esa misma noche, todas las noches... Para él, cada día conservaba una independencia insólita, cada día comenzaba de nuevo al no englobarse en una percepción de continuidad; había perdido totalmente el sentido de la continuidad necesaria en el transcurrir. Así sentía él la marcha del tiempo, donde el futuro estaba bloqueado por la certeza de un acontecimiento espantoso y catastrófico (Minkowski, 1973).

La dimensión temporal, la experiencia del paso del tiempo en los sujetos es diferente en función de variables personales y del entorno, pero parece claro que los ritmos fisiológicos, los sociales y las estimaciones acerca del paso del tiempo y de la duración de los acontecimientos que nos rodean, se ven afectados en presencia de psicopatología.

Dada la alta prevalencia de los trastornos del estado de ánimo, en los que la ansiedad se ve frecuentemente como un componente más de los cuadros depresivos, el interés del presente estudio se centra en buscar, medir y comprender la estimación del paso del tiempo de las personas.

La aplicación práctica de los conocimientos que se pueden adquirir al estudiar en profundidad el tema de la temporalidad en la patología depresiva, podrían explicar mejor el enfermar de estos pacientes, y aportar posibles estrategias de ayuda en el tratamiento de su enfermedad.

Por todo ello nuestro objetivo general es: Estudiar las discrepancias entre el tiempo objetivo y el estimado en un grupo de sujetos con sintomatología depresiva y ansiosa y analizar las diferentes percepciones temporales en función de la intensidad de la Psicopatología. 
El tiempo a todos consuela, Sólo mi mal acibara, pues si estoy triste, se para, y si soy dichoso, vuela.

Ramón de Campoamor. 


\section{2.- ANSIEDAD}

\section{1.- Concepto}

Según Sandín y Chorot (1991), la ansiedad es el concepto de mayor implicación general y, tal vez, de mayor relevancia en toda la Psicopatología, ya que se haya implicada tanto en los trastornos de ansiedad propiamente dichos, como en otros cuadros psicopatológicos como el estrés, la depresión, la hipocondriasis, las disfunciones sexuales e, incluso, la propia enfermedad médica (úlcera péptica, infarto de miocardio, trastornos dermatológicos).

El ser humano no asiste a los acontecimientos de su vida de un modo neutral, sino que de toda vivencia se desprende siempre un colorido afectivo que matiza cualquier acto. En este sentido, la ansiedad es considerada como algo normal, y es tan necesaria como otras emociones, siendo considerada como mecanismo activador o inhibidor de la conducta que puede aumentar o disminuir el rendimiento. Además, el componente anticipatorio que posee, ofrece la utilidad biológico-adaptativa de la anticipación a un peligro real. Esta utilidad, se convierte en desadaptativa cuando se anticipa un peligro irreal (Sandín \& Chorot, 1995, 2008).

Siguiendo a Lewis (1980), existen varias palabras latinas, tales como angor, anxietas, angina y anxious que contienen la raíz indogermánica “áng.", que denota estrechez y constricción, significando también malestar, deficiencia o apuro. Señala además, que ya en el propio latín, se diferenció entre anxietas (predisposición, aspecto duradero) y angor (algo transitorio y explosivo). 
Esta distinción latina, determinó posteriormente la aparición en la literatura psicopatológica francesa la distinción entre "anxieté” y "angoisse” y en la española entre ansiedad y angustia, estando ésta última más relacionada con fenómenos somáticos y físiológicos.

El diccionario de la Real Academia Española (2003), en su vigésima segunda edición, define la palabra ansiedad como un "estado de agitación, inquietud o zozobra del ánimo." La segunda acepción hace referencia a "la angustia que suele acompañar a muchas enfermedades, en particular a ciertas neurosis, y que no permite sosiego a los enfermos."

Ya en el terreno profesional, la definición de ansiedad suele hacerse en términos fenomenológicos. Así, Spielberger, Pollans y Worden (1984), definen la ansiedad como una reacción emocional consistente en sentimientos de tensión, aprensión, nerviosismo y preocupación, así como activación o descarga del sistema nervioso autónomo.

Sin embargo, se hace necesario una definición experimental de la ansiedad, para poder convertirse en un constructo científicamente útil y definido operacionalmente. A este respecto, Wolpe (1972, véase Wolpe, 1979, p. 78; 1981, p 51) ha definido la ansiedad como "la respuesta autónoma de un organismo individual concreto después de la presentación de un estímulo nocivo”, el cual posee la capacidad natural de producir dolor o daño al individuo.

Skinner, B. (1979, pp. 120-121) la define como "miedo a un evento inminente, es más que expectativa...", "la ansiedad implica respuestas emocionales ante un estímulo aversivo condicionado”. 
Beck, A. (1985, p. 9), representante del enfoque cognitivo, la define como un "estado emocional subjetivamente desagradable caracterizado por sentimientos molestos tales como tensión o nerviosismo, y síntomas fisiológicos como palpitaciones cardiacas, temblor, nauseas y vértigo."

En la actualidad, una definición aportada por Vallejo en el año 2006 recoge que la ansiedad, y su correlato fisiológico que es la angustia, son fenómenos que señalan la amenaza que el individuo (yo personal) siente en su integridad, sea esta física o psíquica. 


\section{2.- Sintomatología de la ansiedad}

La ansiedad podemos concebirla como una compleja mezcla de emociones y cogniciones, orientadas hacia el futuro y más imprecisas que el miedo. Desde este punto de vista, la ansiedad supone un estado de ánimo negativo, una preocupación respecto a peligros o amenazas futuras, una preocupación por sí mismo y una sensación de que se es incapaz de predecir futuras amenazas o de controlarlas (Butcher, Mikeka \& Hooley, 2007).

La ansiedad es vivenciada como una amenaza a la propia persona, que normalmente se expresa en forma de temor a morir o, incluso, por un temor ante la nada (López e Higueras, 1996). En el texto clásico "Tratado de las enfermedades mentales", se explicaba la angustia como una asociación entre un sentimiento desagradable y una gran tensión interna que todos hemos sufrido, al menos bajo las formas de preocupaciones, temores, sentimientos de responsabilidad y de espera. En este texto, se habla de la angustia como un sentimiento corporal en el que los pacientes se quejan de opresión y presión en el corazón (angustia precordial), palpitaciones, una sensación a veces como si el corazón se parase y también un nudo en la garganta que dificulta o impide la ingesta de alimentos, dolor de vientre, sensación de hinchazón y pesadez, escalofríos, mareos, vértigos...Muchos hablan de encontrarse extraños y desplazados del medio que les rodea (Bumke, 1926).

Miedo, temor, ansia, anticipación, preocupación, emoción, expectación, aprensión, pánico, ahogo, desmayo, duda, obsesión, fijación, inseguridad, vértigo, parálisis, fobia, filia, convulsión, inestabilidad, tensión muscular, hipervigilancia, obsesión, hipocondría, dolor, anestesia, pavor, espanto, ahogo, sofoco, sensibilidad, 
anancastia, sudoración, rubor, frialdad, palidez, inhibición, percepción de amenaza, parálisis, palpitación, mareo, nausea, nerviosismo, aflicción, fuga, ahogo, evasión, huida, inhibición, impulsión, retención, timidez, zozobra, introversión, evasión, fantasía, ambición, represión, fatiga, agitación, urgencia por paso del tiempo, evitación, arrebato, enfado, sumisión, frustración...son sólo algunos de los términos que podemos escuchar de un paciente que padezca ansiedad de un modo u otro.

Al igual que cualquier otra emoción, la ansiedad implica tres componentes, modos o sistemas de respuesta: subjetivo (o cognitivo), fisiológico (o somático) y motor (o conductual). Siguiendo a Sandín y Chorot $(1995,2008)$, los tres componentes de la ansiedad se describirían como sigue:

- El componente subjetivo-cognitivo, también llamado verbal-cognitivo, es el componente de la ansiedad relacionado con la propia experiencia interna. Incluye variables relacionadas con la percepción y evaluación subjetiva de los estímulos y estados asociados con la ansiedad. A esta dimensión pertenecen las experiencias de miedo, pánico, alarma, inquietud, preocupación, aprensión, obsesiones y pensamientos intrusivos. Este es el elemento central, ya que sin él es difícil que la ansiedad tenga valor clínico.

- Componente fisiológico-somático. La experiencia de ansiedad suele acompañarse de un componente biológico. Los cambios fisiológicos más característicos consisten en un incremento de la actividad del sistema nervioso autónomo (sudoración, dilatación pupilar, incremento de la tensión muscular, palidez facial, pero también, internamente, aceleración cardiaca, descenso de la salivación o aceleración respiratoria). La experiencia subjetiva de estos cambios orgánicos suele ser percibida de forma 
molesta y desagradable, pudiendo contribuir de esta manera a conformar el estado subjetivo de ansiedad.

- Componente motor-conductual: Corresponde a los componentes observables de conducta que, a parte de implicar variables como la expresión facial y movimientos o posturales, fundamentalmente hacen referencia a las respuestas instrumentales de escape (huida) y evitación.

La ansiedad juega un papel mediador en trastornos cardiovasculares (enfermedad coronaria, hipertensión, arritmias, etc.), en trastornos digestivos (colon irritable, úlcera), trastornos respiratorios (asma), trastornos dermatológicos (psoriasis, acné, eczema), y en otros trastornos psicofisiológicos (cefaleas tensionales, dolor crónico, disfunciones sexuales, infertilidad). Además, está asociada a desórdenes relacionados con sistema inmune, como el cáncer o la artritis reumatoide. También encontramos niveles de ansiedad elevados en muchos otros desórdenes mentales, entre ellos:

- Trastornos del estado de ánimo (depresión mayor, distimia, etc.)

- Adicciones (tabaco, alcohol, cafeína, derivados del cannabis, cocaína, heroína)

- Trastornos de la conducta alimentaria (anorexia, bulimia)

- Trastornos del sueño

- Trastornos del control de impulsos (juego patológico, tricotilomanía, compra compulsiva).

- Trastornos somatomorfos (hipocondría, somatización, conversión). 


\section{3.- Etiología}

Los estudios realizados con individuos sanos sometidos a un factor estresante de nueva aparición, demuestran elevaciones de los niveles plasmáticos de catecolaminas, en particular de adrenalina (Dimsdale \& Moss, 1980).

La estimulación eléctrica del locus coeruleus produce una marcada respuesta de miedo y ansiedad en el animal de experimentación, mientras que su ablación disminuye la posibilidad de responder con miedo ante un estímulo amenazador. Los fármacos capaces de aumentar la descarga del locus coeruleus en animales son ansiógenos en los humanos, mientras que muchas sustancias que limitan o disminuyen la actividad noradrenérgica central son ansiolíticas (Hollander \& Simeon, 2006).

Para Charney y Heninger (1986), existe una actividad central noradrenérgica más elevada en el trastorno de angustia, ya que, ante una estimulación con yohimbina, los pacientes con crisis frecuentes desarrollan mayores niveles de ansiedad e incremento de los niveles plasmáticos de los metabolitos noradrenérgicos, que los pacientes con crisis poco frecuentes o que los sujetos pertenecientes al grupo de control.

Las benzodiazepinas se conocen desde hace tiempo por ser un tratamiento sumamente eficaz para la los trastornos de ansiedad. Desde este punto de vista, se plantea la posibilidad de que los pacientes con un trastorno de ansiedad generalizada o con presentación de rasgos elevados de ansiedad, presenten una producción anormal de un ligando endógeno o una alteración en la sensibilidad del receptor que interfiere en el funcionamiento adecuado del receptor benzodiazepínico y que sería el responsable de los síntomas (Hollander y Simeon, 2006). Desde este punto de vista, en un estudio llevado a cabo por Roy-Byrne, Cowley, Greenblatt, Shader y Hommer en 1990, se vio 
que los sujetos con un trastorno de ansiedad presentaban menor disminución de la velocidad de los movimientos sacádicos que los sujetos sanos del grupo de control, ante la administración de una benzodiazepina (diazepan). Más recientemente, los estudios de imagen revelan una alteración en el sistema de GABA-benzodiazepina, ya que, mediante SPECT se ha podido observar que en el hipocampo de los pacientes con un trastorno de ansiedad, existía una disminución de la unión al receptor benzodiazepínico $\mathrm{y}$ en los pacientes que sufrieron una crisis durante la exploración también estaba disminuida la unión con la corteza frontal (Bremmer et al., 2000).

En un estudio de 2001, Goddard et al., observaron una reducción de los niveles totales de GABA occipital del $22 \%$ en los sujetos con trastorno de ansiedad frente a un grupo control.

En cuanto al sistema serotoninérgico, se ha propuesto que los fármacos que actúan sobre este neurotransmisor, pueden hacerlo desensibilizando la red cerebral del miedo mediante proyecciones desde los núcleos del rafe al locus coeruleus, inhibiendo la activación noradrenérgica; a la sustancia gris periacueductual, inhibiendo las respuesta de congelación/huída; al hipotálamo inhibiendo el factor liberador de corticotropina; y a la amígdala, inhibiendo las vías excitadoras desde la corteza y el tálamo (Gorman, Kent, Sullivan \& Coplan, 2000).

El sistema hipotálamo-hipófiso-suprarrenal, que es crucial para la respuesta del organismo al estrés, sería claramente de interés en los trastornos por ansiedad (Horesh, Amir, Kedem, Goldberger \& Kotler, 1997). En un estudio de Hollander et al. (1989), encontraron que las respuestas al cortisol en las crisis de angustia inducidas por lactato, 
sugieren participación del eje hipotálamo-hipófiso-suprarrenal en la ansiedad anticipatoria y en el estrés, si bien no la encontraban en el caso de las crisis de angustia.

Además de los neurotransmisores ya mencionados, merece mención aparte la adenosina. Charney, Heninger y Jatlow (1986) relacionaron el consumo de cafeína y la ansiedad en sujetos normales. Más de $600 \mathrm{mg}$ de cafeína producían nerviosismo y trastornos del sueño, con síndromes clínicos parecidos a la ansiedad generalizada, y en ocasiones a los trastornos de angustia. Cuando experimentó, Charney consiguió inducir crisis en 15 de los 21 sujetos. El mecanismo responsable de los efectos ansiogénicos de la cafeína podrían ser la inhibición de la fosfodiesterasa, el aumento de la actividad catecolaminérgica cerebral, el antagonismo con el receptor benzodiacepínico y el receptor de la adenosina, que parece ser el auténtico mediador para la cafeína como generadora de ansiedad. La adenosina actúa como neuromodulador con importantes efectos reguladores en múltiples sistemas neuronales, siendo inhibidoras de la transmisión sináptica, en parte como consecuencia de la inhibición de la liberación de neurotransmisores, acetilcolina y sobre todo noradrenalina.

También han sido realizados en pacientes ansiosos estudios del sueño, motivados por la supuesta relación de estos trastornos con la patología depresiva y la existencia de crisis de pánico nocturnas (Uhde el al., 1984). Los escasos estudios realizados han encontrado en pacientes con ansiedad generalizada una dificultad para conciliar y mantener el sueño, una disminución de la eficiencia general del sueño y un descenso de la cantidad de sueño, sobre todo en los estadios 3 y 4. Estos pacientes ansiosos comparados con los depresivos, han obtenido un porcentaje REM menor, mayor latencia, menor actividad y mayor porcentaje del estadio 2 (Reynold et al., 1983). 
En el terreno puramente cognitivo, Seligman y Johnston elaboraron en 1973 un modelo sobre la conducta de evitación basado en los conceptos de expectativas de resultado (un estado del organismo que representa contingencias entre respuestas y resultados en una situación determinada) y el de preferencia (control de la elección de respuestas sobre la base de los resultados esperados); afirmando que el organismo posee una preferencia innata, siendo durante el aprendizaje de evitación cuando adquiere dos tipos de expectativa de resultados, la de ejecución y la de no ejecución. Por su parte, Bandura en 1977, añade al modelo anterior su concepto de expectativa de autoeficacia, consistente en la percepción de la propia capacidad para llevar a cabo acciones específicas de forma exitosa. Bandura sostiene que la ansiedad se asocia más específicamente con las expectativas de autoeficacia que con las de resultado. Este modelo teórico ha resultado eficaz para explicar el mantenimiento de la ansiedad y no tanto su origen (Sandín, 1995, 2008).

Desde la Teoría del Procesamiento de la Información, Lang (1985), asumiendo que existen estructuras cognitivas relacionadas con los trastornos de ansiedad, sugirió que la información sobre la ansiedad (y otras emociones) es almacenada en la memoria a largo plazo en redes asociativas consistentes en elementos ligados de forma lógica. La red puede ser activada por diferentes inputs que se acoplan a la información ya presente. Cuando se moviliza suficiente información la red entera es activada, dando lugar a una variedad de conductas y experiencias denominadas emoción. Por último, añaden que ciertos elementos de la red pueden poseer elevada potencia asociativa, de tal forma que basta la activación de unos pocos para acceder al programa completo. Es decir, que una simple señal semejante al estímulo fóbico relevante puede ser suficiente para provocar respuestas de miedo en una persona fóbica. 
Beck (1976) y, posteriormente, Beck y Emery (1985), proponen que existe un esquema disfuncional que juega un papel central en el desarrollo y mantenimiento de la depresión y la ansiedad. Así, las personas con trastornos de ansiedad procesan selectivamente información relevante para la ansiedad, es decir, que estas personas, poseen un sesgo sistemático para procesar selectivamente la información relevante al peligro personal, como resultado de una activación selectiva del esquema asociado representado en la memoria a largo plazo. Añaden además, que los esquemas pueden desempeñar un papel activo como organizadores del flujo de nueva información facilitando la subsiguiente atención, codificación y recuperación futura del material codificado.

La teoría de la Red Asociativa de Bower (1981, 1987), defiende que las emociones están representadas en la memoria en unidades, o nodos, en forma de red asociativa. Así, cada emoción posee en la memoria un nodo específico que a su vez está relacionado con otros tipos de información en la memoria asociativa, como situaciones relevantes, reacciones viscerales, recuerdos de eventos agradables o desagradables, etc. Por tanto, la activación de un nodo emocional facilita la accesibilidad al material congruente al estado de ánimo $\mathrm{y}$, en consecuencia, lleva a un sesgo hacia el procesamiento de la información congruente con tal estado de ánimo. 


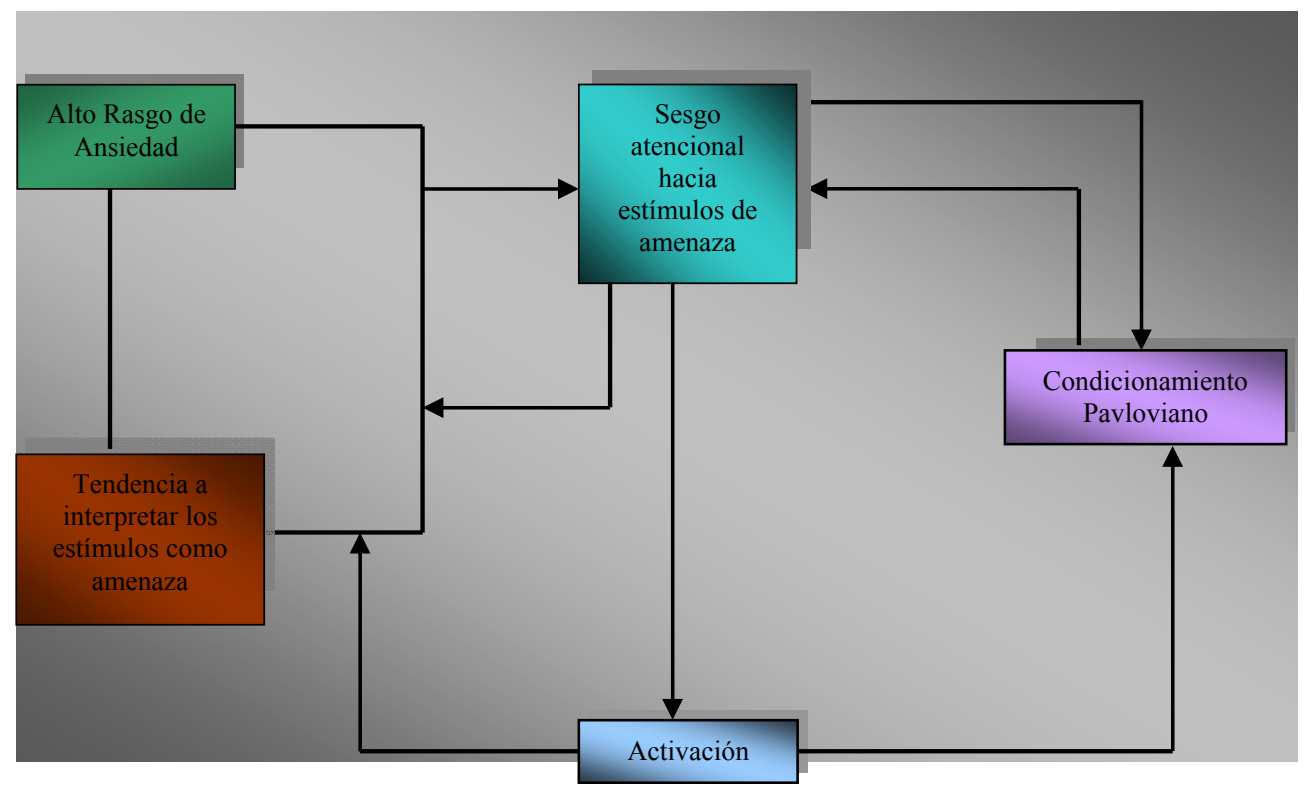

Fig. 1. Ansiedad y sesgos atencionales: Relaciones etiológicas. Sandín, 1995, 2008 


\section{4.- Criterios diagnósticos}

Hasta épocas muy recientes, los sistemas categoriales sobre los trastornos de ansiedad, han estado dominados por el concepto de neurosis, tal y como fue definida por el modelo psicoanalítico (Sandín \& Chorot, 1995, 2008).

En las dos primeras ediciones del Diagnostic and Statistical Manual (DSM) publicadas en 1952 y 1968 respectivamente, se conceptúan los trastornos de ansiedad como trastornos psiconeuróticos en el primero y trastornos neuróticos en el segundo. Ambos términos, que hacen referencia al mismo conjunto de síntomas, se caracterizan fundamentalmente por la presencia de síntomas de malestar emocional (que son síntomas de un "yo distónico"). Además, se asume la noción psicoanalítica de que las neurosis son defensas contra la ansiedad.

El DSM-II establece los siguientes síndromes de neurosis, entre los que se incluyen muchos de los que hoy entendemos como trastornos de ansiedad:

1.Neurosis de ansiedad (la ansiedad no se asocia a un objeto o situación específica).

2.Neurosis histérica.

3.Neurosis fóbica.

4.Neurosis obsesivo-compulsiva.

5.Neurosis depresiva.

6.Neurosis neurasténica.

7.Neurosis de despersonalización.

8.Neurosis hipocondríaca. 
Con la publicación de la tercera edición del DSM en 1980 se consigue una clasificación mucho más descriptiva y detallada. Es una clasificación más fiable y válida, al partir de un punto de vista ateórico y se centra más en conductas observables que en conductas inferidas. Las diferencias respecto al DSM-II son:

1.Desaparece el grupo general de neurosis y la conceptuación de las subsecuentes categorías como trastornos neuróticos.

2.Desaparece el cuadro clínico de neurosis neurasténica.

3. Se define y caracteriza por primera vez el síndrome de estrés postraumático.

4. Mantiene dos grandes grupos de trastornos de ansiedad, los trastornos fóbicos y los estados de ansiedad, que, en cierto modo, derivan de la neurosis fóbica y la neurosis de ansiedad respectivamente de su antecesor el DSM-II.

5.Se definen por primera vez de forma objetiva los principales cuadros clínicos de la ansiedad.

6.Los trastornos de ansiedad se separan de forma definitiva de otras alteraciones más o menos asociadas a la ansiedad, como los trastornos somatoformes y disociativos.

El DSM-III define el grupo de los trastornos de ansiedad como síndromes en los que la ansiedad es la perturbación predominante del cuadro, como en el trastorno de pánico o de ansiedad generalizada, o bien la ansiedad es experimentada cuando la persona trata de dominar sus síntomas, como ocurre cuando afronta las situaciones u objetos temidos en el trastorno fóbico o se resiste a las compulsiones y las obsesiones en el trastorno obsesivo-compulsivo (APA, 1980). 
Además, en cuanto al diagnóstico se refiere, el DSM-III contempla un criterio jerárquico de exclusión, impidiéndose así que se establezca el diagnóstico de ansiedad si esta es debida a otro trastorno, como la esquizofrenia, la depresión o un trastorno mental de causa orgánica. La publicación de la versión revisada del DSM-III en 1987 supuso respecto a la conceptualización de los trastornos de ansiedad, un cambio aclaratorio y no estructural (Sandín y Chorot, 1995, 2008).

En la actualidad, tanto en el DSM-IV (1994), como el Texto Revisado del DSMIV (2000), como la décima versión de las Clasificación Internacional de las Enfermedades de la Organización Mundial de la Salud (CIE-10) (OMS, 1992), son los instrumentos que con mayor frecuencia están siendo utilizados para el diagnóstico de los trastornos de ansiedad.

Siguiendo la clasificación del DSM-IV-TR (APA, 2000), los trastornos de ansiedad descritos son: las crisis de angustia (ataques de pánico), la agorafobia, el trastorno de angustia sin agorafobia y con agorafobia, la fobia específica, la fobia social, el trastorno obsesivo-compulsivo, el trastorno por estrés postraumático, el trastorno por estrés agudo, el trastorno de ansiedad generalizada, el trastorno de ansiedad debido a enfermedad médica, el trastorno de ansiedad inducido por sustancias y el trastorno de ansiedad no especificado.

Las crisis de angustia, también llamadas panic attack, hacen referencia a la aparición aislada y temporal de miedo o malestar de carácter intenso, en ausencia de peligro real, que se acompaña de al menos 4 de 13 síntomas somáticos o cognitivos, que comienza de forma brusca y alcanza su máxima expresión con rapidez. Los 13 síntomas vienen constituidos por palpitaciones, sudación, temblores o sacudidas, sensación de 
falta de aliento o ahogo, sensación de atragantarse, opresión o malestar torácicos, nauseas o molestias abdominales, inestabilidad o mareo, desrealización o despersonalización, miedo a perder el control, miedo a morir, parestesias y escalofríos o sofocaciones.

El trastorno de angustia, también llamado panic disorder (que puede ser con agorafobia o sin ella), hace referencia a la presencia de:

- Crisis de angustia inesperadas y recidivantes.

- Al menos una de las crisis se ha seguido durante un mes (o más) de uno (o más) de los siguientes síntomas:

○ Inquietud persistente ante la posibilidad de tener más crisis.

- Preocupación por las implicaciones de las crisis o sus consecuencias.

- Cambio significativo del comportamiento relacionado con las crisis.

- Las crisis de angustia no se deben a los efectos fisiológicos directos de una sustancia (drogas o fármacos) o una enfermedad médica.

- Las crisis de angustia no pueden explicarse mejor por la presencia de otro trastorno mental (APA, 2000).

En cuanto al trastorno de ansiedad generaliza se habla de la presencia de:

- Ansiedad y preocupación excesivas sobre una amplia gama de acontecimientos o actividades que se prolongan más de 6 meses.

- Al individuo le resulta difícil controlar este estado de constante preocupación.

- La ansiedad y preocupación se asocian a tres (o más) de los siguientes síntomas: 
○ Inquietud o impaciencia.

○ Fatigabilidad fácil.

○ Dificultad para concentrarse o tener la mente en blanco.

○ Irritabilidad.

○ Tensión muscular.

- Alteraciones del sueño (dificultad para conciliar o mantener el sueño o sensación de despertarse de un sueño no reparador).

- El centro de la ansiedad y de la preocupación no se limita a los síntomas de otro trastorno del eje I.

- La ansiedad, la preocupación o los síntomas físicos provocan malestar clínicamente significativo o deterioro social, laboral o de otras áreas importantes de la actividad del individuo.

- Estas alteraciones no se deben a los efectos fisiológicos directos de una sustancia o a una enfermedad médica y no aparecen exclusivamente en el transcurso de una trastorno del estado de ánimo, un trastorno psicótico o un trastorno generalizado del desarrollo (APA, 2000). 
L'amour faite passer les temps. Les temps faite passer l'amour.

(El amor hace pasar el tiempo. El tiempo hace pasar el amor)

Inscripción en un viejo reloj francés 


\section{3.- DEPRESIÓN}

\section{1.- Concepto}

El diccionario de la Real Academia Española (2003), en su vigésimo segunda edición, define la palabra depresión, en su cuarta acepción, como un "síndrome caracterizado por una tristeza profunda y por la inhibición de las funciones psíquicas, a veces con trastornos neurovegetativos".

Los sentimientos de abatimiento, en sus formas menos graves, tienen funciones filogenéticas adaptativas como, por ejemplo, conseguir atención y cuidado de los demás (Gilbert, 1992; Gilbert et al., 2008), constituir un modo de comunicación en situaciones de pérdida o separación, o ser un modo de conservar energía para poder hacer frente a procesos de adaptación (Whybrow, Akiskal \& McKinney, 1984; Whybrow, 1996). Sin embargo, bien por su duración, por su frecuencia o por su intensidad, estos sentimientos pueden llegar a interferir significativamente en la vida de las personas, convirtiéndose en patológicos. Comúnmente, se utiliza el término depresión para referirse a estados de ánimo de distinta cualidad e intensidad, e incluso al sentimiento de tristeza que puede acontecer en el transcurso diario. Este sentimiento no siempre coincide con lo que se entiende en Psicopatología por depresión (Álvarez, 2006). El estado de ánimo puede ser normal, elevado o deprimido. Habitualmente las personas experimentan un amplio abanico de sentimientos y expresiones afectivas, sintiendo que tienen cierto control sobre los mismos (Kaplan \& Sadock, 1999).

La evolución del concepto y las clasificaciones de los trastornos del estado de ánimo a lo largo de la historia ha sido tan diversa como autores se han dedicado a su estudio. 
Las primeras referencias conceptuales y clínicas acerca de la depresión, se deben a Hipócrates (400 a.C.), quien la denominó melancolía. En su Corpus hippocraticum se reconoce un tipo de carácter inclinado a padecer este trastorno, en especial en primavera y otoño, cuya causa sería una patología de los humores básicos (alteración de la bilis negra). Fue Aristóteles (348 - 322 a.C.) el primero en dedicar un monográfico al tema. Galeno (130-200 d.C.), adhiriéndose a la patología humoral, identificó tres formas distintas de melancolía: a) la melancolía localizada en el encéfalo, limitándose el efecto de la bilis negra al cerebro; b) melancolía global, en la que la sangre se sobrecarga de los venenos de la bilis negra, lo que se traduce en una afectación de todo el organismo y c) una melancolía hipocondríaca, con almacenamiento de la bilis negra en el territorio infradiafragmático, dando lugar a modificaciones digestivas y abdominales, acompañadas, por una parte de flatulencia (melancolía flatuosa), y, por otra parte, de síntomas psíquicos como miedo (phobos) y tristeza (dysthymie). Aunque se sitúa en el aparato digestivo, se irradiaba al encéfalo por acción de los vapores (Vallejo \& Crespo, 1999).

En la medicina grecolatina, también se hablaba de tristeza como un complejo proceso al que daban explicaciones con conceptos como bilis, flema, caliente, frío, seco... que permitió organizar una incipiente nosografía en series de emociones relativamente objetivas y, a su vez, establecer normas y un pronóstico de la enfermedad.

En la Edad Media, Alejandro de Tralles (525 - 605) (cit. por Vallejo, 2006, pag. 485), aporta tres formas etiológicas diferentes (exceso de sangre, sangre acre y biliosa y bilis negra) y afirma, que no siempre la tristeza y el temor son los síntomas 
característicos de estos pacientes, sino que en otras ocasiones prevalecen la hilaridad, la ira y la ansiedad.

El concepto evolucionó y maduró hasta llegar al Renacimiento, donde se hizo más amplio y complejo que en su precedente grecolatino. Los humores no se consideraron solamente fluidos patógenos, sino también rasgos, identificables a partir de un estilo de comportamiento individual y social.

En el siglo XVII, Thomas Willis (1621 - 1675) (cit. por Vallejo, 2006, pag. 485), hace notar la sucesión de cuadros maníacos y melancólicos en un mismo paciente. Burton (1577 - 1640) (cit. por Vallejo, 2006, pag. 485), en su obra The Anatomy of Melancholy, supo exponer con acierto las vivencias negativas de esta situación, a la vez que señaló los accesos de alegría desbordante que alternan con el estado depresivo.

En el siglo XVIII, la aportación probablemente más importante corresponde a Piquer (1711 - 1792) (cit. por Vallejo, 2006, pag. 485), quien describió con precisión la enfermedad maníaco-depresiva del rey Fernando VI.

Ya en puertas del siglo XIX, la obra de Pinel (1745 - 1826) (cit. por Vallejo, 2006, pag. 485), destaca cuatro formas de enfermedades mentales: manía, melancolía, demencia e idiocia. Su discípulo, Esquirol (1772 - 1840) incluye la melancolía entre las monomanías o locuras parciales, matizando su visión conceptual al afirmar que la melancolía "es un delirio parcial crónico sin fiebre determinada y mantenido por una pasión triste, debilitante o depresiva..."(cit. por Vallejo, 2006, pag. 485).

En 1854, Jules Falret llamó folie circulaire, a una patología en la que el paciente experimentaba de forma cíclica estados depresivos y maníacos. Baillarger (1854), definió la folie à doble forme: donde los pacientes, profundamente deprimidos, entraban 
en un estado de estupor del que finalmente se recuperaban. En 1882, Kahlbaum, mediante el término ciclotimia, describió la manía y la depresión como fases de la misma enfermedad (cit. por Kaplan \& Sadock, 1999, pag. 593).

Kraepelin (1896) agrupó todos los síndromes depresivos en el apartado de la psicosis maníaco-depresiva, conservando el término de melancolía involutiva para los trastornos depresivos de la senectud.

El psiquiatra alemán Leonhard, en 1957 (cit. por Vázquez \& Sanz 1995, pag. 301) fue el primero en separar los trastornos afectivos en "bipolar" (personas con trastornos maníaco-depresivos o circulares) y "monopolar" (personas con historia sólo de depresión o de manía).

Según Seligman (1989), con un estado de ánimo deprimido nos sentimos tristes, cualquier pequeño esfuerzo nos cansa, perdemos el sentido del humor y las ganas de hacer cualquier cosa, hasta aquello que normalmente más nos entusiasma. En la mayoría de las personas tales estados de ánimo suelen ser poco frecuentes y se disipan rápidamente; sin embargo, hay otras en las que se presentan una y otra vez, penetrando profundamente y pudiendo llegar a tener una intensidad letal. A medida que la depresión va agravándose, el abatimiento se hace más intenso, y con él, el desgaste de la motivación y la pérdida del interés por la realidad. Además, es frecuente encontrar sentimientos de aversión hacia sí mismo, de inutilidad, de culpabilidad, falta de confianza en una mejoría y ven el futuro de color negro. Pueden producirse ataques de llanto, pérdidas de peso e insomnio. La comida no sabe bien, el sexo no es excitante y se pierde el interés por todo. El paciente puede comenzar con ideas esporádicas de suicidio, que con el tiempo, se pueden convertir en planes decididos. "Hay pocos 
trastornos psicológicos que sean tan absolutamente debilitadores y ninguno que produzca tanto sufrimiento como la depresión” (Seligman, 1989, p 115).

Finalmente, llamamos la atención sobre la presentación periódica de algunas depresiones. Los cambios de estación, concretamente primavera y otoño, son épocas especialmente críticas para estos pacientes. No es raro que cuando se padece una fase depresiva clara, la historia clínica del paciente informe sobre la aparición de pequeñas disforias coincidentes con los cambios estacionales de los años precedentes o con el periodo premenstrual (Vallejo, 2006). Para cumplir los criterios diagnósticos de una depresión mayor recurrente con patrón estacional, la persona debe haber tenido al menos dos episodios de depresión durante los últimos dos años, que estos hayan tenido lugar en la misma época del año y que además, ya haya producido una remisión completa de los síntomas también en la misma época del año (APA, 2000). Además, no se debe tener ningún otro episodio depresivo fuera de esta estación durante ese periodo de dos años. 


\section{2.- Sintomatología de la depresión}

En los trastornos del estado de ánimo se pierde la sensación de control y se experimenta un fuerte malestar general. Así, los pacientes deprimidos, muestran pérdida de energía e interés, sentimientos de culpa, dificultad para concentrarse, pérdida de apetito y pensamientos de muerte y suicidio. Además, es frecuente encontrar cambios en el nivel de actividad, en las funciones cognoscitivas, en el lenguaje y en las funciones vegetativas (como el sueño, apetito, actividad sexual y otros ritmos biológicos). Estos cambios casi siempre originan un deterioro del funcionamiento interpersonal, social y laboral (Kaplan \& Sadock, 1999).

Así pues, el cuadro que presenta una persona deprimida puede ser muy variado, y siguiendo la clasificación efectuada por Vázquez y Sanz $(1995,2008)$ podemos hablar de cinco grandes núcleos:

- Síntomas anímicos: La tristeza es el síntoma predominante. Además de estar presente en prácticamente todos los deprimidos, es la queja principal en aproximadamente la mitad de los pacientes (Klerman, 1987). Aunque los sentimientos de tristeza, abatimiento, pesadumbre o infelicidad son los más habituales, a veces el estado de ánimo predominante es de irritabilidad, sensación de vacío o nerviosismo. En casos de depresiones graves el paciente puede llegar incluso a negar sentimientos de tristeza, alegando con aparente calma que es "incapaz de tener ningún sentimiento" (Whybrow, Akiskal, \& McKinney, 1984). Este grupo de síntomas es relativamente fácil de apreciar, ya que al menos un $90 \%$ de los pacientes parece estar triste. Su rostro denota tristeza, los ojos están enrojecidos de llorar y dicen sentirse "mal", "tristes" "hundidos" o "desesperados" 
- Los síntomas motivacionales y conductuales: Uno de los aspectos subjetivos más dolorosos para las personas deprimidas es el estado general de inhibición, la apatía, la indiferencia, en definitiva, la disminución de la capacidad de disfrute (anhedonia), constituye, junto al estado de ánimo deprimido, los síntomas principales. Levantarse de la cama por las mañanas o asearse pueden convertirse en tareas casi imposibles y, en muchos casos, se abandonan los estudios o el trabajo. Tomar decisiones cotidianas puede convertirse también en una tarea compleja. En los casos más graves, este tipo de inhibición conductual se conoce como retardo psicomotor, un enlentecimiento generalizado de las respuestas motoras, el habla, el gesto y una inhibición motivacional casi absoluta (Klerman, 1987).

- Síntomas cognitivos: El rendimiento cognitivo de una persona con depresión está afectado. La memoria, la atención y la capacidad de concentración pueden llegar a resentirse drásticamente incapacitando al paciente en el desempeño de sus tareas cotidianas. Además, el contenido de las cogniciones también está alterado, ya que la valoración que hace una persona deprimida de sí misma, de su entorno y de su futuro suele ser negativa (Triada cognitiva negativa de Beck, 1967). La autodepreciación, la autoculpación y la pérdida de autoestima suelen ser, por lo tanto, contenidos habituales en las cogniciones de estas personas.

- Síntomas físicos: suelen ser uno de los motivos principales por los que se pide ayuda. Los problemas de sueño son el síntoma físico que afecta a la mayoría de los pacientes $(80 \%)$; normalmente se trata de problemas de insomnio (sea pre, inter o postdormicional), si bien en un pequeño porcentaje puede darse hipersomnia. También aparecen la fatiga, la pérdida de apetito, la disminución del deseo y de la actividad 
sexual que, en los hombres, puede incluso derivar en dificultad eréctil. También se han descrito molestias generales difusas (dolores de cabeza, de espalda, náuseas, vómitos, estreñimiento, visión borrosa...etc.).

- Síntomas interpersonales: Una importante característica de las personas con trastornos depresivos es la presencia de deterioro en las relaciones sociales. Según Beck (1976), un 70\% de deprimidos dicen haber disminuido su interés por la gente. Además, se ha demostrado que un funcionamiento interpersonal inadecuado es buen predictor del peor curso de la depresión (Barnett \& Gotlib, 1988).

Desde el DSM-IV-TR, los principales síntomas que se mencionan son: estado de ánimo deprimido, disminución acusada del interés, cambios de peso o de apetito sin hacer régimen, insomnio o hipersomnio, agitación o enlentecimiento psicomotores, fatiga o pérdida de energía, sentimientos de inutilidad o de culpa excesivos o inapropiados, disminución de la capacidad para pensar, concentrarse o indecisión en tareas cotidianas y pensamientos recurrentes de muerte o ideación suicida (APA, 2000). 


\section{3.- Prevalencia}

La prevalencia de los trastornos del estado de ánimo en general oscila entre el 2 y el 25\%. Concretamente, el trastorno depresivo mayor presenta una prevalencia que se acerca al $15 \%$ (pudiendo llegar al $25 \%$ en mujeres). La incidencia es mayor en pacientes de atención primaria, donde se aproxima al 10\%, en enfermos hospitalizados donde puede llegar al 15\% (Kaplan \& Sadock, 1999), y en pacientes psiquiátricos, esta cifra puede llegar al 50\% (Vallejo, 2006). Según un estudio de Cassem (1995), el 48\% de la población norteamericana ha presentado, como mínimo, un episodio de trastornos del estado de ánimo a lo largo de su vida.

Precisamente, parte del problema del impacto vital y funcional de la depresión es que se trata de un cuadro típicamente recurrente (Boland \& Keller, 2002; Reifler, 2006). Se estima que el 50\% de los pacientes que sufren un episodio depresivo tendrán al menos otro en el curso de sus vidas (Mueller et al., 1999). El problema de las recurrencias y las recaídas no es simplemente estadístico. En cada recaída o en cada aparición de un nuevo episodio, el problema agrava progresiva y acumulativamente el funcionamiento psicosocial (problemas de empleo, dificultades en relaciones con los demás, etc.), se derivan mayores necesidades asistenciales con incremento del número de consultas médicas y el consumo de fármacos, y psicológicamente es más devastador, pues aumenta la sensación de indefensión y acrecienta la identidad "depresiva" del

propio individuo (Vázquez, Nieto, Hernangómez \& Hervás, 2005). Además, según aumenta el número de episodios, la duración de los periodos sin síntomas o sin trastorno depresivo se hace menor (Boland \& Keller, 2002). 
La depresión es la cuarta causa más importante de incapacidad (Figiel, Epstein \& McDonald, 1998) y una de las enfermedades más costosas. Los pacientes deprimidos pasan más tiempo en la cama que los que sufren diabetes, hipertensión, artritis o enfermedad pulmonar crónica y muestran tanta incapacidad funcional como los pacientes con cardiopatías (Martin, Figiel \& Mattingly, 1992). Los médicos de atención primaria dedican más tiempo a tratar la depresión que a la hipertensión, la cardiopatía arteriosclerótica o a la diabetes mellitus (Dubovsky, Davies \& Dubovsky, 2006).

En la revisión llevada a cabo por Charney y Weissman (1988) (cit. por Vallejo, 2006, p 486), se precisa que los síntomas depresivos alcanzan una prevalencia del 13 al $20 \%$, describiendo como factores de riesgo: mujeres, varones jóvenes y ancianos, clase social baja, divorciados y separados. Estos mismos autores refiriéndose a la depresión no bipolar consideran que la prevalencia en los varones es el $3.2 \%$ y en las mujeres entre 4.5-9.3\%. En este caso los factores de riesgo son: mujeres de 35 a 45 años, historia familiar de alcoholismo y depresión, marco ambiental desfavorable, escasa relación interpersonal y parto en los 6 meses precedentes al episodio. 


\section{4.- Etiología}

Los diversos estudios sobre los factores etiológicos de los trastornos del estado de ánimo ponen de manifiesto que probablemente no haya una única causa del trastorno del estado de ánimo. No existe ninguna razón para creer que cualquier factor innato, por sí mismo, pueda causar este tipo de trastornos, ya que, interaccionaría con experiencias vitales y con otros factores del entorno para provocar la enfermedad (Dubovsky, Davies \& Dubovsky, 2006).

Conocer los orígenes de las depresiones ha sido uno de los objetivos de la psiquiatría y la psicología a lo largo de los años. Según Vallejo (2006), resulta claro que en un síndrome depresivo intervienen variables de diverso orden (ambientales, bioquímicas, genéticas, etc.). De otro modo, no podría explicarse por qué situaciones externas concretas son capaces de poner en marcha cuadros depresivos de tipo endógeno. Parece que determinadas depresiones pueden iniciarse espontáneamente o a partir de eventos ambientales que, al incidir sobre un terreno genético y constitucionalmente predispuesto, desencadenarían los procesos neurobiológicos propios de estos trastornos. Según Kaplan y Sadock (1999), las causas de los trastornos del estado de ánimo son desconocidas. Los factores causales suelen dividirse en biológicos, genéticos, psicológicos y sociales pero se trata, efectivamente de una división artificial dada la probable interacción entre ellos. Para estos autores se producen relaciones biunívocas entre todos ellos, de tal manera que los psicológicos, sociales y genéticos pueden afectar a los factores biológicos, por ejemplo, en las concentraciones de un determinado neurotransmisor, pero también sucedería en sentido contrario. 


\subsection{1.- Teorías biológicas de la depresión}

A la orientación biológica sobre la etiología de la depresión se deben los conocimientos que en la actualidad poseemos sobre el papel que juegan las aminas biógenas (noradrenalina, serotonina y dopamina), así como la influencia de los aminoácidos neurotransmisores (el GABA), la regulación neuroendocrina y los nuevos avances en genética.

Dubovsky, Davies y Dubovsky (2006), afirman que es posible que alteraciones sutiles en la estructura o en la función de las áreas cerebrales que participan en la regulación afectiva, puedan influir en los trastornos primarios del estado de ánimo. Estas áreas, entre las que se incluyen el córtex prefrontal, estructuras subcorticales (ganglios basales, el tálamo y el hipocampo), el tronco cerebral, las vías de la sustancia blanca que conectan estas estructuras entre sí (circuito límbico-talámico-cortical o circuito límbico-estriado-pálido-talámico-cortical) y, posiblemente, el cerebelo, podrían presentar cambios debido a alteraciones en el desarrollo del cerebro, a lesiones vasculares, al envejecimiento o a enfermedades degenerativas.

Una de las primeras hipótesis planteaba que la disminución en la actividad y en la motivación propia de la depresión se relacionaba con un menor tono noradrenérgico, y que la hiperactividad en la manía se relacionaba con un exceso noradrenérgico (Schildkraut, 1965). Posteriormente, Siever y Davis (1985) sugirieron que la depresión no se relaciona con una actividad marcadamente elevada o reducida de la noradrenalina, sino con una respuesta desigual a factores estresantes que activan los sistemas noradrenérgicos de respuesta al estrés. 
Por otro lado, las neuronas que utilizan serotonina, provienen del núcleo del rafe del tronco cerebral y se proyectan a todo el cerebro. Estas conexiones hacen posible que la serotonina interaccione con otras aminas biógenas y contribuya a la regulación de muchas funciones psicobiológicas que están alteradas en los trastornos del estado de ánimo, incluyendo la afectividad, la ansiedad, la activación (arousal), la alerta, la irritabilidad, el pensamiento, la cognición, el apetito, la agresión, los ritmos circadianos y estacionales, la nocicepción y las funciones neuroendocrinas (Coccaro, 1989, Grahame-Smith, 1992, Leonard, 1992; Montgomery \& Fineberg, 1989; Murphy, 1989).

Algunos estudios han hallado que las concentraciones en Líquido Cefalorraquídeo (LCR) de ácido homovanílico (metabolito de la dopamina), son inferiores en los pacientes con depresión mayor que en los sujetos de un grupo de control. Dado que la realización de conducta dirigida a objetivos está mediada por la dopamina, la actividad deficitaria de los sistemas dopaminérgicos puede relacionarse con la disminución del impulso y la menor motivación observada en la depresión. Los sistemas dopaminérgicos de baja reactividad, podrían ser una de las razones de que la experiencia sea poco gratificante para los sujetos deprimidos (Dubovsky, Davies \& Dubovsky, 2006).

Sin embargo, las hipótesis sobre un único neurotransmisor, ignoran la evidencia de disfunciones en otros neurotransmisores. En la actualidad se considera que todos ellos interactúan y se influyen entre sí. La regla es la cotransmisión, que utiliza más de un neurotransmisor en la misma neurona (Jaim-Etcheverry \& Zieher, 1982; McCormick \& Williamson, 1989). Estas interacciones hacen que la relación de la fisiopatología de los trastornos del estado de ánimo con un único neurotransmisor sea improbable (Dubovsky, Davies \& Dubovsky, 2006). 
El ácido gama amino-butírico (GABA), es el principal neurotransmisor inhibidor del sistema nervioso central. Un impulso GABA inadecuado en los sistemas de activación noradrenérgicos podría provocar la activación no controlada que caracteriza a los trastornos afectivos. En la depresión mayor se ha observado una disminución de los niveles de GABA en Líquido Cefalorraquídeo (Leonard, 1994).

\subsection{2.- Teorías y factores psicológicos}

Según Dubovsky, Davies y Dubovsky (2006), la existencia de dimensiones psicológicas específicas en los trastornos afectivos no es discutida. Así, afirman, que "demostrar que un determinado factor psicológico es causal requiere un seguimiento prospectivo de las personas con riesgo de padecer depresión, para determinar si dicho factor aumenta la probabilidad de desarrollar un trastorno del estado de ánimo" (p. 300).

Tabla 1: Clasificaciones de las Teorías Psicológicas de la Depresión (Sanz y Vázquez, 1995, 2008)

- Teorías Psicoanalíticas.

- Teorías Conductuales.

- Teorías Cognitivas:

○ Teorías del Procesamiento de la Información.

- Teoría de Beck.

- Hipótesis de la activación diferencial de Teasdale.

- Teorías Cognitivo-sociales.

- Teoría de la indefensión aprendida.

- Reformulación de la teoría de la indefensión aprendida.

- Teoría de la desesperanza.

- Teorías Conductuales-cognitivas

- Teoría del autocontrol de Rehm.

- Teoría de la autofocalización de Lewinsohn.

- Teorías interpersonales. 
La revisión sobre factores etiológicos de la depresión desde la perspectiva psicológica llevada a cabo por Dubovsky, Davies y Dubovsky (2006), mantiene la propuesta de Sanz y Vázquez, si bien añade dentro de las teorías cognitivas la hipótesis de las reacciones anormales de pérdida como teoría sobre el origen de los trastornos del estado de ánimo.

Las primeras formulaciones psicológicas sobre los trastornos depresivos provienen del psicoanálisis. Así, Abraham (1924), discípulo de Freud (1856-1939), concibe la depresión como una exacerbación constitucional y heredada del erotismo oral, es decir, como una tendencia exagerada a experimentar placer por medio de la gratificación oral, lo que conducía a una intensificación de las necesidades y, por tanto, de las frustraciones asociadas con los actos de comer, chupar, beber o besar (Sanz y Vázquez, 1995, 2008). Según Vallejo (2006), desde el psicoanálisis se tiende a considerar la melancolía como una situación de "pérdida del objeto amado" y la depresión constituye un estado de duelo por el objeto libidinoso perdido, en el que se produce una internalización del instinto agresivo.

Con ligeras matizaciones, las teorías conductuales enfatizan la idea original de Skinner (1953), de que la principal característica de la depresión es una "reducción generalizada en la frecuencia de las conductas." Según Costello (1972), el rasgo más característico de las personas deprimidas es la pérdida de interés general por el medio que les rodea. Esta característica se explica por una pérdida general de la efectividad de los reforzadores que constituye la causa suficiente y necesaria de la depresión. Para Ferster (1973), es la disminución de la frecuencia de conductas reforzadas positivamente que sirven para controlar el medio y, por el contrario, se produce un 
exceso de conductas de evitación o escape ante estímulos aversivos. En la misma línea, Lewinsohn $(1974,1976)$, defiende que la depresión es una respuesta a la pérdida o falta de refuerzos positivos contingente a la conducta. Esto a su vez podría deberse a la ocurrencia de los siguientes factores: a) un ambiente que no proporciona el reforzamiento suficiente; b) falta de habilidades sociales y c) incapacidad para disfrutar de los reforzadores disponibles debido a ansiedad social.

En general, las teorías conductuales de la depresión sostienen que se caracteriza por una falta de refuerzo de las conductas no depresivas, que origina un déficit en las conductas adaptativas sociales como la asertividad, las respuestas positivas a los desafíos y la búsqueda de reforzadores importantes como la afectividad, los cuidados y la atención. Al mismo tiempo, dejan de aparecer recompensas ambientales a la conducta positiva, comienzan a ser recompensados la indefensión, las manifestaciones de malestar, los síntomas físicos y otras conductas depresivas, sobre todo si las personas allegadas atienden más a la incapacidad que a la competencia. Al igual que las cogniciones negativas, cabe esperar que las conductas depresivas originen un estado de ánimo depresivo (Dubovsky, Davies \& Dubovsky, 2006).

Con respecto a las Teorías Cognitivas y, desde el Procesamiento de la Información, hay una enorme cantidad de literatura sobre la asociación entre factores cognitivos (ej.: atribuciones causales, pensamientos irracionales, sesgos de memoria y atencionales, baja autoestima, etc.) y el estado de ánimo deprimido (Gotlib \& Hammen, 2002) pero evidentemente la gran dificultad, como en cualquier otro modelo etiológico, es establecer la relación causal de esos factores con la depresión. 
Un elemento que sugiere causalidad es el orden temporal de aparición. Los modelos cognitivos de la depresión plantean que los factores de diátesis cognitivos preceden a la manifestación del trastorno depresivo y hay evidencias indicadoras de esto (Garber \& Flynn, 2001; Kuyken, Watkins, Holden \& Cook, 2006), tanto en factores temporalmente próximos como distantes. Por ejemplo, la presencia de atribuciones negativas y una autoestima baja y/o inestable son predictoras de un estado de ánimo negativo tras sufrir una situación estresante (Hilsman \& Garber, 1995). Asimismo, hay estudios que han demostrado que los hijos cuya madre ha tenido episodios de depresión tienen una mayor probabilidad de desarrollar estilos cognitivos negativos (Taylor e Ingram, 1999; Vázquez \& Siles, 1999).

Otra importante fuente indirecta de apoyo a los modelos cognitivos es la eficacia de las terapias cognitivo-conductuales (TCC) en el manejo de la depresión. Multitud de estudios metaanalíticos ponen de manifiesto que la TCC es un método eficaz (Butler, Chapman, Forman \& Beck, 2006). Esta eficacia se ha demostrado en ámbitos de atención primaria (Merrill, Tolbert \& Wade, 2003), en pacientes con depresión moderada y grave (DeRubeis, Gelfand, Tang \& Simons, 1999; Cuijpers, van Lier, van Straten \& Donker, 2005; Hollon et al., 2005) y, resulta un tratamiento eficiente en términos de costes y funcionamiento (Hollon et al., 2005). Aunque la eficacia de una terapia no es argumento decisivo para comprobar la bondad del modelo etiológico subyacente, hay que subrayar los buenos resultados de una terapia cuyo objetivo es cambiar los estilos cognitivos negativos (ej.: estilos de pensamiento) (DeRubeis et al., 1990; Hollon, Stewart \& Strunk, 2006). Además, en el contexto de la causalidad de las cogniciones, la TCC parece reducir el riesgo de recaídas y recurrencias (Hollon et al., 2005). Por ejemplo, en la revisión de la literatura efectuada por Paykel (2007), de siete 
estudios controlados de TCC, la tasa media de recaídas para los tratamientos son menores que los observados en tratamientos estándares $(32.4 \%$ y $58.6 \%$ de los participantes, respectivamente), para un seguimiento medio de 35 meses. Parece por tanto haber indicadores robustos, tanto directos como indirectos, de que los factores cognitivos juegan un papel importante tanto en el inicio como en las recaídas y recurrencias de la depresión (Kuyken, Watkins \& Beck, 2005; Kuyken, Dalgleish \& Holden, 2007).

Beck (1976, 1987), Beck, Rush, Shaw y Emery (1983), y Beck, Jallon y Young (1985), proponen que existe un esquema disfuncional que juega un papel central en el desarrollo y mantenimiento de la ansiedad y la depresión. La premisa básica es que en los trastornos de ansiedad se da un procesamiento selectivo de la información relevante para el sujeto, es decir, que estas personas, presentan un sesgo sistemático para procesar selectivamente la información relevante al peligro personal, mientras que en los trastornos depresivos existe una distorsión sistemática en el procesamiento de dicha información. Es decir, tras un suceso vital que suponga una pérdida o fracaso, es bastante frecuente la aparición de sentimientos de abatimiento y tristeza. Sin embargo, en las personas depresivas aparece una distorsión en el procesamiento de los sucesos que implican una pérdida o privación. Los individuos depresivos valoran excesivamente esos sucesos negativos, los consideran globales, frecuentes e irreversibles.

Siguiendo a Beck, Jallon \& Young (1985) y, más recientemente, a Thase \& Kupfer (1996), la teoría cognitiva sostiene que el pensamiento negativo es una causa y no una consecuencia de la depresión. Según este modelo, la experiencia temprana conduce al desarrollo de creencias negativas globales denominadas esquemas. Los 
esquemas depresivos implican supuestos del tipo "todo o nada" como por ejemplo, "si no soy totalmente feliz, seré un completo infeliz" o "si no consigo controlarme completamente, estoy indefenso"....

Estos esquemas influyen en la anticipación que se haga, ya que las disposiciones optimistas conducen a una anticipación positiva, barajando las posibilidades reales a pesar de la incertidumbre. Por otra parte, la anticipación negativa también será una circunstancia normal que puede proteger de futuros fracasos. El problema surge cuando se realizan anticipaciones distorsionadas, y se pierde la facultad de anticipar positivamente, tal y como ocurre en la depresión.

Siempre que la experiencia apoye un esquema, el estado de ánimo se mantiene positivo de manera no ambivalente. Sin embargo, si algo va en contra de una creencia del tipo todo o nada, predominará el lado negativo del pensamiento. Esas creencias negativas o cogniciones negativas, están apoyadas por profecías de autocumplimiento que refuerzan el pensamiento negativo. Los errores sistemáticos en el pensamiento generan un juicio catastrófico y un único acontecimiento negativo aislado se generaliza en expectativas negativas globales acerca del sí mismo, del entorno y del futuro (la triada cognitiva negativa). Añaden además, que los esquemas pueden desempeñar un papel activo como organizadores del flujo de nueva información facilitando la subsiguiente atención, codificación y recuperación futura del material codificado.

En esta línea, la hipótesis de la activación diferencial de Teasdale (1988), es un modelo de vulnerabilidad - estrés en el que se asume que el tipo de acontecimientos que a la postre provoca una depresión clínica en algunos individuos, es capaz de producir al menos un estado de ánimo deprimido transitorio o leve en la mayoría de las personas. 
Dentro de las teorías cognitivas el modelo de indefensión aprendida de Seligman (1975), surge desde la experimentación animal. El experimento consistió en exponer a una rata a un estímulo nocivo pero inofensivo del que no podía escapar. Al principio el animal trata de eludirlo, pero cuando comprueba que es imposible, decide tumbarse y aceptar pasivamente la descarga. Cuando se modifica la situación experimental permitiendo que el animal pueda huir, éste se mantiene pasivo. Si se tiene información acerca de la contingencia entre la respuesta y la consecuencia, se puede crear el fenómeno de la indefensión aprendida si la consecuencia es incontrolable, es decir, si no hay contingencia entre las acciones y la recompensa. Si se crea la expectativa de que las respuestas y las consecuencias de la misma son independientes, se producen anticipaciones negativas, cuyo efecto motivacional es inhibir la conducta $y$ emocionalmente puede ser origen de un trastorno de ansiedad o depresión.

Abramson, Seligman y Teasdale (1978), con posterioridad a la primera formulación y con el objetivo de superar ciertos problemas que los propios teóricos definían, basándose en las teorías atribucionales de la psicología social, postularon que la simple exposición a situaciones incontrolables no bastaría por sí misma para desencadenar reacciones depresivas. Según estos autores, ante una situación incontrolable las personas intentan encontrar una explicación sobre la causa de la incontrolabilidad. Así, si se atribuye la falta de control a factores internos se produce un descenso de la autoestima (algo que no ocurre si la atribución se hace a factores externos). Si se atribuye a factores estables conduciría a una expectativa de incontrolabilidad en situaciones futuras (indefensión y depresión se extenderían en el tiempo). La atribución a factores globales provocaría expectativa de incontrolabilidad en otras situaciones $\mathrm{y}$, por ende, la indefensión y los déficits depresivos se 
generalizarían a otras situaciones. Añaden, además, que la depresión solamente ocurriría en aquellos casos en los que la expectativa de incontrolabilidad se refiera a la pérdida de control de un suceso altamente deseable o a la ocurrencia de un hecho altamente aversivo. Por último, señalaron la presencia de un factor de vulnerabilidad cognitiva a la depresión: la existencia de un estilo atribucional consistente en la tendencia a atribuir los sucesos incontrolables y aversivos a factores internos, estables y globales, que estaría presente en las personas proclives a la depresión, pero no en otros individuos.

La Teoría de la desesperanza, es una modificación de la teoría de la indefensión aprendida, aunque no está defendida exactamente por los mismos autores. En 1989, Abramson, Metalsky \& Alloy, postulan la existencia de "depresión por desesperanza". Afirman que la causa suficiente y próxima para que aparezca este tipo de depresión es la expectativa negativa acerca de la ocurrencia de un suceso, valorado como muy importante, unida a sentimientos de indefensión sobre la posibilidad de cambiar la probabilidad de ocurrencia de ese suceso. Vemos así, que la indefensión sigue siendo un elemento necesario para causar desesperanza, y es la clave causal de la depresión. El modelo puede resumirse de la siguiente forma (Fig. 2): 


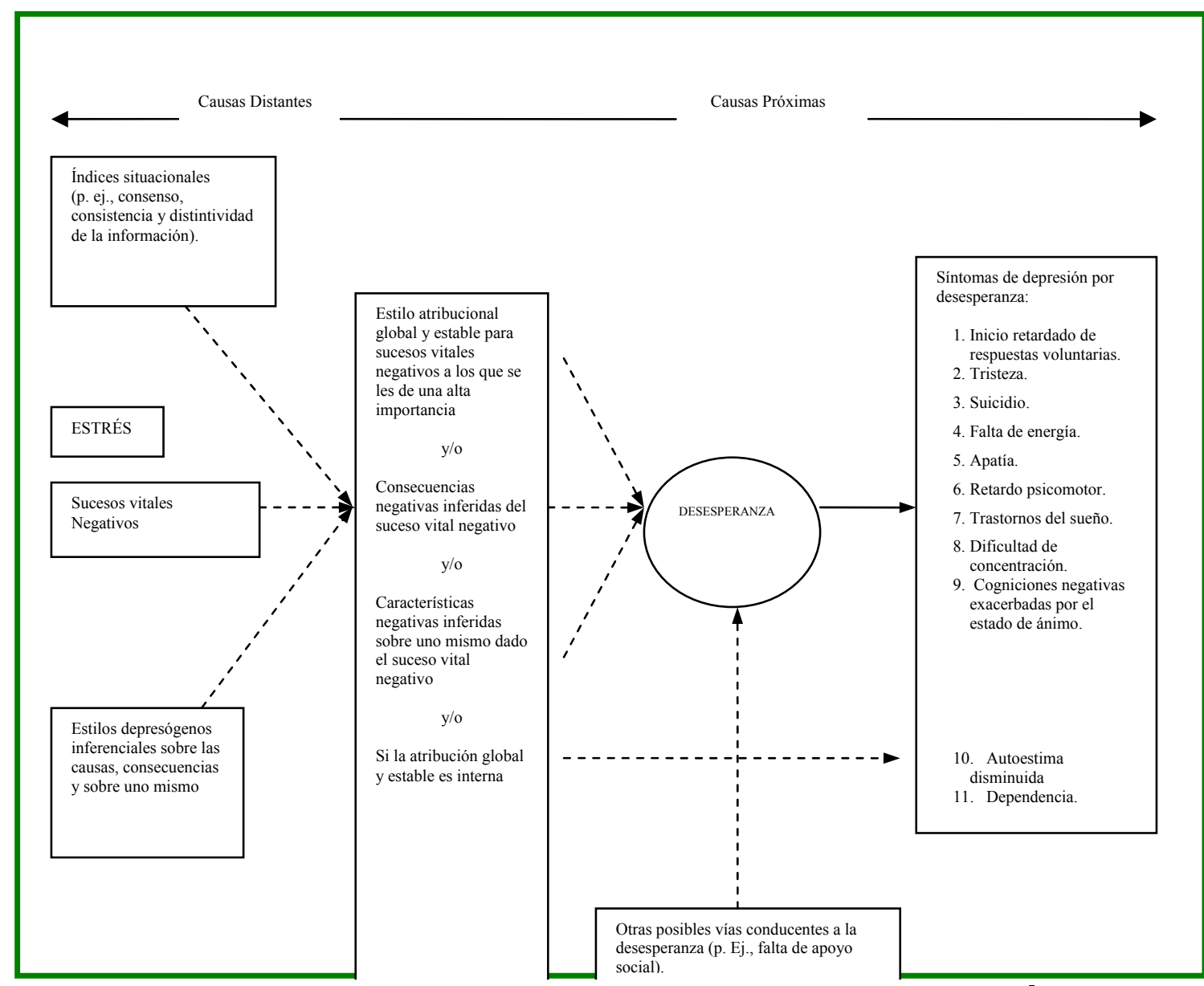

Fig. 2: Teoría de la desesperanza de Abramson, Metalsky y Alloy (1989)

La Teoría del autocontrol de Rehm (1977), considera que la depresión es consecuencia de la pérdida de una fuente de reforzamiento externa $y$, en esas condiciones de ausencia de reforzamiento, el propio control de la conducta es más importante. Así, un déficit en el repertorio de conductas de autocontrol (factor de vulnerabilidad) interactúa con la pérdida o ausencia de reforzadores externos (factor de estrés) para desencadenar un episodio depresivo. Estos déficits en el repertorio de habilidades de autocontrol (autoobservación, autoevaluación y autorreforzamiento) se adquieren durante el proceso de socialización de la persona y parecen constituir rasgos 
más o menos estables que podrían ser detectados con anterioridad a la ocurrencia del episodio depresivo.

Lewinsohn, Hoberman, Teri y Hautzinger, formularon la teoría de la autofocalización (1985), donde se defiende que los factores ambientales son los responsables primarios de la depresión, aunque habría factores cognitivos mediadores. En particular, la principal variable mediadora sería un aumento de la autoconciencia, aumento que sería resultado de los esfuerzos infructuosos del individuo para enfrentarse y resolver los acontecimientos estresantes que le ocurren. Los estresores o sucesos antecedentes son acontecimientos que inician el proceso depresógeno en tanto en cuanto interrumpen patrones adaptativos de conducta del individuo y éste no es capaz de desarrollar otros patrones conductuales que reemplacen a los anteriores. El resultado es una reacción emocional negativa o estado de ánimo deprimido, cuya intensidad depende de la importancia del acontecimiento o del nivel de interrupción de la conducta cotidiana. El incremento en autoconciencia y la intensificación de las emociones negativas, destruyen las autopercepciones que sirven al individuo para proteger su autoestima, produciéndose así muchos de los cambios cognitivos, emocionales y conductuales que están correlacionados con la depresión y que exacerban la autoconciencia, jugando un importante papel en el mantenimiento y agravamiento del estado depresivo. Los cambios cerrarían un círculo vicioso al sesgar negativamente la interpretación que hacen los sujetos de sus experiencias previas y actuales, al aumentar el estado de ánimo deprimido a través de un cambio en el autoconcepto o al reducir la competencia social del individuo. Además, asumen la existencia de características de predisposición (vulnerabilidades e inmunidades) que incrementan o reducen el riesgo de un episodio depresivo. Estas son características relativamente estables, bien de la 
persona o de su ambiente que influyen tanto en la probabilidad de ocurrencia de un episodio depresivo como en la intensidad de éste.

Para otros autores, la depresión es una respuesta a la ruptura de las relaciones interpersonales de las cuales los individuos solían obtener apoyo social (Coyne, 1976). Además, la respuesta de las personas significativas del entorno del depresivo, sirve para mantener o exacerbar los síntomas. Así, se sugiere que cuando se produce una ruptura emocional, los depresivos se vuelven a las personas de su ambiente en busca de apoyo social, convirtiéndose gradualmente en aversivas para los miembros del entorno, sintiéndose frustrados por sus intentos infructuosos de ayuda. Cuando la persona deprimida se da cuenta de estas reacciones negativas de los otros, emite un mayor número de conductas sintomáticas, estableciéndose así un círculo vicioso.

Siguiendo en la teoría Interpersonal, Klerman, Weissman, Rounsaville \& Chevron (1984), subrayan cuatro aspectos básicos relacionados con la etiología de los cuadros depresivos: el duelo no resuelto; disputas entre los cónyuges y los miembros de la familia acerca de los roles y las responsabilidad en la relación; transiciones a nuevos roles, como ser padre o jubilarse y déficit en las habilidades sociales necesarias para mantener una relación.

Con posterioridad, Gotlib \& Hammen (1992) proponen un modelo interpersonal en el que se asume que la cadena causal, que conduce al desarrollo de un episodio depresivo, se inicia con la ocurrencia de un estresor, bien sea de naturaleza interpersonal, intrapsíquico o un cambio bioquímico. Los factores de vulnerabilidad son, bien interpersonales (ej: calidad y cantidad de apoyo social, cohesión de la familia), bien intrapersonales que incluyen tanto elementos cognitivos (ej: esquemas cognitivos 
negativos) como conductuales (habilidades sociales). Lo novedoso en esta teoría, es que se recalca que la adquisición de esos factores de vulnerabilidad es fruto de experiencias familiares adversas durante la infancia.

La pérdida es el acontecimiento vital que se ha relacionado de manera más fiable con la depresión. En estudios con primates, la separación de la madre o de un compañero acaba, de manera fiable, en una conducta depresiva con cambios fisiológicos similares a la depresión humana (Suomi, Seaman \& Lewis, 1978). Los estudios observacionales con bebés humanos han mostrado que la separación temprana puede producir un síndrome depresivo que predispone a la depresión posterior (Bowlby, 1980). Los hallazgos de Paykel (1982), donde se comparan pacientes deprimidos con sujetos control, muestran que las pérdidas en la niñez (especialmente la de uno de los padres), están asociadas positivamente con la aparición de depresión en la adultez. Es posible que las separaciones tempranas sensibilicen los sistemas de activación y de evitación para reaccionar de una manera excesiva a futuras pérdidas tanto reales como simbólicas (Dubovsky, Davies \& Dubovsky, 2006).

En estudios de sueño, las anormalidades observadas en su arquitectura están relacionadas con la depresión. Por ejemplo, estudios clínicos han puesto de manifiesto una mejoría clínica transitoria asociada a la privación del sueño (Miró, Cano-Lozano, Fernández-Espinosa \& Buela-Casal, 2003). El 40-60\% de los sujetos depresivos mejora su estado clínico después de una noche de privación total. Sin embargo, la respuesta antidepresiva es transitoria y se produce generalmente una recaída después del sueño de recuperación. Hasta el momento el mecanismo de acción no ha sido esclarecido y no se ha hecho ninguna propuesta sobre el proceso subyacente al efecto antidepresivo de la 
privación de sueño que explique todos los datos empíricos existentes. Algunos estudios experimentales, señalan que muchos de los tratamientos antidepresivos más utilizados son efectivos para modificar el ritmo de los relojes biológicos internos, también conocidos como los “zeitgebers” endógenos (Kaplan \& Sadock, 1999).

El estado de ánimo deprimido suele presentar una variación diurna y los episodios pueden seguir un patrón de recurrencia mensual o estacional. Algunos trastornos del estado de ánimo, como el trastorno afectivo estacional y el trastorno bipolar con ciclos rápidos, se definen por su periodicidad. Se produce un adelantamiento en algunos ritmos biológicos, por ejemplo, en la fase de inicio del sueño, en el sueño REM, en los cambios de temperatura, en los ritmos hormonales y de los neurotransmisores, e incluso en las variaciones de concentración del cortisol, de la serotonina, dopamina y noradrenalina (Dubovsky, Davies \& Dubovsky, 2006). La existencia de esta clase de ciclos ha sustentado las hipótesis de las causas cronobiológicas de los trastornos del estado de ánimo (Goodwin, Wirz-Justice \& Wehr, 1982; Teicher, Glod \& Magnus, 1997). Según esto, las alteraciones afectivas del trastorno depresivo están relacionadas con un avance en la fase o, al menos, con una desincronización en un regulador fuerte (que controla los ritmos de la temperatura corporal, del sueño REM, del cortisol plasmático y de la melatonina) con respecto a un regulador débil (que controla el ciclo sueño-vigilia y el ciclo actividad-reposo). La falta de capacidad de predicción de los ritmos circadianos podría sugerir un deterioro en el funcionamiento de estos. Los antidepresivos restauran la organización normal de los ritmos circadianos y vuelven a sincronizar los dos reguladores, pero no queda claro si se trata de un mecanismo terapéutico o si es uno de los múltiples marcadores de la mejoría psicobiológica generalizada (Dubovsky, Davies \& Dubovsky, 2006). 
Las alteraciones del sueño constituyen uno de los síntomas más frecuentes de la depresión, por otra parte, en los centros de evaluación del sueño la causa más frecuente de este trastorno es la depresión (Buysse, Reynolds \& Kupfer, 1994). En un estudio de McDermott, Prigerson \& Reynolds (1997) se pudo apreciar que los cambios en el arquitectura del sueño en el trastorno depresivo incluyen la disminución en la continuación del sueño, un mayor número de despertares, disminución de la latencia del sueño REM, mayor intervalo de tiempo en sueño REM y problemas para iniciar y mantener el sueño de onda lenta. Las alteraciones en la sucesión de fases del sueño son más destacables en la depresión melancólica y en la depresión bipolar y psicótica. Sin embargo, en el trastorno afectivo estacional no se ha encontrado latencia de sueño REM reducida (Dubovsky, Davies \& Dubovsky, 2006). Siguiendo a estos autores, la tríada de la reducción de la latencia del sueño REM, el aumento de la densidad de sueño REM y la disminución de la eficacia del sueño, discriminaron de manera fiable a los pacientes con trastorno depresivo mayor de los sujetos control. Dado que los sistemas colinérgicos y muscarínicos aumentan el sueño REM, la hiperactividad colinérgica podría ser una causa del aumento de densidad y del incremento de esta fase de sueño.

En la misma línea, se han realizado investigaciones con pacientes ansiosos, motivadas por la supuesta relación de estos trastornos con la patología depresiva y la existencia de crisis de pánico nocturnas (Uhde el al., 1984). En estos estudios se ha encontrado que pacientes con ansiedad generalizada presentan dificultad para conciliar y mantener el sueño, una disminución en su eficiencia general y un descenso de la cantidad del mismo, sobre todo en los estadios 3 y 4 . Estos pacientes ansiosos comparados con los depresivos, tienen un índice menor de sueño REM, mayor latencia, menor actividad y mayor porcentaje del estadio 2 (Reynolds et al., 1983). 


\section{5.- Criterios de diagnóstico}

Como se ha comentado anteriormente, sentirse triste o deprimido no es un síntoma suficiente para diagnosticar una depresión. La depresión entendida como síntoma está presente en la mayor parte de los cuadros psicopatológicos, sin que por ello constituya un síndrome depresivo, es decir un conjunto covariante de síntomas relacionados. Si se empleara el estado de ánimo como único criterio diagnóstico incurriríamos en un exceso de falsos positivos, por lo que debemos emplear otros criterios simultáneos (Vázquez y Sanz, 1995, 2008).

Los dos principales instrumentos diagnósticos que se utilizan en la actualidad son la Clasificación Internacional de las Enfermedades Mentales (CIE) y el Manual Diagnóstico y Estadístico de los Trastornos Mentales (DSM). La evolución de dichos instrumentos diagnósticos se ha visto influida en gran medida por los paradigmas teóricos dominantes en el momento de cada publicación. La sexta revisión de la Clasificación Internacional de las enfermedades mentales (OMS, 1948), contenía tres categorías de los trastornos depresivos: reacción maníaco-depresiva tipo depresivo, melancolía involutiva y reacción depresiva neurótica. En la séptima revisión (OMS, 1955) se mantuvieron los mismos grupos y en la octava (OMS, 1965) se añadió una cuata categoría: la psicosis depresiva reactiva. La novena edición fue aprobada en la conferencian de 1975 e introducida definitivamente en 1978. Los trastornos afectivos se congregaron entonces en dieciséis apartados, que quedaron reagrupados en ocho categorías diferentes. La depresión neurótica permanecía igual que en las revisiones anteriores, los trastornos esquizoafectivos pasaron al capítulo de esquizofrenia $\mathrm{y}$, como novedad más importante, el paso de la melancolía involutiva al apartado de otras 
psicosis no orgánicas. Los trastornos afectivos no psicóticos aparecen en esta versión descritos en cuatro categorías: depresión neurótica, personalidad afectiva, reacción aguda al estrés y reacción de adaptación.

La CIE-10, versión vigente en la actualidad y publicada por la OMS en 1992, supone un claro avance y ampliación en relación a la CIE-9. Se aumenta de 30 a 100 categorías el capítulo F (V), dedicado a los trastornos mentales y del comportamiento. Filosóficamente acepta los principios marcados por el DSM-III norteamericano, considerando criterios puramente descriptivos de diagnóstico y rechazando la importancia etiológica.

En la sección de trastornos del humor (afectivos) (F30-F39), se establecen nueve apartados: episodio maníaco, trastorno bipolar, episodios depresivos, trastorno depresivo recurrente, trastornos del humor persistentes y trastornos del humor sin especificación. El viejo término de psicosis maniaco-depresiva se ha sustituido por el de trastorno bipolar. En general esta clasificación es más práctica y realista que la de la CIE-9 y se estructura basándose en los trastornos afectivos clásicos (Ver tabla 2). 
TRASTORNOS DEL HUMOR (AFECTIVOS) SEGÚN CIE-10 (OMS, 1992)

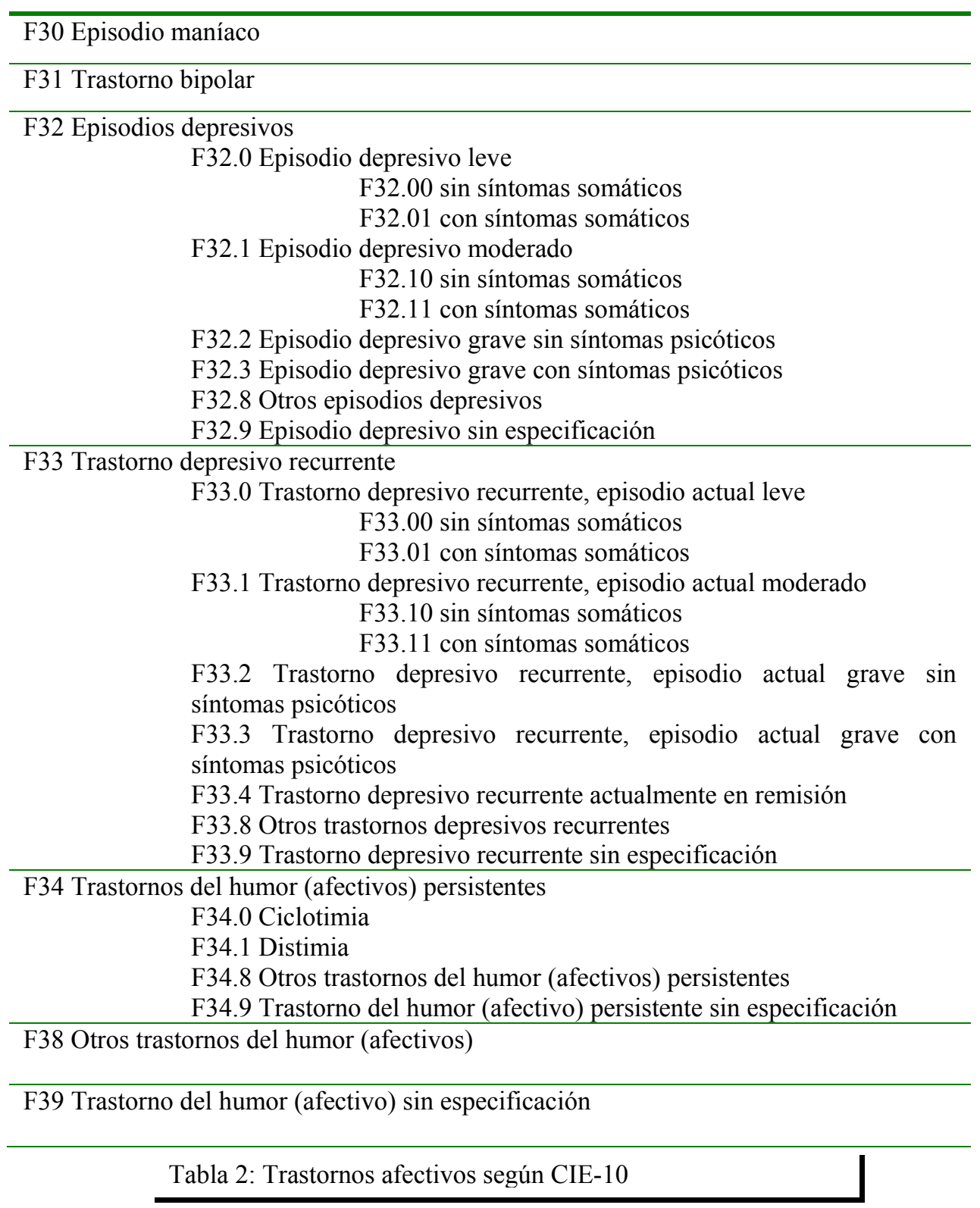

En cuanto al DSM como instrumento diagnóstico de los trastornos afectivos, se puede afirmar que poco tiene que ver la actual versión, aprobada por la APA en el año 2000, con sus predecesores el DSM-I (1952), el DSM-II (1967) y el DSM-III (1980). La primera publicación de este manual reflejó la influencia teórica de Adolph Meyer (1866-1950), quien consideraba los trastornos psiquiátricos como reacciones a 
conflictos o al estrés que eran más específicas del individuo que de la enfermedad. En el DSM-II se añadieron la melancolía involutiva y la psicosis maníaco-depresiva. Se conservó el concepto de una reacción depresiva como neurosis depresiva, que se consideraba una reacción neurótica a un conflicto interno o a un acontecimiento externo. En ausencia de un factor precipitante, el diagnóstico de reacción depresiva psicótica se realizaba en casos de un único episodio, y el de psicosis maníaco-depresiva para los episodios depresivos recurrentes, independientemente de que el paciente cumpliera los criterios tradicionales de psicosis utilizados por muchos clínicos. La alternancia de depresión y elevación se denominó ciclotimia, clasificada junto con los trastornos de la personalidad dado que era crónica y no estaba provocada por una circunstancia específica.

La diferenciación de la depresión según la existencia de un factor precipitante psicosocial se deriva de una primera distinción entre depresión endógena y reactiva. En la utilización original de los psiquiatras alemanes descriptivos, el término reactivo hacía referencia a la capacidad del paciente deprimido de reaccionar de manera positiva ante las interacciones y acontecimientos y, por tanto, implicaba la presencia de síntomas más leves. Sin embargo, cuando se tradujo el término al inglés, pasó a significar una depresión desarrollada como reacción a un determinado estrés externo, lo que implicaba una asociación entre la depresión leve y la depresión en respuesta al estrés. En el DSMII este concepto se conservó como reacción depresiva neurótica. Posteriormente, en los esquemas diagnósticos informales, las formas leves de depresión en la que el estado de ánimo depende más de factores ambientales evolucionaron hacia el concepto de desforma histeroide, un tipo de depresión con síntomas atípicos en pacientes con 
marcada sensibilidad interpersonal y tendencia caracterológica a la exageración (Shea \& Hirschfeld, 1996).

El punto de inflexión lo marca la tercera versión, con claras diferencias respecto a sus dos predecesores y con un planteamiento clasificatorio de los trastornos afectivos bajo un nuevo paradigma teórico-científico. En primer lugar, el diagnóstico pasa a ser multiaxial, de tal manera que cada paciente queda enmarcado según cinco ejes. Por otra parte, no tiene connotaciones etiológicas ni se basa en definiciones generales, sino que valora los trastornos desde el punto de vista descriptivo, amparándose en unos criterios operativos de inclusión y exclusión. Son tres los epígrafes que utiliza el DSM-III para los trastornos afectivos: a) trastornos afectivos mayores (trastorno bipolar y depresión mayor); b) otros trastornos afectivos específicos (trastorno cliclotímico y trastorno distímico), que requieren haber durado un mínimo de 2 años, y c) trastornos afectivos atípicos (trastorno bipolar atípico y depresión atípica). Asimismo, los trastornos esquizoafectivos no se incluyen ni en la esquizofrenia ni en los trastornos afectivos, sino en trastornos psicóticos no clasificados en otros apartados. La versión revisada del DSM-III (APA, 1987), establece algunas modificaciones sobre su predecesor. Se sustituye el término de trastornos afectivos por el de trastornos del estado de ánimo, los cuales quedan redefinidos y reducidos a dos grandes apartados: trastornos bipolares y trastornos depresivos.

El término afecto suele hacer referencia a la manifestación externa y cambiante del tono emocional de una persona, mientras que estado de ánimo significa una orientación emocional más duradera que influye en la psicología de la persona. Sin embargo, el cambio de trastornos afectivos en el DSM-III a trastornos del estado de 
ánimo en el DSM-IV no significa una reconceptualización de lo que implican principalmente estos trastornos.

El DSM-IV y el TR distinguen entre episodios y trastornos del estado de ánimo (Fava \& Davidson, 1996). Un episodio es un periodo que dura el menos 2 semanas, durante las cuales hay suficientes síntomas que cumplen criterios completos para el trastorno.

Una de las diferenciaciones más importantes en los trastornos del estado de ánimo en la distinción entre las categorías unipolar y bipolar. Los trastornos unipolares del estado de ánimo están caracterizados por síntomas depresivos en ausencia de una historia de estado de ánimo patológicamente elevado. En los trastornos bipolares del estado de ánimo, la depresión se alterna o se combina con la manía o lo hipomanía.

La clasificación de los trastornos del estado del ánimo según el DMS-IV-TR, queda resumida en la siguiente tabla: 
TRASTORNOS DEL ESTADO DE ÁNIMO (DSM-IV-TR, APA, 2000)

\begin{tabular}{l} 
Trastornos Depresivos \\
\hline Trastorno Depresivo Mayor, episodio único \\
Trastorno Depresivo Mayor, recurrente \\
Trastorno distímico \\
Trastorno depresivo no especificado \\
\hline Trastornos Bipolares \\
\hline Trastorno bipolar tipo I, episodio maníaco único \\
Trastorno bipolar tipo I, episodio hipomaníaco actual \\
Trastorno bipolar tipo I, episodio maníaco actual \\
Trastorno bipolar tipo I, episodio mixto actual \\
Trastorno bipolar tipo I, episodio depresivo actual \\
Trastorno bipolar tipo I, episodio actual no especificado \\
Trastorno Bipolar tipo II \\
Trastorno Ciclotímico \\
Trastorno Bipolar no especificado. \\
\hline Tabla 3: Trastornos del Estado de Ánimo, según DSM-IV-TR
\end{tabular}

Perris, en el año 1987, llegó a identificar 53 subtipos diferentes de depresión que se habían propuesto a lo largo de la historia, encontrando para esta nosología etiquetas como "enmascarada", "existencial", "endorreactiva", "postéxito" "alcohólica", etc. Sin embargo, prácticamente ninguna de ellas resiste un examen científico riguroso (Vázquez \& Sanz, 1995, 2008).

El término depresión se utiliza en tres sentidos: síntoma, síndrome y enfermedad. Como síntoma puede acompañar a otros trastornos psíquicos, por ejemplo a los trastornos de angustia; como síndrome agrupa unos procesos caracterizados por tristeza, inhibición, culpa, minusvalía y pérdida del impulso vital; y como enfermedad, desde la 
óptica del modelo médico, se considera un trastorno de origen biológico en el que puede delimitarse una etiología, una clínica, un curso, un pronóstico y un tratamiento específico. En este sentido, Vázquez y Sanz (1995, 2008), matizan que si utilizáramos el estado de ánimo como único criterio para diagnosticar la depresión, incurriríamos en un exceso de falsos positivos. Por ello, se han de emplear otros criterios simultáneos, para considerar a la depresión clínica como un síndrome (Vallejo, 2006). 


\section{6.- Comorbilidad ansiedad-depresión}

Frecuentemente los trastornos del estado de ánimo se presentan asociados con otros trastornos psiquiátricos y médicos, sobre todo con los trastornos de ansiedad, los relacionados con sustancias, los trastornos de la conducta alimentaria, los somatomorfos, los trastornos de personalidad y las enfermedades médicas crónicas (Weissman, Bland \& Camino, 1996; Campos \& Martínez-Larrea, 2002).

La ansiedad es un síntoma prominente en el 70\% de los pacientes deprimidos en régimen ambulatorio (Rosenbaum, Fava \& Nierenberg, 1995; ). En el "Collaborative Program on the Psychobiology of Depression” del National Institute of Mental Health (NIMH), se encontró que el $32 \%$ de los pacientes deprimidos presentaban fobias, el $31 \%$ crisis de angustia y el $11 \%$ obsesiones o compulsiones (Glass, Pilkonis \& Leber, 1989). En sentido inverso, pacientes con un trastorno de ansiedad generalizada (8-39\%), con un trastorno de angustia (50-90\%), con fobia social $(35-70 \%)$ o en pacientes con trastorno obsesivo-compulsivo (33\%), presentan episodios depresivos mayores (Gorman \& Coplan, 1996).

La ansiedad en los pacientes deprimidos aumenta la gravedad, la cronicidad y el deterioro asociado a la depresión y hace que ésta sea más refractaria al tratamiento. También hace aumentar el riesgo de suicidio, probablemente debido a que es un marcador de mayores niveles de activación (Keck, Merikangas \& McElroy, 1994; Rudd, Dahm \& Rajab, 1993).

Tal es la relevancia clínica de las manifestaciones ansiosas en los trastornos depresivos, que el estudio de campo publicado por Zinbarg, Barlow y Liebowitz (1994) para el DSM-IV (APA, 1994), proporcionó elementos suficientes para incluir el 
trastorno mixto ansioso-depresivo en el apéndice B, dedicado a propuestas de investigación futuras. En dicho apéndice, se describe como "un estado de ánimo disfórico persistente o recurrente que tiene una duración de al menos 1 mes. Este estado de ánimo se acompaña de síntomas adicionales de idéntica duración, entre los cuales se incluyen un mínimo de cuatro de los siguientes: dificultades de concentración o de memoria, trastornos del sueño, fatiga o falta de energía, irritabilidad, preocupación, llanto fácil, hipervigilancia, anticipación del peligro, desesperanza o pesimismo ante el futuro y baja autoestima o sentimientos de inutilidad. Estos síntomas provocan malestar clínico significativo o deterioro social, laboral o de otras áreas importantes de la actividad del individuo. El trastorno mixto ansioso-depresivo no debe considerarse cuando los síntomas se deban a los efectos fisiológicos directos de una sustancia o de una enfermedad médica, o si en algún momento el individuo ha cumplido los criterios diagnósticos para trastorno depresivo mayor, trastorno distímico, trastorno de angustia o trastorno de ansiedad generalizada. Tampoco debe establecerse el diagnóstico si al mismo tiempo se cumplen los criterios para cualquier otro trastorno de ansiedad o del estado de ánimo, aunque éstos se hallen en remisión parcial. También es preciso que el cuadro sintomático no pueda explicarse mejor por la presencia de otro trastorno mental" (pag. 740 de la edición electrónica). En el DSM-IV-TR (2000) se han mantenido los criterios diagnósticos, aunque todavía permanecen como provisionales.

Por su parte, la CIE-10, incluye el trastorno mixto de ansiedad-depresión dentro de los trastornos de ansiedad (F41) definiéndolo como aquellos casos en que, estando presentes los síntomas de ansiedad y depresión, ninguno de ellos predomine claramente ni tenga la intensidad suficiente como para justificar un diagnóstico por separado (OMS, 1992, p. 86). 
"El futuro nos tortura y el pasado nos encadena. He ahí por qué se nos escapa el presente."

Gustave Flaubert.

TEMPORALIDAD 


\section{4.- TEMPORALIDAD}

\section{1.- Introducción}

Resulta curioso que un concepto tan ampliamente utilizado en nuestra vida como es el tiempo, sea tan difícil de definir desde un punto de vista científico. Sin embargo, el ser humano, desde la más tierna infancia, aprende a discriminar el hoy, el ayer o el mañana $\mathrm{y}$, cuando somos adultos, nos dedicamos con avidez a "ganar", "matar" o "perder" el tiempo. Por otra parte, cuando a alguien se le pregunta qué es el tiempo, la respuesta más frecuente será: lo que miden los relojes. Conocer con precisión lo que es el tiempo es una tarea difícil: nada hay en la física conocida que corresponda al paso del tiempo; en su marco conceptual el tiempo no transcurre sino que simplemente es (Madrid, 2006).

Tanto Aristóteles como Newton creyeron que el tiempo era una magnitud absoluta, por lo que se podía conseguir medir el intervalo entre dos sucesos sin errores. Sin embargo, según la teoría de la relatividad de Einstein, el tiempo transcurriría más lentamente cerca de un cuerpo de gran masa que de otro más pequeño. Además, el transcurrir del tiempo debía ser dependiente de la velocidad a la que se desplaza un objeto en movimiento (Hawking, 2005).

El diccionario de la Real Academia Española propone para la palabra tiempo las siguientes acepciones: a) duración de las cosas sujetas a mudanza; b) parte de esa duración; c) época durante la cual vive una persona o sucede algo; d) cada uno de los actos sucesivos en los que se divide la ejecución de algo (RAE, 2003). 
La dificultad que comporta la comprensión del tiempo nos ha llevado a explicarlo en función de su medida y por eso el hombre se ha dedicado a construir instrumentos para su medición. El desarrollo de la inteligencia y cultura humanas impulsó a los hombres a tratar de utilizar señales celestes para medir el paso del tiempo, con el objetivo de predecir con suficiente antelación los momentos en los que ocurrirían los cambios ambientales de mayor importancia, con el fin de garantizar su supervivencia.

Los calendarios modernos tienen su origen en la civilización mesopotámica y en Egipto. Se basaban en tres ciclos naturales: el día solar, indicado por los períodos de luz y oscuridad resultado de la rotación de la Tierra; el mes lunar, señalado por las fases de la luna al rotar ésta alrededor de la Tierra y el año solar, determinado por el cambio de estaciones producido por la traslación de la Tierra alrededor del sol.

Los primeros astrónomos, observando el movimiento de los astros en cada época del año, llegaron a identificar doce constelaciones, los doce signos zodiacales, que les fueron muy útiles para dividir el año en doce partes iguales cada una de ellas de treinta días. Basándose en esta docena, los egipcios dividieron a su vez el periodo de luz en doce unidades y el de oscuridad en otras doce.

Los astrónomos babilonios fueron los que dividieron el día en las unidades que hoy se utilizan; un día se componía de 24 horas iguales, cada una de ellas de 60 minutos, compuestos por 60 segundos cada uno. Como el calendario astronómico tiene una duración de 365.25 días, se vieron en la necesidad de introducir un mes adicional cada seis años con el fin de corregir la deriva de 5 días por año. Este calendario fue utilizado hasta la corrección hecha por Julio César en el año 45 a. C., al añadir un día a algunos meses e incluir un año bisiesto cada cuatro. Sin embargo, debido a un cómputo 
inexacto, cada año tenía 11 minutos de más, por lo que en el año 1582 se había producido un desfase de 11 días que fue corregido por el Papa Gregorio XII.

El calendario gregoriano mantiene los años bisiestos añadiendo un día en febrero cada 4 años, al igual que el calendario juliano, pero elimina los años bisiestos que coinciden con el comienzo de cada siglo, con la excepción de los que son múltiplos de 400 que sí permanecen bisiestos $(400,800,1200,1600,2000,2400)$. El calendario es pues un sistema de representación del paso del tiempo que dada su utilidad continúa vigente en nuestros días (Madrid, 2006).

El primer instrumento específico para medir el paso del tiempo fue, probablemente, la observación de la sombra del sol proyectada en el suelo por un poste o piedra erigido verticalmente. Los egipcios pusieron su atención en el desarrollo de sistemas capaces de medir el tiempo diario. Hacia el año 2100 a. C. disponían de relojes nocturnos basados en tablas que medían la posición de las estrellas. Durante el día, utilizaban la posición de la sombra proyectada por los conocidos obeliscos. Para los días nublados o durante la noche, surgieron los relojes basados en la caída de arena a través de un orificio calibrado (siglo III a. C.). También tuvo lugar el desarrollo del reloj de agua o clepsidra. El nivel de agua que pasaba al depósito inferior podía ser medido con mayor precisión que el de arena. Además, algunos incorporaban sistemas que aprovechaban el agua para mover mecanismos mecánicos de señalización (campanadas). 

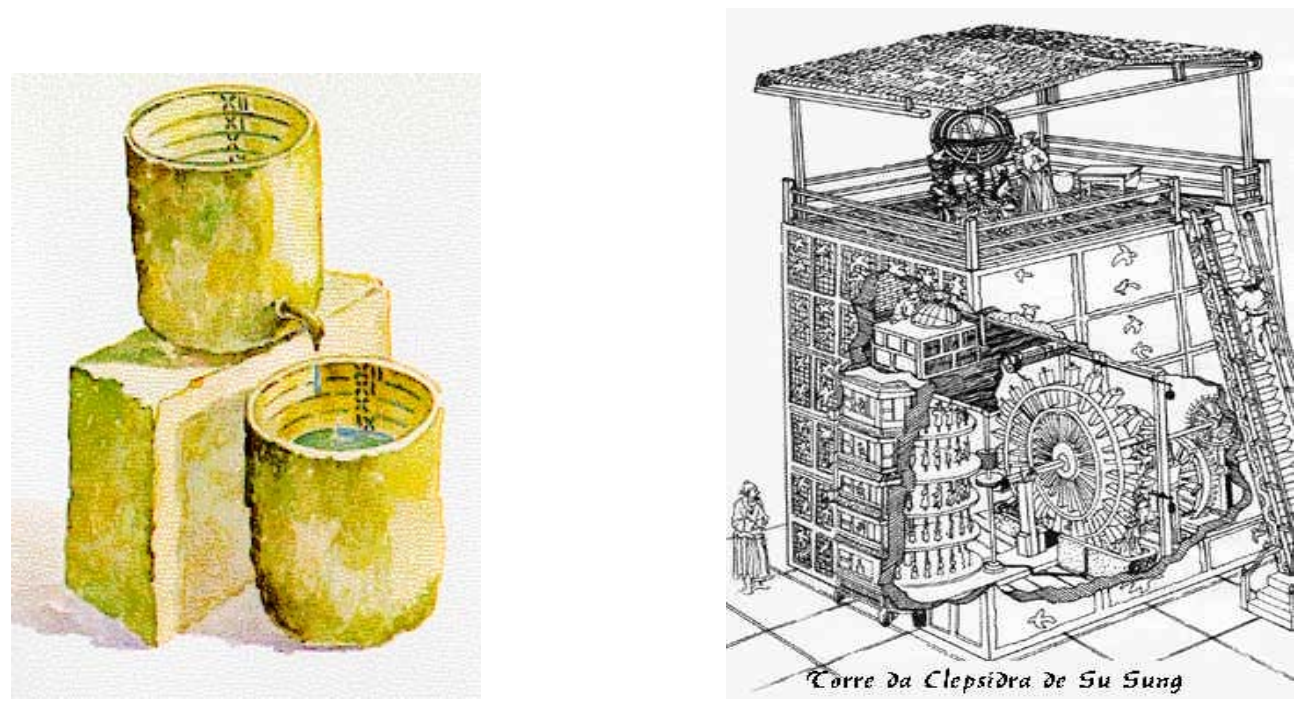

Fig. 3: Ejemplos de relojes de agua. Clepsidras

Alrededor del siglo XIII surgen en Europa los primeros relojes mecánicos. Se trata de mecanismos movidos por un peso que cuelga de un hilo enrollado en un tambor giratorio que mueve, a través de engranajes, las manecillas del reloj. Se mejoró su precisión con la aplicación de los descubrimientos de Galileo. La inclusión de dispositivos para compensar los cambios térmicos permitió finalmente, hacia el año 1714, disponer de relojes lo suficientemente precisos como para permitir a los marinos un cálculo bastante preciso de la longitud (posición con respecto a un meridiano de referencia). Posteriores soluciones técnicas, permitieron la construcción de relojes portátiles que pudieron guardarse en el bolsillo y más tarde en la muñeca.

En la actualidad, los modernos relojes electrónicos carecen de dispositivos mecánicos y permiten precisiones de tal magnitud que han servido para poner a prueba la Teoría de la Relatividad de Einstein (Madrid, 2006). 
Este objetivo casi compulsivo de la medición del paso del tiempo responde a un intento de comprender qué es el tiempo, tiempo vivido por la conciencia como un presente (que a su vez podemos percibir como un presente rápido o un presente de transcurrir lento), pero que también, gracias a la memoria y a nuestra capacidad para planificar acciones, nos permite enlazar con el pasado y con el futuro. 


\section{2.- Epistemología}

El problema del tiempo ha sido valorado por todos los filósofos desde la antigüedad hasta nuestros días. Sería interesante preguntarnos el por qué de la presencia del problema de la temporalidad en el pensamiento filosófico. ¿Cómo aparece la conciencia de temporalidad? (Núñez, 1995).

Para Aristóteles el tiempo físico es la consecuencia en primer lugar de un movimiento, es la expresión de la contingencia entre un antes y un después, y una mente que es capaz de numerar, de contar. Pero, para contar el tiempo hay que salirse de él de alguna manera y esto sólo lo puede hacer la conciencia humana.

Así pues, la temporalidad nace de la conciencia humana del antes y del después y, como tal, podemos afirmar que la raíz más profunda de nuestra conciencia de temporalidad es la conciencia de nuestra vida y de nuestra muerte (Núñez, 1995).

Aristóteles se preguntaba si hay una sucesión de "ahoras" o tan sólo un único ahora. Si hay sucesión, hay diferencia de "ahoras."

Repasando la historia del pensamiento humano sobre el tiempo encontramos una y otra vez parecidas oposiciones: el tiempo medible y el tiempo medido, el tiempo del mundo y el tiempo del alma, el tiempo llamado objetivo y el subjetivo, el biológico y el psicológico... Al confrontar a estos oponentes, se pone de manifiesto la afirmación de S. Agustín: si no nos preguntan qué es el tiempo nos parece obvio el saberlo, pero si nos piden que demos razón de ello descubrimos que no lo sabíamos.

“¿Qué es, pues, el tiempo? Si nadie me lo pregunta, lo sé; pero si quiero explicárselo al que me lo pregunta, no lo sé. Lo que sí digo sin vacilación es que sé que si nada pasase no habría tiempo pasado; y si 
nada sucediese, no habría tiempo futuro; y si nada existiese, no habría tiempo presente. Pero aquellos dos tiempos, pretérito y futuro, ¿cómo pueden ser, si el pretérito ya no es y el futuro todavía no es? Y en cuanto al presente, si fuese siempre presente y no pasase a ser pretérito, ya no sería tiempo, sino eternidad. Si, pues, el presente, para ser tiempo es necesario que pase a ser pretérito, ¿cómo deciros que existe éste, cuya causa o razón de ser está en dejar de ser, de tal modo que no podemos decir con verdad que existe el tiempo sino en cuanto tiende a no ser?" (S. Agustín, Confesiones XI, 14-17).

Nada hay más fácil que medir el tiempo con calendarios y relojes. Nada más difícil que tratar de poner orden en la experiencia humana del tiempo.

Cuando partimos de preguntas como ¿qué hora es?... llegamos a una noción de tiempo semejante a la aristotélica: el tiempo sería el número o la medida determinada por sucesivas etapas iguales de un movimiento local. El tiempo es un número cuando respondemos a la pregunta qué hora es o a cuánto estamos hoy, en cambio, es una medida cuando preguntamos, por ejemplo, cuánto dura una película.

Para S. Agustín sólo un presente preñado de pasado reciente y de futuro próximo es capaz de unificar el pasado y el futuro. En cambio, para Aristóteles distinguir el presente del instante y la relación pasado-futuro de la relación antes-después sería algo que amenazaría la dependencia del tiempo con relación al movimiento, lo cual es fundamental en la física Aristotélica.

Hay un salto del "instante" al "presente". Instante presente es el instante cualquiera de la física en el lenguaje ordinario. Instante presente psicológico es un triple presente de atención, memoria y espera (Masiá, 1995). 
A lo largo del siglo XIV es cuando tienen lugar los principales avances técnicos que permiten el desarrollo del concepto del tiempo desde la física (Galindo, 1995), como por ejemplo, el llevado a cabo por Galileo sobre la constancia del periodo de oscilación de un péndulo de una determinada longitud, en el que, independientemente del arco dibujado por el péndulo, el tiempo empleado en recorrerlo era el mismo (Madrid, 2006).

En el Siglo XV, Newton (1687), en los Principia, comienza con una renuncia a definir el tiempo: "El tiempo, el espacio, el lugar y el movimiento son de todos conocidísimos. Y no los defino." Para, poco después aclarar: "El tiempo absoluto, verdadero y matemático, de suyo y por su propia naturaleza fluye uniformemente sin relación a nada externo y se llama también duración: el tiempo relativo, aparente y vulgar es cualquier medida sensible y externa de la duración por medio del movimiento y se usa normalmente en lugar del tiempo verdadero: tal como la hora, el día, el mes, el año” (citado por Galindo, 1995, pp. 137).

Sin embargo, Kant (1781, véase Kant, 2005) niega al tiempo esa realidad absoluta que le concedía Aristóteles. Según Kant, “el tiempo es únicamente una condición subjetiva de nuestra intuición humana (que es siempre sensible, es decir, en la medida en que somos afectados por objetos), y en sí mismo, fuera del sujeto, no es nada" (p. 32). Además, "el tiempo es la forma de la intuición de nosotros mismos y de nuestro estado interior. El tiempo no puede ser una determinación de los fenómenos externos, no pertenece ni a la figura ni a la situación, sino que determina la relación de las representaciones en nuestros estados internos." (p. 31). En resumen, el tiempo existe como condición de la posibilidad de nuestra percepción y previa a ella. 
Siglos más tarde, William James, en su "Principios de Psicología” de 1890 añadirá que "un día lleno de espera, de deseo insatisfecho de cambio, será percibido como una pequeña eternidad" y que "una noche de dolor parecerá terriblemente larga; miramos hacia el futuro, hacia un momento que nunca llega; el momento en que ha de cesar" (citado por Galindo, 1995).

Desde la física, las ideas que han dominado el panorama científico durante cuatro siglos surgen en el contexto de la mecánica clásica. Newton, al igual que Aristóteles, era fiel defensor de la existencia de un tiempo y un espacio absolutos. No obstante, la Teoría de la Relatividad ha supuesto una gran revolución en la concepción científica sobre el tiempo. Pero, ¿cómo repercute esto en la aproximación psicológica al estudio del tiempo? Básicamente, se introduce un concepto que impulsa una definición del tiempo más ligada a los fenómenos naturales que a los metafísicos, que es la "flecha del tiempo" (Hawking, 1988). El concepto de tiempo siempre va ligado a la idea de cambio, por ejemplo, en el estado de la materia. Este cambio siempre ocurre en la dirección que apunta la flecha del tiempo, es decir, de "atrás" hacia "delante", de "antes" a "después". En principio, se postulan tres flechas del tiempo. La termodinámica es la dirección del tiempo en la que el desorden o entropía aumenta. La cosmológica es la dirección del tiempo en la que el universo está expandiéndose en lugar de contrayéndose. Y la psicológica es la dirección en la que sentimos que pasa el tiempo, la dirección en la que recordamos el pasado pero no el futuro.

Por otro lado, la teoría de la relatividad también aporta el concepto de la dimensión "espacio-tiempo", lo que manifiesta la necesidad de considerar conjuntamente ambos aspectos en el estudio de la cognición, ya que nuestro sistema 
cognitivo, como cualquier elemento de la naturaleza, está constantemente influido y limitado por la dimensión espaciotemporal del contexto. Así, del mismo modo que tradicionalmente se han estudiado procesos cognitivos ligados al espacio (percepción del espacio, atención, memoria o aprendizaje espacial), también es necesario estudiarlos en relación con el tiempo (Rosa \& Travieso, 2002), porque ambas dimensiones se influyen de forma recíproca. De este modo, para comprender profundamente el fenómeno general de la percepción, es tan importante el espacio como el tiempo, ya que ambos son atributos indispensables para la misma (Kubovy, 1981).

En síntesis, puede decirse que el tiempo newtoniano, absoluto y familiar, tuvo que dejar paso al tiempo einsteiniano, que es mutable y relativo; un tiempo que nos confunde con rompecabezas paradójicos como el de los gemelos.

Bergson (1859-1941), que se apoya tácitamente en Aristóteles llama al tiempo físico temps y al tiempo de la conciencia durée. Posteriormente, reduce la noción de temps para una expresión meramente espacial y reserva para la durée todos los acontecimientos puramente temporales (citado por Molero, 1979, p. 32).

Para Heidegger (1927), ser y tiempo son dos aspectos del mismo problema. Ser y tiempo se confunden. Todos los entes contingentes son temporales, es decir, son tiempo, porque todos podemos distinguir un antes y un después. Heidegger ahonda la fenomenología acentuando el "ser-para-la-muerte". Comparte el triple presente agustiniano y habla también de la intra-temporalidad, de "ser-en-el-tiempo". Para Heidegger, el tiempo es "más objetivo que todo objeto en la medida en que acompaña a la revelación del mundo y más subjetivo que todo sujeto en virtud de su arraigo en el cuidado." Sin embargo, no ahonda en el concepto vulgar de tiempo, el de la 
cotidianidad o el de las ciencias, manifestándose así el fracaso del pensamiento que intenta reflexionar sobre el tiempo.

El tiempo, más que el espacio, acompaña, empapa, toda sensación o percepción. Estamos sumergidos en el tiempo, se percibe continuamente. La vida interna, el pensar, discurrir, recordar, proponer, posponer, están en el presente, en el pasado o en el futuro, es decir, en el tiempo (Villapecellín, 1995). Pasado, presente y futuro son categorías de orientación necesarias para los procesos que guían las operaciones de la conciencia, y los necesitamos para orientar y describir el proceso de desarrollo de fenómenos físicos y sociales. Hay elementos de nuestro psiquismo que se instalan como constantes, es decir, que su permanencia se extiende más allá del paso del tiempo y funcionan como leyes de comportamiento. Freud, en sus escritos sobre el inconsciente y los sueños, señala la intemporalidad como una de las cualidades del psiquismo inconsciente (García, 1995).

Hegel (1770-1831), mantiene la dependencia del concepto de tiempo respecto del concepto de espacio. Para este autor "el tiempo es el ser que, mientras es, no es, y mientras no es, es" (citado por Molero, 1979, p. 36), es decir, mantiene la concepción aristotélica de la temporalidad.

Husserl (1859-1938), en su fenomenología de la conciencia íntima del tiempo, pone entre paréntesis el tiempo objetivo, lo ya constituido, y trata de remontarse a su constitución en la conciencia. Trata de hacer aparecer, de hacer visible el tiempo, pero tropieza con la dificultad de su indivisibilidad (citado por Masía, 1995 pag. 88).

Viktor E. Frankl (1946), en el relato de sus experiencias como prisionero de Auschwitz escribió en su famoso libro El hombre en busca de sentido, que todos los supervivientes concuerdan en señalar que la influencia más deprimente de todas las 
sufridas era desconocer cuánto iba a durar su encarcelamiento. En esta obra llega a la conclusión de que cuando existen condiciones extremas de sufrimiento, se debe hallar una razón para vivir; idea que es el punto de partida para el desarrollo de la Logoterapia, considerada la Tercera Escuela de Psicología de Viena, después del Psicoanálisis de Freud y de la Psicología individual de Adler (1870-1937).

El primer investigador que se dedicó experimentalmente al estudio del tiempo fue Paul Fraisse (1911-1996). El objetivo central de la hipótesis de Fraisse consiste en mostrar que la longitud de una duración depende, en primer lugar, del número de cambios que nosotros percibimos, que no tiene porqué coincidir con el número de cambios objetivos; en segundo lugar, depende de las circunstancias subjetivas del perceptor. Además, añade, la apreciación de la duración mantiene una dependencia de la sociedad en la que el individuo se integra (Fraisse, 1957/1982). Este mismo autor, sostiene que cuanta más atención prestamos al paso del tiempo, más largo éste parece, con el máximo de alargamiento cuando se está únicamente pendiente de que se produzca un acontecimiento deseado o temido. Recíprocamente, la duración parece disminuir cuando la tarea que se está realizando es difícil y/o interesante (Fraisse, 1985). 


\section{3.- El tiempo psicológico}

La percepción del tiempo desempeña un papel importante en el funcionamiento psicológico de la vida. Por ejemplo, la evidencia sugiere que la percepción de la velocidad a la que pasa el tiempo está relacionada con trastornos psicológicos tales como la depresión (Mezey \& Cohen, 1961; Prabhu, Agrawal \& Teja, 1969). Además, Carstensen y colaboradores (Carstensen \& Fredrickson, 1998; Carstensen \& TurkCharles, 1994; Fredrickson \& Carstensen, 1990) han demostrado que la percepción de la cantidad de tiempo futuro disponible, influye en los objetivos vitales que persiguen las personas. De hecho, la percepción del tiempo puede tener importantes repercusiones en amplios ámbitos de la psicología (social, personalidad, del desarrollo y cognitiva) (Carstensen, Isaacowitz \& Charles, 1999, McGrath \& Kelly, 1986). Por lo tanto, en la medida en que la percepción del tiempo se ve influenciada por otras personas, la comprensión de la naturaleza de dicha influencia puede proporcionar pistas importantes sobre muchos tipos de experiencias psicológicas. En un nivel más sociológico, las culturas se definen, en parte, por las percepciones de tiempo compartido. Así, puede ser difícil adaptarse a una cultura diferente (a menudo implícitamente diferente) que tenga una concepto del tiempo distinto, o diferente "ritmo de la vida" (Levine, 1997). En un estudio de 1980, Levine, West y Reis, demostraron diferencias estadísticamente significativas entre una muestra de sujetos de nacionalidad estadounidense y una muestra de sujetos brasileños en cuanto a la estimación del paso del tiempo, la orientación temporal, la exactitud en la medición horaria y las actitudes hacia la puntualidad. Entender cómo las personas se influyen mutuamente para construir las 
percepciones de tiempo compartido puede permitir conocer cómo emergen las creencias culturales sobre el tiempo.

El estudio del tiempo como variable psicológica resulta complicado ya que a la vez que lo estudiamos estamos siendo afectados por él. Como se acaba de mencionar, el concepto de temporalidad es una construcción mental muy abstracta, que ha sido distinta en diferentes periodos de la historia y que al mismo tiempo presenta diferencias en función de la cultura de origen, es decir, existen una serie de cuestiones filosóficas sobre el tiempo para las que es imposible encontrar una respuesta única (Sánchez, 1999). Estas cuestiones suponen distintos puntos de vista a la hora de realizar una aproximación al concepto de tiempo y sus respuestas configuran la noción temporal que es adoptada por una cultura, sociedad u organización en un determinado momento histórico.

Cuando intentamos una aproximación al concepto psicológico de tiempo, debemos llevar a cabo una distinción entre la noción de tiempo y la percepción o conciencia del tiempo. Cuando hacemos referencia la noción de tiempo, nos referimos a la concepción temporal descrita anteriormente. En cambio, al referirnos a los conceptos de percepción o conciencia del tiempo nos aproximamos al fenómeno de la duración de los intervalos temporales y a su estimación.

La temporalidad se refiere también a las relaciones entre tiempo y el cambio ya que, desde un punto de vista psicológico, existen dos tipos de cambio:

1.- El cambio relacionado con la estabilidad. Es importante para el estudio de la conducta humana, ya que resulta complicado acotar términos como rasgos de conducta o dimensiones de personalidad, si no existe cierta estabilidad. Desde este punto de vista, 
podemos hablar de cambios normativos, que son los comprendidos en el enfoque evolutivo; y de cambios idiográficos, los que hacen referencia a un cambio extraordinario, personal.

2.- El cambio relacionado con la dinámica. Aquí el cambio pasa a convertirse en objeto de estudio. En ocasiones nos interesa estudiar el patrón de cambio, como descriptor real del sujeto y en otras ocasiones, estudiamos los cambios como característica diferencial, es decir, cuando se produce cambio en la conducta, ¿todo el mundo cambia de la misma forma?

\subsection{1.- Psicogénesis del tiempo}

Es necesario distinguir entre distintos modos de adaptación al tiempo y, además, cada uno de estos niveles de adaptación contribuye a la adquisición del nivel siguiente en la progresión del ser humano, para conseguir el dominio de la noción del tiempo (Fraisse, 1957/1982; Montangero, 1984).

Por un lado estaría el condicionamiento al tiempo, en la medida que, como el resto de animales, somos sensibles a los ritmos de origen tanto endógeno como exógeno y nos condicionamos a los intervalos entre señales, lo que permite orientarnos temporalmente a nivel cognitivo y práctico. Por otro lado está la percepción del tiempo, que se refiere a la percepción de duraciones breves y mediante la cual podemos percibir y adaptarnos a cambios rápidos y, en tercer lugar, está la representación del tiempo, que presenta dos niveles, uno que pertenece al nivel preoperacional, que involucra la representación de cambios pasados y actuales, y otro que permite construir una representación exacta de esos cambios y anticipar y dominar los futuros (Fraisse, 1985). 
Sólo después de haber estudiado la génesis de las operaciones relacionadas con el número y con las cantidades físicas, y después de haberse hecho una idea muy elaborada de los múltiples agrupamientos propios del pensamiento lógico-matemático, es cuando se ha podido, por analogía o por deducción, formular hipótesis sobre la existencia de operaciones temporales susceptibles de sostener las nociones ligadas con el tiempo (Sánchez, 1999).

El autor fundamental cuando tratamos de estudiar la génesis del concepto del tiempo es Piaget (Sánchez, 1999). Los trabajos de Piaget y su concepción sobre el desarrollo de la noción de tiempo en el niño son, sin duda, los más influyentes sobre la concepción psicológica de la adquisición de la noción de tiempo en el ser humano. La temporalidad, se conceptúa como una construcción progresiva, es decir, el desarrollo de la noción de tiempo depende, como otras nociones que va adquiriendo el niño, de una descentración progresiva que se va produciendo a medida que el niño crece y que implica una participación activa del sujeto cada vez mayor.

La idea fundamental de los dos primeros periodos con respecto a la adquisición de la temporalidad, es que son las relaciones temporales entre las acciones del niño (de las que seguramente no es consciente todavía) lo que prepara su capacidad para generalizar su uso (Sánchez, 1999). Para Piaget (1978), el tiempo primitivo no es un tiempo que se percibe fuera, sino una duración que se siente en el curso mismo de la acción.

Posteriormente, el niño comienza a interesarse en las cosas por ellas mismas cuando están en relación directa con su propia acción. Ya existen las relaciones circulares secundarias, pero no tiene conciencia de la relación temporal "antes-después" 
que existe entre su acción y el movimiento de un objeto. La primera vez que se percibe la temporalidad psicológicamente, es el propio sujeto el ejecutor de las realidades sucesivamente percibidas que dan lugar a la misma.

Más tarde, el niño comienza a ser capaz de combinar los esquemas conocidos para conseguir un fin determinado, pero todavía percibe la objetividad de los acontecimientos de manera imperfecta, es decir, no tiene la noción de un tiempo objetivo, independiente de él mismo.

En el estadio llamado de las series temporales objetivas, el niño sabe que un acontecimiento se produce antes que otro, porque el segundo es la causa de la desaparición del primero. El niño es capaz de construir series con los acontecimientos, al menos los que pertenecen al pasado o al futuro más inmediato.

Por último, comienzan las series temporales representativas. Aquí, el niño tiene ya la capacidad de reconstruir los acontecimientos que han sucedido en el pasado, porque ya conoce las relaciones de desplazamiento o causales entre los objetos.

En el periodo de la inteligencia representativa, el tiempo consiste en relaciones de sucesión y de duración fundadas sobre operaciones análogas a las operaciones lógicas (Piaget, 1971).

En el estadio preoperatorio encontramos que el niño no es capaz de reconstruir correctamente el orden; la intervención de la velocidad interfiere en su manera de entender cómo se producen dos series de acontecimientos. Confunde la duración con el espacio, juzga que el movimiento más rápido es el que tiene la duración más grande porque ha recorrido un camino más largo. En cuanto al tiempo psicológico, ocurre lo 
mismo, el niño más alto es el que juzgan que tiene más edad y las actividades hechas más deprisa son las que llevan más tiempo de realizar.

En el periodo de las operaciones concretas se consiguen seriaciones correctas pero de forma empírica; tiene la intuición de que los órdenes de sucesión de los acontecimientos y sus duraciones están relacionados. Comienzan a tener en cuenta la velocidad de la acción y empiezan a admitir que las acciones que producen más resultados no tienen por qué ser más duraderas.

Por último, ya en el periodo operatorio, aparece en los niños una coordinación entre tiempo, velocidad y espacio. Es capaz de ordenar los acontecimientos y de juzgar las duraciones. Además es capaz de comprender y utilizar la medida del tiempo, por lo que comprende el principio del reloj y puede utilizarlo.

En resumen, podría decirse que Piaget sostiene que, por parte del niño, no hay una intuición primaria de la duración, sino que el sujeto la evalúa a partir de la relación que establece entre una acción y la velocidad con la que ésta se realiza. Por lo tanto, el concepto de tiempo es una resultante, una construcción, basado en la velocidad. Al principio, la velocidad es una intuición: el niño intuye que alcanza un objeto, o que le sobrepasa. Después, a medida que se va produciendo la evolución operatoria, el niño concibe la velocidad con la relación entre el espacio recorrido y el tiempo empleado. Es decir, la noción de tiempo se construye, se hace a partir de nociones espaciales y de la experiencia de distintas velocidades. Y el proceso de construcción se hace imprescindible para que el niño alcance la noción de tiempo, porque no puede percibir la duración directamente (Sánchez, 1999). 
Ahora bien, hay poca información sobre los precursores de las habilidades temporales en la primera infancia (Bueno, 1993); dicho vacío resulta sorprendente si tenemos en cuenta que, ya en 1954, Piaget consideró que el tiempo era, junto con el espacio, el objeto y la causalidad, una categoría fundamental de la experiencia mental de los niños.

Ya se ha comentado anteriormente que para Piaget, los niños se involucran en las reacciones circulares secundarias o movimientos estereotipados, a causa de su conocimiento de la causalidad o de las consecuencias secuenciales de sus propias acciones. Con posterioridad, otros autores como Thelen (1981), conciben los estereotipos como el producto de la generación de patrones espaciales y temporales intrínsecos del sistema nervioso, lo cual no sería impedimento para que tales conductas tuviesen funciones instrumentales, entre las que figurarían la de ser precursores de la conducta habilidosa, la de proporcionar control inteligente sobre los cuidadores, las de servir como vehículo de comunicación o para medir la duración de los sucesos (Pouthas, 1985).

Además, la regularidad temporal o secuenciación de los sucesos en el mundo infantil, arroja información importante para su funcionamiento adaptativo. Su capacidad para funcionar en un dominio temporal es crítica para el desarrollo de conductas afectivas, lingüísticas, cognitivas, perceptivas y sociales (Lewkowicz, 1989).

Sabemos que el niño está sometido a los ritmos biológicos desde su nacimiento, siendo claros ejemplos los periodos sucesivos de sueño-vigilia, así como los movimientos rítmicos y estereotipados que realizan con pocos meses (Thelen, 1979). A 
pesar de esto, el acercamiento ontogenético ha estado muy olvidado en lo relativo a los ritmos bioconductuales (Davies, 1981; Estaun-Ferrer, 1985).

Los factores temporales desempeñan un papel crítico en las interacciones sociales que los pequeños mantienen con las personas que los cuidan, tanto en aquellas que involucran actos comunicativos como en los que no (Bueno, 1993). Así, se ha encontrado que con unos pocos meses de edad, el niño se forma expectativas temporales en los intercambios comunicativos con su cuidador, gracias a que éste varía poco la duración de las frases que emplea (Jasnow \& Feldstein, 1986), variaciones que, por otro lado, sirven para mantener su atención (Stern \& Gibbon, 1979).

Se ha encontrado que es posible el condicionamiento a una duración periódica en niños recién nacidos (Brackbill \& Fitzgerald, 1972), aunque parece ser que su éxito depende de factores tales como la modalidad del estímulo condicionado, la complejidad de la tarea, el sistema de respuesta utilizado, el sexo y la edad del niño (Turco \& Stamps, 1980).

\subsection{2.- La experiencia temporal}

Siguiendo a Ornstein (1997), pueden identificarse cuatro variedades de experiencia temporal: de simultaneidad y de sucesión; de intervalos muy breves (el presente); de intervalos más largos; y de perspectiva temporal u orientación temporal.

\subsubsection{1.- La experiencia de la simultaneidad y de sucesión}

Hace referencia a las diferencias entre lo que pasa al mismo tiempo y lo que pasa en momentos sucesivos. Toda modificación, es decir, toda sucesión de los fenómenos de la naturaleza es percibida por el sujeto gracias a la existencia de la imaginación, ya 
que es ésta la que enlaza las percepciones sucesivas en el tiempo. El problema viene por que este enlace llevado a cabo por la imaginación únicamente implica saber que una cosa va antes y otra después, pero no que un fenómeno preceda a otro. Para que una sucesión siga la ley de la causalidad, debemos de pensar de tal forma la relación entre dos estados, que quede determinado necesariamente cuál es el estado que debemos poner antes y cuál va después, y no a la inversa.

Por otro lado, la simultaneidad es la existencia en el mismo tiempo y al mismo tiempo. Las cosas son simultáneas cuando la percepción de una puede seguir a la de otra y al revés (Kant, 1787/2005).

\subsubsection{2.- La experiencia de intervalos muy breves (el presente)}

Es el tiempo de nuestro contacto más inmediato con el mundo, que cambia continuamente, que siempre es reemplazado por un nuevo "ahora." Las investigaciones en este campo se han centrado en estudiar la relación de este presente con la capacidad de procesamiento de la información de la memoria inmediata (Sánchez, 1999).

El primero en distinguir una memoria transitoria frente a una permanente fue William James (1842-1910), quien hablaba de memoria primaria y secundaria. Según James (1890, citado por Briales \& Grzib, 1999, p. 487), la información en la memoria primaria está en la conciencia, es el presente psicológico al que atiende el sujeto. Lo almacenado en la memoria secundaria está ausente de la conciencia, es el pasado psicológico que requiere un proceso activo de recuperación para hacerse consciente. En física, se denomina presente de un suceso A, a todos los puntos del espacio tiempo que no pertenecen ni al pasado ni al futuro. Es decir, todos los puntos que no pueden influir 
en lo que ocurre en A ni ser influidos por lo que ocurre en A (Hawking, 1988). Desde la teoría de la física clásica, el presente puede ser representado de la siguiente forma:

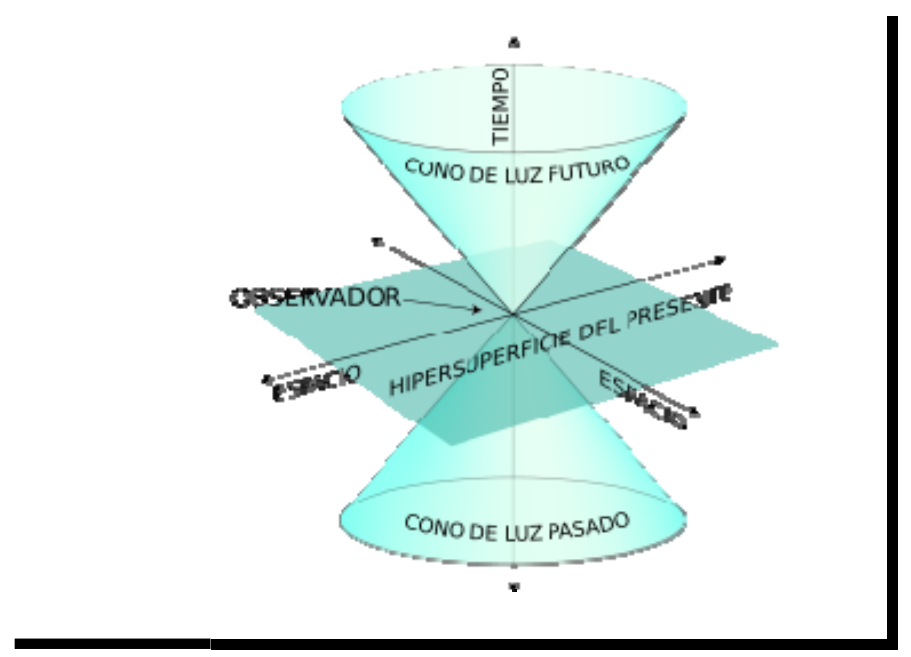

Fig. 4: Representación del presente (Hawking, 1988)

\subsubsection{3.- La experiencia de intervalos más largos}

El otro modo continuo de la experiencia del tiempo es el de la duración, que tiene cierta permanencia. Es la experiencia del paso de las horas, que pueden pasar más rápidamente o más lentamente, la experiencia de algo que ha pasado "hace tiempo", del paso de un intervalo que ha pasado más rápidamente para una persona que para otra (diferencias interindividuales) o para la misma persona en dos situaciones distintas (diferencias intraindividuales) (Sánchez, 1999).

Existen discrepancias entre el tiempo medido y el estimado. Dentro de los trabajos que se han realizado sobre esta temática, deben distinguirse aquellos centrados en los efectos de ciertas variables personales sobre la conducta de estimación del tiempo, que normalmente provienen de la investigación clínica y aquellos centrados 
sobre las características del estímulo que influyen sobre el procesamiento cognitivo de la duración del acontecimiento.

Aquellos investigadores que han centrado sus estudios en los efectos de variables personales (estrés y nivel de vigilancia -Delay \& Mathey, 1985-; rasgos de personalidad y desórdenes psiquiátricos -Melges, 1982-; drogas -Fisher, 1966-; hipnosis -Zimbardo, Marshall, White \& Maslach, 1973) atribuyen las discrepancias entre el tiempo medido y el estimado a los cambios en el "tempo interno" o personal. Es decir, asumen que cada individuo tiene su propia tasa de actividad que se relaciona con su estilo y su modo de vida. Para ellos, el tempo del sujeto permanece estable a lo largo de periodos prolongados, pero hay una serie de agentes que pueden aumentar o disminuir su velocidad. Así, cuando se acelera el tempo interno, se acortan las unidades internas de tiempo, de tal forma que el tiempo del reloj parece pasar más lentamente. Por el contrario, a una desaceleración del tempo interno corresponde un relativo aumento de las unidades de tiempo interno, de tal forma que el tiempo del reloj parece pasar más rápidamente.

Para otros autores, los cambios de conducta dependen del tipo de tarea usado (Droit-Volet, Clemen \& Fayol, 2008). En tareas verbales, un aumento del tempo interno lleva a la sobreestimación (5 minutos que parecen 8 ), porque el tiempo del reloj parece relativamente más lento. En tareas de producción y reproducción, el relativo aumento o disminución del tempo interno produce duraciones que son relativamente más cortas o más largas que el estándar (Sánchez, 1999).

Por otra parte, ya Fraisse (1957/1982) considera que las variables situacionales influyen sobre la conducta de estimación de tiempo. Se puede hablar de tres modelos 
que intentan explicar la intervención de estas variables: el modelo centrado en el tamaño del almacenamiento de Ornstein (1969), que predice que al aumentar la cantidad o la complejidad de la información presentada durante un intervalo, los juicios de los sujetos sobre el tiempo transcurrido serán de más larga duración; el modelo centrado en el cambio contextual de Block (1978), que predice que cuando aumenta el número de cambios percibidos por el sujeto (que no tiene por qué coincidir con el número real de cambios), aumenta la estimación del tiempo; y el modelo centrado en la localización de la atención (Hiks, Millar \& Kinsbourne, 1976; Thomas \& Weaver, 1975), parte de la idea básica de que el tiempo estimado está influido por el foco de atención. Arlin (1986), reportó que la estimación del tiempo hecha inmediatamente después de la tarea tiende a acortarse cuando a los sujetos se les pedía una tarea que requería un procesamiento en profundidad. Por ende, las tareas menos demandantes ahorraban más capacidad para procesar los indicios temporales, por lo que las estimaciones eran más largas.

4.3.2.4.- La experiencia de perspectiva temporal u orientación temporal

Definida como la orientación hacia el pasado, presente o futuro que es predominante en el sujeto. La perspectiva de tiempo futuro es la más estudiada. Está definida por la densidad del número de acontecimientos anticipados, por el contenido de las anticipaciones de acontecimientos que hace el sujeto y por la extensión o longitud del intervalo temporal entre el presente y el futuro (Sánchez, 1999).

El espacio vital de cada persona no está limitado al aquí y al ahora, sino que se extiende hacia el pasado y el futuro. Se vive en el presente, pero el recuerdo del pasado y el futuro anticipado se integran en éste, afectando a las acciones, pensamientos, 
sentimientos y bienestar subjetivo. A partir de la memoria episódica se pueden traer al presente partes importantes del pasado, se puede imaginar qué vendrá, qué se quiere que ocurra o no, mañana, la próxima semana, el próximo mes, etc. Este futuro anticipado se convierte en parte del presente psicológico.

La experiencia o perspectiva temporal se inscribe dentro de este contexto y puede definirse como la integración del pasado, presente y futuro en el espacio vital de una persona.

Algunas personas perciben el pasado como la parte más importante de su espacio vital, otros no tienen en cuenta el pasado ni el futuro, únicamente orientan sus acciones en el presente y, por último, existen personas cuyos comportamientos están orientados exclusivamente hacia el futuro.

En referencia a este aspecto, estudios correlacionales (Fong \& Hall, 2003; Keough, Zimbardo \& Boyd, 1999; Zimbardo \& Boyd, 1999; Zimbardo, Keough \& Boyd, 1997), han mostrado que tener una perspectiva de tiempo corta, es decir, estar focalizados en el "aquí y ahora", está negativamente asociado con hábitos conductuales saludables. Sin embargo, poseer una perspectiva de tiempo larga, lo está positivamente.

La actitud temporal se ha definido como los pensamientos positivos, negativos o neutrales expresados por una persona hacia el tiempo (Lennings, Burns \& Cooney, 1998). Tener actitudes positivas reflejaría el tiempo como un continuo integrado con el énfasis en creer o lograr diferentes metas. Por el contrario, las actitudes negativas reflejarían el tiempo como inconsistente y limitado, con sentido de discontinuidad.

Estas actitudes tienen una importante carga afectiva o emocional. Además son muy relevantes por su impacto en la motivación presente y, por tanto, en la conducta. 
De este modo, el optimismo representa el "dominio futuro" de la satisfacción vital (Shmotkin, 1991). Correspondería con una actitud positiva hacia el futuro. Éste ha sido relacionado con diferentes consecuencias de salud positivas tales como bienestar subjetivo, búsqueda de cuidado, menor ansiedad y mejor respuesta al tratamiento (Fitzgerald, Tennen, Affleck \& Pransky, 1993; Lauver \& Tak, 1995; Rijken, Komproe, Ross, Winnbust \& Van Heesch, 1995). Además, las personas con altos niveles de optimismo experimentan los acontecimientos diarios como más positivos y esperan resultados más satisfactorios que los pesimistas (Kivimaäki, et al., 2005).

Por último, la orientación temporal se refiere a la direccionalidad de la perspectiva de tiempo. Lens (1986) la definió como la dirección predominante de la conducta y el pensamiento de la persona en la medida en que se encuentra orientado hacia objetos y acontecimientos del pasado, el presente o el futuro. Tiene una influencia dinámica en los juicios, decisiones y acciones de una persona.

Según Zimbardo y Boyd (1999), la orientación temporal se relaciona con la actitud temporal. Una persona puede estar hedónica o fatídicamente centrada en el presente, nostálgica o negativamente orientada al pasado, esperanzada o temerosa en su orientación al futuro. Por este motivo, en su investigación identificó cinco tipos de orientaciones predominantes: orientación positiva y negativa al pasado, orientación al futuro y dos orientaciones hacia el presente, una hedónica y otra fatalista.

Las personas orientadas positivamente al pasado tienen tendencia a reflejarse en experiencias pasadas, lo que les genera sentimientos de fortaleza y bienestar. Por el contrario, aquellas orientadas negativamente muestran una visión pesimista y aversiva hacia el pasado, problemas con las relaciones interpersonales, falta de ejercicio físico e 
insatisfacción con las circunstancias de vida presentes. Las personas que están orientadas hacia el futuro se preocupan por sus metas y refuerzos futuros. Finalmente, las personas centradas hedónicamente en el presente se caracterizan por "vivir el momento" y por mayores hábitos no saludables (tabaco, alcohol, drogas, etc.). Muestran una orientación hacia el bienestar presente con poca preocupación por las consecuencias futuras. Sin embargo, las centradas fatídicamente, muestran desesperanza y falta de control en las situaciones a las que deben enfrentarse, además de correlacionar significativamente con la agresividad, ansiedad y depresión (Zimbardo \& Boyd, 1999). La mayor parte de las investigaciones se han centrado en la perspectiva de tiempo futura, desarrollada originalmente por Lewin (1942) que la definió como el grado o el modo en el cual el futuro cronológico se integra en el espacio presente del individuo. Es una variable esencialmente motivacional en tanto que implica la anticipación presente de metas futuras (Lens, Simons \& Dewitte, 2001). Está representada por las metas concretas que las personas desean obtener, por las tareas que le gustaría realizar y en lo que la persona espera convertirse.

\subsection{3.- Cronopsicología}

Es necesario recordar aquí, que el modelo de activación general del organismo juega un papel importante en la explicación y comprensión de la ritmicidad diaria de la actividad humana, sobre todo la intelectual. Desde 1908, cuando Yerkes y Dodson lanzaron su hipótesis del nivel óptimo de activación, sabemos que el modelo general de la relación entre activación y rendimiento adopta la forma de $\mathrm{U}$ invertida, tal y como puede apreciarse en la figura 5: 


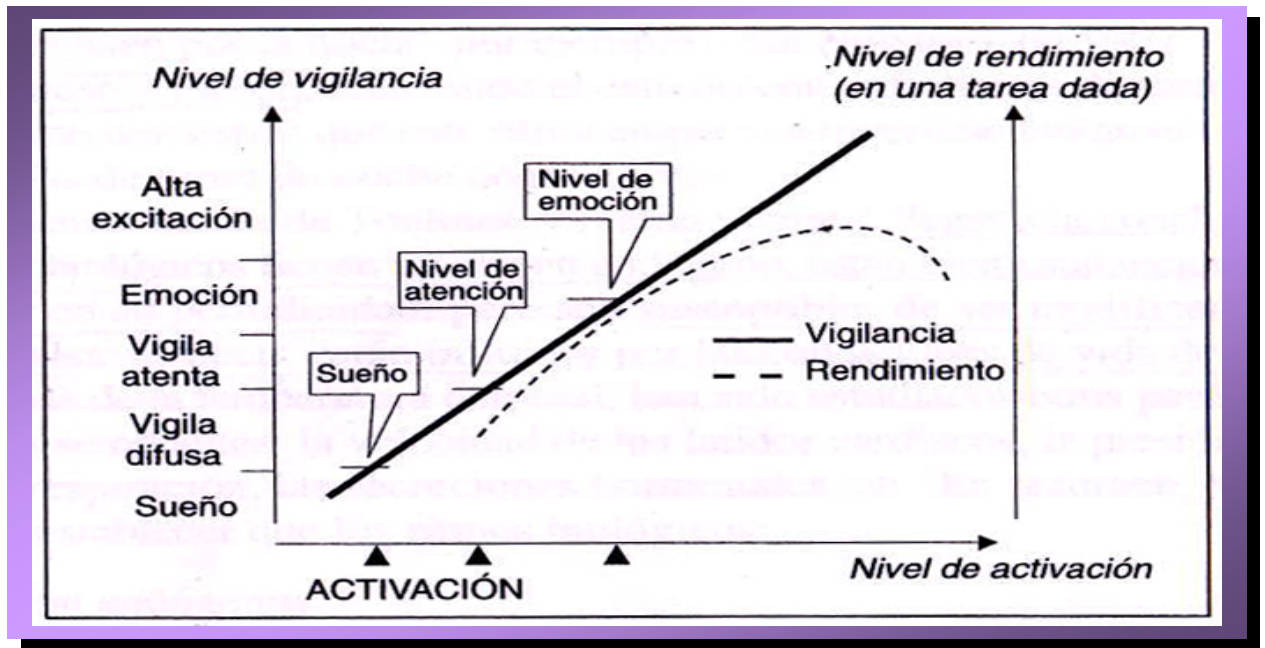

Fig. 5: Modelo de Activación y Rendimiento (Yerkes \& Dobson, 1908)

\subsubsection{1.- Los ritmos biológicos}

La existencia de ritmos biológicos es conocida desde la antigüedad. Los griegos ya sabían que las hojas de ciertas plantas no guardaban la misma posición durante las horas del día y de la noche. Sin embargo, hechos como la migración de las aves y la hibernación de algunos mamíferos y reptiles, fueron considerados durante mucho tiempo como simples consecuencias de la acción de factores ambientales y astronómicos (Cardinali \& Golombek, 1994).

Esto fue así hasta que en el año 1729, el botánico Jean-Jacques d'Ortous de Mairan, observó que los movimientos diarios de las hojas de la Mimosa pudica persistían aun situando la planta en la oscuridad en el interior de un armario. Esta idea, chocaba directamente con la creencia de la época que afirmaba que los cambios periódicos del medio ambiente eran los únicos agentes causales de los ritmos biológicos. 
Las observaciones sobre las plantas tardaron casi un siglo en ser trasladadas a los animales y los humanos, y no fue hasta finales del siglo XIX cuando aparecieron algunas descripciones sobre los ritmos diarios de la temperatura en trabajadores a turnos o en soldados durante guardias nocturnas.

En la década de los años 30 del siglo XX, se funda la primera sociedad científica dedicada al estudio de los ritmos biológicos (Society for Biological Rhythms). En 1958, otro botánico, E. Bünning, publica el libro “El reloj fisiológico” y en 1960 tiene lugar en Estados Unidos el primer simposio sobre ritmos biológicos, considerado como el nacimiento de la cronobiología como disciplina científica.

Si aislamos al hombre de su medio natural y lo colocamos en condiciones constantes de laboratorio, se repiten los ritmos que habían experimentado antes del aislamiento, aunque con ligeras diferencias en la longitud de los periodos. Esto lleva a poder afirmar que, en la práctica, todo organismo viviente funciona como si tuviera un reloj biológico endógeno (Cardinali \& Golombek, 1994).

Es muy importante diferenciar los conceptos de marcapasos y oscilador (Wever, 1985). Un oscilador es cualquier sistema capaz de generar cambios cíclicos. Un marcapasos puede estar constituido por uno o más osciladores. Un oscilador puede no constituir un marcapasos, como ocurre en muchas regiones del sistema nervioso central, mientras que un marcapasos debe ser un oscilador.

Cuando un organismo se encuentra aislado de cualquier referencia temporal externa, es decir, bajo condiciones ambientales constantes, decimos que se encuentra en curso libre (Weitzman, Zimmerman \& Czeisler, 1983; Wever, 1985). El periodo del ritmo que se manifiesta en curso libre se conoce como periodo endógeno y se designa 
con la letra griega tau $(\tau)$. Si las condiciones ambientales se mantienen constantes, el valor de tau es muy estable, de forma que es una de las características más estables del ritmo de un organismo. El ritmo tau es una característica propia de cada especie que se transmite de forma mendeliana y que por tanto es probable que se encuentre determinada genéticamente. Como la duración de los ciclos circadianos en curso libre no siempre es de 24 horas, debemos referirnos a ellos como días subjetivos que, esto sí, se dividen en 24 horas subjetivas y horas circadianas $(1$ hora circadiana $=$ tau/24). En este caso nos referimos a tiempo circadiano (Weitzman, et al., 1983).

Los ritmos biológicos se caracterizan por una alta gama de frecuencias que van desde un ciclo por milisegundo, hasta un ciclo cada varios años. La tabla 4 muestra un resumen de la clasificación de los ritmos biológicos:

\begin{tabular}{|c|c|c|c|}
\hline & $\begin{array}{l}\text { Alta frecuencia } \\
(\tau>0.5 \mathrm{~h})\end{array}$ & $\begin{array}{l}\text { Frecuencia Media } \\
(0.5 \mathrm{~h}<\tau<6 \text { días })\end{array}$ & $\begin{array}{l}\text { Baja Frecuencia } \\
\text { ( } \tau>6 \text { días) }\end{array}$ \\
\hline PERIODOS & $\begin{array}{l}\tau=0.10 \mathrm{~s} \\
\tau=0.01 \mathrm{~s}\end{array}$ & $\begin{array}{l}\text { Ultradiano }(\tau=0.5 \mathrm{~h}-20 \mathrm{~h}) \\
\text { Circadiano }(\tau=20-28 \mathrm{~h}) \\
\text { Infradiano }(\tau>28 \mathrm{~h}) \\
\text { Circamareal }(\tau=12 \mathrm{~h})\end{array}$ & $\begin{array}{l}\text { Circaseptano } \\
\text { ( } \tau=7 \text { días) } \\
\text { Circadiseptano } \\
(\tau=14 \text { días }) \\
\text { Circavigintano } \\
(\tau=20 \text { días }) \\
\text { Circatrigintano } \\
\text { ( } \tau=30 \text { días) } \\
\text { Circanual } \\
\text { ( } \tau=1 \text { año) }\end{array}$ \\
\hline Ritmos en: & $\begin{array}{l}\text { - Electroencefalograma } \\
\text { - Electrocardiograma. } \\
\text { - Respiración. } \\
\text { - Peristalsis. }\end{array}$ & $\begin{array}{l}\text { - Sueño - vigilia. } \\
\text { - Reposo - Actividad. } \\
\text { - Movimientos oculares. } \\
\text { - Componentes en sangre y } \\
\text { orina. } \\
\text { - Procesos Metabólicos. }\end{array}$ & $\begin{array}{l}\text { - Apareamiento. } \\
\text { - Migración. } \\
\text { - Menstruación. }\end{array}$ \\
\hline
\end{tabular}

Tabla 4: Clasificación de ritmos biológicos

Puede definirse la Cronobiología como el estudio de las estructuras asociadas al tiempo en el ámbito de los seres vivos (Pérez, 1995). También ha sido definida como el 
estudio de la naturaleza y el origen de las actividades bioperíodicas en toda la jerarquía de los seres vivos y en todos los niveles de organización humana (Sánchez, 1999).

Un ritmo está caracterizado por los siguientes parámetros:

Periodo: definido como el intervalo en el tiempo entre dos acontecimientos idénticos, es decir, la duración de un ciclo completo. Algunas veces, en lugar de periodo, se utiliza el término frecuencia, definido como el número de ciclos que ocurren por unidad de tiempo. Por lo general, la frecuencia se utiliza para caracterizar ritmos más bien rápidos (electroencefalograma, electrocardiograma).

Nivel medio (o mesor): valor medio de la variable estudiada, calculado a lo largo de un periodo completo.

Amplitud: diferencia entre el mesor y el valor máximo alcanzado por la variable durante el periodo. Si bien es de enorme importancia en la fisiología clásica, su valor como marcador de un ritmo biológico es menos relevante.

Fase: describe la relación entre dos o más ritmos. En ocasiones este término se utiliza para definir una parte del ciclo (fase ascendente o descendente). Nos indica en qué momento del curso temporal está situado el ritmo biológico en estudio. La fase está referida a otra función periódica que puede ser externa (hora del día) o interna (otro ritmo biológico). Para caracterizar la fase, lo más usual es determinar el momento (hora del día) en el que la variable estudiada alcanza su valor máximo a lo largo del ciclo periódico; a este tiempo se lo denomina acrofase, y batifase al momento en el que la variable muestra su menor amplitud. 
Actualmente, el término ritmo biológico es aplicado a toda oscilación, regular en el tiempo, de una variable biológica, cualquiera que sea el nivel de organización considerado (Cardinalli \& Golombek, 1994). Los ciclos que más atención han recibido, debido a su creciente importancia biomédica, son aquellos cuyo periodo fluctúa alrededor de 24 horas (circadianos). Los ritmos circadianos presentan un periodo de 20 22 horas como límite inferior y de 26-28 horas como límite superior. Los ritmos de periodicidades más rápidas son llamados ultradianos, mientras que los de menos frecuencia se denominan infradianos (Cardinalli \& Golombek, 1994; Madrid, 2006).

Madrid (2006) propone la existencia de relojes biológicos asociados a diferentes estructuras anatómicas. El primero de ellos - etiquetado cerebral de los sucesos-, no es estrictamente un reloj biológico, pero es importante para saber cuándo han tenido lugar los acontecimientos almacenados en nuestra memoria. Todos los recuerdos van asociados a una dimensión temporal. En la actualidad se han identificado tres áreas cerebrales relacionadas con la percepción temporal de los acontecimientos. Los estudios llevados a cabo en pacientes con lesiones cerebrales, ponen de relieve que estructuras del lóbulo temporal, del hipocampo y del prosencéfalo basal son importantes para guardar y recuperar la información relacionada con la temporalidad de los acontecimientos, áreas consideradas esenciales en los estudios sobre la memoria.

En segundo, llamado reloj de intervalos, es importante porque nos permite conocer y juzgar el paso subjetivo del tiempo. No es muy preciso, pero nos ayuda a sentir cómo el tiempo se expande o se acorta en función del tipo de vivencias. Según Meck (2005), los circuitos implicados en este reloj se establecen entre la corteza, la sustancia negra y el núcleo estriado, estando ciertos neurotransmisores como la 
dopamina y la noradrenalina implicados en su funcionamiento. Por ejemplo, los pacientes con Parkinson que liberan menos dopamina en el estriado, sus relojes se retrasan y tienden a infravalorar sistemáticamente la duración de los intervalos temporales. Por el contrario, drogas estimulantes como la cocaína, aumentan la disponibilidad de dopamina y, por lo tanto aceleran el reloj de intervalos, con lo que el tiempo parece discurrir más deprisa. Además, añade que los estados de concentración profunda o de emoción intensa podrían bloquear este sistema, produciendo la sensación de que el tiempo se detiene por completo.

El tercer reloj propuesto por Madrid (2006) se establece a nivel celular. Cada célula de nuestro organismo posee su propio reloj interior, el cual funciona según el principio del reloj de arena. Cuando una célula se divide, la longitud de los telómeros se acorta, de tal modo que se puede determinar la edad de una célula examinando la longitud de su telómero. Hay estudios que demuestran que esta pérdida de longitud es progresiva y participa en el envejecimiento, ya que cuando los telómeros se han acortado un número determinado de veces, se producen desestabilizaciones cromosómicas que llevan a la apoptosis celular (Nordfjäll, et al., 2009). 

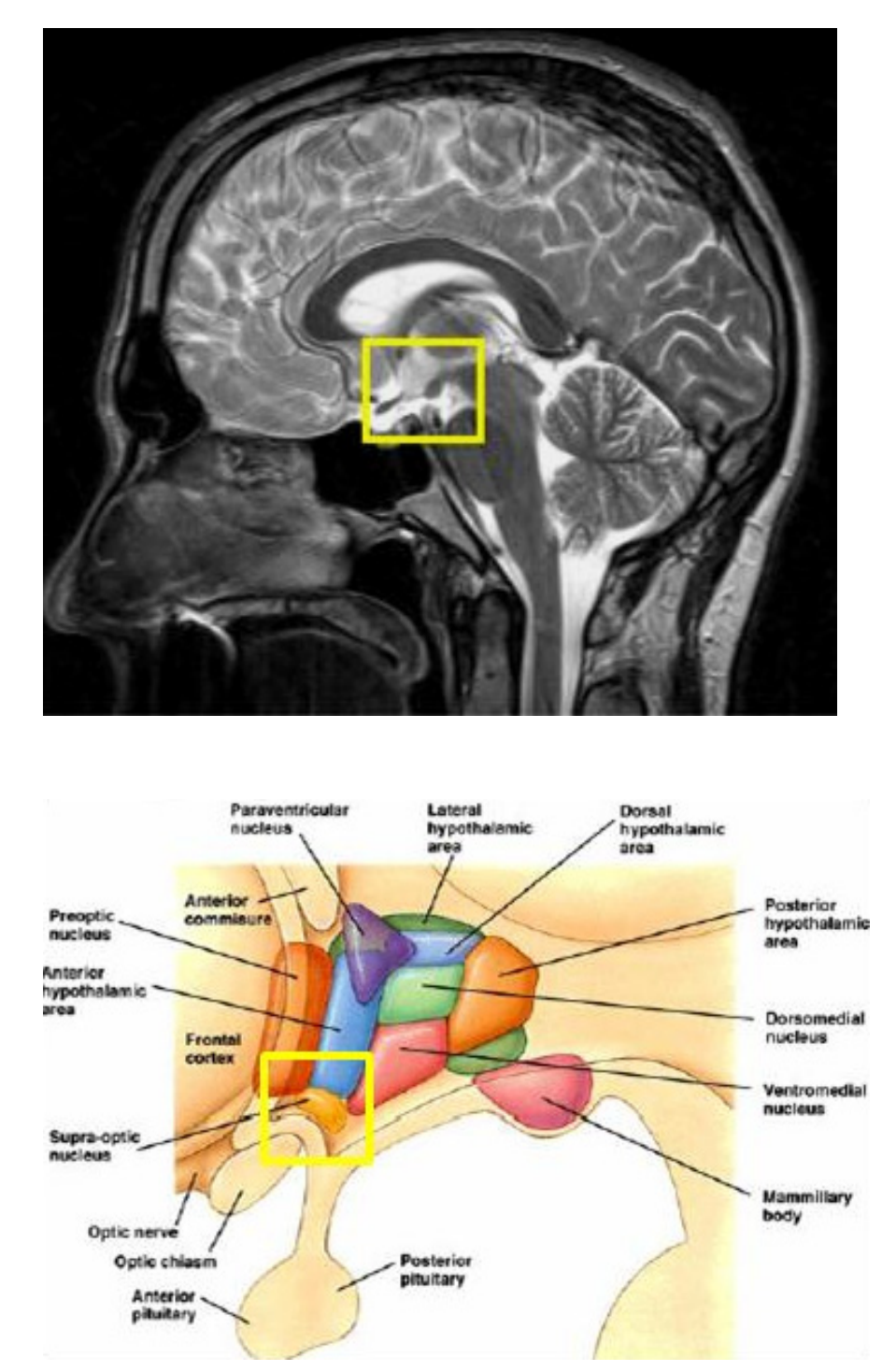

Fig. 6: Núcleos supraquiasmáticos del hipotálamo

Por último, el reloj circadiano es de vital importancia para la supervivencia de las especies. La selección natural ha favorecido que todos los organismos posean relojes que generan oscilaciones con periodos de aproximadamente 24 horas. En los mamíferos, el reloj o marcapasos circadiano principal se localiza en los núcleos supraquiasmáticos del hipotálamo (NSQ). Los NSQ son dos estructuras ovales 
localizadas en la base del hipotálamo, dorsales al tercio caudal del quiasma óptico y ventrolaterales al tercer ventrículo. Los núcleos están constituidos por cerca de 16.000 neuronas, pequeñas y densamente empaquetadas junto con otras células de sostén como las células de la glía (Cambras, 2006) y un volumen total de $0,068 \mathrm{~mm}^{3}$ (Moore, 1983).

La generación de oscilaciones parece ser el resultado de la actuación de relojes moleculares en cada una de las neuronas individuales de los núcleos supraquiasmáticos. Éstos, son los responsables de la mayoría de los ritmos circadianos, como ha sido demostrado en los estudios de lesión y posterior registro de actividades, como la actividad motora o la temperatura corporal.

Es evidente que si el curso de la evolución ha mantenido el reloj circadiano es porque los individuos que lo poseen tienen ciertas ventajas sobre los demás, ya que realiza funciones importantes:

1.- Permite una organización temporal, de manera que las actividades y la conducta de los organismos tengan lugar en "el tiempo correcto".

2.- Por otra parte, una estructura rítmica permite también la organización temporal entre especies (especies diurnas y nocturnas que comparten un mismo nicho ecológico).

3.- El reloj biológico permite también una anticipación a los cambios del medio ambiente (estacionales, luz-oscuridad), lo cual incrementa la probabilidad de supervivencia de la especie (Cambras, 2006).

Las características fundamentales de los ritmos circadianos son tres: 
1.- Los ritmos tienen carácter endógeno, es decir, un organismo es capaz de generar ritmos por sí mismo, sin necesidad de cambios externos.

2.- Capacidad de sincronización, que permite que los organismos que se encuentran bajo condiciones ambientales rítmicas cambien el valor del periodo de su ritmo endógeno y adopten el mismo período que el medio ambiente.

3.- El reloj circadiano tiene capacidad para compensar los cambios de temperatura. Esta característica fue descrita por Pittendrigh en 1960, y es importante en la naturaleza para evitar cambios innecesarios de periodo como consecuencia de un cambio brusco en la temperatura ambiente de un día.

El reloj circadiano es un reloj automático, independiente de las condiciones externas, con un mecanismo que le permite ser autónomo y otro que le permite ponerse en hora con el ciclo externo. Es decir, tener un ritmo endógeno no es suficiente para garantizar la supervivencia del individuo, hace falta una sincronización al medio externo, de manera que las funciones del organismo tengan lugar en el momento más adecuado. Los ritmos biológicos tienen la capacidad de ser encarrilados con los ciclos ambientales. Los agentes externos cíclicos capaces de encarrilar los ritmos biológicos reciben el nombre de agentes "sincronizadores" o Zeitgebers, siendo el más importante el ciclo luz-oscuridad (Cambras, 2006; Madrid, 2006).

A nivel neurobiológico, el sistema circadiano es el conjunto de estructuras cuya misión consiste en organizar los ritmos de determinados procesos fisiológicos (MillarCraig, Bishop \& Raftery, 1978; Sokolow, Werdegnar, Kaim \& Hinman, 1996). Este sistema consta de las siguientes estructuras:

- El Núcleo supraquiasmático (NSQ). 
- Las vías aferentes, que conducen información de señales externas al organismo u otras zonas del sistema nervioso al NSQ.

- Vías eferentes, que acoplan el marcapasos con los sistemas efectores que producen los ritmos.

Como ya se ha mencionado, los mamíferos se caracterizan por la actividad de un reloj primario localizado en los Núcleos Supraquiasmáticos en la zona ventral del hipotálamo anterior (Ver figura 6, página 110).

Estructuralmente no son homogéneos: existen por lo menos dos zonas citoquímicamente bien diferenciadas conocidas como centro (core) y corteza (shell). El centro recibe principalmente señales de tipo fóticas, críticas para la sincronización del marcapasos al ciclo luz-oscuridad, mientras que la corteza recibe aferencias no fóticas de tipo moduladoras. Ambas regiones contienen GABA, angiotensina II y factor liberador de tirotrofina.

La vía directa desde las células glanglionares de la retina al reloj es el Tracto retinohipotálamico (RHT). En los somas de las células ganglionares se han descubierto los fotorreceptores circadianos, además de los clásicos (conos y bastones), que utilizan el pigmento melanopsina. En esta vía principal se libera el neurotrasmisor glutamato.

Así mismo, existe una vía indirecta desde la retina: proviene de la lámina intergeniculada (IGL) vía el tracto genículo hipotalámico (GHT). Aquí se liberan GABA y encefalinas.

Una tercera inervación nace en los núcleos del rafe y libera fundamentalmente serotonina. 
Todas las vías provenientes de la retina, de estructuras talámicas y del tronco encefálico son importantes porque serán las responsables de "informar" al reloj de lo que ocurre en el ambiente, y, sobre todo, qué sucede con la luz.

Las vías eferentes se pueden clasificar según la zona del sistema nervioso central a la que se proyectan. Entre las eferencias desde los NSQ se cuentan la inervación al núcleo paraventricular del hipotálamo y una proyección a los ganglios cervicales superiores, que proyectan a su vez a la glándula pineal. Los destinos hipotalámicos son áreas involucradas en el control endocrino y autonómico. También existen eferencias al área preóptica, involucrada en la regulación de la temperatura, balance de fluidos y la conducta sexual; y, finalmente, vías eferentes al área retroquiasmática, desde la cual se envían señales a los hemisferios cerebrales (regulación de la conducta), tronco encefálico (regulación autonómica) y a la médula espinal (control sensorial y motor). Por otro lado, las vías eferentes que se dirigen a partes fuera del hipotálamo incluyen las que se proyectan al tálamo (locomoción), sistema límbico (memoria y tono afectivo) y al núcleo geniculado lateral (Aguilar-Robledo, Mercado, Guadarrama \& Chávez, 2004).

La glándula pineal secreta la hormona melatonina, considerada como la hormona de la oscuridad, ya que tiene un máximo durante la noche y ha sido implicada en la regulación del sueño y los ciclos estacionales. El modo en que los NSQ comunican a la pineal el fotoperiodo, es mediante una conexión que parte de los mismos hacia el núcleo paraventricular del tálamo y la estación de relevo autonómica del ganglio cervical superior. Desde allí las fibras noradrenérgicas inervan a la pineal, donde los receptores adrenérgicos alfa y beta regulan a las encimas que participan en el metabolismo de la melatonina. 
La melatonina actúa como un sincronizador endógeno de los ritmos circadianos. Entre los ritmos sincronizados por esta hormona están aquellos relacionados con la liberación de los neurotransmisores en el cerebro y los de sus receptores. Es lógico pensar que si la melatonina regula a los neurotransmisores, la función de éstos también dependerá de dicha hormona. Tal es el caso de la capacidad de concentración, la destreza o el ritmo sueño-vigilia, que siguen un ritmo circadiano dependiente de la melatonina.

Los efectos centrales de la melatonina consisten en una inhibición de la actividad cerebral, es decir, que la secreción de melatonina al torrente sanguíneo va a impedir la existencia de situaciones de hiperexcitabilidad cerebral (Acuña \& Escames, 2006).

Esta actividad depresora de la melatonina sobre el cerebro puede producirse principalmente por tres mecanismos:

1.- Aumento de la neurotransmisión inhibidora, fundamentalmente actuando en el complejo receptor GABA-Benzociazepinas.

2.- Disminución de la neurotransmisión excitadora, actuando sobre los aminoácidos excitadores.

3.- Produciendo cambios en la permeabilidad de la membrana, conduciendo a cambios en el potencial de membrana y/o en los sistemas de segundos mensajeros.

También conviene destacar el efecto sobre los niveles de Dopamina de la melatonina. La Dopamina es un neurotransmisor que está implicado en el control motor, en la conducta dirigida a meta, en el deseo, en el placer, en el control de la ingesta de alimentos y líquidos, etc. Además, se sabe que su déficit está implicado con la 
enfermedad de Parkinson, debido a las alteraciones motoras que aparecen tras la degeneración de la vía nigro-estrial dopaminérgica. Se ha observado la existencia de un ritmo circadiano de la dopamina en la retina, con un pico diurno, mientras que en el caso de la melatonina el pico de su ritmo circadiano es nocturno. El aumento nocturno de melatonina es el responsable de la inhibición de la dopamina retiniana (Acuña \& Escames, 2006).

\subsubsection{2.- Cronopatología}

Podemos definir la Cronopatología como la especialización de la cronología que estudia las alteraciones de las características temporales que determinan un estado patológico o un resultante de éste (Beugnet-Lambert, Lancry \& Leconte, 1988).

Toda alteración de los ritmos biológicos, cualquiera que sea su procedencia, interna (trastornos neurofisiológicos) o externa (turnos rotativos de trabajo, por ejemplo), puede tener muchas consecuencias sobre nuestro equilibrio psicológico (Sánchez, 1999).

Si ciertos neurotransmisores se producen y actúan siguiendo un ritmo circadiano y si estos ritmos, tanto de la síntesis de los neurotransmisores como de sus receptores, están sincronizados por el ritmo circadiano de la melatonina, cabría preguntarse si la alteración de los ritmos puede producir enfermedad. La respuesta, según los datos debe ser afirmativa. Es decir, si la alteración del sistema circadiano desincroniza el balance entre los ritmos de los neurotransmisores excitadores e inhibidores, la actividad eléctrica cerebral se verá afectada $\mathrm{y}$, por tanto, deberían ponerse de manifiesto estados patológicos más o menos severos. Esto se pone de manifiesto en los efectos anticonvulsionantes encontrados en la melatonina en el tratamiento de la epilepsia y en 
la disminución de los temblores y de la somnolencia en los enfermos de Parkinson (Acuña y Escames, 2006).

Para el diagnóstico de los trastornos del ritmo circadiano según el DSM-IV (APA, 1994) deben cumplirse los siguientes criterios:

a-Presencia persistente o recurrente de un patrón de sueño desestructurado que obedece a una mala sincronización entre el sistema circadiano endógeno de sueñovigilia del individuo, por una parte, y las exigencias exógenas de espaciamiento y duración del sueño, por otra.

b-Las alteraciones del sueño provocan un malestar clínicamente significativo o deterioro social, laboral o de otras áreas importantes de la actividad del individuo.

c-Las alteraciones del sueño no aparecen exclusivamente en el transcurso de otro trastorno del sueño u otro trastorno mental.

d-El trastorno no se debe a los efectos fisiológicos directos de una sustancia (por ejemplo, drogas o fármacos) o de una enfermedad médica.

El manual señala que hay que especificar un tipo, entre los siguientes:

1.Tipo sueño retrasado: patrón de sueño persistente que consiste en acostarse y despertarse tarde, con incapacidad para conciliar el sueño y levantarse a horas más tempranas pese a desearlo.

2. Tipo jet lag: somnolencia y estado de alerta presentes en momentos del día inadecuados, y que aparece después de repetidos viajes transmeridionales a zonas con diferente huso horario. 
3.Tipo cambio de turno de trabajo: insomnio que aparece durante las horas que el individuo debería dormir o somnolencia excesiva durante las horas en que debería estar despierto, debido a un turno de trabajo nocturno o a un cambio repetido del turno de trabajo.

Los trabajadores a turnos, están más insatisfechos con su trabajo, y muchas veces se traduce en deterioros en la vida familiar y en la autoestima. Es sabido que el número de divorcios y la violencia doméstica aumentan en los hogares en los que uno de los miembros trabaja a turnos (Rial, Garau, Aparicio \& Esteban, 2006).

4.Tipo no especificado: (por ejemplo, patrón de sueño avanzado, ausencia de patrón sueño-vigilia de 24 horas o patrón de sueño-vigilia irregular).

En cuanto al tipo no especificado, otros autores como Buela-Casal y Sierra (1995, 2008), describieron los trastornos señalados dentro de este grupo. Así, señalan las características que siguen:

1.Insomnio relacionado con un ciclo diferente a 24 horas: este tipo de paciente presenta un ritmo de sueño-vigilia que no sigue las 24 horas habituales produciéndose una desincronía con el horario habitual del ambiente. Cuando el ritmo se acerca a 180 grados de desplazamiento con el ambiente, el sujeto manifiesta somnolencia durante el día y una gran activación durante la noche; a continuación, de forma gradual, el ritmo se sincroniza y, nuevamente, se desincroniza.

2.Insomnio por pauta irregular del ciclo vigilia-sueño: este trastorno está presente en aquellos sujetos que no tienen un horario regular mínimo para acostarse, entre los que cabe destacar la tripulación de vuelos intercontinentales y los trabajadores a turnos. 
3.Insomnio por tendencia de sueño retrasado e insomnio por tendencia de sueño adelantado: en el primer caso, la fase de sueño del ritmo circadiano aparece más tarde debido al horario normal de acostarse; así, el sujeto cuando se acuesta no se duerme y al levantarse se encuentra con sueño y cansado. En el segundo caso, sucede lo contrario; estos pacientes se levantan temprano por la mañana y se acuestan pronto, puesto que a última hora de la tarde, ya se sienten somnolientos.

La melatonina actúa como un zeitgeber endógeno y sus efectos sobre el sistema circadiano son opuestos a los de la luz: cuando la luz avanza la fase de un ritmo, la administración de melatonina lo retrasa y viceversa. La capacidad de la melatonina para sincronizar ritmos depende de la integridad del NSQ, por lo que puede ser razonable que la administración de melatonina pueda tener importancia terapéutica para el tratamiento de los insomnios de tipo circadiano.

Con respecto a la alteración del ritmo sueño/vigilia por desincronización a las 24 horas, la administración de melatonina sincroniza dicho ritmo, aunque en algunos casos el ritmo endógeno de melatonina permanece desincronizado (período mayor de $24 \mathrm{~h}$.). En el síndrome por avance de fase del sueño, la administración de melatonina al final de la noche puede ser útil para retrasar la fase del ciclo sueño/vigilia. En pacientes pediátricos con perfil sueño/vigilia irregular, con un sueño muy fragmentado, la melatonina puede resincronizarlo, lo que sugiere que ésta actúa en el acoplamiento de los subosciladores que constituyen el oscilador circadiano central.

\subsubsection{3.- Componentes rítmicos de la personalidad}

Las relaciones entre la tipología circadiana y otras variables, tanto fisiológicas como psicológicas, han despertado el interés de los investigadores (Tankova, Adan \& 
Buela-Casal, 1994). El estudio de las diferencias interindividuales en estas variaciones rítmicas, ha permitido establecer tres tipos de sujetos o "cronotipos": el matutino, el vespertino y el indiferenciado. Estas etiquetas denominan a los tipos extremos de un espectro de diferencias individuales en la preferencia temporal por realizar las actividades diarias (Díaz \& Aparicio, 2003).

Las personas matutinas prefieren realizar sus actividades durante la mañana, mientras que las personas vespertinas prefieren la tarde. Las personas intermedias no mostrarían una clara preferencia.

Esta diferencia entre las fases de los dos tipos de sujetos está causada por diferencias entre los sistemas circadianos de los individuos y no por factores ambientales. Recientemente se ha demostrado que existe un polimorfismo en un nucleótido simple en el gen CLOCK que puede explicar la diferencia entre madrugadores y trasnochadores (De la Iglesia, 2006).

Desde un punto de vista fisiológico, las personas matutinas y vespertinas se diferencian en sus ritmos biológicos, siendo la temperatura corporal una de las variables más estudiada. Las personas matutinas tienen un pico máximo (acrofase) antes que los vespertinos (de una a tres horas) (Tankova et al., 1994).

Desde un punto de vista psicológico, aún no se conoce con precisión el perfil de personalidad de las personas matutinas y las vespertinas. La tipología circadiana es considerada una variable de personalidad (Matthews, 1988) y, como tal, muestra relaciones convergentes y divergentes con otras características personales (Díaz \& Aparicio, 2003). 
En general, los resultados indican que la matutinidad se asocia negativamente con la extroversión (Adan, 1997; Tankova et al., 1994). Larsen (1985), señala que la tendencia a la vespertinidad se relaciona con la sociabilidad, pero no con la impulsividad. Wilson (1990) encuentra un mayor nivel de activación en los introvertidos, particularmente por la mañana. Para este autor, la sociabilidad, más que la impulsividad, parece que es el componente que explicaría esta interacción. Neubauer (1992) también encuentra una mayor tendencia a la extraversión en los vespertinos, concluyendo que es la impulsividad, más que la sociabilidad, la responsable de esta asociación. Siguiendo el modelo de personalidad de Millon, Díaz y Aparicio (2003), indican una relación entre la matutinidad y las escalas sensación, intuición, innovación y conformismo, describiendo la tendencia que tendrían estos sujetos a procesar la información del entorno atendiendo a datos concretos y a la experiencia directa (sensación), más que orientándose a datos simbólicos, experiencias abstractas o ambiguas (intuición). Además, se relacionaría de manera inversa con la innovación, es decir, con la tendencia a acomodar la información del entorno a esquemas de conocimiento nuevos, o a adoptar un punto de vista creativo. Por último, señalan, que las personas matutinas adoptan un estilo de personalidad respetuoso con las normas y los convencionalismos sociales (conformismo).

Los resultados sobre la relación entre matutinidad/vespertinidad y otras variables de personalidad no son concluyentes, a pesar de lo importante que podría ser dilucidar estas discrepancias con su aplicación práctica en ámbitos como el diseño de horarios laborales (Smith, Reilly \& Midkiff, 1989; Furham \& Hughes, 1999), rendimiento deportivo (Smith, Guilleminault \& Efron, 1997) y el desempeño escolar (Testu, 1989). 
El desajuste entre la orientación de la persona y los horarios de su entorno, puede producir o incrementar el riesgo de problemas psicológicos y psicosomáticos (Folkard \& Monk, 1985). Por ejemplo, para Mecacci y Rochetti (1998) las personas vespertinas muestran dificultades de afrontamiento del entorno y de las demandas sociales, así como mayor nivel de estrés percibido. La hipótesis de estos autores es que las personas vespertinas muestran un desajuste con respecto a las actividades laborales y sociales que se desarrollan principalmente durante la mañana y, en este sentido, postulan que las personas vespertinas pueden mostrar estilos de vida con un mayor nivel de estrés, indicando su posible relación con un mayor riesgo de padecer problemas cardiovasculares (Nebel, et al., 1996).

Entre las vías de estudio en relación con las alteraciones relacionadas con la variable tiempo destaca lo que se denomina "procrastination." Este rasgo de personalidad se caracteriza por la incapacidad que tienen determinadas personas para gestionar su tiempo de forma efectiva, de modo que llevan a cabo conductas dilatorias por las cuales van "dejando para mañana” las tareas que deben realizar (Sánchez, 1999). En un estudio de Flett, Blankstein y Martin (1995), se mostró que las personas con "procrastination" tendían a evaluarse de forma más negativa que los "no procrastination". Anteriormente, Ferrari, (1991a), encontró un estilo evitativo en la toma de decisiones y una intensa preocupación por llevar a cabo conductas socialmente adecuadas. Más recientemente, en un estudio longitudinal realizado con estudiantes, Tice y Baumeister (1997) reflejaron que los "procrastinators" informaban de niveles más bajos de estrés y enfermedad que los "nonprocrastinators" en el primer semestre del curso, pero que al final del curso presentaban niveles de estrés y enfermedad mucho más elevados, lo que indica que la procrastination o dejarlo para mañana tiene 
beneficios a corto plazo, pero costes importante a largo plazo. Para medir este rasgo existen cuestionarios como la "General Procrastination Scale, de Lay (Lay \& Brokenshire, 1997). 


\subsection{Tiempo y Psicopatología}

El primer autor que se esfuerza por unir lo dicho por la filosofía respecto a la temporalidad con la psicopatología del tiempo y el tiempo vivido fue Minkowski (18851972). Así, a través de sus estudios sobre esquizofrenia y depresión plasmó su concepción de la temporalidad en el libro "El tiempo vivido" (1933/1973). Los postulados centrales del autor se pueden resumir en los siguientes puntos:

- Ni la idea de tiempo mensurable en el dominio de lo "normal", ni la noción de desorientación en el tiempo en el dominio de lo patológico, son capaces de describir totalmente y con exactitud el fenómeno del tiempo vivido.

- El punto de partida es el concepto de tiempo que usa Bergson según el cual el tiempo fluye, pasa, huye de modo inevitable, pero también avanza, progresa, y va hacia un futuro indefinible e inasible (citado por Minkowsky, 1973, Pag. 22).

- Nuestra vida está esencialmente orientada hacia el futuro, lo vivimos de un modo más directo e inmediato, todas nuestras miradas se dirigen a él.

- Los fenómenos vitales susceptibles de dar respuesta a cómo vivimos el futuro son la actividad y la espera, el deseo y la esperanza.

- La actividad es una manifestación global del ser viviente, dirigida hacia un objetivo preciso. Es un fenómeno esencial de la vida: todo lo que vive es activo y todo lo que es activo vive. Es un fenómeno de naturaleza temporal, no forma parte del ser, sino del devenir. Por su actividad, el ser viviente avanza, tiende hacia el futuro, lo crea delante de él. Entraña también el factor duración, la duración activa o la orientada hacia el futuro. La actividad es un 
auténtico marchar hacia delante y constituye el único medio de avanzar realmente en la vida.

○ La espera es un fenómeno vital que se opone a la actividad. Existe la espera de un acontecimiento preciso que se producirá en un momento determinado, por ejemplo, la espera de un tren que debe pasar dentro de media hora. Esta espera estaría impregnada de tiempo mensurable. Tiempo que puedo emplear en otra actividad. En la actividad tendemos hacia el futuro; en la espera vivimos el tiempo en un sentido inverso, lo vemos venir y esperamos que este futuro previsto se haga presente. Pero también tenemos la espera en cuanto actitud vital que abarca a todo el ser, suspende su actividad y lo congela, angustiado, en la espera. Dicha actitud contiene un factor de detención y hace ansioso al individuo. La espera puede tender a infinito, con el límite de la psicopatología o de la muerte. La espera está más próxima a la sucesión, a la instantaneidad, que a la duración.

- El deseo y la esperanza están por encima de la actividad y de la espera. Se dirigen hacia el futuro y contribuyen a crearlo delante de nosotros. Alejan lo inmediato, y nos ponen en relación con lo mediato alargando singularmente la perspectiva que tenemos del futuro.

"Lo que hace de la esperanza un placer tan intenso es que el futuro, del que disponemos a nuestro antojo, se nos presenta al mismo tiempo bajo una multitud de formas igualmente sonrientes $e$ igualmente posibles. Hasta en el caso de que la más deseada de ellas se realice, será necesario sacrificar las otras y habremos perdido mucho. La idea de futuro, grávido de una infinidad de posibilidades, es así más fecunda que el futuro mismo, y por ello se encuentra más 
encanto en la esperanza que en la posesión, en el ensueño que en la realidad” (Bergson, citado por Minkowsky, 1973, pag, 89).

Las consideraciones fenomenológicas, a veces demasiado abstractas en sí, se hacen más evidentes por el hecho de aplicarlas a la psicopatología. Por otra parte, investigaciones psicopatológicas han ayudado, más de una vez, a revisar los datos fenomenológicos, a completarlos, encauzando la atención hacia puntos que hasta entonces habían quedado en la sombra.

Los esquizofrénicos y los esquizoides presentan incapacidad para disfrutar el descanso. Presentan tendencia a llenar completamente el tiempo, como un simple recipiente de ideas y acciones preestablecidas.

El fin que persigue el análisis de la estructura espaciotemporal de las perturbaciones mentales busca, no sólo encontrar los síntomas en los cuales el enfermo expresa directamente una deficiencia cualquiera en relación al tiempo y al espacio, sino que amplía, investiga, intenta que el investigador adopte una actitud de penetración del substrato espaciotemporal de todo síndrome psicopatológico.

En primer lugar, en los esquizofrénicos, las experiencias personales relativas al tiempo y al espacio vividos se producen sobre un fondo mental profundamente perturbado por la enfermedad; vinculadas también a las perturbaciones de la ideación y a la disgregación que padece el psiquismo a consecuencia de la pérdida del contacto vital con la realidad. Dado que el proceso esquizofrénico ataca el dinamismo mental, las perturbaciones del tiempo vivido son especialmente profundas. El tiempo se desfonda por completo, contrariamente a lo que sucede en otras perturbaciones mentales en las que se produce una modificación en el dominio del tiempo mismo. 
En el lado opuesto a la esquizofrenia, la clínica coloca a la locura maniacodepresiva (identificada en la actualidad como trastorno Bipolar). Un excitado maníaco contrariamente al esquizofrénico excitado, sigue en contacto con la realidad y hasta absorbe con avidez el mundo exterior. El contacto existe, se entiende, pero es únicamente un contacto instantáneo, sin penetración, no hay duración vivida en él. Lo que le falta al maníaco es el despliegue en el tiempo, no vive más que en el ahora; no hay presente en él. En sus frases, da preferencia a la forma gramatical del presente, contrariamente a los esquizofrénicos, que evocan, de una manera más o menos deshilvanada, recuerdos del pasado (Minkowski, 1973).

Straus, (1928), acuñó las expresiones "tiempo del Yo" (Ich-Zeit) y "tiempo del mundo" (Welt-Zeit). Estos dos modos que intervienen en el fenómeno del tiempo vivido pueden encontrarse en armonía, pero pueden manifestarse en desacuerdo. A veces el tiempo del Yo parece avanzar más de prisa que el tiempo del mundo; tenemos la impresión de que el tiempo fluye rápidamente; la vida nos sonríe y somos felices; a veces, por el contrario, el tiempo del Yo parece ir con retardo respecto al del mundo, el tiempo entonces se eterniza, estamos tristes y el aburrimiento se apodera de nosotros. Estas diferencias en percepción del tiempo vivido dependen, por una parte de nuestros estados de ánimo y, por la otra, del ambiente con lo que éste ofrece de interesante, estimulante y variado. En los estados patológicos y particularmente en los llamados clásicamente de depresión endógena, es donde el tiempo inmanente, el tiempo del Yo, retarda su marcha hasta casi detenerse. Nuestra vida está esencialmente orientada hacia el futuro, cuando se produce un retraso patológico, está orientación se ve profundamente modificada. Según el grado de retraso será unas veces el presente y otras el pasado el que ejercerá un dominio anormal. Las perturbaciones que tienen relación con el pasar 
del tiempo se dirigirán contra la facultad de liquidar el presente y contra el sentimiento de independencia en relación al pasado. Cuando el paso del tiempo es retardado, se dan fenómenos obsesivos, fenómenos que parecen responder a la imposibilidad de avanzar y de resolver problemas. Si la inhibición aumenta y el tiempo ya no es retardado sino que parece detenerse, la degradación da un paso más y el psiquismo se ve dominado de forma absoluta por el pasado. Los diversos síntomas observados en la depresión parecen dar a entender que se produce una modificación profunda de la estructura del tiempo, modificación que implica un contraste, mayor o menor, entre el tiempo inmanente y el tiempo transitivo, es decir, entre el tiempo del Yo y el tiempo del mundo (Straus, 1928, (citado por Minkowski, 1973 pp. 276-278).

Los trastornos afectivos tienen que ver con el tiempo, con la percepción del tiempo, con el patrón cíclico del tiempo, diario o estacional (Yannielli, 2007).

Las patologías que involucran desórdenes de la afectividad o emocionalidad se caracterizan a menudo por presentar patrones anormales en los ritmos circadianos, o más genéricamente, en la estructura temporal (Wirz-Justice, 2003).

La prevalencia de la disfunción circadiana en los estados afectivos sugiere que el sistema circadiano humano proporciona una información importante relacionada con la etiología y el tratamiento de la enfermedad. De hecho, se ha confirmado que algunas alteraciones circadianas producen enfermedad, y que la corrección de dichas alteraciones rítmicas normaliza la función conductual alterada (Acuña et al., 2002).

Existe una estrecha asociación entre modificaciones en los ritmos circadianos y la depresión (Healy \& Waterhouse, 1990). Dichas modificaciones las podemos observar en: 
a.- Variación circadiana del estado de ánimo, o humor, con una tendencia a mejorar a lo largo del día (Gordjin, Beersma, Bouhuys, Korte \& Van den Hoofdakker, 1995).

b.- Alteraciones en el ciclo sueño/vigilia, en general se observa que tanto el comienzo del sueño, como el despertar ocurren temprano. También se ha verificado la existencia de insomnio, con una disminución de la cantidad de sueño total (Bórbely \& Wirz-Justice, 1982). Según Urretavizcaya, Soria \& Cambras (2006), dos tercios de los pacientes depresivos presentan algún tipo de insomnio.

c.- Una variación estacional en la incidencia de los síntomas depresivos, con un máximo en la época invernal (Rosenthal et al., 1984).

d.- Otras alteraciones del sueño incluyen: menor latencia del primer episodio de sueño REM y un aumento en el número de episodios y duración de los mismos (Van den Hoofdakker, 1994).

e.- Adelanto de fases de los ritmos de temperatura, cortisol, actividad/reposo, melatonina y metabolitos de neurotransmisores (Wehr \& Wirz-Justice, 1982).

f.- Disminución en la amplitud de los ritmos mencionados, especialmente en el de actividad/reposo, temperatura, sueño y secreción de hormonas como la melatonina y la tiroidea (Van den Hoofdakker, 1994).

Existen diversas hipótesis para explicar las relaciones patológicas entre el sistema circadiano, depresión y remisión, tales como la desincronización, avance y retraso de fases, coincidencia externa e interna, amplitud, zeitgebers sociales y trabajos en turnos, 
entre otras. Ninguna de ellas explica totalmente el curso del cambio del humor durante la depresión o la eficacia del tratamiento antidepresivo (Acuña et al., 2002).

Entre estas hipótesis, se encuentra la denominada "hipótesis de adelanto de fase", y como consecuencia de la misma, los tratamientos que retrasan la fase hasta valores normales se han mostrado exitosos en el tratamiento de la patología, como son la luminoterapia y la supresión de sueño (Yannielli, 2007).

El tratamiento con fármacos antidepresivos también modifica la fase, la amplitud y el periodo de los ritmos y alteran la proporción de sueño REM, tanto en situaciones clínicas como experimentales (Duncan, 1996). Se sabe que el sistema serotoninérgico, sitio principal de la acción de los fármacos antidepresivos, está anatómicamente vinculado a los NSQ por la inervación procedente de los núcleos del rafe, y tiene además influencia sobre la sincronización fótica, sobre el estado de alerta y la actividad motora, que a su vez son importantes moduladores de la sincronización no-fótica (Morin, 1999). Por ejemplo, se ha demostrado que los antidepresivos tricíclicos potencian la transmisión serotoninérgica en las vías del núcleo del rafe dorsalhipocampo (conducta emocional) a partir de las dos semanas de administración, que además coincide con el tiempo que tarda este tipo de antidepresivo en ejercer su acción terapéutica (Fernández \& Carpizo, 1994).

La investigación clínica ha desvelado una compleja relación entre los efectos terapéuticos y cronobiológicos de los fármacos antidepresivos. Muchas alteraciones afectivas cursan con perfiles anormales de determinados ritmos circadianos. Por ejemplo, las depresiones uni y bipolares (Asberg, Thoren, Traksman, Bertilsson \& Ringerber, 1976; Van Cauter \& Turek, 1986), manía, síndrome afectivo estacional 
(Lewy, Sack, Singer, White \& Hoban 1988), depresión melancólica y no melancólica (Frazer et al., 1986), anorexia nerviosa (Delvenne et al., 1992), síndrome premenstrual (Severino, et al., 1991) y esquizofrenia (Van Cauter et al., 1991), presentan ritmos circadianos conductuales y fisiológicos anormales.

Distintos tipos de anormalidades circadianas distinguen muchas veces diagnósticos diferentes. Por ejemplo, en los casos de depresión estacional se observa un inicio tardío del pico de melatonina, acompañado de hipersomnia y retardo general de la fase de sueño, mientras que en la depresión melancólica se caracteriza por variaciones diarias en el estado de ánimo, presencia de un componente de ansiedad y bajo contenido de melatonina nocturna (Yannielli, 2007). A su vez, un adelanto en el máximo de cortisol y en la fase de sueño activo son comunes en la depresión mayor (Duncan, 1996).

Existe la noción tradicional que los sujetos depresivos se sienten peor por la mañana y su humor mejora a lo largo del día. Esto parece ser una característica relativamente estable de las depresiones endógenas, y apoya la existencia de una alteración del reloj circadiano en la depresión, aunque no hay evidencia completa de ello.

En pacientes depresivos el umbral anormal de adaptación a la oscuridad, así como los electroretinogramas, sugieren una respuesta anormal a la luz. La interacción de la luz y medicamentos sobre la información visual al sistema circadiano puede alterar la respuesta de sincronización al ciclo Luz-Oscuridad. Tratamientos como las sales de litio alteran la sensibilidad a la luz y la doxepina (antidepresivo tricíclico), disminuye la misma. 
Los zeitgebers sociales, como el trabajo, las demandas sociales o las relaciones interpersonales pueden actuar directa o indirectamente sobre los NSQ. Estos zeitgebers, sobre todo en las sociedades industrializadas, determinan el ciclo de la alimentación, horarios de sueño, ejercicio físico y la exposición a la luz ambiente, de forma que estos factores sociales tienen capacidad potencial de alterar los ritmos circadianos. Algunos de los aspectos psicosociales implicados en la depresión, como los acontecimientos vitales o la falta de sistemas de soporte social adecuado, podrían actuar como precipitantes mediante la disrupción de los ritmos circadianos (Urretavizcaya, Soria \& Cambras, 2006).

En relación con la ansiedad, los ritmos circadianos están poco estudiados (Urretavizcaya, Soria \& Cambras, 2006). A nivel epidemiológico, se ha detectado que la patología ansiosa se asocia frecuentemente a las quejas de insomnio (Lewy, 2003). Diferentes estudios mediante polisomnografía en los trastornos de ansiedad, muestran una latencia de sueño incrementada, una disminución del sueño REM y una disminución de la eficacia del sueño (Urretavizcaya, Soria \& Cambras, 2006). También se han descrito fluctuaciones diarias en los síntomas de ataques de pánico, en la presentación de los propios ataques de pánico, en la ansiedad generalizada en pacientes con patologías asociadas, así como alteraciones en la secrección circadiana y ultradiana de cortisol en este tipo de trastornos (Rustig \& Larsen, 1998). Por lo que se refiere al ritmo de secreción de melatonina, algunos estudios han encontrado niveles nocturnos más elevados de esta hormona y un retraso de fase de dos horas respecto a controles sanos, hipotetizando que este exceso de melatonina pretende reducir el estado de ansiedad (Urretavizcaya, Soria \& Cambras, 2006). 
Por otra parte, el ácido gamma-aminobutírico (GABA), neurotransmisor inhibidor por excelencia, está involucrado, por un lado en la neurobiología de la ansiedad y, por otro, en la regulación de la ritmicidad circadiana, ya que es el principal neurotransmisor de los NSQ. Este sería el principio a través del cual podría explicarse el funcionamiento de las benzodiazepinas en el tratamiento de los trastornos de ansiedad (Yannielli, 2007).

\subsubsection{Cronofarmacología y Cronotoxicología}

Un agente exógeno, actuando en un sistema que cambia rítmicamente, puede causar tres tipos fundamentales de cambios que serán tiempo-dependientes: cronopatología, causada por agentes patológicos; cronofarmacología, en respuesta a fármacos; y cronotoxicología, producida por agentes tóxicos. La cronoterapia, basada en todos estos cambios periódicos, contribuye a la optimización del uso de fármacos (se busca aumentar los efectos farmacológicos favorables y disminuir los no deseables) mediante la implantación de tratamientos cronomodulados (Madrid, Martínez-Nicolás y Sánchez-Gálvez, 2006).

Identificar la base fisiológica de las alteraciones circadianas específicas de cada patología tendría importancia en la elección de los fármacos para la normalización de cada "desorden del tiempo" particular. La posibilidad de que la acción de una droga dependa de la hora del día a la que es administrada fue planteada ya en los orígenes de la cronobiología, cuando, en el año 1814, Julien Joseph Virey publica su tesis doctoral, en la que afirma:

"...Todos los medicamentos no son igualmente indicados a todas las horas, y aqui la periodicidad diurna debe ser tenida en cuenta. Los hipnóticos, los narcóticos, el opio, salvo conjeturas extremas, no serían bien indicadas por la 
mañana, cuando todas nuestras facultades tienden a despertarse; pero estos remedios tienen una acción más intensa y más saludable en el atardecer, porque las fuerzas de la naturaleza aspiran al sueño y al reposo..." (Citado por Reinberg, Lewy \& Smolensky, 2001).

La cronofarmacología estudia los efectos de los medicamentos en función del tiempo, y también la acción de dichos medicamentos sobre distintos parámetros de los ritmos biológicos (Yannielli, 2007).

Las primeras observaciones cronotoxicológicas se deben a los estudios de Carlson y Serin en 1950 (citados por Madrid, Martínez-Nicolás y Sánchez-Gálvez, 2006, pp. 600), quienes mostraron que la mortalidad inducida por niketamida, variaba de un $33 \%$ a las 2.00 horas hasta un $67 \%$ a las 14.00 horas. Posteriormente el grupo de Halberg, a finales de la década de 1950 (Halberg, 1969), demostró que la mortalidad inducida por ouabaína (glicósido cardiaco) presentaba una variación del $60 \%$ en un intervalo de 12 horas en el ratón, hecho que vino a romper el paradigma homeostático.

Posteriormente se han obtenido resultados similares para sustancias tóxicas como la nicotina, etanol, propanolol, anestésicos locales o agentes anticancerosos (Madrid, Martínez-Nicolás y Sánchez-Gálvez, 2006). En este contexto, se ha visto como los ritmos de las mitosis en los tejidos tumorales tienen un ritmo siempre inferior a las 20 horas y llega en algunos casos a ser tan breve como 8 horas. El objetivo de la cronoterapia sería, no solo controlar el crecimiento del tumor, sino restaurar la naturaleza rítmica de la función celular. Según esto, por un lado el ritmo de vulnerabilidad tumoral podría ser utilizado para suministrar el agente anticanceroso en 
el momento en que tenga mejores posibilidades de destruir células malignas y, por otro lado, el ritmo circadiano de sensibilidad del paciente al tratamiento debería ser tenido en cuenta con el fin de administrar la mayor dosis posible de la droga en el momento en que el enfermo tolere mejor el tratamiento (Agostino \& Golombeck, 2007).

Uno de los objetivos de la cronoterapia es restaurar la estructura temporal del individuo, que ha sido perturbada por la enfermedad. Otro propósito consiste en la optimización de la administración de un medicamento teniendo en cuenta sus horas de mayor eficacia y menor toxicidad (Madrid, Martínez-Nicolás y Sánchez-Gálvez, 2006), también se ha estudiado en el campo de los psicofármacos, encontrándose cierta relación entre determinados fármacos y el funcionamiento del sistema circadiano.

Estudios en animales muestran que los inhibidores específicos de la recaptación de serotonina (ISRS) regulan a la baja el receptor $5-\mathrm{HT}_{7}$ en $\operatorname{los} \mathrm{NSQ}$, acortando el periodo del ritmo circadiano de actividad y modulando las respuestas de fase de los ritmos a la luz. En humanos, la temperatura nocturna, que se ha descrito incrementada en pacientes depresivos, puede volver a sus valores normales tras la administración de antidepresivos tricíclicos e inhibidores selectivos de la recaptación de serotonina. Hay también estudios clínicos que describen que los efectos antidepresivos de un ISRS, el citalopram, son mejores cuando el tratamiento farmacológico se combina con terapia de luz (Urretavizcaya, Soria \& Cambras, 2006).

En pacientes con trastorno afectivo estacional (TAE), dosis bajas de melatonina disminuyen los síntomas depresivos, presumiblemente por avanzar la fase del reloj endógeno. Así, de acuerdo con la hipótesis del retraso de fase en la depresión estacional, la exposición a una iluminación intensa debe ejercer un efecto antidepresivo mayor 
cuando se utiliza por la mañana, ya que entonces causa un avance de fase. De hecho, la asociación de la depresión estacional, principalmente en invierno, con la reducción en la longitud del día, sugiere que el mecanismo de medida del fotoperíodo juega un papel en este trastorno. El hipersomnio y fatiga diurnas son marcadores del retraso de fase en los ritmos circadianos. Existe una correlación significativa entre la dificultad de despertarse por la mañana y la gravedad de la depresión. De hecho, la presencia de hipersomnio se correlaciona muy bien con la respuesta clínica a la fototerapia. Esos datos también indican que otro agente capaz de reiniciar el reloj biológico debería ser igualmente efectivo, este es el caso de la melatonina (Acuña et al., 2002). Para evitar que su efecto hipnótico enmascare su acción sobre el reloj biológico, ya que los pacientes con depresión estacional son especialmente sensibles a la acción soporífera de la melatonina, se realizó un estudio administrando $0.125 \mathrm{mg}$. en dos dosis separadas cuatro horas por la tarde. Este régimen de administración produjo un avance de fase y una notable mejoría en los pacientes estudiados. Los resultados de un estudio reciente muestran una estrecha relación entre los cambios estacionales en el fotoperiodo y las variaciones estacionales en los síntomas del TAE de invierno. Este estudio también sugiere la naturaleza múltiple de la respuesta fisiológica a la fototerapia. La luz intensa trata los síntomas depresivos vía normalización en distintos sistemas de regulación fisiológica, y el ritmo de melatonina está relacionado en mayor o menor grado con el efecto terapéutico de la luz. Aunque este estudio no demuestra claramente que la depresión de invierno esté causada por un retraso de fase en el ritmo de melatonina, sí se observa una tendencia a cambios en dicho ritmo en pacientes depresivos (Nurnberger, et al. 2000). Varios estudios indican que la secreción de melatonina en pacientes depresivos es más sensible a la luz que la de sujetos normales, el aumento de 
sensibilidad más que el retraso inicial de fase puede explicar los cambios de fase en los pacientes depresivos (Putilov, Russkikh \& Danilenko, 2000).

Los efectos de las drogas antidepresivas en general hablan a favor de la hipótesis de que los trastornos afectivos están en relación con alteraciones del reloj biológico. Los antidepresivos, al contrario que cualquier otro agente psicotrópico, no parecen tener efectos conductuales agudos. Aunque ciertos antidepresivos pueden producir efectos ansiolíticos relativamente rápido, sus efectos principales sobre el humor depresivo tardan en aparecer en general una o dos semanas. Esto es consistente con una acción para reorganizar el sistema circadiano. Los antidepresivos pueden por tanto modificar la sensibilidad de los sistemas fisiológicos incluido el reloj biológico a influencias ambientales, o bien modulan la sensibilidad de los sistemas fisiológicos a su control por el propio reloj biológico. Todavía no existen suficientes experimentos con antidepresivos en este campo para sacar conclusiones definitivas.

La acción que un fármaco ejerce sobre las células diana varía según el momento de administración. Este hecho contradice el principio homeostático según el cual una misma dosis de fármaco produciría el mismo efecto independientemente de la hora de administración, siendo su objetivo final en de conseguir concentraciones constantes de fármaco en plasma. Sin embargo, los procesos metabólicos presentan variaciones circadianas, de modo que la susceptibilidad de un proceso determinado a un fármaco varía a lo largo del tiempo. Algunos autores han mostrado que el triazolam (benzodiacepina) y el carbacol (agonista colinérgico) pueden tener efectos claros sobre el reloj circadiano. El carbacol minimiza los efectos de la luz y, administrado a una hora en que el organismo es sensible a la luz (según la curva de respuesta de fase a la luz), 
induce cambios de fase en los ritmos circadianos que pueden ser bloqueados específicamente por antagonistas colinérgicos. A su vez, el triazolam puede inducir avances y retrasos de fase, dependiendo del momento de su administración. El triazolam también induce cambios en el período del reloj biológico (Madrid, Martínez-Nicolás y Sánchez-Gálvez, 2006). 
El tiempo es el mejor autor;

siempre encuentra un final perfecto.

Charles Chaplin

"Como no tenemos nada más precioso que el tiempo, no hay mayor generosidad que dedicarlo a alguien sin tenerlo en cuenta."

Marcel Jouhandeau (1888-1979), escritor francés.

ESTAD@ ACTVAL BL PR OBLEMA 


\section{5.- ESTADO ACTUAL DEL PROBLEMA}

\section{1.- Introducción}

Durante el S. XIX, sociólogos como Weber (1864-1920) o Durkheim (18581917), destacaron que el pensamiento científico estaba en estrecha relación con la sociedad en el que se producía (López, 1996). El desarrollo de la ciencia, por tanto, no sólo depende del método científico, sino de los procesos sociales de colaboración, negociación, consenso y comunicación.

La necesidad de desarrollar métodos e indicadores sociales para el estudio de la ciencia inspira, a mediados del siglo XX, lo que se denominó Ciencia de la Ciencia (Noguer-Carmona et al., 2006). La cuantificación de los aspectos sociales de la ciencia requiere el concurso de una disciplina metodológica específica: la Cienciometría. Para Kragh (1987) la cienciometría debe entenderse como una técnica de sociología cuantitativa de la ciencia.

La Bibliometría, nace como una herramienta para la cuantificación de ciertos aspectos de la Ciencia, y se podría entender como una aproximación cuantitativa al estudio y análisis de la producción científica en todas sus formas de comunicación escrita (Noguer-Carmona et al., 2006).

Los trabajos bibliométricos tienen una larga tradición. Con el antecedente histórico de Alphonse de Condolle de 1885, quien aplicó métodos matemáticos al estudio de los factores relacionados con el desarrollo científico, en 1926, Alfred J. Lotka publicó un estudio pionero sobre la distribución de frecuencias de la productividad científica. Lotka concluía que el número de autores que hacen $n$ contribuciones es igual 
a $1 / n^{2}$ sobre aquellos que hacen una contribución; y que la proporción de los que contribuyen sólo con una publicación era del 60\% (Lotka, 1926). Casi 85 años después estos resultados pueden considerarse aún vigentes (Noguer-Carmona et al., 2006).

Casi al mismo tiempo, en 1927, Gross \& Gross estudiaron y publicaron sus reflexiones sobre las citaciones, es decir, sobre cómo un trabajo científico servía de referencia para otros y éstos otros recogían esa importancia citando el trabajo original.

En 1931 llega el impulso definitivo a la Bibliometría. Se celebró en Londres el “II Congreso Internacional de Historia de la Ciencia", cuyas conclusiones influyeron en que Bernal publicara después "The Social Function of Science” (Bernal, 1939). Pritchard en 1969, define la bibliometría como la aplicación de métodos estadísticos y matemáticos a la definición de los procesos de la comunicación escrita y la naturaleza y desarrollo de las disciplinas científicas, mediante el recuento y análisis de las distintas facetas de dicha comunicación.

En 1971 aparece la primera revista especializada; Science Studies, título modificado en 1975 por Social Studies of Science, revista internacional de investigación sobre los aspectos sociales de la ciencia y la tecnología. Hoy, una de las más representativas del enfoque cienciométrico-bibliométrico es la húngara-holandesa Scientometrics, que nace en 1978 con el subtítulo de "revista internacional sobre todos los aspectos cuantitativos de la ciencia, la comunicación en la ciencia y la política científica."

En España, el primer antecedente documentado sobre bibliometría es del año 1935. El autor es Ortega y Gasset, y la obra "La misión del bibliotecario.” En ella, se habla de la necesidad de una estadística de las ideas, que ayude a precisar cuándo 
brotan, su periodo de expansión y vigencia, y su declive. Los primeros artículos bibliométricos no aparecen hasta la década de los setenta de la mano de $\mathrm{M}^{\mathrm{a}}$ Luz Terrada y José Ma López Piñero, autores de libros como El análisis estadístico y sociométrico de la literatura científica (López Piñero, 1972) y La literatura médica española contemporánea: Estudio estadístico y sociométrico (Ma Luz Terrada, 1973).

El desarrollo de la bibliometría ha sido, y es posible hoy, gracias a lo que sin duda es el rasgo principal de la ciencia desde el siglo XVII: la comunicación científica (Ziman, 1980). En este sentido, subrayamos con Kuhn (1991), la relevancia de la estructura comunicativa de la ciencia y justificamos la pertinencia de la aplicación de la metodología a la comunicación científica, como un aporte más que contribuye, sin ninguna duda, al desarrollo. E incluso se llega a afirmar que sin comunicación no hay ciencia (López, 1996).

Ya que la ciencia se constituye en conocimiento compartido, los científicos, conscientes del papel que desempeña la comunicación, han generado, potenciado y protegido los canales y medios que puedan contribuir al intercambio de información. La importancia de las revistas queda reflejada en la ingente cantidad que se editan en todo el mundo, y en las funciones que cumplen: evaluación de trabajos publicados, compactación del conocimiento existente, identificación de autores y especialidades emergentes, dirección de investigación hacia nuevas áreas, entre otras (Woodward, 1977).

Se distinguen dos grandes campos en los estudios bibliométricos (Romera Iruela, 1992): estudios bibliométricos descriptivos y los análisis de citas. 
Los estudios bibliométricos descriptivos se centran en cuestiones de productividad, colaboración y análisis de materias. La productividad nos señala qué autores, revistas, países, etc. son más activos en la producción de una determinada literatura científica. La colaboración, es un rasgo fundamental de la ciencia moderna. Crane (1972) señala que la ciencia hoy día es tanto un proceso cognitivo como un proceso social. Sancho (1990) argumenta que, desde una perspectiva histórica y sociológica, la participación de varios autores en la elaboración de un trabajo es consecuencia de la profesionalización de la comunidad científica. El nivel de colaboración se concreta explorando la coautoría en los trabajos publicados y el número medio de firmas/autores por documento (índice de colaboración). A modo de ejemplo, a principios de siglo el número de documentos escritos en colaboración representaban sólo el $20 \%$ del total, mientras que actualmente la coautoría es la pauta casi unánime de la comunicación científica (Peters, 1991).

Los estudios bibliométricos de análisis de citas estudian el consumo de información científica y el impacto de los trabajos publicados en la comunidad científica. Al hecho de ser citado se le atribuye la bondad de la utilidad de lo escrito para otro investigador.

En la época actual, sumergidos de lleno en la era de las telecomunicaciones, ante la vertiginosa producción de trabajos es imposible, no sólo leer todo lo que aparece publicado, sino saber qué se ha editado sobre un tema. Los soportes de la información se diversifican y multiplican sin cesar, por lo que resulta esencial conocer cómo obtener y utilizar la documentación, así como aprovechar los recursos de numerosas 
instituciones y fuentes dedicadas a recoger, clasificar, recuperar y distribuir todo tipo de trabajos.

El uso de indicadores bibliométricos para analizar la actividad investigadora de un equipo científico, un área o un país, se basa en que las publicaciones científicas son un resultado esencial de dicha actividad. Un nuevo conocimiento adquiere valor cuando se da a conocer y se difunde, ya que es así como progresa la ciencia (Camps, Recuero, Samar \& Ávila 2005).

Prácticamente toda la literatura científica publicada en revistas contiene citas o referencias bibliográficas que proporcionan los precedentes sobre lo que el autor desea exponer en su trabajo. Por ello, las citas constituyen una fuente de datos que nos permite conocer qué información consumen los autores y cuánto envejece esa información (López \& Terrada, 1992).

Las nuevas técnicas aplicadas al análisis bibliométrico constituyen, sin duda, una herramienta básica para procesar la información y construir redes que faciliten la vertebración del conocimiento.

En suma, la Bibliometría hace referencia al estudio de los aspectos cuantitativos de la producción, dispersión y utilización de la bibliografía empleada en una ciencia. Por medio de la aplicación de modelos de análisis y medidas estadísticas se obtienen datos relevantes sobre la situación de un determinado campo científico. 


\section{2.- Objetivos y método}

El objetivo principal es obtener datos objetivos que describan la realidad de la investigación sobre estimación de intervalos temporales, tanto en sujetos sanos como en afectados de trastornos depresivos con sintomatología ansiosa.

Como objetivos específicos destacamos los siguientes:

- Describir el tamaño y distribución de la producción científica en el tema de estudio.

- Analizar la producción por autores.

- Conocer el título de las revistas más representativas en las que se publica sobre esta temática.

- Analizar el tamaño y crecimiento de las co-autorías en las publicaciones.

Para llevar a cabo nuestros objetivos, se procedió a consultar las bases de datos PsicINFO y Medline, suscritas por la Universidad de Salamanca. También se llevó a cabo una búsqueda de los términos en la Social Science Citation Index (ISI web of Knowledge $^{\mathrm{SM}}$ by Thomson Reuters ${ }^{\circledR}$ ), cuyo servicio es proporcionado desde la Fundación Española de Ciencia y Tecnología y el Ministerio de Ciencia e Innovación. El principal descriptor utilizado fue "time estimation", si bien se utilizaron otras palabras clave como "estimation time span", "time awareness", "subjective vs. objective time", "duration judgements", "passage of time y "time measurement."

Con posterioridad, se llevó a cabo una búsqueda refinada con el fin de localizar aquellos artículos en los que se investigaba la estimación del paso del tiempo en 
población con psicopatología, usando como descriptores en este caso las palabras “anxiety” y "depression."

\section{3.- Resultados}

El primer resultado destacable es que sin limitar el número de años aparecen 14.349 resultados usando el keyword "time estimation."

Con el fin de manejar la mayor cantidad de información actual, se llevó a cabo una consulta, en ambas bases de datos, teniendo en cuenta tan sólo desde el año 1990 (incluido). Esta vez el número total de referencias encontradas fue de 13.689 Cruzando esta búsqueda con “anxiety” y "depression," obtuvimos un total de 331 referencias.

Aparecen un total de 40.915 autores para las 13.689 referencias, por lo que nos encontramos con un índice de colaboración de 2.99 autores por cada publicación.

De los 40.915 autores, un $95.84 \%$ han aportado 1 ó 2 publicaciones. Tan sólo un $0.98 \%$ tienen 5 ó más aportaciones y un $0.14 \%, 10$ ó más publicaciones.

El autor con mayor número de autorías es Meck, con 41 estudios, seguido de Wearden con 38 y de Pouthas con 29.

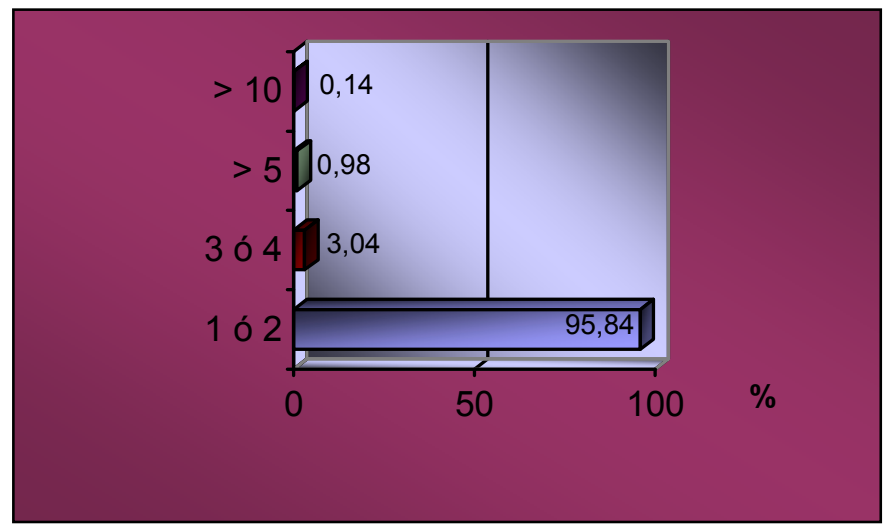

Fig. 7: Análisis por número de publicaciones 
En la figura 8 puede apreciarse como desde el año 2000 el incremento del número de publicaciones sobre la temática ha ido en ascenso, aumentando su número con el paso de los años (1419 referencias en el transcurso del 2008). La tónica general ha sido que el número de publicaciones de un año con respecto al anterior se incremente en torno a 95 referencias, si bien entre 2002 y 2003 hubo un estancamiento con apenas un aumento de 33 y entre el 2003 y el 2004 hubo un repunte con 189.

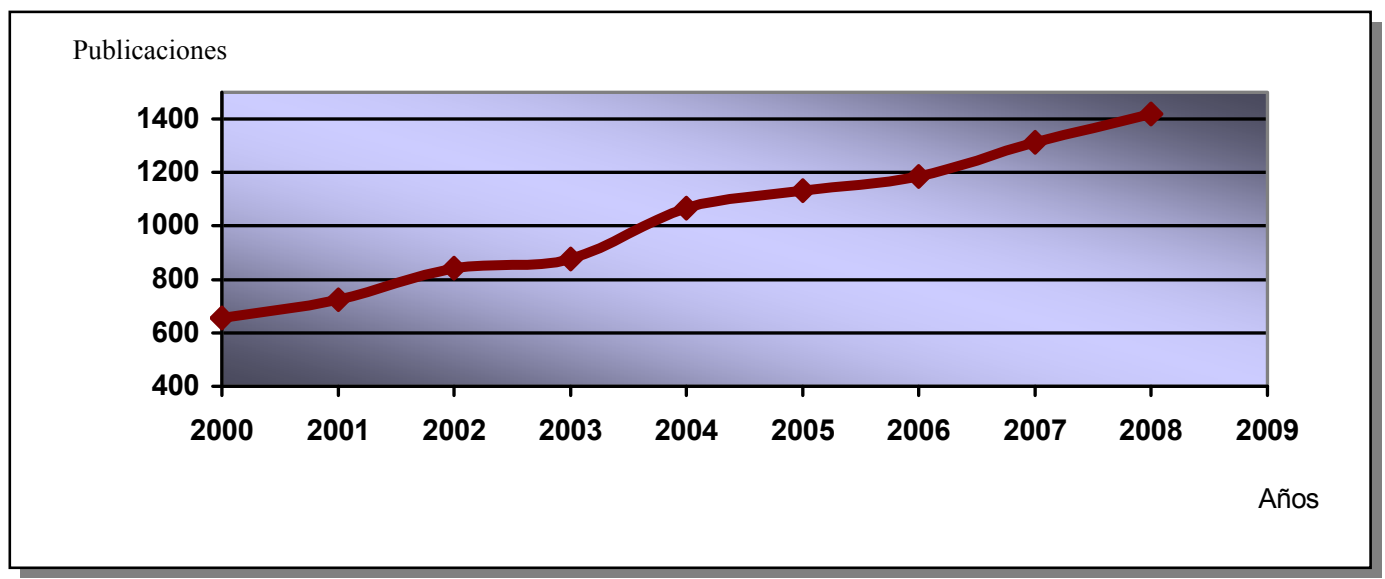

Fig. 8: Análisis por año de publicación

La palabra clave más utilizada es HUMANS (8246 veces), por lo que podemos concluir que el $60.24 \%$ de los estudios tienen como población objeto de estudio a los humanos (fig. 9), de ellos, el 51\% son hombres y el resto mujeres (fig. 10).

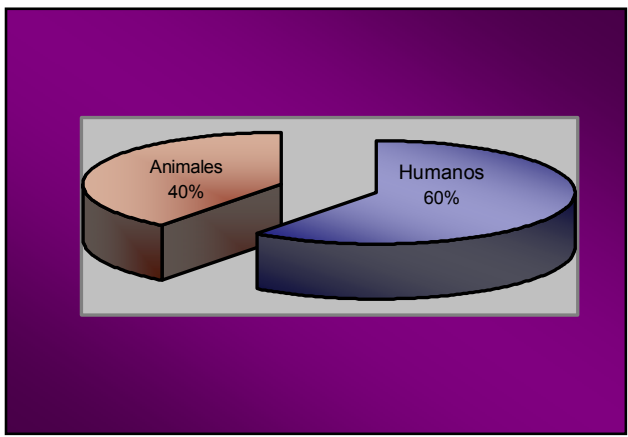

Fig. 9: Población objeto de estudio

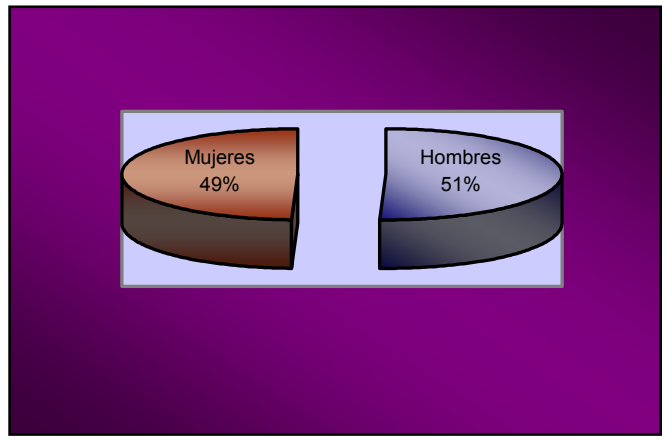

Fig. 10: Población por género 


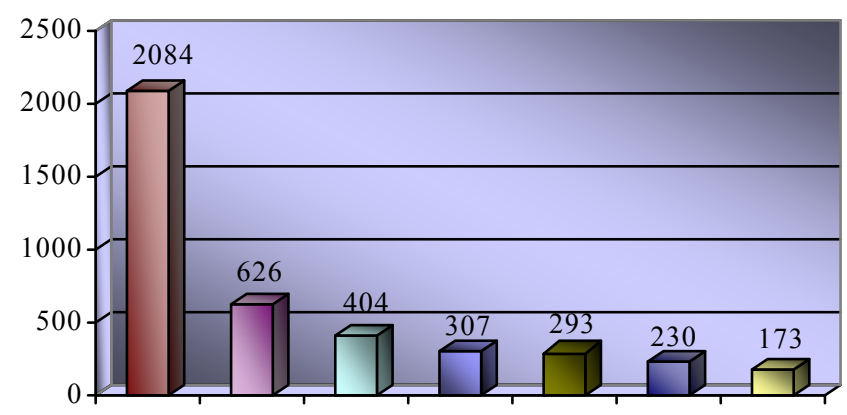

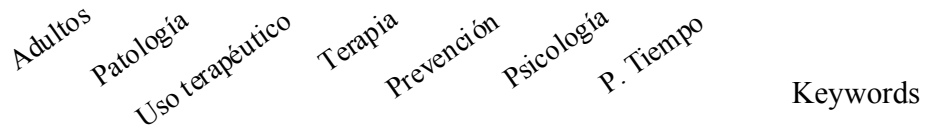

Fig. 11: Principales palabras clave (1)

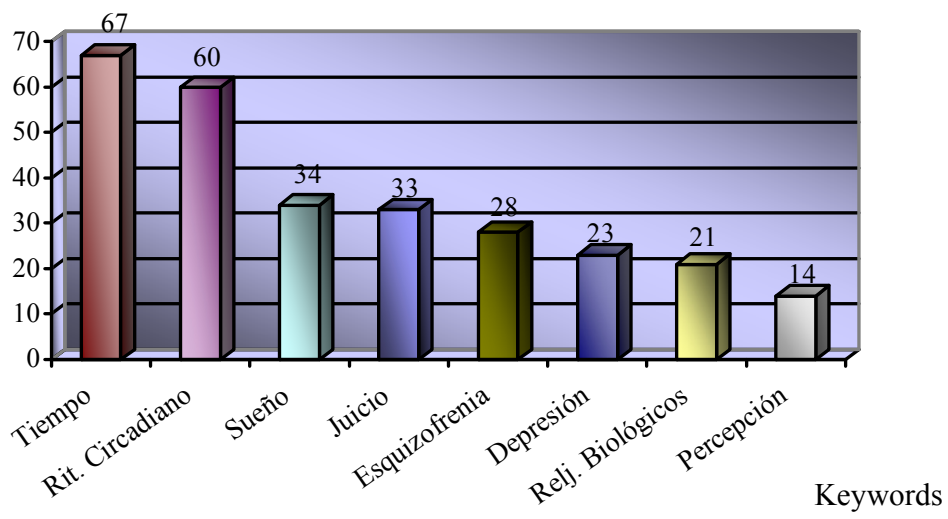

Fig. 12: Principales palabras clave (2)
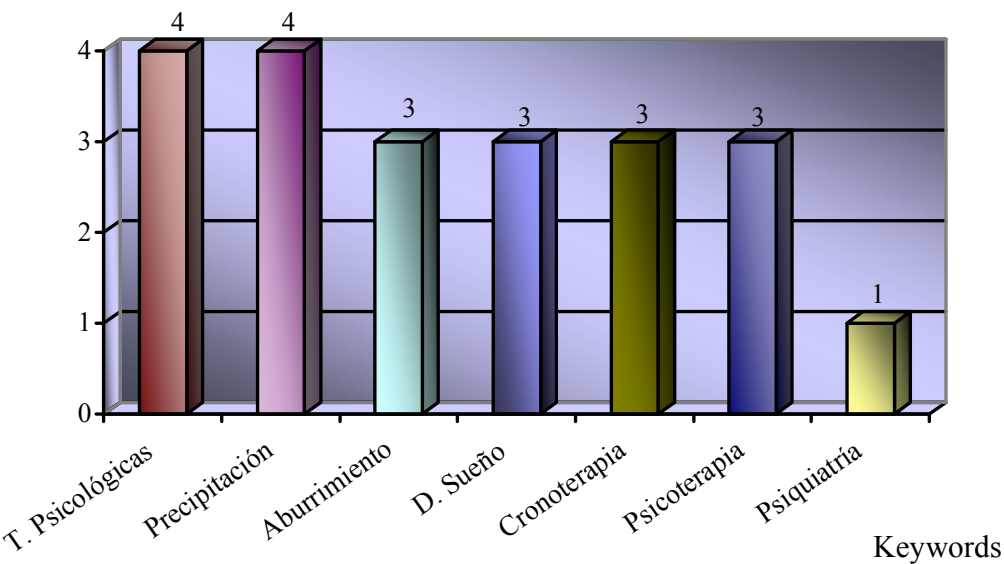

Fig. 13: Principales palabras clave (3) 
Los 13.689 artículos relacionados con la temática se encuentran recogidos en un total de 2925 revistas diferentes, de ellas, la que presenta un mayor número de publicaciones (201) es Statistics in Medicine. No se puede hablar de que exista una serie de revistas especializadas en el tema, ya que la distribución de frecuencias presenta un rango muy amplio, sin embargo hay 5 revistas con 100 ó más publicaciones, 79 con 20 ó más publicaciones y 208 con más de10. Resumiendo, más del 90\% de las revistas científicas que han publicado sobre la estimación del tiempo, han incluido menos de 9 artículos sobre dicha temática. El número de publicaciones medio, por revista se sitúa en algo más de 4 (4.25).

Entre las revistas más relevantes tendiendo en cuenta los objetivos específicos del presente trabajo, podemos citar a la revista Acta Psychologica, con 38 publicaciones en la filial holandesa y 18 en la genérica.

Teniendo en cuenta únicamente los 331 artículos resultantes de la búsqueda final, donde se cruzaron los términos relevantes en este estudio, encontramos las siguientes características:

-. El idioma de publicación del 82.18\% de los artículos es el inglés (272). Seguido a gran distancia del ruso con 15 publicaciones $(4.5 \%) \mathrm{y}$, por último, encontramos tan sólo 2 publicaciones en castellano (1.21\%).

-. La progresión del número de artículos publicados por años no refleja una línea ascendente progresiva como ocurría anteriormente, pero puede apreciarse un incremento desde las 5 publicaciones en 1990 a las 30 del año 2008 (fig. 14). 


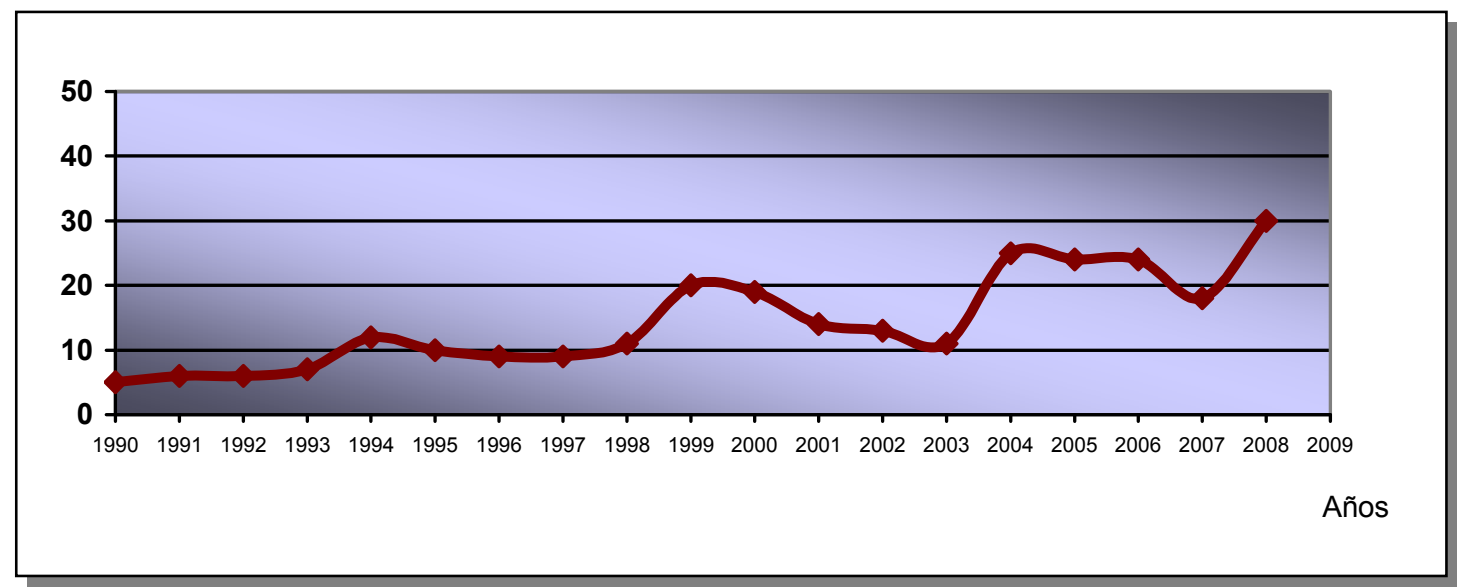

Fig. 14: Evolución número de publicaciones por año

La revista con mayor número de publicaciones acerca de esta temática tan específica es Journal of Affective Disorders, con un total de 8 artículos. También aparecen Biological Psychiatry, Journal Of Clinic Psychology, Journal of Psychiatric Research, Psychiatry and Clinical Neurosciences y Psychiatry Research con un total de 3 publicaciones.

Llama la atención el paso a la primera línea de palabras clave como psicología, ciencias conductuales, psiquiatría o neurociencias y neurología. Así, tal y como puede apreciarse en la fig. 15, casi la mitad de estos artículos tienen la palabra "Psychology" (159), seguido de cerca por "Behevioral sciences" (158) y "Psychiatry" (117). 


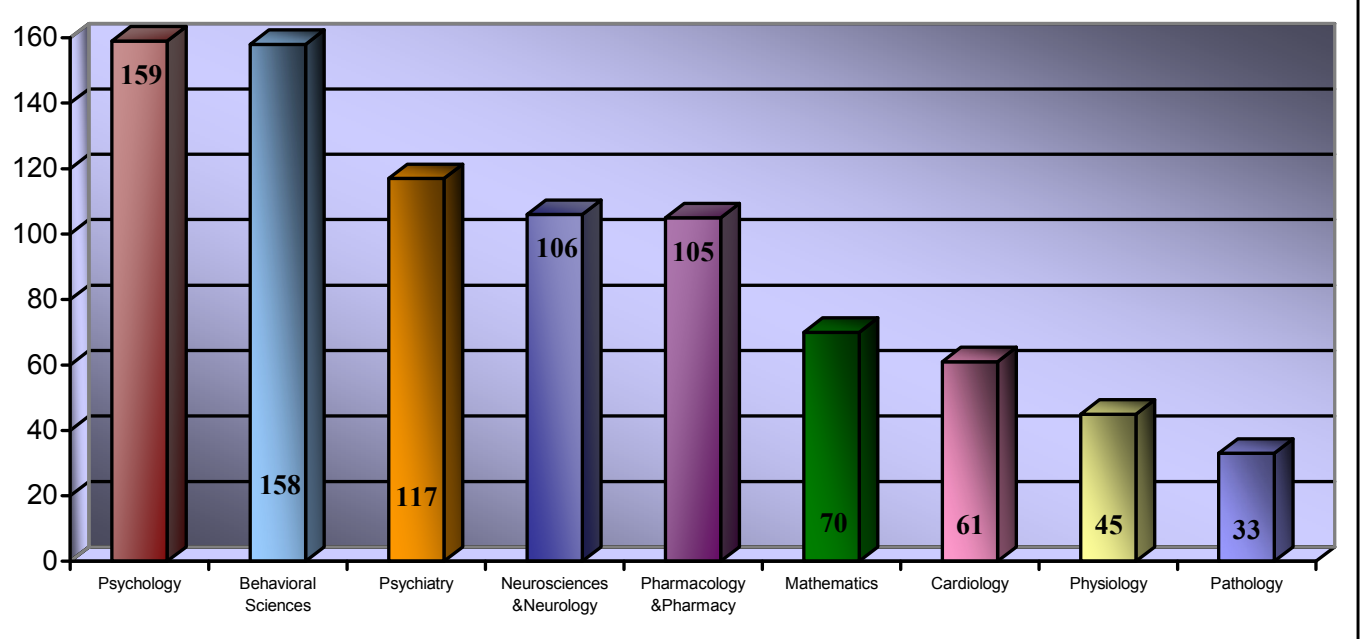

Fig. 15: Principales palabras clave

-. Otra de las características es el elevado número de autores firmantes (1268 en las 331 publicaciones), lo que nos arroja un índice de colaboración de casi cuatro autores (3.83) por artículo, es decir, un índice de especialización muy elevado. La mayoría de ellos (95.66\%), sólo tienen una aportación al tema aunque hay un autor con 4 estudios sobre dicha temática.

\subsection{1.- Análisis de la temática}

Cuando se analizaron los contenidos de los 331 artículos y con el fin de llevar a cabo una aproximación al contenido principal de las investigaciones sobre el tema que nos ocupa, se clasificaron las aportaciones científicas sobre la materia en dos áreas principales: 
1.- Investigación científica sobre percepción temporal.

Dentro de esta área se hace necesario distinguir entre publicaciones científicas básicas y publicaciones científicas clínicas.

Dentro de la investigación básica sobre percepción de intervalos temporales, el mayor número de estudios busca diferencias en estimación en función de: a) las características del estímulo, b) dificultad de la tarea distractora (recursos cognitivos dedicados) o c) características de los sujetos experimentales y las circunstancias que les rodean.

a) El estudio que sienta las bases y propone los dos paradigmas experimentales que deben usarse en la investigación sobre la percepción del paso del tiempo en humanos fue el realizado por Block, Hancock \& Zakay (2000), realizado sobre un elevado número de casos (9482 participantes, balanceados por género y edad). Para estos autores, las estimaciones temporales que se piden a los sujetos se pueden preguntar mediante la adopción de un paradigma prospectivo (cuando en las instrucciones de la tarea los sujetos son informados del objetivo real de la misma, es decir, saben que se les va a pedir una estimación temporal) o mediante un paradigma retrospectivo (cuando los sujetos desconocen el objetivo real de la estimación, es decir, que cuando se presenta la tarea no se especifica que el objetivo sea una estimación de la duración). La gran mayoría de los estudios consultados especifican si están usando un paradigma, otro, o los dos. Estos autores no encontraron diferencias estadísticamente significativas en cuanto al género en el paradigma prospectivo. En cambio, en el retrospectivo las mujeres presentaban una mayor tasa de errores. Un estudio anterior, llevado a cabo por Beck (1988), en un grupo de 95 mujeres divididas por edad, encontró 
una tendencia general a la sobrestimación en una prueba de estimación del tiempo de 40 segundos, también bajo un enfoque retrospectivo. Sin embargo, a pesar de los resultados de este estudio, la producción científica muestra la inexistencia de diferencias estadísticamente significativas en cuanto al género en las tareas de estimación y percepción del paso del tiempo. Tan sólo en tres estudios hemos encontrado la búsqueda de diferencias por género dentro de los objetivos del mismo, uno del año 1989, con una muestra de 256 sujetos donde sólo aparecieron diferencias por grupos de edad pero no por género (Polyukhov, 1989), otro del año 1991, en el que se buscaban diferencias en la capacidad de estimación bajo hipnosis y en el que no existían diferencias por género (Von Kirchenheim \& Persinger, 1991), y otro, el único que podríamos considerar reciente al ser del año 2007, en el que de nuevo no aparecieron diferencias en cuanto al género en la estimación de intervalos de 15, 30 y 45 segundos usando ambos paradigmas de investigación (Klapproth, 2007). En los demás estudios consultados, si bien la búsqueda de diferencias de género en la estimación temporal no aparece planteada como objetivo del estudio, podemos encontrar al consultar el apartado metodológico de los mismos, que todos los investigadores efectúan la comprobación y, al no encontrar dichas diferencias, continúan en pos de falsar las hipótesis planteadas.

Profundizando un poco más en los grupos de edad, con el fin de conocer las diferencias en estimación en función de la edad, podemos concluir que las personas mayores, en general, llevan a cabo predicciones de duración más cortas que las personas jóvenes (Polyukhov, 1989; Carrasco, Bernal \& Redolat, 2001; Mahlberg \& Bschor, 2007), tienen peor discriminación entre intervalos largos y cortos de tiempo (Hertzog, Touron \& Hines, 2007), y experimentan los cambios en el tiempo como más rápidos (Lehofer \& Retzer, 2005). Este ultimo estudio de Lehofer \& Retzer (2005), establece 
además un paralelismo entre la percepción del tiempo de las personas deprimidas y los adultos mayores, por un lado, y entre los estados maníacos y la percepción del tiempo en los niños, por otro.

Entrando más en detalle respecto a las características de los estímulos utilizados, encontramos, por ejemplo que a mayor nivel de complejidad del mismo, se da una mayor tendencia a sobrestimar su duración, independientemente del paradigma experimental utilizado (Bueno, Firmino \& Engelman, 2002; Bueno \& Ramos, 2007). También sabemos que existen diferencias en estimación en función de la modalidad sensorial utilizada, siendo que los estímulos auditivos son juzgados como más largos que los estímulos visuales (Wearden, Edwards, Fakhri \& Percival, 1998; Lustig \& Meck, 2001; Wearden \& Todd, 2006). Además, los estímulos auditivos catalogados como "llenos" (cuando toda la duración a estimar está ocupada por el estímulo) se entienden más largos que cuando dichos estímulos son "vacíos" (cuando sólo se emite un tono de inicio y otro de final y hay que estimar el intervalo entre ambos) (Wearden, Norton, Martin \& Montford-Bebb, 2007). En cuanto al contenido del estimulo cuya duración hay que calcular, vemos que los que tienen un contenido estresante se estiman con una duración mayor de la real (Anderson, Reis-Costa \& Misanin, 2007), así como los que son desagradables para los sujetos (imágenes de personas mayores vs. imágenes de personas jóvenes) (Chambon, Droit-Volet \& Niedenthal, 2008) o los de contenido emocional (Effron, Niedenthal, Gil \& Droit-Volet, 2007; Vohs \& Schmeichel, 2003; Tipples, 2008).

En cuanto a la duración de los estímulos, encontramos mayor variabilidad en los resultados de los estudios publicados, debido a que suelen entrar en juego variables 
como las características específicas de la muestra y la tarea a realizar durante la estimación. En los pocos estudios donde no se tienen en cuenta estas variables, la tendencia encontrada es que subestimamos la duración de intervalos mayores a los 2 minutos. Por ejemplo, Grondin \& Plourde, (2007), ante la tarea de estimar la duración de estímulos de 120,210, 300, 390 y 480 segundos respectivamente encontraron tendencia a la sobrestimación en la de 120 segundos y a subestimación en las demás. En cambio, parece que nos comportamos de manera más exacta cuando tenemos que estimar la duración de intervalos de menor duración. Por ejemplo, Predebon (1995), con estímulos de 10,18, 26, 34, 42 y 50 segundos, encontró que los intervalos menores de 42 segundos se calculan con mayor exactitud que los mayores.

b) Lo que sí parece bastante claro es que es necesario dedicar recursos cognitivos específicos en el procesamiento de información temporal (Coull, Vidal, Nazarian \& Macar, 2004; Venneri, Pestell \& Nichelli, 2003). Si nos fijamos en la tarea que los sujetos deben llevar a cabo mientras hacen la estimación (en el paradigma retrospectivo se la conoce como tarea distractora) la idea general que sacamos es que a mayor complejidad de dicha tarea, es decir, a medida que aumentan los recursos cognitivos necesarios para acometerla, mayor es el número de errores cometidos en la estimación de la duración y mayor es la tendencia a juzgarla como más corta (Barrero et al., 2009; Carmeci, Misuraca \& Cardaci, 2009; Chaston \& Kingstone, 2004; Pedri \& Hesketh, 1993; Tobin \& Grondin, 2009).

Estos últimos autores, Tobin \& Grondin (2009), llevaron a cabo una investigación sobre la percepción de la duración de intervalos largos en adolescentes que jugaban con videojuegos. Con una muestra de 116 adolescentes, se les pidió que juzgaran 
(retrospectiva o prospectivamente) la duración de 3 tareas: 1) 8 minutos jugando; 2) 24 minutos jugando; y 3) 8 minutos con una tarea control. El resultado mostró que la tarea de estudio se estimo como más corta que la tarea control. Además, a medida que los jugadores eran más expertos, aparecían mayores niveles de subestimación.

Otro resultado destacable, apareció al investigar el papel del estado emocional en la percepción del tiempo mientras se llevaba a cabo una tarea muy estresante. Para ello se tomó una muestra de 76 paracaidistas nóveles en los que se midieron los niveles de miedo y de excitabilidad antes y después de saltar. Al aterrizar les preguntaban cuánto tiempo creían que había durado su experiencia. Los resultados reflejaron que cuando el sentimiento de miedo era predominante, se tendía a estimar el tiempo con un paso lento. En cambio, si el estado emocional era de excitación, el tiempo se veía como rápido (Campbell \& Bryant, 2007). Lo mismo parece ocurrir si la tarea distractora utilizada es una tarea tediosa. En una muestra de 110 estudiantes, a los que se les pidió realizaran una tarea desagradable y que fueron divididos en alta o baja tendencia al aburrimiento, se encontró que el grupo de personas propensas al aburrimiento percibieron el tiempo de la tarea como más lento que el grupo de personas con bajo aburrimiento (Watt, 1991). Este autor, en la misma publicación, establece un paralelismo entre el aburrimiento y la tendencia a tener un afecto deprimido, durante el cual se produciría una desaceleración subjetiva del paso del tiempo.

Dentro del paradigma retrospectivo, existe una modalidad experimental en la que la tarea distractora es un evento real de los sujetos, no es un artificio creado por los investigadores, sino una situación real que viven las personas (que, por supuesto, ignoran que van a ser interrogados con posterioridad sobre la cantidad de tiempo 
transcurrido). Tal es el caso de los accidentes de tráfico y otras situaciones en las que es necesaria la presencia de una ambulancia. Los sujetos, al ser interrogados por el tiempo desde la solicitud de ayuda médica o al requerir información sobre la percepción temporal en los instantes posteriores a los accidentes de tráfico, sufren consistentemente un fenómeno de enlentecimiento perceptual de intensidad notable (Kelly, Shulman, Khine \& Avner, 2007; Tse, Intriligator, Rivest \& Cavanagh, 2004).

c) A la hora de buscar características diferenciales entre las diferentes muestras utilizadas en las investigaciones sobre percepción temporal, si bien algunos estudios pueden encuadrarse dentro de la investigación psicológica básica, lo más habitual es encontrarnos con estudios que manejan poblaciones clínicas, que tienen como objetivo principal establecer un punto de comparación con población control sana.

Entre los estudios básicos que tienen en cuenta características especiales de la muestra o las circunstancias que les rodean, cabe destacar la investigación sobre estimación temporal en relación con diferentes fases del ciclo menstrual de las mujeres o en mujeres que han dado a luz recientemente (Beck, Reynolds, \& Rutowski, 1992; Morita, Nishijima \& Tokura, 2005; Morofushi, Shinohara \& Kimura, 2001). En estos estudios sobre los ritmos circadianos y el ciclo menstrual en la estimación del paso del tiempo, se tomaron muestras de mujeres en diferentes fases de su ciclo menstrual y se pidió que estimaran intervalos temporales de $6,12,24,36,48$ y 60 segundos. Las estimaciones las tenían que llevar a cabo a las 8:00 h, a las 14:00 h y a las 20:00 h, con el fin de establecer un ciclo de estimación. En la fase lútea del ciclo, las mujeres sobrestimaron los intervalos a las 8 de la mañana. También se observó tendencia a la sobrestimación en las mujeres en tareas de estimación de intervalos de 40 segundos 
durante los 7 días posteriores a dar a luz. Otros autores afirman que las estimaciones de duración de un estímulo de larga duración están determinadas en parte por la fase circadiana en la que se encuentran los individuos (Nakajima et al., 1998). Así, se estima el paso del tiempo más rápido cuando la temperatura corporal está en fase de ascenso y existe una tendencia al enlentecimiento subjetivo del paso del tiempo cuando se entra en la fase de descenso de la temperatura corporal (Campbell, Murphy \& Boothroyd, 2001). En este sentido, se ha encontrado que la capacidad para estimar intervalos de tiempo cortos, está más determinada por los ritmos circadianos que por el estado psicofisiológico o la carga de la memoria de trabajo (Kuriyama et al., 2003).

Los humanos tienen la capacidad para estimar la cantidad de tiempo que ha transcurrido durante el sueño aunque no es habitual encontrar investigaciones sistemáticas acerca de cómo el ser humano lleva a cabo dicha estimación (Aritake et al., 2004). En general, las dificultades en la conciliación del sueño no están vinculadas a dificultades en la estimación del tiempo (Rioux, Tremblay, \& Bastien, 2006). La precisión a la hora de llevar a cabo esta tarea fluctúa desde la sobrestimación en las primeras horas de sueño a la subestimación en las últimas horas (Aritake-Okada et al., 2009). En los estudios sobre deprivación de sueño en voluntarios, se ha observado un incremento del número de errores de estimación y un alargamiento en la estimación de la duración de los intervalos presentados (Babkoff, Zukerman, Fostick \& Ben-Artzi, 2005; Miro, Cano, Espinosa-Fernandez \& Buela-Casal, 2003). En las personas que informan de mala calidad en el sueño, encontramos que sobrestiman el tiempo que tardan en dormirse y subestiman el tiempo que han dormido, pero se sabe poco respecto al porqué puede ser esto (Tang \& Harvey, 2005). 
Otro fenómeno que se ha investigado es el aburrimiento. La experiencia de aburrimiento es normal en individuos sanos y puede darse más a menudo en personas con afectaciones neurológicas y/o psiquiátricas. En un estudio con sujetos sanos que informaban de ALTO y BAJO nivel de aburrimiento se encontró que los sujetos con niveles de aburrimiento bajo presentaban una tendencia a la subestimación del paso del tiempo y los sujetos con alto aburrimiento la tendencia contraria. Además, estos últimos, tenían porcentualmente una mayor tasa de errores de estimación (Danckert \& Allman, 2005; Goddard, 2000).

Se ha encontrado tendencia a la percepción acelerada de intervalos temporales en sujetos que presentan alta motivación intrínseca (Conti, 2001), en las personas que son excluidas socialmente (Twenge, Catanese \& Baumeister, 2003), en las personas que tienden a ser impulsivas en su proceso de toma de decisiones (Wittmann \& Paulus, 2008), en el personal de vuelos transoceánicos con desfase horario habitual (Ariznavarreta et al., 2002), en las personas con cronotipo matutino extremo (Esposito et al., 2007) y en las personas sometidas a terapia lumínica (Morita, Fukui, Morofushi \& Tokura, 2007).

También sabemos que la exactitud en la estimación es peor en las personas con problemas de impulsividad y/o agresividad (Dougherty et al., 2007; Partridge \& Fox, 2000) y en los sujetos que han fumado marihuana, con tendencia al enlentecimiento incluso con pequeñas dosis (Lieving, Lane, Cherek, \& Tcheremissine, 2006).

En cuánto a los niveles de cafeína de los sujetos sometidos a una evaluación de su capacidad de estimación de intervalos temporales, hemos podido ver una distribución en forma de $\cap$, es decir, que las estimaciones más precisas se dan con niveles medios de 
cafeína en sangre, por encima de los niveles bajos y de los altos (Gruber \& Block, 2003, 2005; Stine, O'Connor, Yatko, Grunberg \& Klein, 2002).

Las personas con discapacidades para el aprendizaje a menudo tienen dificultades para comprender conceptos abstractos tales como el concepto de tiempo. Un buen concepto del discurrir temporal nos permite predecir eventos futuros, tener presente los pasados y una sensación de control sobre los actuales, además de contribuir a la comprensión de nosotros mismos. La mejora en la capacidad para la percepción del tiempo puede reducir la capacidad de los sentimientos de impotencia y la ansiedad y aumentar los sentimientos de autoeficacia (Owen \& Wilson, 2006). Tan solo hemos encontrado un grupo de investigadores interesados en encontrar métodos para mejorar la capacidad de estimación de los seres humanos. Usando grupos de voluntarios de personas jóvenes, a los que se les hacen estudios longitudinales de dos meses de duración, han encontrado que la administración de una dosis baja de hormona melatonina $(0.75 \mathrm{mg}$.) consigue mejoras en la capacidad de la memoria visual y en la exactitud de las estimaciones de intervalos temporales. Además, los efectos son duraderos semanas después de interrumpir la ingesta (Arushanian, Baida \& Mastiagin, 2006).

Las investigaciones clínicas sobre percepción del paso del tiempo, buscan una mejor comprensión de los sujetos enfermos a través de la comparación con sujetos sanos. Dentro de esta área sobre percepción temporal, el grupo de mayor interés es el formado por las personas con déficit de atención con hiperactividad (TDAH). La capacidad de juzgar el paso del tiempo es fundamental para la regulación del comportamiento y la planificación de acciones y puede verse afectada entre las personas 
con déficit de atención (Seri, Kofman \& Shay, 2002), ya que se ha encontrado una relación inversa entre velocidad de procesamiento cerebral y percepción del paso del tiempo de tal forma que un procesamiento lento da lugar a una percepción rápida. De este modo, en el TDAH podría existir una distorsión en el sentido del tiempo en el que el éste pasa tan rápido que dificulta la concentración en una sola tarea (Goddard, 2000). Un grupo de adultos con TDAH se comparó con un G.C en una tarea de estimación de tiempo y se vio que con intervalos de tiempo cortos (de 15 a 60 segundos), el grupo con TDAH llevó a cabo estimaciones subjetivas más cortas y con más errores que el GC, controlando variables como el cociente intelectual y la presencia de trastornos de ansiedad o depresión (Barkley, Murphy \& Bush, 2001).

Otro campo objeto de estudio consiste en comprobar la exactitud de las personas con afectaciones neurológicas, como demencias o daños cerebrales, en sus estimaciones del paso del tiempo. La idea que fundamenta estos estudios es que la capacidad para estimar el tiempo de manera correcta nos permite un desempeño eficiente en las actividades básicas de la vida diaria y es necesaria su correcta evaluación para estimar el grado de dependencia de las personas afectadas (Schmitter-Edgecombe \& Rueda, 2008). En un estudio con 17 personas con demencia tipo Alzheimer se ha demostrado mayor variabilidad y error en sus estimaciones de intervalos temporales (Rueda \& SchmitterEdgecombe, 2009). En un estudio anterior, se mostró que pacientes con daño frontal y síndrome Korsakoff estimaban intervalos entre 10 y 120 segundos con menor exactitud que los alcohólicos sin daño cerebral y que sujetos sanos. Viendo además que los sujetos con síndrome de Korsakoff aumentan la tendencia a la subestimación a medida que aumentaba el intervalo de tiempo a estimar (Mimura, Kinsbourne \& O'Connor, 2000). 
Por el contrario, se ha encontrado tendencia a la sobrestimación en el cálculo de intervalos temporales en personas con deficiencias auditivas primarias (Kowalska \& Szelag, 2006), en personas con la enfermedad de Parkinson sin tratamiento con L-dopa (Lange, Tucha, Steup, Gsell \& Naumann, 1995; Riesen \& Schnider, 2001) y en personas adultas con trastornos de la fluidez verbal (tartamudez) (Ezrati-Vinacour \& Levin, 2001).

Queremos llamar la atención sobre un campo de investigación desconocido, como es el caso del síndrome de Smith-Magenis, considerado por los autores como un jet-lag congénito. El síndrome de Smith-Magenis es un tipo de retraso mental debido a múltiples anormalidades congénitas provocadas por una cancelación del cromosoma 17 y fue descubierto en los años 80 por un grupo de investigadoras de las Universidades de Oregon y Washington (Smith et al, 1986). Los sujetos afectos por esta enfermedad, presentan un fenotipo característico consistente en anormalidades cráneo-faciales, hipotonía muscular, voz ronca, dedos cortos, baja estatura, escoliosis, problemas de adaptación y problemas con la conciliación del sueño. En estos sujetos se ha encontrado una alteración en la secreción al torrente sanguíneo del la hormona pineal melatonina, de tal forma que pico de subida que normalmente se produce al anochecer, en estos individuos se da por la mañana con la consiguiente alteración del ciclo vigilia-sueño. Al igual que el personal de vuelos transoceánicos, las personas con síndrome de SmithMagenis presentan una percepción acelerada del paso del tiempo (Boudreau et al, 2009; Hino-Fukuyo et al, 2008).

Los estudios sobre enfermedad mental de nuestra revisión se remontan al año 1988 en el que Munzel, Gendner, Steinberg \& Raith con una muestra de 47 depresivos y 
un grupo de control con sujetos sanos de 16, encontraron sobrestimación en tareas de juicios de duración en los depresivos. Son muy numerosos los trabajos que han intentado comprobar la asociación entre depresión, ansiedad y alteraciones en el sentido del tiempo. Por ejemplo, a lo largo de los últimos años del siglo pasado, con diferentes criterios de muestreo y criterios diagnósticos, se puso de manifiesto la existencia de diferencias entre el tiempo medido y el tiempo estimado por parte de sujetos con síntomas depresivos o síntomas ansiosos. En todos los casos, se demostraba un enlentecimiento en el sentido del tiempo en los sujetos con depresión (Bidzan, 1991; Blewett, 1992; Iarovitskii \& Baturin, 1991; Kallert, 1994; Kuhs, 1991; Kuhs, Hermann, Kammer \& Tolle, 1991; Mathey, 1992; Meluzzi, Gasco, Francesetti \& Gecele, 1991; Mundt, Richter, van Hees \& Stumpf, 1998; Nosachev, 1992; Rammsayer, 1990; UnrugNeervoort, Kaiser \& Coenen, 1992).

A comienzos del presente siglo, se demostró la existencia de un ritmo circadiano en las variaciones afectivas (Murray, Allen \& Trinder, 2002) y un año después, en un estudio desde la teoría del procesamiento de información, se vio que la depresión afecta a varias funciones cognitivas. Así, se vio que la discriminación entre dos intervalos, uno de 1120 ms. y otro de $1280 \mathrm{~ms}$., fue peor en las personas con trastornos depresivos. No se encontró esta diferencia si los intervalos eran más cortos $(80-120 \mathrm{~ms})$ por lo que se concluyó que los déficit atencionales para el procesamiento de intervalos más largos podrían ser un factor descriptor de la depresión (Sevigny, Everett \& Grondin, 2003).

Más recientemente, utilizando los criterios diagnósticos del DSM-IV-TR (APA, 2000), sobre episodios depresivos y episodios maníacos, los resultados de una prueba de 
estimación del paso del tiempo revelaron aceleración en los maníacos, enlentecimiento en el grupo de depresión y exactitud en el grupo de comparación (Bschor et al., 2004).

También se ha visto que la experiencia del tiempo está estrechamente relacionada con nuestros estados de ánimo momentáneo. Los pacientes que padecen una enfermedad potencialmente mortal, experimentan un cambio drástico en su estado de ánimo pudiendo desarrollar trastornos mentales de tipo ansioso-depresivo. En un estudio en el se investigaron las asociaciones entre la percepción subjetiva del tiempo, la angustia psicológica y la calidad de vida en pacientes con neoplasias hematológicas, los pacientes que informaron de peor calidad de vida, menor bienestar espiritual y mayores niveles de ansiedad presentaban una percepción enlentecida del paso del tiempo y sobrestimaron un intervalo de 13 minutos. Estos pacientes tienen una atención desfocalizada de pensamientos y acciones significativas y eso hace que perciban el tiempo como más lento (Wittmann, Vollmer, Schweiger \& Hiddemann, 2006).

Otro campo de investigación son los cambios rápidos en la emocionalidad de los sujetos con el fin de demostrar que los estímulos emocionales modulan nuestra percepción temporal. Así, se ha visto que ante un estímulo emocional se juzga un intervalo como más largo que con un estímulo neutro (con el mismo nivel de arousal), y que los sonidos con valencia negativa son juzgados más largos que si son de valencia positiva, por lo que podemos afirmar la existencia de una relación entre el estado emocional y la fidelidad de los juicios temporales (Noulhiane, Mella, Samson, Ragot, \& Pouthas, 2007).

Por último, resaltar el hecho de que los autoinformes de los sujetos con sintomatología ansioso-depresiva y de los sujetos con episodios maníacos respecto a su 
percepción del paso del tiempo, concuerdan con los resultados observados en laboratorio. Los pacientes con trastornos afectivos a menudo informan de cambios en la experiencia subjetiva del paso del tiempo y en la forma en que perciben el flujo del tiempo y, en una tarea de reproducción del intervalo presentado ( 3 intervalos diferentes de 1, 6 y 37 segundos), los pacientes maníacos, en promedio, hacen estimaciones más cortas que los pacientes con depresión. En cambio, cuando se les preguntaba cuánto tiempo creían haber reproducido, los deprimidos estimaban los intervalos más largos (Mahlberg, Kienast, Bschor \& Adli, 2008).

2.- Investigación científica orientación temporal.

La orientación temporal se refiere a la direccionalidad de la perspectiva de tiempo. Lens (1986) la definió como la dirección predominante de la conducta y el pensamiento de la persona en la medida en que se encuentra orientado hacia objetos y acontecimientos del pasado, el presente o el futuro. Tiene una influencia dinámica en los juicios, decisiones y acciones de una persona.

Por otro lado, la actitud temporal se ha definido como los pensamientos positivos, negativos o neutrales expresados por una persona hacia el tiempo (Lennings, Burns \& Cooney, 1998). Tener actitudes positivas reflejaría el tiempo como un continuo integrado con el énfasis en creer o lograr diferentes metas. Por el contrario, las actitudes negativas reflejarían el tiempo como inconsistente y limitado, con sentido de discontinuidad.

Son variados los estudios sobre orientación temporal o perspectiva temporal los publicados ya que la forma en que recordamos el pasado o recreamos el futuro se ve mediatizada por nuestros objetivos actuales (D'Argembeau \& Van der Linden, 2004) y 
el desarrollo de un horizonte temporal es algo necesario, inherente, para la conciencia humana (Kruse, 2000).

Como se ha mencionado anteriormente, las personas que presentan procrastination tienen peor autoestima, mayor autoconciencia $\mathrm{y}$ ansiedad social $\mathrm{y}$ mayor incapacidad percibida, así como una menor búsqueda de identidad propia (Ferrari, 1991b). Recientemente, se ha examinado cómo la orientación en el tiempo y el cronotipo matutino-vespertino llevan a la existencia de dos tipos de procrastination. Procrastination de indecisión o de evitación. Se midió la orientación en el tiempo, el cronotipo, la indecisión o la evitación en la toma de decisiones en un grupo de 509 adultos con una edad media de 49.8 años. Los resultados otorgan a los "procrastinators" de tipo evitativo menor matutinidad y menor orientación al futuro y a los "procrastinators" indecisos un bajo presente hedonístico y bajos niveles de futuro positivo (Díaz-Morales, Ferrari, \& Cohen, 2008).

Respecto a las diferencias en género en la orientación y las perspectivas temporales, hemos encontrado que los hombres tienen la creencia de vivir más allá de la esperanza de vida y que las mujeres (pero no los hombres) que tenían niveles altos de felicidad consideraban que habían vivido un porcentaje menor de sus vidas (Joubert, 1992).

Los sujetos más centrados en el presente como norma general han tenido más parejas sexuales y se han permitido asumir más conductas de riesgo que aquellos con una construcción adecuada del futuro (Rothspan \& Read, 1996). En consonancia con este resultado, se ha encontrado que a mejor perspectiva de tiempo futuro se tienen mejores hábitos saludables respecto al consumo de drogas, las conductas sexuales de 
riesgo y la práctica habitual de ejercicio físico (Mahon, Yarcheski \& Yarcheski, 2000). Además, en otra investigación se ha demostrado que estar bien orientados hacia el futuro hace que los sujetos perciban sus objetivos como más cercanos que si no lo están (Halvari, 1991) y que estos sujetos presentan mayores garantías para la consecución de resultados académicos de éxito (Horstmanshof \& Zimitat, 2007).

Otro aspecto estudiado es el hecho que los seres humanos siempre subestimamos el tiempo que nos va a llevar la realización de tareas y la duración de eventos futuros (Roy, Christenfeld \& McKenzie, 2005). Según los autores, esto es debido a que se utiliza mal la memoria para eventos del pasado de similares características, de tal modo que las tareas largas y con coste se almacenan con menor duración de la real (Roy, Mitten \& Christenfeld, 2008). Esta tendencia a subestimar la duración de tareas futuras desaparece cuando la tarea a la que nos enfrentamos es totalmente nueva (Roy \& Christenfeld, 2007).

Por último, dentro de la investigación clínica sobre esta área, se ha encontrado que los jugadores patológicos presentan un horizonte de tiempo más corto que los jugadores sociales. En un grupo de 66 personas con problemas de juego en el que se analizaron las perspectivas de tiempo futuro, no se encontraron diferencias entre este grupo y el grupo con enfermedades mentales por lo que se concluyó que un horizonte de tiempo corto no es una característica única de los adictos (Hodgins \& Engel, 2002). También se ha encontrado que las personas afectadas de tinnitus de manera crónica anticipan un mayor número de eventos negativos en el futuro (Andersson, Kyrre Svalastog, Kaldo \& Sarkohi, 2007). 
La inseparable propiedad del tiempo consiste en revelar siempre la verdad. Francis Bacon 


\section{6.- OBJETIVOS E HIPÓTESIS}

\section{1.- Objetivo}

Desde un enfoque multidisciplinar nuestro objetivo es estudiar las discrepancias entre el tiempo objetivo y el estimado en un grupo de sujetos con sintomatología depresiva y ansiosa, analizar las diferentes percepciones temporales en función de la intensidad de la Psicopatología e investigar si determinadas características de personalidad son variables incidentes en la percepción temporal.

\section{2.- Hipótesis}

Este objetivo se operacionaliza en las siguientes hipótesis:

$1^{\text {a }}$ - El paciente ansioso-depresivo tiene una percepción enlentecida del paso del tiempo, en especial con tareas mecánicas.

$2^{a}$.- Las diferencias en estimación del paso del tiempo implican un perfil diferencial de expectativas de control generalizadas.

3a.- La perspectiva de tiempo futuro es diferente entre los sujetos sanos y los deprimidos. 
"Si conocieras el tiempo tan bien como lo conozco yo -dijo el Sombrero-, no habrías de derrocharlo como una cosa. El tiempo es una persona."

Lewis Carroll (1832-1898), Alicia en el país de las maravillas 


\section{7.- MATERIAL Y MÉTODO}

\section{1.- Participantes}

Se llevó a cabo un muestreo aleatorio intencionado entre los pacientes que acudían al servicio de Psiquiatría de Enlace del Hospital Clínico Universitario de Salamanca durante un periodo de seis meses.

\subsubsection{Criterios de inclusión del grupo de estudio}

Los sujetos pertenecientes al grupo de estudio estaban todos diagnosticados de trastornos depresivos. Debido a los objetivos del estudio anteriormente mencionados, se consideraron los siguientes criterios de inclusión en muestra, con el fin de intentar controlar las posibles variables que pudieran interferir en los resultados:

- Tener una edad comprendida entre los 18 y los 65 años

- Acudir al servicio de forma voluntaria

- Presentar, en el momento de la evaluación puntuaciones clínicamente significativas en depresión $\mathrm{y} / \mathrm{o}$ ansiedad. Dichas puntuaciones fueron obtenidas mediante la pasación de Inventario para la Depresión de Beck y el Cuestionario de ansiedad estado-rasgo de Spielberger. Se adoptaron como puntos de corte clínicamente significativos los siguientes:

BDI puntuación superior a 16

Cuestionario de Ansiedad Estado Rasgo: Puntuaciones superiores al centil 50 (Bobes, González y Sáinz, 2000) (ver tabla 5, página 182). 
Así, el grupo de estudio, estuvo compuesto por 61 sujetos, 43 mujeres y 18 hombres, con una edad media de 41.98 y una Dt. $=12.59$. La distribución de la edad queda reflejada en la figura 16:

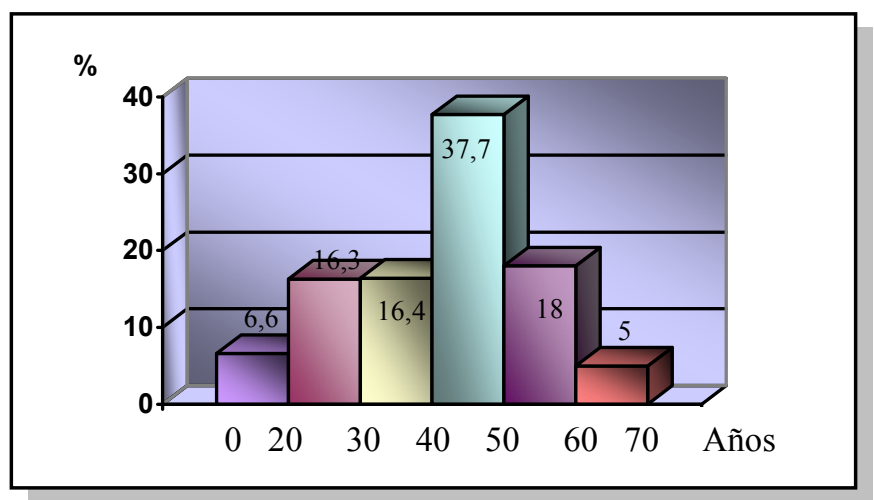

Fig. 16: Distribución de la edad. Grupo Experimental

Las puntuaciones oscilan entre 18 y 65 años y, como se puede observar, la distribución de la variable edad tiene una asimetría negativa (-.35), predominan las puntuaciones medias y tiene una forma platicúrtica (-.73).

El nivel de formación educacional se distribuye de la siguiente forma:

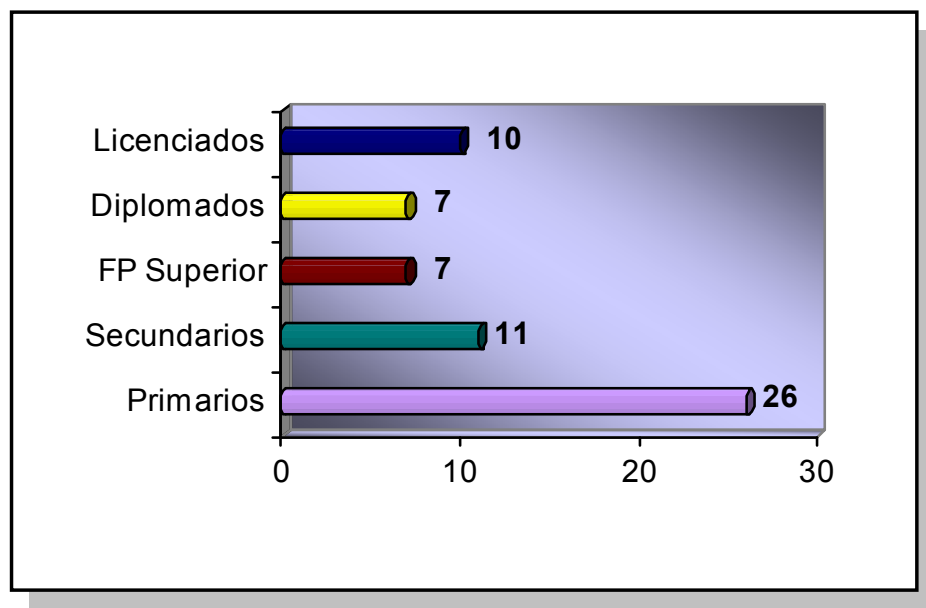

Fig. 17: Nivel Educacional. Grupo Experimental 
Con respecto al estado civil, algo más de la mitad están casados $(50.8 \%)$, siendo un $34.4 \%$ solteros, un $11.5 \%$ separados y un $3 \%$ viudos.

Otro aspecto de interés es la situación laboral de los sujetos. En la figura 18, se puede observar que en activo se encuentra el $59 \%$ (asumiendo en estado activo a las mujeres que trabajan en casa), los sujetos en situación de legal de desempleo y en situación de incapacidad temporal representan un $11.5 \%$ respectivamente $\mathrm{y}$, un $8.5 \%$ de los sujetos están jubilados. Se ha generado una categoría "Otros" para contemplar aquellos casos que no encajaban en las demás categorías.

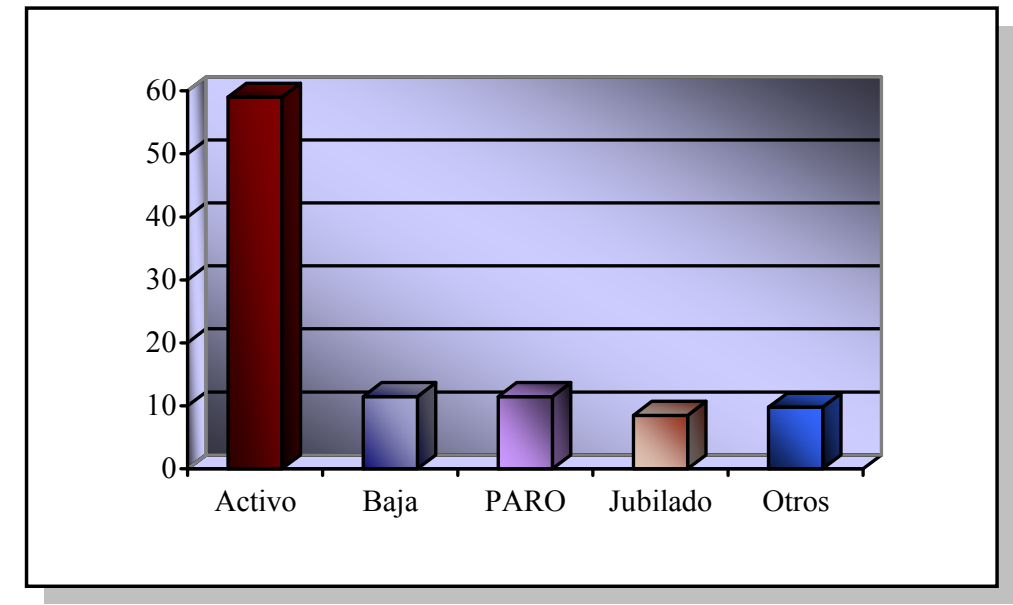

Fig. 18: Situación Laboral. Grupo Experimental

\subsubsection{Grupo control}

Al seleccionar al grupo control, se intentó que el conjunto de variables sociodemográficas fueran similares a las del grupo experimental, con el fin de controlar el efecto de las mismas.

El grupo de control está compuesto por 62 sujetos y los análisis de control efectuados indican que no había efectos de las variables analizadas entre el GC y el GE. 
Así, el grupo de comparación, o grupo control estuvo compuesto por 44 mujeres y 18 hombres. La edad media es 42.84 (Dt. = 12.11). Puede apreciarse en la fig. 19 que la distribución de la variable edad en el grupo de comparación presenta también una asimetría negativa (-.51) y que también es platicúrtica (-.57).

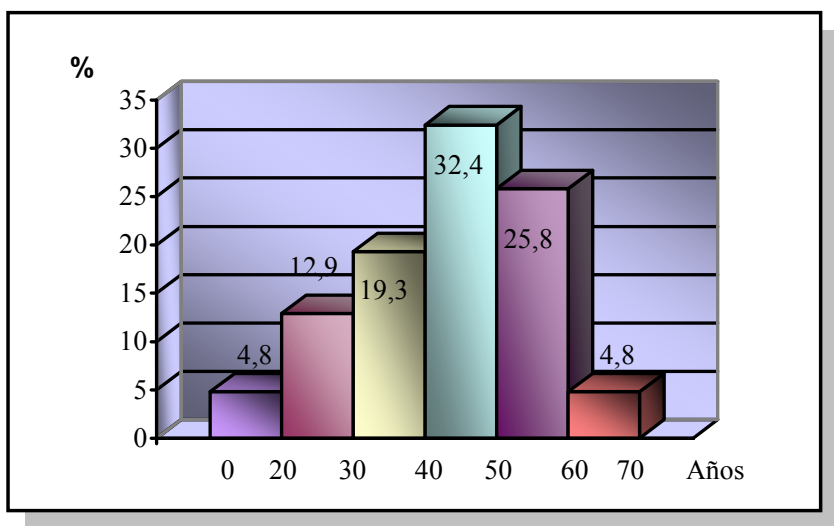

Fig. 19: Distribución de la edad. Grupo Control

En cuanto al nivel educacional, como puede apreciarse en la figura 20, encontramos que un $41.9 \%$ tenían estudios primarios, un $17.7 \%$ secundarios, un 12.9 \% habían alcanzado el nivel de grado superior de formación profesional y diplomados respectivamente y un $14.5 \%$ eran licenciados.

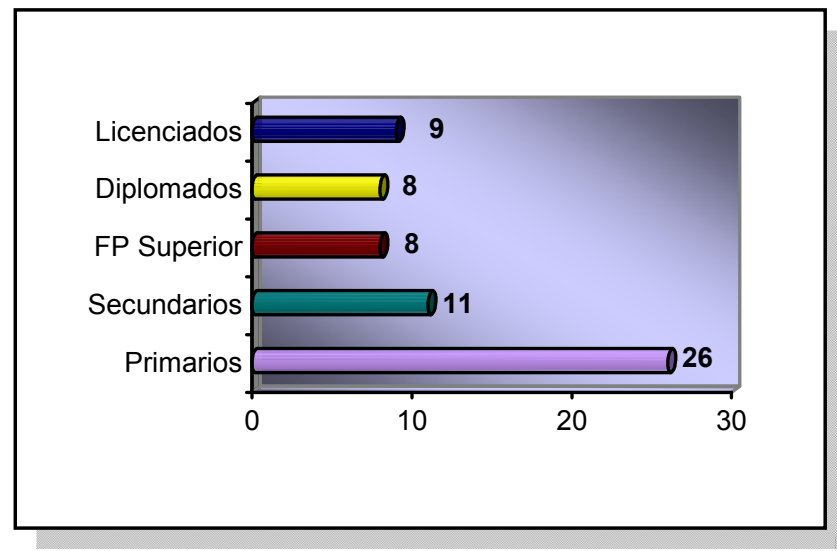

Fig. 20: Nivel Educacional. Grupo Control. 
Por último, la situación laboral de este grupo refleja casi un $84 \%$ de población activa, no se evidencia la presencia de ningún sujeto en situación de incapacidad temporal, ni la necesidad de la categoría "otros." Las puntuaciones se reflejan en la siguiente tabla:

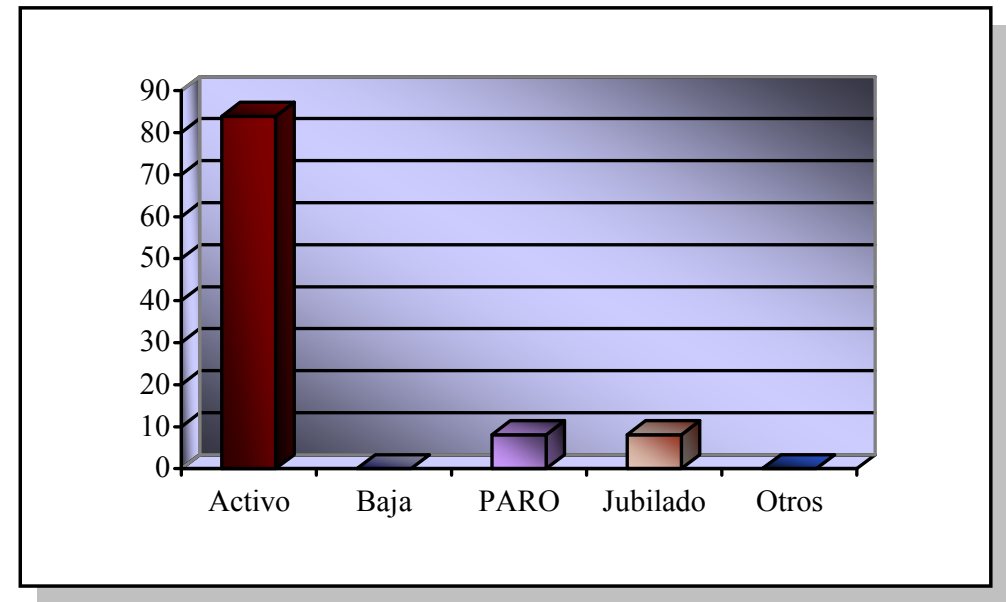

Fig. 21: Situación Laboral Grupo Control

Con el fin de asegurar la no existencia de diferencias estadísticamente significativas entre ambos grupos en las variables Edad, Género y Nivel Educacional, se llevó a cabo un estudio de diferencia de medias (prueba t para muestras independientes), en el que puede apreciarse dicha condición $\left(\mathrm{t}_{(121)}=-.43: \mathrm{P}_{\mathrm{a}}: 0.669 ; \mathrm{t}_{(121)}=.06: \mathrm{P}_{\mathrm{a}}\right.$ : $0.954 \mathrm{y} \mathrm{t}_{(121)}=.024: \mathrm{P}_{\mathrm{a}}: 0.981$, respectivamente). 


\section{2.- Instrumentos de medida}

7.2.1. Descripción de los instrumentos de medida

La batería de instrumentos utilizada estaba compuesta por:

a) Entrevista semiestructurada

Donde se recogen datos personales, datos demográficos, clínicos, antecedentes, tiempo de evolución y tratamiento psicofarmacológico.

b) Cuestionario de cogniciones anticipatorias (QCA de Légeron, Rivière \& Marboutin, 1991)

Este instrumento fue concebido con la finalidad de medir las tendencias de las personas a producir pensamientos tanto positivos como negativos. Está demostrado que las cogniciones anticipatorias negativas están correlacionadas con el trastorno depresivo (Légeron, Rivière \& Marboutin, 1991).

González-Tablas, Díez \& Llorca (1996), afirman que el cuestionario es un buen predictor del índice de depresión medido por el cuestionario de Depresión de Beck (BDI).

Se presenta como un cuestionario donde se valora la importancia de los pensamientos anticipatorios del sujeto. Está formado por 8 ítems, cada uno describe una situación con la que el individuo se puede encontrar y que necesita una anticipación por su parte, proponiendo una respuesta cognitiva.

El sujeto indica cómo se aplica a sí mismo esta cognición y se asignan valores entre 0 y 3 para las respectivas respuestas según la situación le parezca verdadera, casi siempre verdadera, casi siempre falsa o falsa. 
Las puntuaciones pueden oscilar entre 0 y 27 , y se ha establecido el umbral en 7. La puntuación mínima califica la ausencia de anticipación negativa y la máxima, la presencia de este tipo de pensamientos (González Tablas et al., 1996).

c) Batería de Escalas de Expectativas Generalizadas de Control (BEEGC de Palenzuela et al., 1992).

La batería se compone de tres escalas: Locus de control (LOC), autoeficacia (A) y expectativa de éxito (E). La primera de ellas es multidimensional y contiene a su vez otras tres subescalas, que son: expectativa de contingencia (C), expectativa de indefensión (I) y expectativa de suerte (S), conteniendo cada una 5 ítems. La segunda y la tercera (A y E), en cambio, son unidimensionales con 6 y 7 ítems respectivamente.

Cada ítem se valora de 1 a 9, marcando en qué grado se identifica el sujeto con cada afirmación, desde 1 cuando no se identifica nada, hasta 9 si se identifica totalmente. Las puntuaciones en la expectativa de contingencia (C), de indefensión (I) y de suerte (S) oscilan entre 5 y 45 puntos, la expectativa de autoeficacia (A) entre 6 y 54 y la de éxito entre 7 y 63.

La utilización de esta escala está motivada por su enfoque teórico integrativo y multidimensional del control personal y evalúa algunos de los constructos más representativos del mismo, enfatizando sobre medidas generalizadas de la personalidad (Palenzuela, et al., 1992; 1993).

d) Inventario de Depresión de Beck (Beck Depresión Inventory. BDI de Beck et al., 1961; versión española de Conde et al., 1975). 
El BDI en una de los instrumentos utilizados con más frecuencia en la investigación sobre la depresión. Aporta la capacidad de evaluación del estado de ánimo, pero además tienen la particularidad de otorgar mayor importancia a los componentes cognitivos del estado de ánimo que a los conductuales y somáticos. No es un instrumento de diagnóstico, pero ofrece unas puntuaciones que estiman la profundidad de la depresión.

La versión empleada fue la de 21 ítems, cada uno de los cuales describe una manifestación específica del comportamiento depresivo. Los valores medios para los niveles de depresión se exponen en la tabla 5 (Sanz y Vázquez, 1998):

\begin{tabular}{ll}
\hline Rasgo de depresión & Valor medio \\
Ausente o mínima & 10.9 \\
Leve & 18.7 \\
Moderada & 25.4 \\
Grave & 30.0 \\
\hline
\end{tabular}

La puntuación final se consigue a partir de la suma de las valoraciones realizadas para cada ítem. Las 13 primeras preguntas constituyen la subescala cognitivo-afectiva, y las ocho restantes, la subescala somática del rendimiento (Llorca, 2004).

e) Cuestionario de Ansiedad Estado-Rasgo (STAI de Spielberger, Gorsuch y Lushene, 1968; TEA, 1994).

El inventario para evaluar la ansiedad estado-rasgo de Spielberger (STAI) es un cuestionario de 40 preguntas, fácil de aplicar y puntuar (Spielberger, Jacobs, Russel y Crane, 1983). Se ha demostrado que tiene una fiabilidad y validez buenas, pero tiene el 
inconveniente de no aportar puntos de corte, tan sólo una escala percentual por género. En la tabla 6 se contemplan los percentiles normativos para la población general:

\begin{tabular}{|c|c|c|c|c|c|c|c|c|}
\hline & \multicolumn{2}{|c|}{ Centil 50} & \multicolumn{2}{|c|}{ Centil 75} & \multicolumn{2}{|c|}{ Centil 85} & \multicolumn{2}{|c|}{ Centil 99} \\
\hline & $\mathrm{AE}$ & AR & $\mathrm{AE}$ & AR & $\mathrm{AE}$ & AR & $\mathrm{AE}$ & AR \\
\hline \multicolumn{9}{|l|}{ HOMBRES } \\
\hline Adolescentes & 20 & 20 & 31 & 26 & 36 & 30 & $47-60$ & $46-60$ \\
\hline Adultos & 19 & 19 & 28 & 25 & 33 & 29 & $47-60$ & $46-60$ \\
\hline \multicolumn{9}{|l|}{ MUJERES } \\
\hline Adolescentes & 22 & 22 & 31 & 29 & 36 & 33 & $53-60$ & $49-60$ \\
\hline Adultas & 23 & 24 & 31 & 32 & 37 & 37 & $54-60$ & $49-60$ \\
\hline
\end{tabular}

Spielberger (1966) explica que el uso indiscriminado del que ha sido objeto el concepto de ansiedad ha producido gran confusión y ambigüedad, y posteriormente (1972a), añade que una teoría adecuada de la ansiedad ha de distinguir conceptual y operacionalmente entre ansiedad como un estado transitorio y ansiedad como un rasgo relativamente estable de personalidad.

Los estados de personalidad pueden ser considerados como un corte temporal en la corriente temporal de una persona (Thorne, 1966). En contraste, los rasgos de personalidad pueden conceptuarse como diferencias individuales relativamente estables, como tendencia a percibir el mundo de una cierta manera y como una disposición a reaccionar o comportarse de una manera determinada con una regularidad predecible. Por ello, rasgos de personalidad pueden ser considerados como reflejo de las diferencias individuales en la frecuencia e intensidad con que se han manifestado ciertos estados 
emocionales en el pasado, y las diferencias en la probabilidad de que tales estados serán experimentados en el futuro.

El estado de ansiedad (A-State), ha sido conceptuado por Spielberger (1972) como un "estado emocional transitorio o condición del organismo humano que varía en intensidad y fluctúa en el tiempo. Esta condición es caracterizada por sentimientos subjetivos de tensión y aprehensión conscientemente percibidos y activación del sistema nervioso autónomo. El estado de ansiedad es evocado cuando una persona percibe un estímulo o circunstancia como potencialmente peligrosa, dolorosa o amenazante para él” (p. 39). La intensidad del estado de ansiedad será elevada en circunstancias que son percibidas por el sujeto como amenazantes, independientemente del peligro objetivo; el nivel del estado de ansiedad sería bajo en situaciones no estresantes o en circunstancias en las que el peligro existente no es percibido como amenazante.

El rasgo de ansiedad (A-Trait) "se refiere a las diferencias individuales relativamente estables en propensión a la ansiedad, como rasgo de personalidad, esto es, a las diferencias en la disposición a percibir un amplio rango de situaciones o estímulos como peligrosos o amenazantes, y en la tendencia a responder a tales amenazas con diferentes elevaciones en estado de ansiedad" (Spierbelger, 1972b, p. $317)$.

Para Doleys y Doherty (2002) la prueba fue diseñada para medir:

1.- La ansiedad-rasgo (AR), considerándose una característica estable de la personalidad y se describe como la tendencia global de un individuo a responder con ansiedad, independientemente del estímulo específico. Señala una propensión ansiosa, 
relativamente estable, que caracteriza a los individuos con tendencia a percibir las situaciones como amenazadoras.

2.- La ansiedad-estado (AE), que pretende medir la ansiedad experimentada en respuesta a condiciones específicas, muestra un mayor grado de variabilidad. Es un estado emocional transitorio caracterizado por sentimientos subjetivos conscientemente percibidos de atención y aprensión y por la hiperactividad del sistema nervioso autónomo.

f) Historia de Babcock (The Babcock Story Recall Test; Babcock, 1930).

Evalúa la memoria verbal lógica inmediata y retardada. El explorador lee al sujeto una historia, y éste deberá evocarla inmediatamente, y valorar así la memoria de retención y evocación inmediata, de un material verbal estructurado lógico. Tras una labor de interferencia no mnésica (aproximadamente de 15 minutos), el sujeto debe repetir lo que recuerde de la historia (memoria retardada verbal lógica), presentado por vía auditiva.

Es una historia de contenido emocionalmente negativo que se divide en 18 unidades de recuerdo. La puntuación que obtienen los sujetos se consigue haciendo la suma directa de las unidades recordadas.

\subsubsection{Pruebas de evaluación de la estimación del paso del tiempo}

Nuestro objetivo principal obligó a diseñar una serie de situaciones que nos permitieran llevar a cabo una correcta evaluación del paso del tiempo por parte de los sujetos estudiados. Se diseñaron 3 tareas siguiendo un paradigma experimental de tipo prospectivo (sujetos informados del objetivo de estimación) y 2 tareas de tipo 
retrospectivo (sujetos no informados del objetivo de estimación). Consisten en intentar que el participante en el estudio estime el tiempo transcurrido en diferentes contextos:

1.- Contexto Historia. Paradigma retrospectivo.

La primera estimación del paso del tiempo se les pide cuando escuchan por primera vez la Historia de Babcock (Babcock, 1930). Dicha historia, fue grabada en un medio digital con una duración exacta de 30 segundos. Después de pedir a los sujetos que trataran de recuperar el mayor número posible de elementos (Evaluación de la capacidad de memoria inmediata), se les hacía la pregunta directa “¿cuánto ha durado la historia que hemos oido? ¿Durante cuánto tiempo ha sonado la historia?”

Los sujetos no tienen una previsión de la petición de estimación del paso del tiempo, no pueden saber qué se les va a pedir ni saben todavía que van a tener que llevar a cabo más estimaciones, por lo que es una prueba pura de estimación, bajo el paradigma experimental retrospectivo.

2.- Contexto interferencia mecánica. Paradigma prospectivo.

La segunda estimación de tiempo consistió en pedir a los sujetos que clasificaran unas tarjetas de dos tamaños y de cinco colores diferentes durante lo que ellos estimaran que eran dos minutos de tiempo. La instrucción era: "Me gustaría que estuviera entretenido clasificando estas tarjetas. Me da igual a qué velocidad lo haga. Lo que me interesa es que lo esté haciendo durante un periodo de dos minutos. Lo que usted crea que son 2 minutos." Debido a la instrucción, los sujetos tenían tiempo para elaborar una estrategia acerca de la estimación que debían llevar a cabo. Este supuesto fue evaluado con posterioridad con el fin de conocer dichas estrategias y establecer la idoneidad de las mismas. 
3.- Contexto sin tarea interfiriente. Paradigma prospectivo.

La tercera medición consistió en pedir a los sujetos que estimaran también 2 minutos de tiempo, pero esta vez sin tarea de interferencia. Instrucción: "Me gustaría que calculara cuándo han pasado dos minutos de tiempo." En este caso también existe un sobreaviso de la tarea de estimación.

4.- Contexto interferencia emocional. Paradigma prospectivo.

Semejante a las anteriores, pero esta vez la tarea de interferencia consistía en escuchar un pequeño relato mientras se efectuaba el cálculo de los 2 minutos. La historia fue grabada en formato digital con una duración próxima a los 5 minutos. También se les advertía a los sujetos la necesidad de conocer el argumento de la historia que iban a escuchar, a fin de evitar que la tarea de interferencia fuera excluida del procesamiento de la información por parte de los sujetos. Dicho argumento, extraído del libro "Juan Salvador Gaviota" de Bach (1970), consiste en un fragmento en el que se habla de superación de obstáculos, de ensayo y trabajo hasta la consecución de un éxito y de lucha contra las adversidades. Este es el motivo por el que la tarea interfiriente de este contexto ha sido clasificada como emocional.

5.- Contexto estimación de larga duración. Paradigma retrospectivo.

La última estimación del paso del tiempo que se pidió a los sujetos fue acerca de la duración total de la entrevista. Al comienzo del protocolo lo primero que se hacía era anotar la hora de comienzo y la última pregunta que se hacía a los sujetos era “¿cuánto tiempo cree que ha pasado desde el comienzo de esta entrevista?" Al finalizar la misma se hacía la resta del tiempo real trascurrido menos el tiempo estimado por el sujeto y se anotaba. Al igual que en el contexto historia, los sujetos en esta tarea no tienen un 
sobreaviso de la misma, aunque el resto de la entrevista han tenido que trabajar con la temporalidad y pueden "sospechar" más evaluaciones sobre su capacidad para estimar el paso del tiempo, como ocurría con la primera tarea, no pueden establecer una estrategia para enfrentarse a la misma.

Las tres tareas de estimación del paso de 120 segundos pertenecen al paradigma prospectivo de investigación sobre temporalidad y se basan en un estudio del año 1996, llevado a cabo por el psicólogo P. A. Mangan, quien mandó a grupos de personas de diferentes edades que calcularan cuando habían pasado tres minutos de tiempo, bajo dos condiciones diferentes, la primera en silencio, sin hacer nada, y la segunda, realizando una tarea de clasificación (Mangan, Bolinskey, Rutherford \& Wolfe, 1996).

Con el fin de tener claro cómo se debían clasificar a los sujetos en cuanto a las pruebas de estimación del paso del tiempo que se le pasaban, establecimos tres posibilidades de clasificación:

a.- Lentificación del paso del tiempo.

Cuando el paso del tiempo es percibido de una forma más lenta de la que realmente es. Estos sujetos, cuando llevan a cabo una estimación del tiempo transcurrido, siempre tenderán a pensar que ha pasado más tiempo del que realmente ha pasado.

Así, en las pruebas anteriormente descritas, pertenecientes al paradigma prospectivo, de estimación de 2 minutos de tiempo, los sujetos con una estimación enlentecida del paso del mismo, pararán el cronómetro antes de haber llegado a los 120 segundos. 
En cambio, en las 2 tareas del paradigma retrospectivo, al ser una pregunta directa sobre la duración de un acontecimiento, aquellos sujetos que informen de una duración mayor a la real, estarán percibiendo un transcurrir temporal enlentecido.

b.- Aceleración del paso del tiempo.

Cuando el paso del tiempo es percibido de una forma más rápida de la que realmente es. Los sujetos, al llevar a cabo una estimación del tiempo transcurrido, tenderán a pensar que ha pasado menos tiempo del real.

En las pruebas de estimación prospectivas de 2 minutos, los sujetos con una estimación rápida del paso del tiempo, pararán el cronómetro después de haber llegado a los 120 segundos.

En cambio, en las 2 tareas del paradigma retrospectivo, al ser una pregunta directa sobre la duración de un acontecimiento, aquellos sujetos que informen de una duración menor a la real, estarán percibiendo un trasncurrir temporal acelerado.

c.- Puntualidad del paso del tiempo.

Cuando el paso del tiempo es percibido de forma exacta. Los sujetos perciben y dan el resultado fielmente.

Se presenta a continuación una tabla aclaratoria de estos conceptos: 


\begin{tabular}{|c|c|c|c|c|c|}
\hline Contextos & $\begin{array}{l}\text { Cálculo de } \\
\text { la variable }\end{array}$ & \multicolumn{2}{|c|}{ Significado } & G. E. & G. C. \\
\hline \multirow{3}{*}{ Sin tarea interfiriente } & \multirow{3}{*}{$X-120$} & \multirow{3}{*}{$\begin{array}{c}\text { Aceleración: } \\
\text { Diferencia positiva } \\
=\text { signo positivo }= \\
\text { les pasa el tiempo } \\
\text { rápidamente. }\end{array}$} & \multirow{3}{*}{$\begin{array}{c}\text { Lentificación: } \\
\text { Diferencia } \\
\text { negativa = signo } \\
\text { negativo = les } \\
\text { pasa el tiempo } \\
\text { lentamente. }\end{array}$} & $\begin{array}{c}+ \text { (rápido) } \\
\mathrm{n}=17\end{array}$ & $\begin{array}{c}+ \text { (rápido) } \\
\mathrm{n}=31\end{array}$ \\
\hline & & & & $\begin{array}{c}\text { - (lento) } \\
n=44\end{array}$ & $\begin{array}{c}-(\text { lento }) \\
n=27\end{array}$ \\
\hline & & & & $\begin{array}{c}\text { Exacto } \\
n=0\end{array}$ & $\begin{array}{c}\text { Exacto } \\
n=4\end{array}$ \\
\hline \multirow{3}{*}{ Tarea Mecánica } & \multirow{3}{*}{$X-120$} & \multirow{3}{*}{$\begin{array}{l}\text { Diferencia positiva } \\
=\text { signo positivo = } \\
\text { les pasa el tiempo } \\
\text { rápidamente. Es } \\
\text { decir, aceleración. }\end{array}$} & \multirow{3}{*}{$\begin{array}{c}\text { Diferencia } \\
\text { negativa = signo } \\
\text { negativo = les } \\
\text { pasa el tiempo } \\
\text { lentamente. Es } \\
\text { decir, largo. }\end{array}$} & $\begin{array}{c}+ \text { (rápido) } \\
n=31\end{array}$ & $\begin{array}{c}+ \text { (rápido) } \\
\mathrm{n}=20\end{array}$ \\
\hline & & & & $\begin{array}{c}\text { - (lento) } \\
n=30\end{array}$ & $\begin{array}{c}-(\text { lento }) \\
n=42 \\
\end{array}$ \\
\hline & & & & $\begin{array}{c}\text { Exacto } \\
n=0\end{array}$ & $\begin{array}{c}\text { Exacto } \\
n=0\end{array}$ \\
\hline \multirow{3}{*}{ Tarea Emocional } & \multirow{3}{*}{$X-120$} & \multirow{3}{*}{$\begin{array}{l}\text { Diferencia positiva } \\
=\text { signo positivo = } \\
\text { les pasa el tiempo } \\
\text { rápidamente. Es } \\
\text { decir, aceleración. }\end{array}$} & \multirow{3}{*}{$\begin{array}{c}\text { Diferencia } \\
\text { negativa }=\text { signo } \\
\text { negativo }=\text { les } \\
\text { pasa el tiempo } \\
\text { lentamente. Es } \\
\text { decir, largo. }\end{array}$} & $\begin{array}{c}+ \text { (rápido) } \\
n=41\end{array}$ & $\begin{array}{c}+ \text { (rápido) } \\
n=30\end{array}$ \\
\hline & & & & $\begin{array}{c}- \text { (lento) } \\
\mathrm{n}=20\end{array}$ & $\begin{array}{c}-(\text { lento }) \\
n=29\end{array}$ \\
\hline & & & & $\begin{array}{c}\text { Exacto } \\
n=0\end{array}$ & $\begin{array}{c}\text { Exacto } \\
n=3\end{array}$ \\
\hline \multirow{3}{*}{ Historia } & \multirow{3}{*}{$30-X$} & \multirow{3}{*}{$\begin{array}{l}\text { Diferencia positiva } \\
=\text { signo positivo = } \\
\text { les pasa el tiempo } \\
\text { rápidamente. Es } \\
\text { decir, aceleración. }\end{array}$} & \multirow{3}{*}{$\begin{array}{c}\text { Diferencia } \\
\text { negativa }=\text { signo } \\
\text { negativo }=\text { les } \\
\text { pasa el tiempo } \\
\text { lentamente. Es } \\
\text { decir, largo. }\end{array}$} & $\begin{array}{c}+ \text { (rápido) } \\
\mathrm{n}=40\end{array}$ & $\begin{array}{c}+ \text { (rápido }) \\
n=27\end{array}$ \\
\hline & & & & $\begin{array}{c}-(\text { lento }) \\
n=14 \\
\end{array}$ & $\begin{array}{c}-(\text { lento }) \\
n=6 \\
\end{array}$ \\
\hline & & & & $\begin{array}{c}\text { Exacto } \\
n=7\end{array}$ & $\begin{array}{c}\text { Exacto } \\
n=29\end{array}$ \\
\hline \multirow{3}{*}{$\begin{array}{c}\text { Tiempo entrevista } \\
\text { duración estimada } \\
\text { (TEDE) }\end{array}$} & \multirow{3}{*}{$\begin{array}{c}\text { Tiempo } \\
\text { real - } \\
\text { tiempo } \\
\text { estimado } \\
\text { entrevista }\end{array}$} & \multirow{3}{*}{$\begin{array}{l}\text { Diferencia positiva } \\
=\text { signo positivo = } \\
\text { les pasa el tiempo } \\
\text { rápidamente. Es } \\
\text { decir, aceleración. }\end{array}$} & \multirow{3}{*}{$\begin{array}{c}\text { Diferencia } \\
\text { negativa = signo } \\
\text { negativo = les } \\
\text { pasa el tiempo } \\
\text { lentamente. Es } \\
\text { decir, largo. }\end{array}$} & $\begin{array}{c}+ \text { (rápido) } \\
n=16\end{array}$ & $\begin{array}{c}+ \text { (rápido }) \\
n=28\end{array}$ \\
\hline & & & & $-($ lento $)$ & \\
\hline & & & & $\begin{array}{c}\text { Exacto } \\
n=0\end{array}$ & $\begin{array}{c}\text { Exacto } \\
n=7\end{array}$ \\
\hline
\end{tabular}

Tabla 7: Lentificación, aceleración o exactitud en la estimación del tiempo

En los contextos de estimación según el paradigma retrospectivo, si los sujetos mandan parar el tiempo antes de los 120 segundos, significa que para ellos ya ha pasado ese tiempo. Han estimado que han pasado 2 minutos cuando en realidad no ha sido así. Es decir, el paso del tiempo se les ha hecho LARGO, el tiempo ha ido MÁS DESPACIO para ellos. Más LENTAMENTE. En caso contrario, es decir, si los sujetos paran el tiempo después de los 120 segundos, implica que para ellos el tiempo no ha llegado aún a su destino cuando en realidad sí lo ha hecho. Han estimado que el tiempo no ha alcanzado los 2 minutos cuando en realidad sí ha llegado. En este caso, el tiempo 
para los sujetos pasa de forma más rápida, el tiempo se les ha hecho CORTO, el tiempo ha ido más RÁPIDO para ellos.

En las pruebas de estimación bajo el paradigma prospectivo, al ser una pregunta directa sobre la duración de un acontecimiento, si el tiempo estimado es menor al real indicaría aceleración del paso del tiempo. En caso contrario, es decir, si la diferencia entre la duración real del acontecimiento y la duración estimada por el sujeto fuera negativa, indicaría una lentificación del paso del tiempo.

La segunda columna es la operación llevada a cabo para efectuar dicho cálculo. X representa la duración estimada por cada uno de los sujetos en las pruebas de estimación del paso del tiempo.

Las dos siguientes son los dos posibles resultados de llevar a cabo la operación anteriormente descrita.

Se han añadido las dos últimas columnas con el fin de completar la información del tamaño muestral de cada una de las opciones, así, el número debajo de la clasificación de sujetos en rápidos, lentos o exactos, hace referencia al número de casos que se encuentran en cada contexto. 


\subsubsection{Descriptivos de los instrumentos}

Teniendo en cuenta los sujetos pertenecientes al grupo de estudio, se analizan a continuación los resultados obtenidos a nivel grupal en las pruebas administradas. En primer lugar se analiza el Inventario para la depresión de Beck (Conde, et al., 1975):

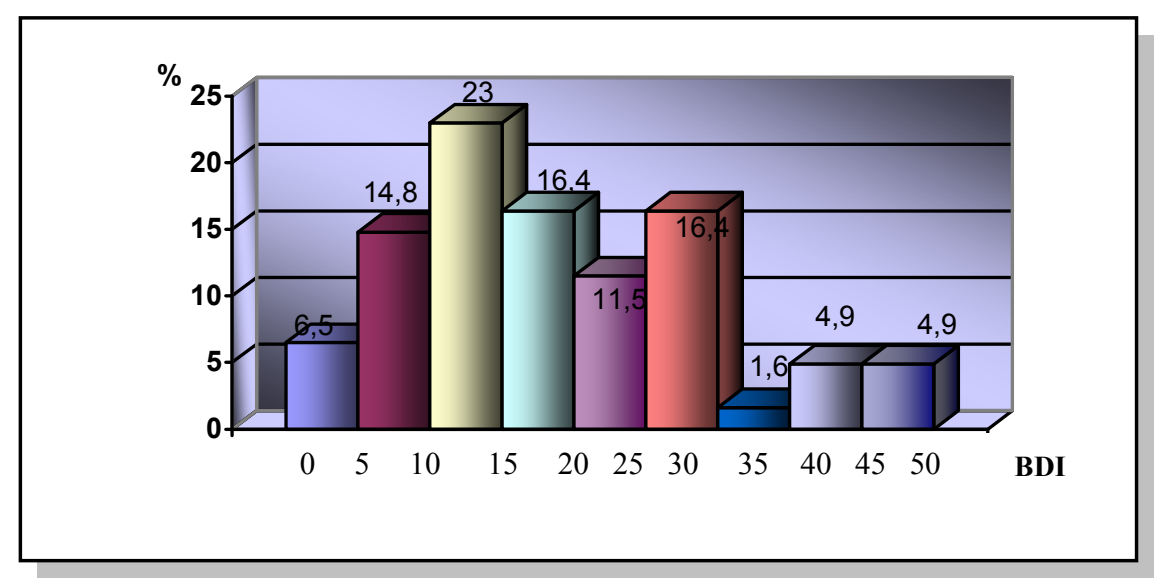

Fig. 22: Distribución de la variable depresión. Grupo experimental

La variable depresión en el grupo de estudio ofrece una puntuación media de 18.98, con una desviación típica de 10.53, destacando que la mediana se encuentra situada en 18.00. La distribución de las puntuaciones es moderadamente asimétrica (.55) y su curtosis es ligeramente negativa (-.14). El 55.7\% tiene puntuaciones por encima de 16, punto de corte para entrar a formar parte del estudio. Los sujetos que no alcanzan dicha puntuación, el $44.3 \%$ restante, cumplieron los criterios de inclusión referentes a las puntuaciones en la Escala de Ansiedad Estado-Rasgo.

En el caso del grupo control, el valor medio para el Inventario de depresión de Beck fue de 3.43 (Dt. = 3.11).

Con respecto al Cuestionario de Ansiedad Estado-Rasgo (STAI) de Spielberger, se estudia en primer lugar la ansiedad estado. 
La media ofrece un valor de 33.77 y una desviación típica de 11.88. La distribución de las puntuaciones es prácticamente simétrica (.068) y se observa un índice de curtosis negativo (-.52) (fig. 23):

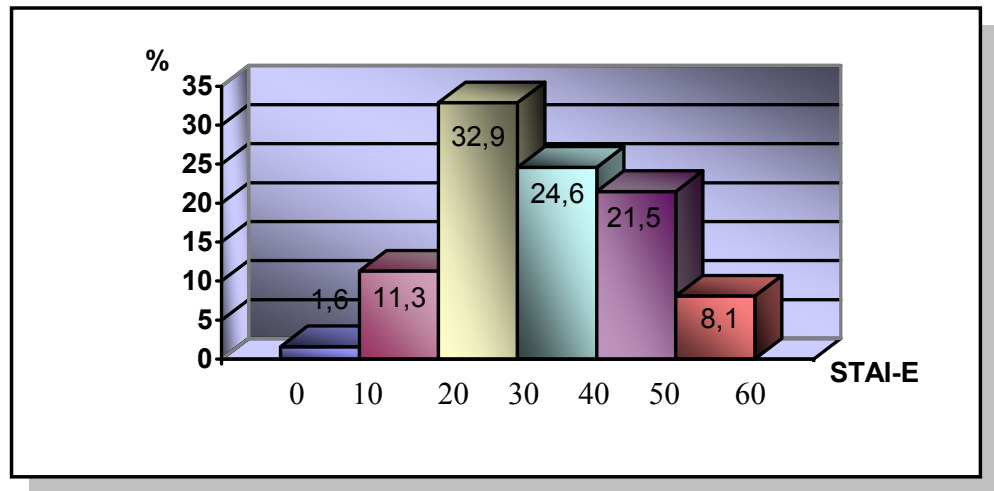

Fig. 23: Distribución de la variable ansiedad estado (Grupo experimental)

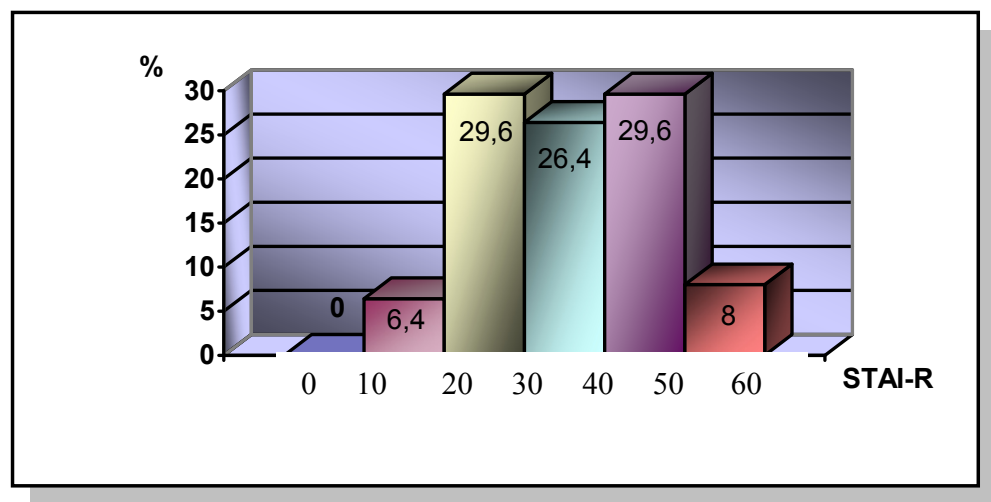

Fig. 24: Distribución de la variable ansiedad rasgo (Grupo experimental)

Si tenemos en cuenta la puntuación ofrecida en población normalizada, la mayoría de nuestros participantes superan el percentil 75 , es decir, tienen una alta ansiedad estado.

Cuando se analizaron las puntuaciones de ansiedad rasgo (STAI-R) (fig. 24), la media ofreció un valor de 35.31 y desviación típica 10.86. La distribución de las puntuaciones tiende a la simetría (0.092) y se observa un índice de curtosis de signo 
negativo (-.73). Al igual que ocurría con la ansiedad estado, la comparación con las puntuaciones de la población normal, coloca a la mayoría de los sujetos por encima del percentil 75 en ansiedad rasgo, por lo que podemos hablar de un grupo de sujetos caracterialmente ansiosos, con puntuaciones elevadas también en el momento de la evaluación.

En el caso del grupo de sujetos sanos, la media de las puntuaciones de ansiedad estado fue de $5.39(\mathrm{Dt} .=5.04)$ y las de ansiedad rasgo de $5.51(\mathrm{Dt} .=4.99)$, por lo que de nuevo se observan puntuaciones dentro de la normalidad, si bien, puede detectarse claramente cierta deseabilidad social.

En tercer lugar, se analizaron las expectativas medidas con la Batería de Escalas de Expectativas Generalizadas de Control (BEEGC). En la tabla 8, figuran las medias y la variabilidad de las puntuaciones:

\begin{tabular}{lll}
\hline Expectativa & Media & Dt \\
\hline Contingencia & 33.95 & 5.53 \\
Autoeficacia & 29.52 & 11.11 \\
Indefensión & 24.95 & 8.73 \\
Éxito & 29.90 & 9.11 \\
Suerte & 29.26 & 8.18 \\
\hline
\end{tabular}

Tabla 8: Valores medios y variabilidad de las expectativas de control (G.E)

\begin{tabular}{ll}
\hline Expectativa & Me Dt \\
\hline Contingencia & $39 .(3.82$ \\
Autoeficacia & 49.110 .68 \\
Indefensión & $17 . \vdots 7.90$ \\
Éxito & $43 .: 8.20$ \\
Suerte & $25 .\{6.08$ \\
\hline Tabla 9: Valores medios y variabilidad de las expectativas de control (G.C) \\
\hline
\end{tabular}




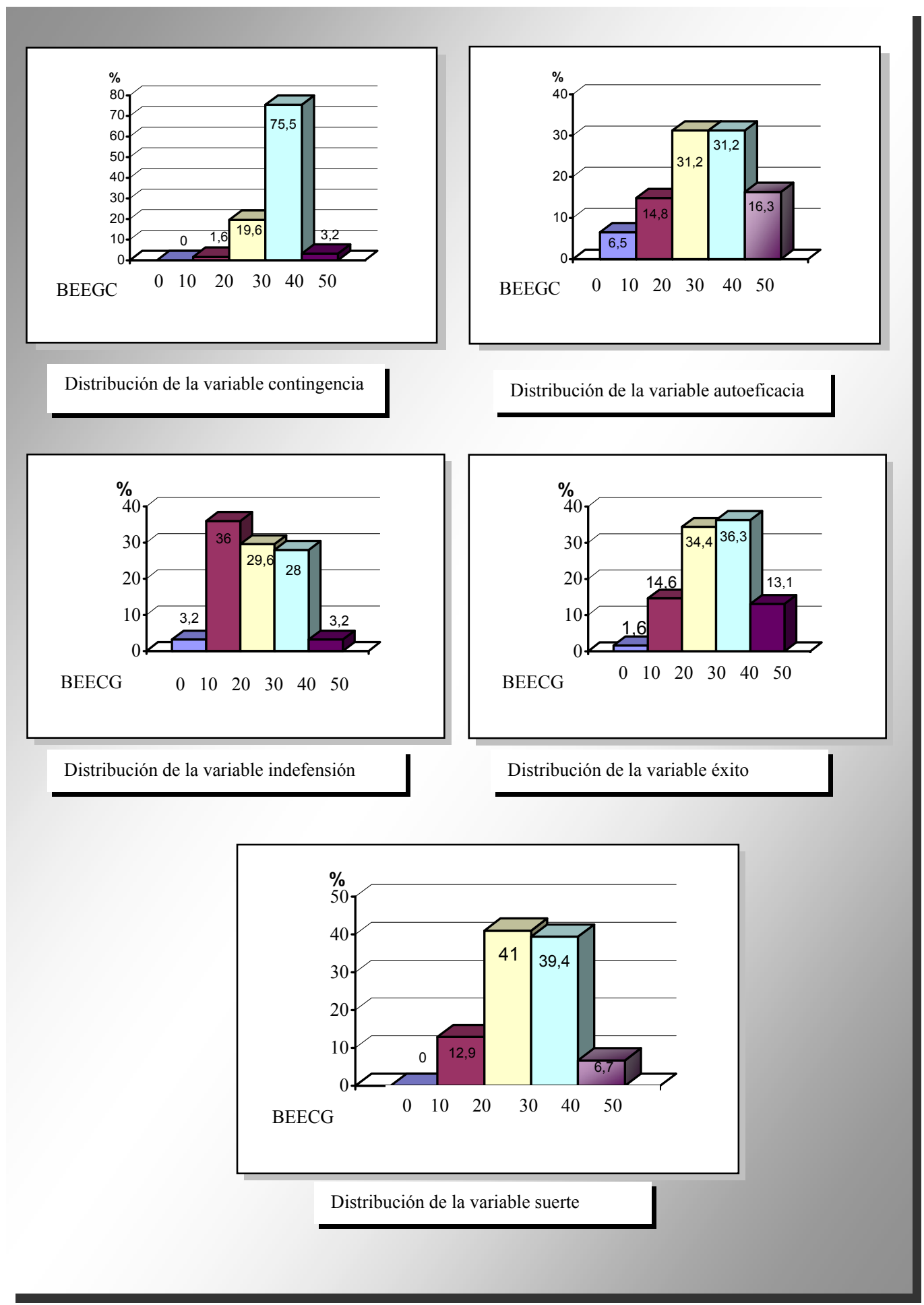

Fig. 25: Distribución de las expectativas (BEEGC) del Grupo experimental 


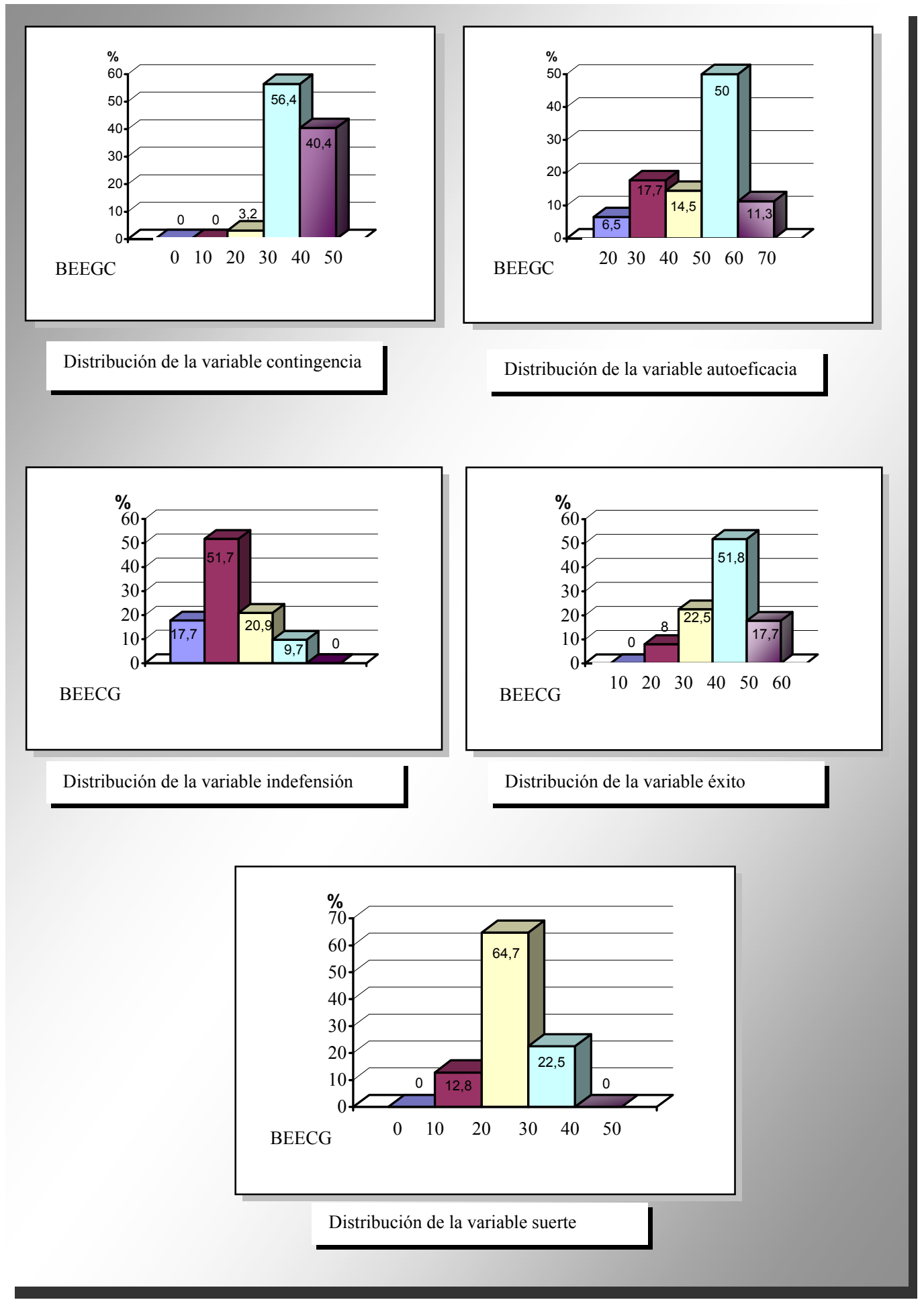

Fig. 26: Distribución de las expectativas (BEEGC) del Grupo control 
Al representar las distribuciones de las expectativas por grupos (figuras 25 y 26 ) se pueden observar niveles más bajos de autoeficacia, contingencia y éxito y más altos de indefensión y creencia en la suerte por parte del grupo de estudio.

Al analizar el Cuestionario de Cogniciones Anticipatorias (QCA de Lègeron, Riviere y Marboutin, 1991), las puntuaciones en el pensamiento anticipatorio ofrecen, en el caso del grupo experimental, una media 7.52 y una Dt. $=5.02$. La distribución de frecuencias en el QCA tiene una asimetría positiva de .80 y la curtosis (.26) es ligeramente positiva (fig. 27). En cambio, puede apreciarse un claro descenso de las puntuaciones en el caso del grupo de sujetos sanos, con una media de $1.60(\mathrm{Dt} .=1.92)$ (fig. 28).

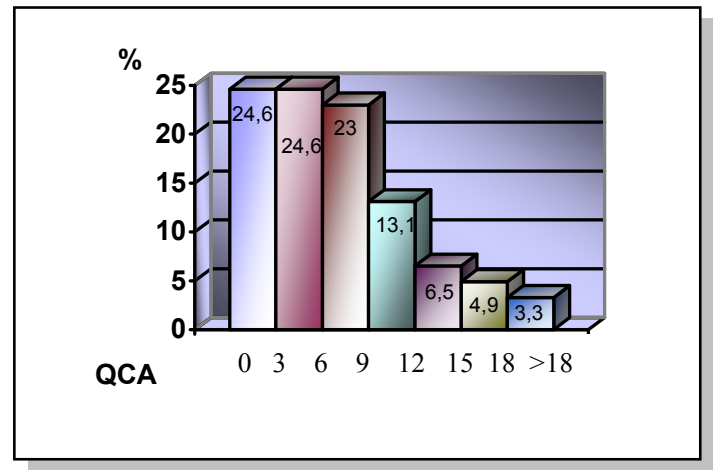

Fig. 27: Distribución de la anticipación (G.E.)

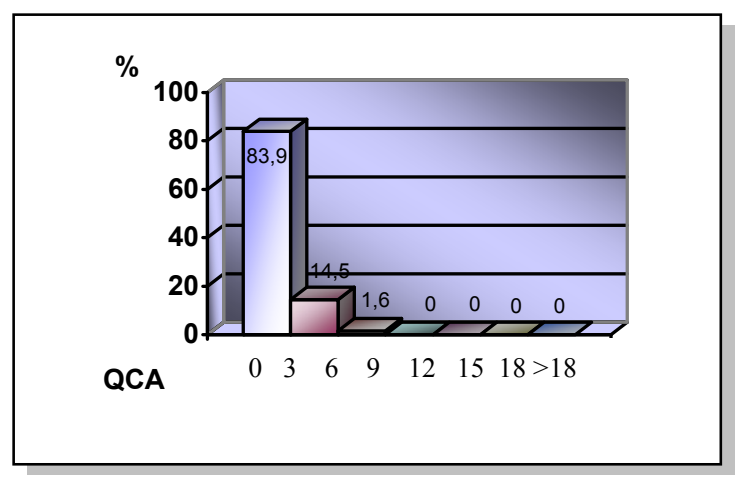

Fig. 28: Distribución de la anticipación (G.C.)

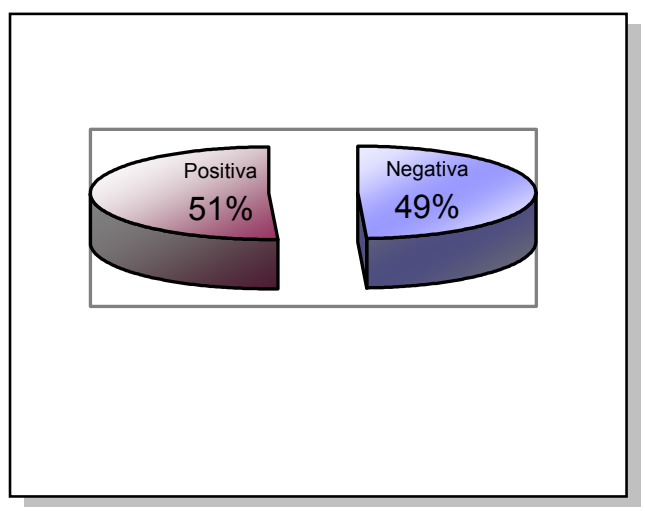

Fig. 29: Tipos de anticipación 
Cuando se realiza el estudio dicotomizando el grupo de estudio en función del punto de corte que ofrece la escala situado en 7 , se obtiene un pictograma que evidencia que el $51 \%$ de los sujetos tienen pensamiento positivo y el resto negativo (fig. 29).

En el grupo de comparación, el $98.4 \%$ tienen pensamiento positivo.

\subsection{Diseño}

Con los datos y las condiciones anteriormente descritas, se llevó a cabo un diseño de tipo cuasi-experimental. Dicho diseño es de tipo inter-intra (2X5). Las variables inter son la pertenencia al grupo de control o al grupo de pacientes con psicopatología, y las variables intrasujetos son las diferentes condiciones de estimación del paso del tiempo.

\begin{tabular}{llllll}
\hline Condiciones & $\mathrm{T}_{1}$ & $\mathrm{~T}_{2}$ & $\mathrm{~T}_{3}$ & $\mathrm{~T}_{4}$ & $\mathrm{~T}_{5}$ \\
\hline G. E & GExT $_{1}$ & GExT $_{2}$ & $\mathrm{GExT}_{3}$ & $\mathrm{GExT}_{4}$ & $\mathrm{GExT}_{5}$ \\
G. C & GCxT $_{1}$ & $\mathrm{GCxT}_{2}$ & $\mathrm{GCxT}_{3}$ & $\mathrm{GCXT}_{4}$ & $\mathrm{GCxT}_{5}$ \\
\hline & & & & & \\
& \multicolumn{4}{c}{ Tabla 10: Diseño experimental } \\
\hline
\end{tabular}




\subsection{Procedimiento}

En un primero momento, para establecer una buena relación (rapport) con el paciente, se les dio una explicación del contexto evaluativo, solicitando su participación voluntaria y proactiva. A continuación, se pedía a los participantes que se quitaran el reloj y que apagaran el teléfono móvil, en caso de llevarlo. Debido al estricto orden de las diferentes pruebas, la entrevista semiestructurada fue pospuesta al cuarto lugar en el orden de la sesión, por lo que era imprescindible llevar a cabo una buena acogida de los sujetos con el fin de que se sintieran cómodos y relajados.

Una vez finalizada la presentación del estudio a todos los participantes, se les administraron las pruebas psicodiagnósticas de cribado, aquellos que cumplían los criterios de inclusión se les pasaba al resto de las pruebas experimentales. Tan sólo al finalizar, se les explicaba la finalidad del estudio y, los que voluntariamente concedían su consentimiento, entraban a formar parte del mismo. Se les garantizaba la confidencialidad de los datos y el uso exclusivo con fines de investigación y tratamiento (en este caso sólo al grupo experimental). A los sujetos, tanto del grupo experimental como del grupo de control, que no cumplían con los criterios de inclusión, se les agradecía su colaboración en la entrevista no continuando con el resto del protocolo.

La entrevista completa siempre fue efectuada por el mismo psicólogo, los test se pasaron en forma heteroaplicada, en una sesión, siguiendo las normas de aplicación de los cuestionarios y respetando el mismo orden de pasación. Además, la entrevista se llevó a cabo siempre en la misma sala, por lo que las condiciones de temperatura y ruido ambiente fueron controladas. 
El orden de la entrevista completa fue el siguiente:

-. Inventario de Depresión de Beck (Beck Depresión Inventory. BDI de Beck, Ward, Meldenson, Mock \& Erbaugh, 1961; versión española de Conde \& Useros, 1975).

-. STAI-E Cuestionario de Ansiedad Estado (STAI de Spielberger, Gorsuch y Lushene, 1968; TEA, 1994).

-. Babcock 1 (Babcock, 1930). Prueba de evaluación de la memoria inmediata.

-. Prueba de estimación de la duración de la Historia de Babcock.

-. STAI-R Cuestionario de Ansiedad Rasgo (STAI de Spielberger, Gorsuch y Lushene, 1968; TEA, 1994).

-. Babcock 2 (Babcock, 1930). Prueba de evaluación de memoria diferida.

-. Primera prueba de estimación del paso del tiempo: Contexto tarea mecánica, clasificación de tarjetas.

-. Entrevista semiestructurada.

-. Segunda prueba de estimación del paso del tiempo: Contexto sin tarea interfiriente.

-. Batería de Escalas de Expectativas Generalizadas de Control (BEEGC, de Palenzuela, Prieto, Da Silva \& Oliveira, 1992).

-. Tercera prueba de estimación del paso del tiempo: Contexto tarea emocional.

-. Cuestionario de Cogniciones anticipatorias (QCA de Légeron, Rivière \& Marboutin, 1991).

-. Preguntas finales: Cálculo de la hora actual y estimación de la duración total de la entrevista (estimación del paso del tiempo a largo plazo). 
Una vez finalizada la sesión se les agradecía la colaboración prestada y se procedía al triaje de los pacientes en el caso del grupo experimental.

El reproductor que se usó para que los sujetos escucharan la historia de Babcock (Babcock, 1930) y la tarea de estimación del tiempo anteriormente descrita, fue cambiado de pilas cada 10 entrevistas con el fin de evitar posibles cambios en la duración total de las historias. Se utilizó un reproductor de la marca $\mathrm{SONY}^{\circledR}$, modelo TCM-465V. Así mismo, el reloj-cronómetro usado para los cálculos del tiempo por parte el experimentador, posee una tecnología que permite una precisión de 1/100 segundos, además de una duración de la pila garantizada a 10 años. En este caso se usó el modelo W-753 de la marca CASIO ${ }^{\circledR}$ 


\subsection{Búsqueda bibliográfica}

La búsqueda bibliográfica se llevó a cabo a través de las bases de datos PsycInfo y Medline abarcando desde 1990 hasta 2009. El procedimiento de búsqueda incluía como palabras claves: temporalidad, cronobiología, ritmos circadianos, depresión, ansiedad, orientación temporal, cronofarmacología, cronotoxicología. Se han encontrado y consultado un total de 13.689 artículos.

La revisión temática ha incluido:

Fuentes Documentales Primarias (textos, manuales, compilaciones, monografías, revistas, boletines, informes de investigación, y tesis doctorales).

Fuentes Documentales Secundarias (revisiones, catálogos, recensiones, resúmenes/abstracts, índices/index bibliográficos: de citas, de sumarios, directorios y bases de datos).

Fuentes Documentales Terciarias (diccionarios y enciclopedias, Thesaurus).

Los resultados de la búsqueda nos han permitido una:

- Valoración de los conocimientos actuales sobre el tema.

- Valoración de la pertinencia y viabilidad del proyecto.

- Provisión del marco conceptual para la investigación.

- Ayuda en la delimitación del objetivo específico.

- Información sobre aspectos concretos del diseño.

- Comparación de los propios resultados con estudios similares. 
Sintomatología ansioso depresiva y su relación con la temporalidad

\subsection{Análisis de los datos}

La información se recogió en una base de datos del programa Microsoft Excel 2003 de la suite ofimática Microsoft Office, para ser analizados con posterioridad mediante programa Statistical Package for the Social Sciences (SPSS), versión 15 para Personal Computer.

Para describir la muestra se llevaron a cabo análisis descriptivos, que incluían cálculos y gráficos de los diferentes estadísticos de las variables analizadas. Para poner a prueba las hipótesis planteadas se realizaron diferentes análisis:

- ANOVAS o Análisis de varianza de un factor y de medidas repetidas.

Informan sobre la existencia de diferencias significativas entre los diferentes subgrupos en los que se han separado los sujetos. Se realizaron comparaciones "a posteriori” entre los diferentes grupos, mediante el test de Scheffé.

- Análisis Multivariado:

Posee la propiedad de poder establecer correspondencias entre distintas variables o factores con una o más variables dependientes. Permite además contrastar tanto los modelos equilibrados como los no equilibrados. En un modelo multivariado, las sumas de cuadrados debidas a los efectos del modelo y las sumas de cuadrados error se encuentran en forma de matriz en lugar de en la forma escalar del análisis univariado. Si se especifica más de una variable dependiente, se proporciona el análisis multivariado de varianzas usando la traza de Pillai, la lambda de Wilks, la traza de Hotelling y el criterio de mayor raíz de Roy con el estadístico F aproximado, así como 
el análisis univariado de varianza para cada variable dependiente. Además de contratar hipótesis, MLG Multivariante genera estimaciones de los parámetros.

El análisis multivariado es útil para explicar relaciones entre una gran cantidad de indicadores o para explorar efectos no conocidos entre éstos. Mediante ellos se pueden abordar todos los indicadores disponibles para un fenómeno determinado. De los métodos existentes se han elegido algunos que permiten organizar variables, por ejemplo los modelos de regresión y el análisis factorial; y los métodos dirigidos a organizar sujetos como el análisis discriminate.

- Análisis discriminante: es una de las técnicas de clasificación de sujetos en grupos ya definidos. Se parte de un criterio de clasificación de sujetos en grupos y de una muestra en la que se han medido determinadas variables cuantitativas independientes, que son las que se utilizarán para tomar la decisión en cuanto al grupo en el que se clasifica cada sujeto, mediante un modelo matemático estimado a partir de los datos. Concretamente, el análisis discriminante predictivo, trata de estimar a partir de los datos, unas ecuaciones para la utilización de éstas con un nuevo sujeto, del cuál se desconoce el grupo de pertenencia. Permite clasificarlo en su grupo, proporcionando una regla de clasificación lo más precisa posible. Se trata pues de formular un algoritmo por el que se pueda determinar a qué grupo pertenece un sujeto. En el análisis discriminante predictivo es importante cuantificar con qué precisión se clasificará a un nuevo sujeto. 
"El futuro es algo que cada cual alcanza a un ritmo de sesenta minutos por hora, haga lo que haga y sea quien sea."

Clive Staples Lewis (1898-1963)

"El tiempo muda unos lugares y respeta otros, concluyó.

Pero siempre te cambia el corazón"

Arturo Pérez-Reverte. Corsarios de Levante.

RESVLTAD@S Y DiSCVSi@́N 


\section{8.- RESULTADOS Y DISCUSIÓN}

\section{1.- Primera hipótesis}

\section{1'.- El paciente ansioso-depresivo tiene una percepción enlentecida del paso del} tiempo.

Para comprobar esta hipótesis se han llevado a cabo varias pruebas estadísticas con el fin de poder contrastarla adecuadamente.

En primer lugar se hizo un análisis de varianza de medidas repetidas, para un diseño 2x3, siendo el factor Inter el grupo de pertenencia (Grupo de control o grupo experimental) y el factor Intra las 3 tareas de estimación de 2 minutos, en donde la medida de la estimación del tiempo se realizó, como ya se ha indicado en el procedimiento, como la diferencia entre el tiempo real que duraba la prueba y el tiempo que calculaban los sujetos que había durado, estando los participantes informados de que se trataba de una tarea de estimación temporal lo más precisa posible.

Los resultados de este primer análisis indican:

1.- Los efectos principales debidos al factor grupo son significativos $\left(\mathrm{F}_{(1,121)}=\right.$ 13.42; $\mathrm{P}_{\mathrm{a}}=.000$ ). En promedio los pacientes (grupo experimental) sobrestiman el paso del tiempo en tareas bajo un paradigma retrospectivo.

\begin{tabular}{lr|c|cc}
\hline $\begin{array}{l}\text { Posible } \\
\text { participante }\end{array}$ & $\begin{array}{c}\text { Media(tiempo real }- \\
\text { tiempo estimado) }\end{array}$ & Error típ. & \multicolumn{2}{c}{$\begin{array}{c}\text { Intervalo de } \\
\text { confianza al 95\%. }\end{array}$} \\
\hline & & & $\begin{array}{l}\text { Límite } \\
\text { inferior }\end{array}$ & $\begin{array}{c}\text { Límite } \\
\text { superior }\end{array}$ \\
\cline { 4 - 5 } G. E. & $-18,552$ & 3,745 & $-25,966$ & $-11,138$ \\
G.C. &, 769 & 3,714 & $-6,585$ & 8,122 \\
\hline
\end{tabular}

Tabla 11: Estimación según el grupo de pertenencia 
Según lo esperado, cuando a las personas se les solicita la estimación de un intervalo temporal fijo, independientemente de si existe tarea distractora o no, en el caso de la existencia de sintomatología ansioso-depresiva se tiende a percibir que el tiempo pasa más lentamente (puntuación diferencial promedio $=-18.55$ segundos). Sin embargo, no ocurre lo mismo cuando se trata de personas psicopatológicamente sanas, estas realizan una correcta estimación (puntuación diferencial promedio $=0.77$ segundos) (ver tabla 11).

2.- Aparecen diferencias estadísticamente significativas en la estimación del intervalo temporal dependiendo de las características de la tarea distractora utilizada $\left(\mathrm{F}_{(2,242)}=16.25 ; \mathrm{P}_{\mathrm{a}}=.000\right)$. Independientemente del grupo de pertenencia, en promedio, la estimación más ajustada a la realidad se realiza cuando el distractor usado durante la prueba es de tipo manipulativo-mecánico (puntuación diferencial promedio 0.05 segundos). Por el contrario, cuando el distractor es emocional o no existe, se produce una sobrestimación del tiempo (ver tabla 12).

\begin{tabular}{lrrcc}
\hline $\begin{array}{l}\text { Intervalo temporal } \\
\text { (tarea) }\end{array}$ & Media & Error típ. & Intervalo de confianza al 95\%. \\
\hline & & & $\begin{array}{c}\text { Límite } \\
\text { inferior }\end{array}$ & $\begin{array}{c}\text { Límite } \\
\text { superior }\end{array}$ \\
1 sin distractor & $-16,410$ & 3,005 & $-22,359$ & $-10,462$ \\
2 distractor &, 046 & 3,256 & $-6,399$ & 6,492 \\
mecánico & $-10,311$ & 3,123 & $-16,494$ & $-4,127$ \\
$\begin{array}{l}3 \text { distractor } \\
\text { emocional }\end{array}$ & & & & \\
\hline
\end{tabular}

Tabla 12: Estimación según las tareas (retrospectivo)

En suma, cuando se analiza la estimación de un intervalo temporal fijo parece que la ausencia de distractores no favorece la mejor estimación. Ésta tiende a realizarse cuando la tarea interferente es de tipo mecánico. 
3.- La interacción tareas*muestra resultó estadísticamente significativa $\left(\mathrm{F}_{(2,242)}=\right.$ 8.72; $\left.\mathrm{P}_{\mathrm{a}}=.000\right)$. La estimación del intervalo temporal por parte de los pacientes es enlentecida en el caso de ausencia de distractor y distractor emocional, pero, se ajusta al tiempo real cuando el distractor es una tarea mecánica (ver tabla 13). Por contra, en ausencia de patología, las tres situaciones de estimación del intervalo temporal se ajustan al tiempo real de duración, es decir, los participantes perciben con precisión el intervalo temporal (ver tabla 13).

\begin{tabular}{|c|c|c|c|c|c|}
\hline \multirow[t]{2}{*}{ Posible participante } & \multirow[t]{2}{*}{$\begin{array}{l}\text { Tareas de } \\
\text { Estimación }\end{array}$} & \multirow[t]{2}{*}{ Media } & \multirow[t]{2}{*}{ Error típ. } & \multicolumn{2}{|c|}{$\begin{array}{c}\text { Intervalo de } \\
\text { confianza al } 95 \% .\end{array}$} \\
\hline & & & & $\begin{array}{l}\text { Límite } \\
\text { inferior }\end{array}$ & $\begin{array}{l}\text { Límite } \\
\text { superior }\end{array}$ \\
\hline \multirow[t]{3}{*}{ G. Experimental. } & 1(sin distractor) & $-31,869 * *$ & 4,266 & $-40,315$ & $-23,423$ \\
\hline & 2(mecánica) & $-3,262$ & 4,623 & $-12,415$ & 5,890 \\
\hline & 3 (emocional) & $-20,525 * *$ & 4,435 & $-29,305$ & $-11,744$ \\
\hline \multirow[t]{3}{*}{ G. Control } & 1(sin distractor) &,- 952 & 4,232 & $-9,329$ & 7,426 \\
\hline & 2(mecánica) & 3,355 & 4,585 & $-5,723$ & 12,433 \\
\hline & 3 (emocional) &,- 097 & 4,399 & $-8,806$ & 8,612 \\
\hline
\end{tabular}

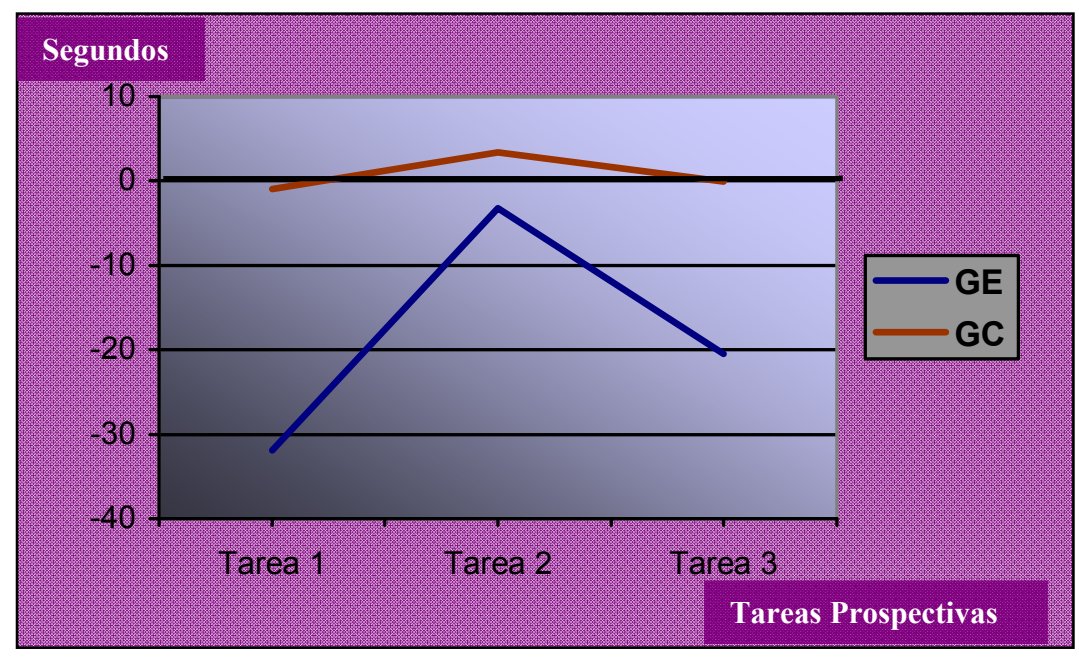

Fig. 30: Representación de la interacción 
En segundo lugar, se llevaron a cabo contrastes t de diferencia de medias entre el grupo de control y el grupo experimental para analizar las discrepancias en estimaciones temporales bajo un paradigma retrospectivo. Para ello se utilizó, por una parte, la prueba "Historia de Babcock" y se pidió a los sujetos una estimación del tiempo de duración de la historia en el momento en el que los participantes esperaban más preguntas sobre el contenido de la misma, y, por otra, al finalizar la entrevista, se les solicitó un cálculo de su duración. Los resultados indican:

1.- Diferencias estadísticamente significativas entre los grupos experimental y control en la prueba de estimación de la duración de la Historia de Babcock $\left(\mathrm{t}_{(121)}=\right.$ $-4.65 ; \mathrm{P}_{\mathrm{a}}=.000$ ). En promedio, los pacientes (grupo experimental) estiman la duración de la Historia de Babcock en 65.68 segundos, es decir, piensan que ha durado 35.68 segundo más que su tiempo real, por lo que perciben el trascurso del tiempo de forma enlentecida (ver tabla 14).

Cuando se trata de personas psicopatológicamente sanas, en promedio estiman la duración de la Historia de Babcock en 33.03 segundos, es decir, piensan que ha durado 3.03 segundos más que su tiempo real, por lo que tienden a realizar una correcta estimación (ver tabla 14).

\begin{tabular}{|c|c|c|c|c|c|}
\hline \multirow[t]{2}{*}{$\begin{array}{l}\text { Variable } \\
\text { dependiente }\end{array}$} & \multirow[t]{2}{*}{$\begin{array}{l}\text { Posible } \\
\text { participante }\end{array}$} & \multirow[t]{2}{*}{$\begin{array}{c}\text { Media de la puntuación } \\
\text { diferencial }\end{array}$} & \multirow[t]{2}{*}{ Error típ. } & \multicolumn{2}{|c|}{$\begin{array}{c}\text { Intervalo de } \\
\text { confianza al } 95 \% .\end{array}$} \\
\hline & & & & $\begin{array}{l}\text { Límite } \\
\text { inferior }\end{array}$ & $\begin{array}{l}\text { Límite } \\
\text { superior }\end{array}$ \\
\hline \multirow[t]{2}{*}{ Babcock } & GE & $-35,767$ & 5,177 & $-46,016$ & $-25,517$ \\
\hline & $\mathrm{GC}$ & $-3,032$ & 5,093 & $-13,115$ & 7,051 \\
\hline
\end{tabular}

Tabla 14: Estimacion de la tarea prospectiva contexto Historia de Babcock 
2.- Se encontraron diferencias estadísticamente significativas entre los grupos experimental y control en la realización de la entrevista $\left(\mathrm{t}_{121}=7.01 ; \mathrm{p}_{\mathrm{a}}<0.000\right)$. Además existen diferencias significativas entre el tiempo real y el estimado cuando lo realizaba el grupo experimental $\left(t_{59}=3.25 ; p_{a}<0.002\right)$ pero no así en el caso del grupo control $\left(\mathrm{t}_{61}=-0.455 ; \mathrm{p}_{\mathrm{a}} \leq 0.651\right)$.

\begin{tabular}{lllrrr}
\hline & $\begin{array}{l}\text { Posible } \\
\text { participante }\end{array}$ & N & Media & Desviación típ. & \multicolumn{1}{c}{$\begin{array}{c}\text { Error típ. de } \\
\text { la media }\end{array}$} \\
& GE & 61 & 3407,7049 & 649,40073 & 83,14724 \\
tiempo entrevista real & GC & 62 & 2680,6452 & 491,99451 & 62,48336 \\
$\begin{array}{l}\text { tiempo percibido } \\
\text { entrevista total }\end{array}$ & GE & 60 & 2955,0000 & 1044,82989 & 134,88696 \\
& GC & 62 & 2701,9355 & 490,93701 & 62,34906 \\
\hline
\end{tabular}

Tabla 15: Estimación de la tarea prospectiva contexto duración de la entrevista

La duración total de la entrevista realizada a los participantes del grupo experimental fue mayor en promedio (3407,71 seg.), que el tiempo empleado por el grupo control (2680,64 seg.). Los pacientes además, perciben que la duración total de la entrevista es menor que la real, es decir, se les pasa el tiempo rápidamente $(2955,00$ seg.). En cuanto al grupo control, sus valores reales y estimados no se diferencian significativamente entre sí (ver tabla 15).

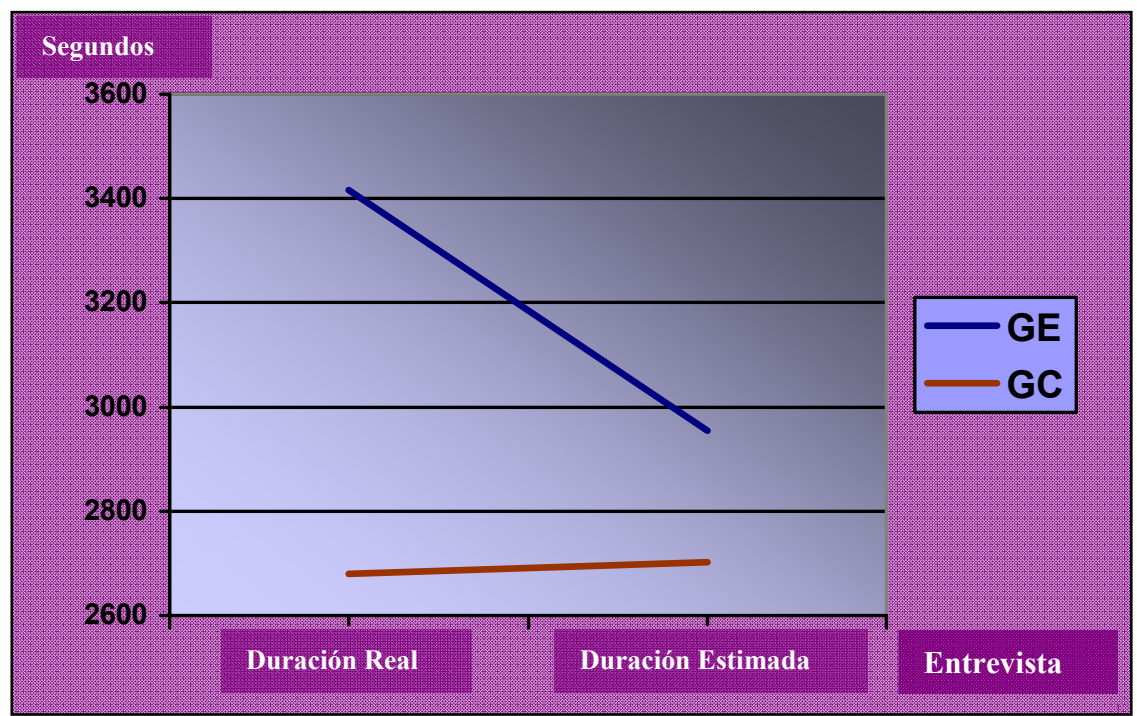

Fig. 31: Duración de la entrevista total para el G.E. y el G. C. 
En suma, podemos afirmar que los sujetos psicopatológicamente sanos, en promedio, realizan una estimación del paso del tiempo de forma correcta tanto en pruebas prospectivas como retrospectivas. Por otro lado, cuando las pruebas de estimación son prospectivas los pacientes tienden a considerar que el tiempo pasa más lentamente de lo que realmente ocurre, es decir, tienen una percepción distorsionada del mismo (salvo cuando se usa un distractor manipulativo mecánico). Cuando se utilizan pruebas basadas en un paradigma retrospectivo, los pacientes perciben el paso del tiempo de forma lenta realizando una sobrestimación de su duración si la prueba es de corta duración y, por el contrario, si es de larga duración tienden a estimar menos tiempo que el pasado realmente, es decir, el tiempo se les pasa más rápidamente.

Con el fin de profundizar en el análisis de los resultados obtenidos, nos preguntamos si las diferencias encontradas en los anteriores resultados se podrían mantener cuando además se tiene en cuenta el género del participante.

Los análisis de varianza efectuados no arrojaron efectos significativos debidos a: la interacción género*grupo de pertenencia*tarea $\left(\mathrm{F}_{(1,119)}=0.178 ; \mathrm{p}_{\mathrm{a}} \leq .674\right)$, la interacción género*grupo de pertenencia en la prueba "Historia de Babcock" $\left(F_{(1,119)}=\right.$ $\left.3.211 ; p_{a} \leq .076\right)$, ni para género*grupo de pertenencia en la prueba duración total de la entrevista $\left(\mathrm{F}_{(1,118)}=0.322 ; \mathrm{p}_{\mathrm{a}} \leq .571\right)$. En función de estos resultados se podría afirmar que el género no afecta la manera de estimar el tiempo y que las discrepancias que aparecen en las diferentes estimaciones se pueden atribuir a la presencia o no de patología. 
Barrero et al., 2009 encontraron diferencias en la precisión con que los sujetos estimaban la duración de una serie de tareas en función de la demanda cognitiva o del esfuerzo físico necesario para acometerla, concluyendo que las tareas con alta demanda de recursos cognitivos tendían a ser sobrestimadas en parámetros como la duración y la dificultad, por lo que afirmaron la existencia de una relación entre el uso de recursos atencionales y la adecuada percepción de intervalos temporales. En el presente trabajo los distractores utilizados se construyeron para que requirieran la misma cantidad de recursos atencionales, por lo que se esperaba que en condiciones normales no interfirieran en la precisión de la estimación, de tal manera que las diferencias en precisión pudieran ser resultado de la presencia de psicopatología. Nuestros resultados por lo que se refiere al grupo de control serían congruentes con los obtenidos por estos autores ya que la muestra utilizada por ellos estaba compuesta por participantes sanos, no se puede afirmar lo mismo para el grupo experimental, en el que se hace una sobrestimación del tiempo transcurrido tanto con distractor emocional, como en ausencia del mismo y no se comenten errores (se hace una buena estimación) con la tarea mecánica. En las personas con sintomatología ansioso-depresiva la ausencia de tarea parece obligarlos a utilizar más recursos atencionales que cuando el distractor es una tarea mecánica. Siguiendo el razonamiento de estos autores, se podría decir que estos pacientes usan más recursos atencionales para las tareas que los que precisan utilizar las personas psicopatológicamente sanas. Este hecho podría explicarse por el inadecuado uso de dichos recursos cognitivos que pueden llevar a cabo los pacientes, según el cual podrían dedicar demasiada atención a su estado general de salud o a tener pensamientos negativos sobre su capacidad para llevar a cabo la prueba de manera correcta en lugar de poner en práctica una estrategia adecuada de estimación. 
En la misma línea, Carmeci, Misuraca, \& Cardaci (2009), investigaron la precisión en la estimación que las personas realizaban sobre la duración de tareas con diferente dificultad estructural. Tanto en la condición prospectiva como en la retrospectiva, sujetos psicopatológicamente sanos tenían que evaluar la duración de un estímulo sonoro de complejidad estructural variable. La conclusión a la que llegan las autoras es que las tareas que requieren mayor volumen de trabajo mental, son percibidas por las personas como más duraderas de lo que realmente son. Nuestros resultados, haciendo referencia al grupo libre de psicopatología se muestran en consonancia con estos hallazgos, dado que la dificultad estructural de nuestras pruebas era similar en todas ellas y no se produjo variación en la exactitud de las estimaciones. Por el contrario, los resultados obtenidos para el grupo de pacientes van en contra de lo publicado, al encontrar, de nuevo, variaciones en la exactitud con la que estiman las diferentes pruebas.

Chaston \& Kingstone, (2004) matizan en cierta medida los anteriores resultados sobre la relación directa entre recursos cognitivos empleados y sobrestimación temporal, ya que, afirman que una determinada tarea puede requerir alto grado de atención, pero, si no es difícil de realizar, no consumirá todos nuestros mecanismos atencionales. Cuando se da una tarea de este tipo, los sujetos manifiestan sentirse "entretenidos". Bajo un paradigma prospectivo, los autores diseñaron una serie de tareas en las que los sujetos podían sentirse entretenidos o, mediante un incremento de la dificultad, cognitivamente saturados y encontraron que en la condición "entretenidos" los sujetos presentaban una percepción acelerada del paso del tiempo, al calcular las duraciones como más cortas de lo que realmente eran. Cuando la dificultad aumentaba al máximo, 
el sentido de las estimaciones cambiaba hacia la sobrestimación, en consonancia con los estudios de Barrero et al., 2009, comentados anteriormente.

Las tareas distractoras empleadas en nuestro estudio, poseen un grado de dificultad intermedio entre las descritas por Chaston \& Kingstone (2004) para la condición “cognitivamente entretenidos” y la condición "cognitivamente saturados.” En línea con estos autores, los participantes deberían hacer una estimación adecuada del tiempo y no situarse cognitivamente en ninguno de estos extremos. Según los resultados obtenidos, el grupo de control confirma esta hipótesis, sin embargo, el grupo con patología podrían ser definidos como "cognitivamente saturados” con una estimación temporal tendente a la sobrestimación.

Pedri \& Hesketh (1993), llevaron a cabo un diseño $2 * 2$ en el que las tareas que los sujetos tenían que hacer mientras calculaban el paso del tiempo podían ser rápidas o lentas y, la petición de la estimación podía realizarse inmediatamente después de finalizada la tarea o con demora. Encontraron que con la tarea distractora de velocidad elevada, los sujetos acortaban el tiempo si la estimación se les solicitaba de manera inmediata y lo alargaban en la condición de demora. En nuestro estudio, todas las estimaciones se solicitaron en forma inmediata a la conclusión de la prueba, por lo que no podemos establecer un paralelismo al respecto, pero la velocidad de las tareas distractoras sí varió de unas a otras, desde una velocidad muy lenta en la condición “distractor emocional” a una velocidad elevada en la condición "distractor manipulativo mecánico.” Aquí nos encontramos de nuevo que los sujetos psicopatológicamente sanos no difieren en la exactitud de sus estimaciones en función de la velocidad requerida para realizar la tarea distractora, pero podemos sugerir la posibilidad de que tareas que 
requieran velocidad en sujetos con depresión (y su consecuente retraso psicomotor) puedan, en cierta medida, paliar la sobrestimación temporal habitual de estos sujetos, lo que les llevaría a acercarse más a estimaciones temporales correctas, tal y como realmente ocurre en el caso del distractor más veloz utilizado por nosotros (distractor manipulativo mecánico).

Effron, Niedenthal, Gil, \& Droit-Volet, 2006; Vohs \& Schmeichel, 2003 у Tipples, 2008, utilizando estímulos emocionales negativos (imágenes de rostros mostrando ira, enfado o tristeza) en población emocionalmente sana (estudiantes de pregrado o posgrado) encontraron que las estimaciones de la duración de estos estímulos tienden a efectuarse de manera acelerada, es decir, se tiende a sobrestimar la duración de los acontecimientos que puedan suponer un aumento de los niveles de estrés (Vohs \& Schmeichel, 2003) o una fluctuación en el estado de ánimo momentáneo (Tipples, 2008). En línea con estos trabajos, nuestro estudio muestra también una sobrestimación del paso del tiempo, pero esto ocurre sólo con la población psicopatológicamente afectada. Una posible explicación podría residir en la valencia del estímulo emocional utilizado, ya que en nuestro trabajo se ha utilizado un estímulo de contenido positivo, de esfuerzo, motivación de logro y resultados obtenidos, es decir, una historia de autosuperación y en los estudios comentados dicha valencia es negativa.

En la literatura consultada, en general no se describen diferencias en la precisión de la estimación que las personas realizan del paso del tiempo en función de su género. Sin embargo, Block, Hancock y Zakay (2000) encontraron diferencias, cuando se adoptaba un paradigma experimental de tipo prospectivo. La muestra de este estudio estaba compuesta por un número elevado de sujetos sanos. En nuestro trabajo, la 
estimación de paso del tiempo inadecuada sólo se da en el caso de los sujetos con presencia de sintomatología ansioso-depresiva y, la poca precisión con que realizan la estimación no es atribuible ni al hecho de ser un hombre o una mujer, ni al de haber usado tareas de estimación adoptando un paradigma retrospectivo o prospectivo, sino que, sólo podría atribuirse a la presencia de psicopatología.

En suma, encontramos que la estimación del paso del tiempo está afectada en presencia de sintomatología ansioso-depresiva. Ya en 1992, Blewett, asumió la anormalidad en la experiencia subjetiva del tiempo en los enfermos psiquiátricos y expuso su explicación por el retraso psicomotor que acompaña a la depresión, que a su vez está relacionado con la gravedad del cuadro. Incluso, un año antes, un grupo de investigadores rusos, con una muestra de 21 pacientes internados en el hospital, puso de manifiesto alteraciones en la estimación del paso de un minuto en los sujetos, si bien, dicha estimación se les preguntaba a los sujetos a diferentes horas unos de otros, por diferentes experimentadores y no compararon los resultados con sujetos sanos (Iarovitskii \& Baturin, 1991). Mahlberg, Kienast, Bschor \& Adli, del año 2008, utilizando tres grupos de sujetos: depresión aguda $(\mathrm{n}=30)$; manía aguda $(\mathrm{n}=30)$ y sanos $(n=30)$, encontraron que los pacientes con trastornos del estado del ánimo presentaban una percepción enlentecida del paso del tiempo en tareas de estimación de intervalos. En un estudio reciente (Gil \& Droit-Volet, 2009), se mostró la existencia de cambios en la percepción del tiempo en función de los síntomas depresivos. De acuerdo con criterios diagnósticos del DSM-IV-TR y usando el Inventario para la Depresión de Beck con el fin de conocer el grado de depresión de los sujetos participantes, se pidió a 92 sujetos que llevaran a cabo una tarea consistente en clasificar una señal de duración entre 400 y 1600 mls. Nuestros resultados son consistentes con los obtenidos por estas 
autoras, al producirse un enlentecimiento perceptivo en los sujetos con niveles elevados de depresión. Las autoras apuntan a una desaceleración del reloj interno de los sujetos con depresión como explicación al fenómeno, estableciendo un paralelismo con el retardo psicomotor típico de este trastorno.

Encontramos que el grupo experimental presenta una percepción enlentecida del paso del tiempo en la estimación sin tarea interfiriente, con tarea interfiriente de tipo emocional y en la Historia de Babcock. Dicho grupo realiza una estimación correcta con la tarea tipo mecánica y presenta una estimación rápida del paso del tiempo en la estimación a largo plazo (duración total de la entrevista).

Por otra parte, en ninguno de los estudios consultados se han encontrado pruebas de estimación de intervalos de larga duración, en general oscilan en torno a intervalos de 3 a 13 minutos por lo que es difícil contextualizar el hecho de que los sujetos experimentales de nuestro estudio perciban una aceleración temporal respecto a un intervalo de aproximadamente 60 minutos de duración (duración total de la entrevista). Podemos apuntar como posible explicación variables externas tipo rapport investigadorenfermo, ya que, las pruebas fueron realizadas en un contexto hospitalario y, tanto los factores emocionales, como el grado de dificultad de la tarea podrían estar interviniendo en la estimación. En este sentido, siguiendo las líneas apuntadas por Chaston \& Kingstone (2004), los sujetos experimentales se hallarían en el polo "cognitivamente entretenidos" $\mathrm{y}$, en consecuencia, realizarían estimaciones aceleradas del paso del tiempo.

Los resultados confirman nuestra hipótesis de partida, al haberse encontrado efectos debidos a la presencia o no de patología en la precisión con que se estiman 
diferentes intervalos temporales. Además, la tendencia encontrada apunta a un enlentecimiento de la sensación subjetiva del paso del tiempo, acorde a lo hipotetizado. 


\section{2.- Segunda hipótesis}

\section{$2^{\text {a.- }}$ - El grado de exactitud en la estimación del tiempo implica un perfil}

\section{diferencial de expectativas de control generalizadas.}

Si las personas tienden a percibir el paso del tiempo siempre de la misma manera independientemente del contexto en el que se percibe, se debería encontrar relación fuerte y directa entre los diversos contextos planteados en este trabajo, es decir, que si una persona tiende a sobrestimar el paso del tiempo, lo hará siempre independientemente de la tarea. Se llevó a cabo un estudio correlacional cuyos resultados aparecen en la siguiente tabla:

\begin{tabular}{|l|l|l|l|l|l|l|}
\hline \multicolumn{2}{|c|}{ Contextos } & Sin tarea & Mecánica & Emocional & Historia & TEDE \\
\hline Sin tarea & Correlación de Pearson & 1 &, $508(* *)$ &, $756(* *)$ &, $424(* *)$ &, 039 \\
Mecánica & Correlación de Pearson &, $508(* *)$ & 1 &, $463(* *)$ &, $370(* *)$ &, $299(* *)$ \\
Emocional & Correlación de Pearson &, $756(* *)$ &, $463(* *)$ & 1 &, $363(* *)$ &, 015 \\
Historia & Correlación de Pearson &, $424(* *)$ &, $370(* *)$ &, $363(* *)$ & 1 &, 072 \\
TEDE & Correlación de Pearson &, 039 &, $299(* *)$ &, 015 &, 072 & 1 \\
\hline
\end{tabular}

En línea con la propuesta, todos los coeficientes de correlación obtenidos son de signo positivo, lo que indica una relación directa. Por ejemplo, la correlación hallada entre el contexto emocional y el contexto tarea sin interferencia asciende a 0.756 (p $<$ 0.01), es decir, aquellos participantes que realizan una medición del paso del tiempo por exceso en la primera, tienden a hacer lo mismo en las siguientes. Asimismo, aquellos que tienden a hacer una medición del paso del tiempo por defecto en la primera, también tienden a hacerlo en el resto. 
Si la estimación del tiempo en diferentes contextos está influenciada por variables de tipo afectivo-emocional, dichas estimaciones permitirían predecir, pronosticar, el estado emocional de los sujetos. Así pues, a partir de las estimaciones del tiempo en diferentes contextos se podría clasificar a los participantes como pertenecientes o no al grupo de pacientes. Con el objeto de intentar probar si se puede mantener esta hipótesis, se llevó a cabo un análisis discrimínate paso a paso, que, como se indicó en el procedimiento, permite establecer una clasificación de la muestra en base a cómo se sitúen en torno a la función o funciones discriminantes calculadas con variables independientes al proceso de clasificación externo.

Encontramos que son tres los contextos de estimación del paso del tiempo que entran en el análisis: el contexto sin interferencia $\left(\mathrm{F}_{(1,120)}=26.06 ; \mathrm{p}_{\mathrm{a}}=.000\right)$, el contexto duración total entrevista $\left(\mathrm{F}_{(1,119)}=22.03 ; \mathrm{p}_{\mathrm{a}}=.000\right)$ y el contexto historia $\left(\mathrm{F}_{(1,118)}=\right.$ $\left.19.16 ; \mathrm{p}_{\mathrm{a}}=.000\right)$

Tabla 17: Funciones discriminates

\begin{tabular}{llll}
\hline Función & Lamdda de Wilks & \% Varianza & R Canónica \\
\hline 1 & .672 & 100 & .572 \\
\hline
\end{tabular}

Los coeficientes estandarizados de la función discriminante canónica se describen en la tabla 18:

\begin{tabular}{lc}
\hline & Función \\
\cline { 2 - 2 } Contextos & 1 \\
\hline Sin tarea & .619 \\
Historia & .524 \\
Entrevista & -.649 \\
\hline
\end{tabular}




\begin{tabular}{|l|c|c|}
\hline \multirow{2}{*}{$\begin{array}{c}\text { Grupo Pertenencia } \\
\text { Real }\end{array}$} & \multicolumn{2}{|c|}{$\begin{array}{c}\text { Grupo Pertenencia } \\
\text { Pronosticado }\end{array}$} \\
\cline { 2 - 3 } & G. Pacientes & G. Control \\
\hline Grupo Pacientes & $66,7 \%$ & $33,3 \%$ \\
\hline Grupo Control & $3,2 \%$ & $96,8 \%$ \\
\hline
\end{tabular}

Tabla 19: Clasificación de sujetos en función del análisis discriminate

La función discriminante clasificó correctamente al $82 \%$ de la muestra. Al analizar los resultados se puede considerar que la función discriminante es buena predictora de la ausencia de patología ya que sólo clasificó como pacientes a 2 casos del grupo control, lo que representa una tasa del 3.2\% de falsos positivos. Cuando se comparó el grupo experimental según el criterio externo con los resultados de la función discriminante, de los 60 pacientes integrantes de este grupo, la función clasificó correctamente a 40. Es decir, que a 20 personas con patología afectiva, las valoró como sujetos sanos psicopatológicamente hablando, lo que supone un $33.3 \%$ de falsos negativos (tabla 19).

Se ha pretendido comprobar si puede existir un perfil diferencial de expectativas de control en función de cómo se percibe el paso del tiempo. Para poderlo realizar era necesario tener participantes de todas las condiciones, por lo que se decidió utilizar la prueba retrospectiva de la "Historia de Babcock" debido a que cumplía:

1.- Fue la primera prueba donde se solicitaba la estimación del tiempo.

2.- No se informó sobre el objetivo ni el tipo de prueba que debían realizar. Es decir, se evaluó según el paradigma retrospectivo. 
3.- Se comprobó que hubiera participantes para todas las condiciones de este contexto (Ver tabla 20):

\begin{tabular}{cc}
\hline G. & G. \\
Experimental & Control \\
\hline+ (rápido) & + (rápido) \\
$\mathrm{n}=40$ & $\mathrm{n}=27$ \\
- (lento) & - (lento) \\
$\mathrm{n}=14$ & $\mathrm{n}=6$ \\
Exacto & Exacto \\
$\mathrm{n}=7$ & $\mathrm{n}=29$ \\
\hline
\end{tabular}

Tabla 20: Número de sujetos y su estimación "Histora de Babcock"

Una vez establecido qué contexto de estimación se iba a usar, se llevó a cabo una recodificación de los valores de la estimación de la duración de la Historia de Babcock en una nueva variable según presentaran lentificación, aceleración o fidelidad en la percepción. La nueva variable se utilizó como factor midiendo el efecto sobre las expectativas de control y permitiendo, en su caso, generar un perfil diferencial.

Para ello se utilizó el Modelo Lineal General Multivariante, con dos factores fijos (el grupo de pertenencia y la "Historia de Babcock" recodificada). En dicho análisis se tomaron como variables dependientes las puntuaciones en las expectativas generalizadas de control.

El resultado fue significativo, encontrando efectos debidos al factor grupo y al factor contexto historia, no encontrándose efectos de interacción (ver tabla 21). 


\begin{tabular}{|c|c|c|c|c|c|c|c|c|}
\hline Efecto & & Valor & $\mathrm{F}$ & $\begin{array}{l}\text { Gl de la } \\
\text { hipótesis }\end{array}$ & $\begin{array}{l}\text { Gl del } \\
\text { error }\end{array}$ & $\begin{array}{c}\text { Sign } \\
\cdot\end{array}$ & $\begin{array}{l}\text { Parámetro } \\
\text { de no } \\
\text { centralidad }\end{array}$ & $\begin{array}{l}\text { Potencia } \\
\text { observada }^{\text {a }}\end{array}$ \\
\hline \multirow{4}{*}{$\begin{array}{l}\text { Grupo de } \\
\text { pertenencia }\end{array}$} & Traza de Pillai &, 384 & 14,077 & 5,000 & 113,000 & ,000 & 70,384 & 1,000 \\
\hline & Lambda de Wilks & ,616 & 14,077 & 5,000 & 113,000 & ,000 & 70,384 & 1,000 \\
\hline & $\begin{array}{l}\text { Traza de } \\
\text { Hotelling }\end{array}$ & ,623 & 14,077 & 5,000 & 113,000 &, 000 & 70,384 & 1,000 \\
\hline & $\begin{array}{l}\text { Raíz mayor de } \\
\text { Roy }\end{array}$ & ,623 & 14,077 & 5,000 & 113,000 & ,000 & 70,384 & 1,000 \\
\hline \multirow{4}{*}{$\begin{array}{l}\text { Babcock } \\
\text { recodificado }\end{array}$} & Traza de Pillai & , 188 & 2,371 & 10,000 & 228,000 & ,011 & 23,706 & ,933 \\
\hline & Lambda de Wilks &, 815 & 2,430 & 10,000 & 226,000 & ,009 & 24,296 & ,939 \\
\hline & $\begin{array}{l}\text { Traza de } \\
\text { Hotelling }\end{array}$ & ,222 & 2,488 & 10,000 & 224,000 & ,008 & 24,875 & ,945 \\
\hline & $\begin{array}{l}\text { Raíz mayor de } \\
\text { Roy }\end{array}$ & ,200 & 4,553 & 5,000 & 114,000 & ,001 & 22,767 & ,967 \\
\hline \multirow{4}{*}{$\begin{array}{l}\text { Grupo * } \\
\text { Babcock } \\
\text { recodificado }\end{array}$} & Traza de Pillai &, 088 & 1,046 & 10,000 & 228,000 & ,406 & 10,462 &, 545 \\
\hline & Lambda de Wilks & ,913 & 1,052 & 10,000 & 226,000 & ,401 & 10,515 & ,548 \\
\hline & $\begin{array}{l}\text { Traza de } \\
\text { Hotelling }\end{array}$ & ,094 & 1,057 & 10,000 & 224,000 & ,397 & 10,565 &, 550 \\
\hline & $\begin{array}{l}\text { Raíz mayor de } \\
\text { Roy }\end{array}$ &, 084 & 1,910 & 5,000 & 114,000 & ,098 & 9,552 & ,629 \\
\hline
\end{tabular}

a Calculado con alfa $=, 05$

Tabla 21: Resultados Modelo lineal general.

Es decir, que en función de si los sujetos estiman de forma rápida, lenta o exacta la duración de la Historia de Babcock, tendrán puntuaciones diferenciales en las expectativas.

El grupo de pacientes obtuvo unos valores promedio en las expectativas de control que aparecen reflejados en la tabla 22, los contrastes de diferencias de medias entre los dos grupos arrojan diferencias estadísticamente significativas en todas las expectativas. 


\begin{tabular}{|c|c|c|c|c|}
\hline & $\begin{array}{c}\text { Posible } \\
\text { participante }\end{array}$ & Media & Desv. típ. & $\mathrm{N}$ \\
\hline \multirow[t]{3}{*}{ Autoeficacia } & $\mathrm{GE}$ & 29,5246 & 11,11097 & 61 \\
\hline & $\mathrm{GC}$ & 49,6290 & 10,67897 & 62 \\
\hline & $\mathrm{t}_{(121)}$ & 10.23 & & $\mathrm{p}<0.000$ \\
\hline \multirow[t]{3}{*}{ Contingencia } & $\mathrm{GE}$ & 33,9508 & 5,52698 & 61 \\
\hline & GC & 39,0161 & 3,81753 & 62 \\
\hline & $\mathrm{t}_{(121)}$ & 5.92 & & $\mathrm{p}<0.000$ \\
\hline \multirow[t]{3}{*}{ Indefensión } & GE & 24,9508 & 8,73389 & 61 \\
\hline & $\mathrm{GC}$ & 17,3548 & 7,89708 & 62 \\
\hline & $\mathrm{t}_{(121)}$ & 5.06 & & $\mathrm{p}<0.000$ \\
\hline \multirow[t]{3}{*}{ Éxito } & GE & 29,9016 & 9,10989 & 61 \\
\hline & $\mathrm{GC}$ & 43,1613 & 8,19875 & 62 \\
\hline & $\mathrm{t}_{(121)}$ & 8.49 & & $\mathrm{p}<0.000$ \\
\hline \multirow[t]{3}{*}{ Suerte } & GE & 29,2623 & 8,18312 & 61 \\
\hline & $\mathrm{GC}$ & 25,8871 & 6,08439 & 62 \\
\hline & $\mathrm{t}_{(121)}$ & 2.60 & & $\mathrm{p}<0.011$ \\
\hline
\end{tabular}

Tabla 22. Diferencias en expectativas entre el GE y el GC

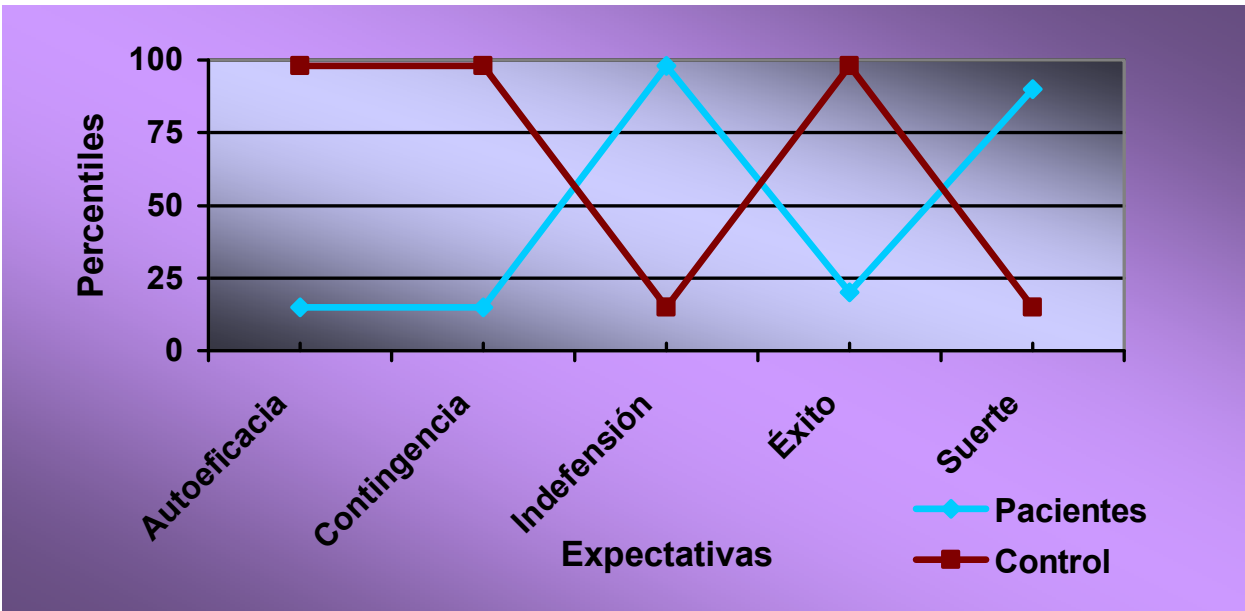

Fig. 32: Perfil diferencial en expectativas en función del grupo de pertenencia

En la representación de la figura 32, puede observarse que el grupo de pacientes presenta: Autoeficacia, Contingencia y Éxito bajos y niveles altos de Indefensión y creencia en la Suerte. Este perfil se invierte totalmente en el grupo de control, presentando niveles altos de Autoeficacia, Contingencia y Éxito y bajos de Indefensión y creencia en la Suerte. 
A continuación se llevó a cabo el mismo análisis sobre diferencia de medias pero tomando ahora como variable independiente la variable Babcock recodificada en tres niveles. Los sujetos obtuvieron unos valores promedio en las expectativas de control que aparecen reflejados en la tabla 23 , los contrastes de diferencias de medias entre los niveles arrojan diferencias estadísticamente significativas en todas las expectativas, excepto en la Suerte.

\begin{tabular}{|c|c|c|c|c|}
\hline & $\begin{array}{l}\text { Babcock } \\
\text { recodificado }\end{array}$ & Media & Desv. típ. & $\mathrm{N}$ \\
\hline \multirow[t]{4}{*}{ Autoeficacia } & Lento & 34,2687 & 12,37003 & 67 \\
\hline & Rápido & 36,4500 & 14,32140 & 20 \\
\hline & Exacto & 51,4722 & 12,67052 & 36 \\
\hline & $\mathrm{F}_{(2,120)}$ & 21.952 & & $\mathrm{p}<0.000$ \\
\hline \multirow[t]{4}{*}{ Contingencia } & Lento & 35,0299 & 5,42433 & 67 \\
\hline & Rápido & 35,7500 & 4,76694 & 20 \\
\hline & Exacto & 39,6667 & 4,20883 & 36 \\
\hline & $\mathrm{F}_{(2,120)}$ & 10.363 & & $\mathrm{p}<0.000$ \\
\hline \multirow[t]{4}{*}{ Indefensión } & Lento & 24,0000 & 8,66200 & 67 \\
\hline & Rápido & 23,4000 & 8,76836 & 20 \\
\hline & Exacto & 14,5000 & 6,55744 & 36 \\
\hline & $\mathrm{F}_{(2,120)}$ & 16.954 & & $\mathrm{p}<0.000$ \\
\hline \multirow[t]{4}{*}{ Éxito } & Lento & 32,2836 & 9,44491 & 67 \\
\hline & Rápido & 35,4500 & 10,92787 & 20 \\
\hline & Exacto & 45,2222 & 8,24313 & 36 \\
\hline & $\mathrm{F}_{(2,120)}$ & 22.503 & & $\mathrm{p}<0.000$ \\
\hline \multirow[t]{4}{*}{ Suerte } & Lento & 28,2985 & 7,75577 & 67 \\
\hline & Rápido & 27,8000 & 9,11101 & 20 \\
\hline & Exacto & 26,0556 & 5,23693 & 36 \\
\hline & $F_{(2,120)}$ & 1.099 & & $\mathrm{p}<0.337$ \\
\hline
\end{tabular}

La representación de los perfiles en expectativas generalizadas de control de los sujetos con una estimación lentificada, otro para los sujetos con una estimación acelerada y otro para los sujetos con una estimación fiel a la real en el contexto "Historia de Babcock" (ver figura 33). 


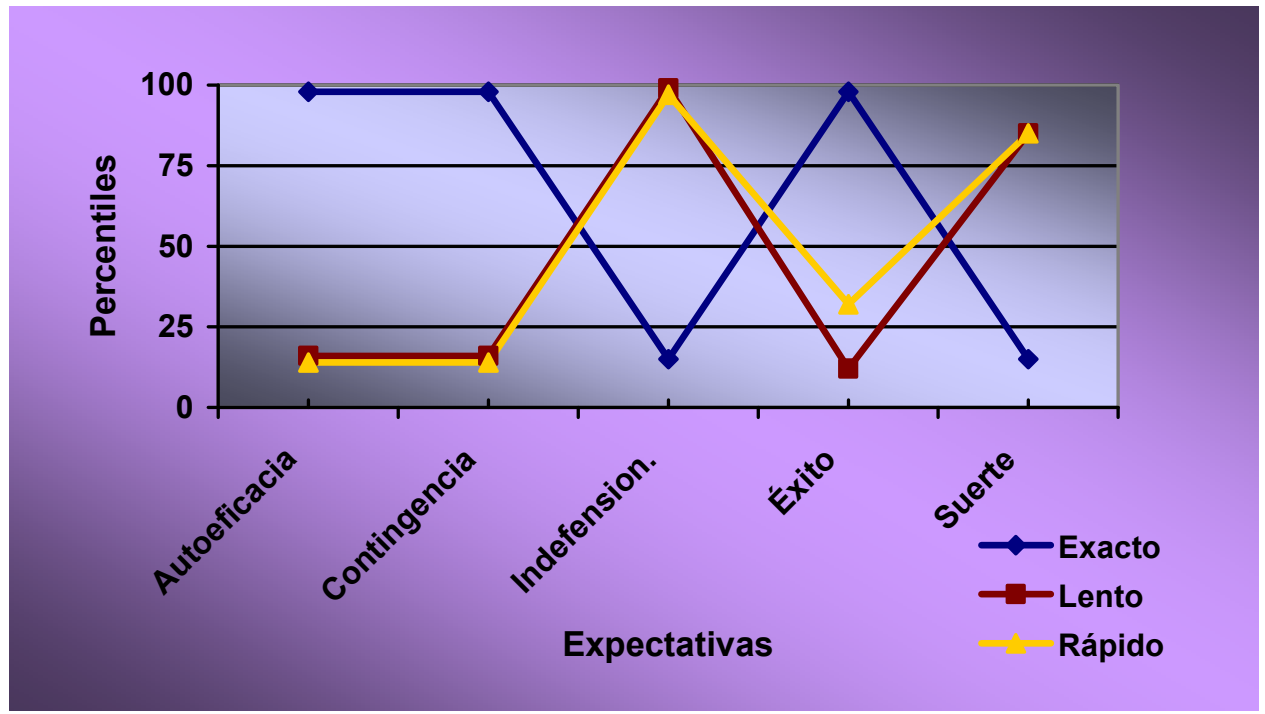

Fig. 33: Perfil diferencial de expectativas en función de la estimación realizada

Si se comparan las figuras 32 y33, se puede ver que el perfil en expectativas que presentan los participantes del grupo de control es aproximadamente el mismo que el obtenido por los sujetos realizaron una estimación exacta de la duración de la historia de Babcock. Además, puede apreciarse un perfil en expectativas muy parecido entre los sujetos pertenecientes al grupo de pacientes y aquellos que realizaron una estimación lenta o rápida de la duración de la historia de Babcock.

En suma, podemos afirmar que se cumple nuestra hipótesis de partida, ya que se ha encontrado un perfil de expectativas de control diferente en función de cómo se percibe el paso del tiempo. Además, el perfil encontrado para los diferentes niveles permite informar sobre la pertenencia a un grupo u otro de la muestra. Por tanto, una buena estimación del tiempo en la Historia de Babcock lleva a pensar en la inexistencia de patología afectiva en el sujeto que realiza la estimación. 
Las personas que hacen una estimación exacta de la duración de la Historia de Babcock (grupo estimación exacta, ver figura 32) que coinciden con el grupo de control, presentan un perfil de expectativas acorde a lo que Palenzuela, Prieto, Da Silva y de Olivera (1992), denominaron alto control percibido, es decir, buena atribución de las conductas a los resultados, buen control para elegir una determinada conducta en un momento dado, adecuado locus de control y alta autoeficacia y percepción de éxito.

Por lo que se refiere a los que hacen una estimación inexacta, coinciden con el grupo experimental y el perfil de expectativas que presentan confirma los hallazgos encontrados por Palenzuela et al. en los que se muestra asociación entre la depresión y la autoeficacia percibida (Palenzuela y Rodríguez Morejón, 1994). Esqueda y Linares (2007), en un estudio realizado con estudiantes de enfermería, sobre la evaluación de los rasgos suicidas, detectaron que la presencia de depresión y ansiedad estaba asociada con valores bajos en autoeficacia y en expectativa de éxito. Resultados similares se han encontrado en estudios llevados a cabo en pacientes afectos de dolor crónico en los que se muestra que la autoeficacia correlaciona inversamente con el malestar emocional (ansiedad y depresión) (Vallejo Pareja, et al., 2009).

Côté, et al. (2009), hallaron que la autoeficacia percibida de los adolescentes en su paso a la edad adulta correlaciona inversamente con la posibilidad de padecer depresión en el futuro. La autoeficacia se muestra como una expectativa de control interno cuyos niveles percibidos por las personas determinan en cierta medida su bienestar emocional y la consecución de resultados en función de la propia valía. Los sujetos del grupo experimental de nuestro estudio, presentan niveles de autoeficacia muy bajos y los resultados obtenidos en la prueba de estimación de 30 segundos de 
duración son incorrectos (tanto por exceso como por defecto), por lo que los resultados obtenidos se hayan en la misma línea que los estudios mencionados.

En mayor medida que en otros problemas crónicos, las personas con cáncer creen que su salud depende de factores externos, en términos de suerte, azar y destino (Thompson \& Collins, 1995). Un estudio longitudinal realizado por López-Roig, Neipp, Pastor et al. (2004), en mujeres con cáncer de mama en fase de seguimiento, encontró que todas las pacientes tenían altas creencias en el azar y la suerte. Las que presentaban mejor calidad de vida fueron aquellas que se percibían a sí mismas altamente competentes para mantener su salud y manejar las situaciones difíciles de su vida. En todas ellas, percibirse competentes para controlar su salud, fue el mejor predictor del estado emocional y de la adaptación psicosocial a lo largo del tiempo por lo que resulta determinante que los enfermos desarrollen la sensación de haber sido y ser capaces de conseguir resultados para la propia salud, y no alimentar las creencias en factores externos como la casualidad o la suerte. Nuestros resultados se hallan en la misma línea que la de estos investigadores ya que podemos apreciar niveles elevados de creencia en la suerte en el grupo de personas que hacen una inadecuada estimación de la duración de la Historia de Babcock (tanto por defecto, como por exceso) y coincide con las puntuaciones en esta expectativa de los sujetos del grupo experimental.

Son varios los estudios que confirman la relación entre tener un locus de control externo y la posibilidad de tener dificultades emocionales. Por ejemplo, Harrow, Hansford \& Astrachan-Fletcher (2009), en un estudio longitudinal de 15 años de duración en el que siguieron a 128 sujetos, encontraron que las personas que habían mostrado mayor tendencia a atribuir las causas de sus aciertos a factores externos ajenos 
a ellos, como la suerte, habían desarrollado mayores niveles de estrés en situaciones complejas, habían tenido menores logros académicos y habían experimentado mayor número de episodios depresivos en comparación con los datos epidemiológicos de la población de referencia. En nuestro estudio las personas con locus de control externo, es decir, con puntuaciones altas en indefensión y suerte y bajas en contingencia, coinciden con el grupo de sujetos con sintomatología ansioso-depresiva.

En un estudio de Kuhs, Hermann, Kammer, \& Tolle, (1991) en el que se tomó una muestra de 25 personas con depresión endógena (según la CIE-9) y un grupo de sujetos sanos y se les pidió que llevaran a cabo estimaciones de 30 segundos a lo largo de varios días en diferentes horas del día, se pudo discriminar a qué grupo pertenecían los sujetos observando la fidelidad de las estimaciones realizadas. En nuestro estudio, encontramos que tanto los sujetos que perciben el intervalo temporal enlentecido, como aquellos que lo experimentan como acelerado, presentan el mismo perfil diferencial de expectativas, por lo que la explicación podría inclinarse hacia la fidelidad o no en la estimación y no tanto en el sentido de dicha inadecuación. Además, los sujetos con sintomatología ansioso-depresiva estiman tanto por defecto como por exceso, lo que podría dar lugar a valores intermedios y eso provocaría que en el análisis discriminante los sujetos quedaran mal clasificados. Serían necesarios posteriores estudios, más potentes, para delimitar los adecuados límites de estos resultados. Tres años después de la publicación del estudio de Kuhs et al., Kallert (1994), defendió que el estudio sistemático y exhaustivo de las alteraciones en la percepción temporal de las personas con depresión, podría convertirse en un instrumento diagnóstico potente y fiable, además de resultar fácil de aplicar en multitud de contextos. En nuestra investigación, la exactitud en la estimación de los 30 segundos que duraba la "Historia de Babcock" 
podría convertirse, en estudios posteriores, en un instrumento de screening diagnóstico, ya que hemos obtenido un $82 \%$ de sujetos clasificados correctamente en función de su estimación y del grupo de pertenencia, observándose una tasa del $3.2 \%$ de falsos positivos.

En suma, si se lleva a cabo una división de los sujetos que componen el total de la muestra por los resultados obtenidos en la estimación de la historia de Babcok en tres niveles (lenta, rápida o exacta), se puede observar que aquellos que se desempeñan de manera exacta corresponden con aquellos que forman el grupo control y que el grupo de pacientes realizan la prueba de manera inadecuada, bien por exceso o por defecto. Las características en expectativas de estos últimos, presentan un perfil que es similar al obtenido por el grupo de sujetos con sintomatología ansioso-depresiva. Este perfil cosiste en tener un constructo del locus de control inadecuado, es decir, locus de control externo, que sería poco protector de los fracasos habituales de las personas. Por el contrario, las personas que realizan la prueba de manera exacta tienen un perfil de alto control percibido, lo que les permite atribuir de manera adecuada los éxitos y los fracasos a las causas reales que los motivan. 
Sintomatología ansioso depresiva y su relación con la temporalidad

\section{3.- Tercera hipótesis}

$3^{a}$.- La perspectiva de tiempo futuro es diferente entre los sujetos sanos y los

\section{deprimidos.}

Dado que el espacio vital de cada persona no está limitado al aquí y al ahora, sino que se extiende hacia el pasado y el futuro, es decir, que se vive en el presente, pero el recuerdo del pasado y el futuro anticipado se integran en éste, afectando a las acciones, pensamientos, sentimientos y bienestar subjetivo, se planteó la posibilidad de explorar las diferencias en la orientación de las personas hacia los acontecimientos futuros. Es decir, se pretendió evaluar las diferencias en la perspectiva temporal de las personas en función del grupo de pertenencia (grupo experimental o grupo de control).

Para poder responder a esta cuestión, se llevó a cabo un análisis correlacional de los ítems del "Cuestionario de Cogniciones Anticipatorias" (QCA), el cual fue concebido con la finalidad de medir las tendencias de las personas a producir pensamientos de cara al futuro tanto positivos como negativos (QCA, Légeron, Rivière \& Marboutin, 1991). Los resultados aportan información detallada acerca de los

contenidos más relevantes en la orientación hacia el futuro (para saber cómo lo construyen los sujetos). 
El la tabla 24 aparece un resumen de los resultados de este estudio correlacional:

\begin{tabular}{lll}
\hline Ítems & & $\begin{array}{l}\text { Grupo de } \\
\text { Pertenencia }\end{array}$ \\
& &,$- 46^{* *}$ \\
qca1 & Correlación &, 000 \\
& Significación (bilateral) &,$- 32^{* *}$ \\
qca2 & Correlación &, 000 \\
& Significación (bilateral) &,$- 30^{* *}$ \\
qca3 & Correlación &, 001 \\
& Significación (bilateral) &,$- 48^{* *}$ \\
qca4 & Correlación &, 000 \\
& Significación (bilateral) &,$- 23{ }^{*}$ \\
qca5 & Correlación &, 012 \\
& Significación (bilateral) &,$- 44^{* *}$ \\
qca6 & Correlación &, 000 \\
& Significación (bilateral) &,$- 40^{* *}$ \\
qca7 & Correlación &, 000 \\
& Significación (bilateral) &,$- 35^{* *}$ \\
qca8 & Correlación &, 000 \\
& Significación (bilateral) & \\
& &
\end{tabular}

*. La correlación es significativa al nivel 0.05
**. La correlación es significativa al nivel 0.01

Puede apreciarse que se trata en todos los casos de una relación inversa. Al ser la variable "posible participante" una variable dicotómica con valores 1 para el grupo experimental y 2 para el grupo control, el análisis debe ser interpretado en el sentido que los sujetos pertenecientes al grupo 1 (grupo experimental) tienen mayores niveles de pensamiento anticipatorio negativo que los sujetos del grupo de control de manera significativa.

Los ítems con más peso fueron seleccionados para llevar a cabo un análisis multivariado de diferencia de medias, para ello recurrimos de nuevo al Modelo Lineal General siendo el factor el grupo de pertenencia y teniendo como variables dependientes las puntuaciones de los ítems $1,4,6,7$ y 8 del cuestionario de pensamiento 
anticipatorio. Tanto para el efecto del factor inter $\left(\mathrm{F}_{(1,121)}=63.52 ; \mathrm{p}<0.000\right)$ como para el intra $\left(\mathrm{F}_{(4,484)}=20.08 ; \mathrm{p}<0.000\right)$, el análisis resultó significativo, no así la interacción $\left(\mathrm{F}_{(4,484)}=2.54 ; \mathrm{p}<0.114\right)$

\begin{tabular}{ccc|cc}
\hline Posible participante & Media & Error típ. & \multicolumn{2}{|c}{ Intervalo de confianza al 95\%. } \\
\cline { 4 - 5 } & & & $\begin{array}{c}\text { Límite } \\
\text { inferior }\end{array}$ & $\begin{array}{c}\text { Límite } \\
\text { superior }\end{array}$ \\
\cline { 4 - 5 } GE & 1,046 &, 077 &, 893 & 1,198 \\
GC &, 181 &, 076 &, 029 &, 332 \\
\hline
\end{tabular}

Tabla 25: Estadísticos descriptivos de la anticipación

Como puede apreciarse en la tabla 25, la puntuación media en la variable anticipación para el grupo experimental fue mayor que la puntuación media en dicha variable en el grupo control.

En la prueba de contrastes intrasujetos, es decir, en el análisis de las puntuaciones medias de cada ítem, podemos encontrar significación estadística en todos ellos, excepto entre el qca6 y el 7. Por lo tanto, se encuentra diferencia en puntuación media entre los ítems, sin tener en cuenta el grupo de pertenencia de los sujetos.

\begin{tabular}{llrrr}
\hline & anticipación & $\begin{array}{l}\text { Diferencia } \\
\text { de medias }\end{array}$ & $\mathrm{F}_{(1,121)}$ & Significación \\
\hline anticipación & qca1 - qca4 &,- 707 & 30,853 &, 000 \\
& qca4- qca6 &, 699 & 43,194 &, 000 \\
& qca6 - qca7 &,- 073 &, 560 &, 456 \\
& qca7- qca8 &, 228 & 7,104 &, 009 \\
\hline
\end{tabular}

Tabla 26: Diferencia de puntuaciones sin tener en cuenta el grupo de pertenencia

El mayor índice de pensamiento anticipatorio negativo se produce cuando esta prospección de futuro se refiere a aspectos relacionados con trabajo. A continuación se encontrarían los aspectos relacionados con la salud, después los referentes a relaciones 
interpersonales y por último a la capacidad para llevar a cabo actividades básicas de la vida diaria.

Los resultados muestran también diferencias estadísticamente significativas entre el grupo control y experimental en la variable promedio de anticipación, definida por los 5 ítems del cuestionario anteriormente citados. Es interesante resaltar las diferencias observadas en función del grupo de pertenencia, ya que la orientación temporal hacia el futuro tiene connotaciones más negativas en todos los aspectos medidos en el grupo experimental. A través de la anticipación de las consecuencias potenciales (positivas o negativas) de futuras acciones, las personas pueden ejercer un control anticipatorio de sus conductas. La experiencia temporal integra al pasado, presente y futuro en el espacio vital de una persona, ya que, los seres humanos pueden traer al presente partes importantes del pasado, imaginando qué vendrá, qué se quiere que ocurra o no, mañana, la próxima semana, el próximo mes, etc. Este futuro anticipado se convierte en parte del presente psicológico, presente según el cual planificamos nuestros objetivos y actividades futuras (Díez, 1994)

\begin{tabular}{|c|c|c|c|c|c|}
\hline & \multirow[t]{2}{*}{$\mathrm{t}_{(121)}$} & \multirow[t]{2}{*}{$\begin{array}{c}\text { Sig. } \\
\text { (bilateral) }\end{array}$} & \multirow[t]{2}{*}{$\begin{array}{l}\text { Diferencia de } \\
\text { medias }\end{array}$} & \multicolumn{2}{|c|}{$\begin{array}{l}95 \% \text { Intervalo de confianza } \\
\text { para la diferencia }\end{array}$} \\
\hline & & & & Superior & Inferior \\
\hline qca1 & 5,732 & ,000 & ,96721 & 63315 & 1,30128 \\
\hline qca4 & 5,944 & ,000 & 1,19011 & ,79372 & 1,58650 \\
\hline qca6 & 5,389 & ,000 & ,88604 &, 56051 & 1,21157 \\
\hline qca7 & 3,963 & ,000 & ,70836 & ,35449 & 1,06222 \\
\hline qca8 & 4,042 & ,000 &, 57456 & 29313 & ,85599 \\
\hline & Tabl & erencia & edias en an & ación & \\
\hline
\end{tabular}


En la representación gráfica que se muestra a continuación se puede observar con claridad como el proceso de prospección de futuro es similar en ambos grupos. La única diferencia, radica en una perspectiva de tiempo futuro más negativa en el grupo de pacientes.

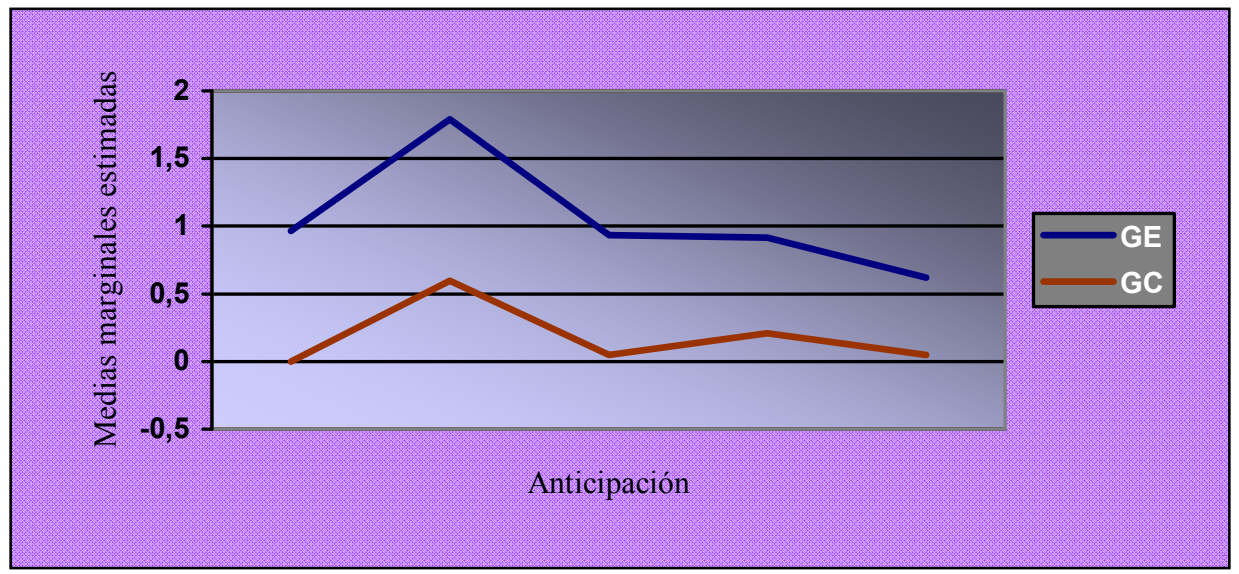

Fig. 34: Diferencias en perspectiva de tiempo futuro entre el GE y el GC

A raíz de los resultados obtenidos podemos afirmar que se cumple nuestra hipótesis de partida ya que se ha podido encontrar una diferente forma de construir la perspectiva de tiempo futuro, en función de si las personas pertenecen al grupo de experimental o al control.

La mayoría de los estudios publicados sobre perspectiva de tiempo u orientación temporal tienen un corte evolutivo en el que se buscan las variaciones en función de los grupos de edad y se establecen comparaciones entre jóvenes, adultos y mayores. Se sabe que las personas con depresión tienen alteraciones en la integración del presente con los actos y los objetivos futuros, llegando incluso a producirse una alteración cognitiva (por ejemplo, creyendo firmemente en la consecución de un objetivo realmente inalcanzable o poco probable) (Meluzzi et al., 1991). Además, estos pacientes presentan habitualmente una tendencia a la anticipación de las consecuencias de los 
acontecimientos futuros que en ocasiones llega a generar una inhibición de la conducta con el fin de evitar dichas consecuencias. Es más, esa inhibición conductual convierte al paso del tiempo en un estímulo vacío, sin actividad, el cual es mucho más difícil de estimar, de controlar, de llenar y esto tiene como consecuencia una percepción subjetiva alterada del paso del tiempo (Mundt et al., 1998).

Usando el Inventario de Perspectiva Temporal de Zimbardo (Zimbardo Time Perspective Inventory - Zimbardo \& Boyd, 1999), Pluck, et al., (2008), encontraron que las personas sin hogar tienen un recuerdo del pasado más negativo si se comparan las puntuaciones con un grupo de control. Pero, en contra de lo hipotetizado, se mostraban esperanzados de conseguir sus objetivos futuros a pesar de tener puntuaciones elevadas en depresión. Además, no encontraron relación entre el abuso de sustancias estupefacientes y las prospecciones de tiempo futuro que llevaban a cabo los participantes. Sin embargo, haciendo uso de la misma escala, Livneh \& Martz, (2007), encontraron, en una muestra de 106 enfermos de diabetes insulinodependientes, que las percepciones negativas del pasado predecían la existencia de depresión, ansiedad o manifestaciones de ira y que éstas se asociaban con una disminución de la orientación futura. También la negación de la enfermedad como mecanismo de defensa, estaba relacionada con menores conductas positivas en el presente y peores imágenes del futuro. En nuestro estudio, a pesar de utilizar otro instrumento de medida, se ha encontrado que los pacientes, en general construyen una perspectiva de tiempo futuro más negativa que la de los sujetos de grupo de control, en consonancia con este último estudio. En la misma línea, Moore, Höfer, McGee \& Ring (2005), en un estudio con 18 pacientes a lo largo de 12 semanas de tratamiento, encontraron que la depresión y la desesperanza se relacionan con niveles pobres de calidad de vida en el presente y que 
las personas que tenían depresión presentaban una diferencia más grande entre su futuro estimado y su futuro deseado. Recientemente, Smoski et al., (2009), empleando técnicas de neuroimagen, encontraron enlentecimiento de respuesta en las regiones estriatales cuando los sujetos debían llevar a cabo tareas de anticipación de un resultado en pacientes afectos de episodio depresivo en comparación con sujetos sanos.

Martz \& Livneh, (2003), encontraron que las personas con niveles altos de ansiedad y depresión presentaban una perspectiva del tiempo futuro menos estructurada, menos realista y con creencia en la ocurrencia de eventos negativos, lo que les llevaba a tener conductas en el presente más autodestructivas (tabaco, alcohol) (Martz \& Livneh, 2003). Un año más tarde, Martz, (2004), encontró que factores como haber sufrido un trauma anterior o tener depresión, explicaban un $24 \%$ de la varianza de la perspectiva de tiempo futuro patológicamente alterada (anclaje en el presente). En un estudio metaanalítico del año 2004, Yarcheski, Mahon, Yarcheski \& Cannella, buscando predictores de prácticas saludables, encontraron que tener una adecuada construcción de cómo será el futuro, tenía un alto efecto sobre los hábitos de salud adecuados. En nuestro estudio, el grupo de personas sanas informaron de menores problemas de salud general y de menor uso de tratamientos farmacológicos prolongados que los miembros del grupo de pacientes, lo que confirmaría la idea de que una imagen positiva acerca de cómo será el futuro, interviene directamente sobre las conductas del presente. 
"Nosotros matamos el tiempo, pero él nos entierra."

J. Machado

CONCLVSIONES 


\section{9.- CONCLUSIONES}

$1^{\mathrm{a}}$.- La estimación del paso del tiempo, es decir, la precisión con la que los sujetos calculan la duración de una serie de intervalos, es diferente tanto en función de la presencia de psicopatología ansioso-depresiva como en función del tipo de paradigma y de la tarea de estimación.

$2^{\text {a }}$ - Bajo un paradigma experimental de tipo retrospectivo, en el que los participantes conocen de antemano el objetivo de estimación, los enfermos tienen una percepción enlentecida del paso del tiempo, frente a los sujetos sanos cuya estimación es fiel. En ambos casos el resultado es independiente del tipo de tarea distractora utilizada, excepto en el caso de la tarea manipulativo-mecánica.

$3^{\mathrm{a}}$.- Cuando se adopta un paradigma de tipo prospectivo, en el que se pregunta por el tiempo que dura un acontecimiento a posteriori, los pacientes presentan una percepción temporal enlentecida ante una tarea de duración corta y una percepción acelerada ante las de larga duración, hecho que podría quedar explicado por variables externas como el que se sientan escuchados y atendidos o variables relacionales entrevistador-entrevistado.

4a.- Al tomar como referencia la exactitud en los resultados en la prueba de estimación llevada a cabo con la Historia de Babcock, se pueden clasificar correctamente a los participantes emocionalmente alterados con un $82 \%$ de probabilidad de éxito y una tasa de falsos positivos de tan sólo un 3.2\%.

5a.- Se han encontrado perfiles diferenciales en expectativas de control generalizadas; los participantes con una estimación temporal inexacta (lentificada o 
acelerada) presentan bajo control percibido o locus de control externo, mientras que los que perciben el tiempo con exactitud evidencian mayor control percibido, es decir, poseen un locus de control interno.

6 .- En relación con la anticipación del tiempo futuro o planificación de acciones, objetivos y afrontamiento ante nuevas situaciones, las personas que tienen afectado su estado de ánimo evidencian una perspectiva del tiempo futuro más negativa que los que no tienen estos síntomas psicopatológicos.

$7^{\mathrm{a}}$.- La alteración en la percepción del paso del tiempo en pacientes ansiosodepresivos, pone de manifiesto dificultades en el eje temporal por lo que sería necesario mayor profundización en los conocimientos sobre el tema que permita la construcción de instrumentos de evaluación sensibles en este eje como futuras herramientas a utilizar en el diagnóstico clínico, objetivo que dejamos abierto para futuras investigaciones. 
"Dios ha ordenado al tiempo que consuele a los desgraciados."

Joseph Joubert

INNDICE $\mathrm{B}$ TABLAS Y FIGVRAS 


\section{0.- INDICE DE TABLAS Y FIGURAS}

Figura 1: Ansiedad y sesgos atencionales.

Relaciones etiológicas. Sandín, 1995, 2008

Figura 2: Teoría de la Desesperanza de

Abramson, Metalsky y Alloy (1989).....

Figura 3: Ejemplos de relojes de agua. Clepsidras 80

Figura 4: Representación del presente (Hawking, 1988)....

Figura 5: Modelo de activación y rendimiento (Yerkes \& Dobson, 1908)

Figura 6: Núcleos Supraquiasmáticos del hipotálamo

Figura 7: Análisis por número de publicaciones.

Figura 8: Análisis por año de publicación

Figura 9: Población objeto de estudio

Figura 10: Población por género

Figura 11: Principales palabras clave (1)

Figura 12: Principales palabras clave (2)

Figura 13: Principales palabras clave (3)

Figura 14: Análisis por año de publicación

Figura 15: Principales palabras clave

Figura 16: Distribución de la edad. Grupo Experimental

Figura 17: Nivel educacional. Grupo Experimental

Figura 18: Situación laboral. Grupo Experimental

Figura 19: Distribución de la edad. Grupo Control

Figura 20: Nivel educacional. Grupo Control.

Figura 21: Situación laboral. Grupo Control 
Figura 22: Niveles de depresión. Grupo Experimental

Figura 23: Niveles de Ansiedad-Estado. Gr. Experimental

Figura 24: Niveles de Ansiedad-Rasgo. Gr. Experimental

Figura 25: Expectativas Generalizadas de control. Gr. Experimental

Figura 26: Expectativas Generalizadas de control. Gr. Control

Figura 27: Cogniciones anticipatorias. Gr. Experimental

Figura 28: Cogniciones anticipatorias. Gr. Control

Figura 29: Tipos de anticipación

Figura 30: Interacción grupo de pertenencia $\mathrm{X}$ tareas retrospectivas

Figura 31: Duración total de la entrevista para G. E. y G. C.

Figura 32: Perfil diferencial en expectativas en función del grupo de pertenencia.

Figura 33: Perfil diferencial de expectativas en función de la estimación realizada 222

Figura 34: Diferencias en perspectiva de tiempo futuro entre el GE y el GC

Tabla 1: Clasificación de las teorías psicológicas de la depresión

(Sánz y Vázquez, 1995, 2008)

Tabla 2: Trastornos afectivos según CIE-10

Tabla 3: Trastornos del estado de ánimo según DSM-IV-TR

Tabla 4: Clasificación de ritmos biológicos

Tabla 5: Valores medios depresión en BDI 178

Tabla 6: Centiles STAI (Bobes, González y Sáinz, 2000)

Tabla 7: Lentificación, aceleración o exactitud en la estimación del tiempo.

Tabla 8: Valores medios y variabilidad en expectativas de control G. E. 
Tabla 11: Estimación según el grupo de pertenencia:

Tabla 12: Estimación según las tareas (retrospectivo)

Tabla 13: Estimación según las tareas y el grupo de pertenencia

Tabla 14: Estimación de la tarea prospectiva contexto $\mathrm{H}^{\mathrm{a}}$ de Babcock 205

Tabla 15: Estimación de la tarea prospectiva duración de la entrevista 206

Tabla 16: Correlaciones entre las pruebas de estimación

Tabla 17: Funciones discriminantes

Tabla 18: Coeficientes estandarizados de la función discriminante

Tabla 19: Clasificación de sujetos

Tabla 20: Número de sujetos y su estimación en la $\mathrm{H}^{\mathrm{a}}$ de Babcock

Tabla 21: Resultados modelo lineal general

Tabla 22: Diferencias en expectativas entre el G.E. y el G.C.

Tabla 23: Diferencias en expectativas según la estimación

Tabla 24: Estudio correlacional de la anticipación

Tabla 25: Estadísticos descriptivos de la anticipación.

Tabla 26: Diferencia de puntuaciones en anticipación sin tener en cuenta el grupo de pertenencia

Tabla 27: Diferencias de medias en anticipación. 230 
"No hay recuerdo que el tiempo no borre ni pena que la muerte no acabe."

Miguel de Cervantes

"Ciencia es el intento de hacer que la caótica diversidad de nuestra experiencia sensorial se corresponda con un sistema de pensamiento lógicamente uniforme"

Einstein

REFERENCíAS BỉBLiOGRÁFiCAS 


\section{1.- REFERENCIAS BIBLIOGRÁFICAS}

Abraham, K. (1924/1960). A short study of the development of libido. En Selected papers on psychoanalysis. Nueva York, Basic Books.

Abramson, L. Y., Metalsky, G. I. \& Alloy, L. Y. (1989). Hopelessness depression: A theory-based subtype of depression. Psychological Review, 96, 358-372.

Abramson, L. Y., Seligman, M. \& Teasdale J. D. (1978). Learned helplessness in humans: critique and reformulation. Journal of Abnormal Psychology, 87, 49-74.

Acuña-Castroviejo, D. \& Escames, G. (2006). Ritmos circadianos de neurotransmisores y melatonina. Implicaciones en la salud y enfermedad. En J. A. Madrid y A. Rol de Lama (eds.), Cronobiología básica y clínica. (pp. 291-328). Madrid: Editec.

Acuña-Castroviejo, D., Khaldy, H., Bikjdaouene, L., León, J., Martín, M. \& Escames, G. (2002). Melatonina, ritmos circadianos y psiquiatría. En F. Pallardó (Ed.). Depresión. Estado actual. (pp. 19-52). Valencia: Fundación Valenciana de Estudios Avanzados.

Adan, A. (1997). Diferencias individuales en las variaciones diurnas fisiológicas y comportamentales. Revista latinoamericana de Psicología, 29, 81-114.

Agostino, P. V. \& Golombeck, D. A. (2007). Cronofarmacología y cronotoxicología. En D. A. Golombeck (Ed.). Cronobiología humana. Ritmos biológicos en la salud y en la enfermedad, (pp 395- 422). Bernal, Buenos Aires: Universidad Nacional de Quilmas.

Aguilar-Robledo, R., Mercado, C., Guadarrama, P. \& Chávez, J. L. (2004). Aspectos celulares y moleculares del núcleo supraquiasmático. En M. E. Hernández y A. Ortega (Eds.). Fisiología celular y molecular. Principios y conceptos (pp. 181-192). México: Universidad de Veracruz.

Alonso, F. (1968). Fundamentos de la Psiquiatría actual, 2 t. Madrid: Paz Montalvo.

Álvarez San Miguel, C. (2006). Influencia de variables personales y socioculturales en la eficacia del tratamiento con ISRS. Tesis Doctoral. Departamento de Psiquiatría y Psicología Médica, Medicina Legal e Historia de la Ciencia. Universidad de Salamanca.

American Psychiatric Association (APA) (1952). Diagnostic and statistical manual of mental disorders. (1 ${ }^{\mathrm{a}}$ edición) (DSM-I) Washington, DC: APA 
American Psychiatric Association (APA) (1968). Diagnostic and statistical manual of mental disorders. (2 $2^{\mathrm{a}}$ edición) (DSM-II) Washington, DC: APA

American Psychiatric Association (APA) (1980). Diagnostic and statistical manual of mental disorders. ( $3^{\mathrm{a}}$ edición) (DSM-III) Washington, DC: APA.

American Psychiatric Association (APA) (1987). Diagnostic and statistical manual of mental disorders. ( $3^{\mathrm{a}}$ edición revisada) (DSM-III-R) Washington, DC: APA.

American Psychiatric Association (APA) (1994). Diagnostic and statistical manual of mental disorders. (4 ${ }^{\mathrm{a}}$ edición) (DSM-IV) Washington, DC: APA.

American Psychiatric Association (APA) (2000). Diagnostic and statiltical manual of mental disorders. (4 ${ }^{\mathrm{a}}$ edición texto revisado) (DSM-IV-TR) Washington, DC: APA.

Anderson, M. J., Reis-Costa, K. \& Misanin, J. R. (2007). Effects of september 11th terrorism stress on estimated duration. Percept Mot Skills, 104(3 Pt 1), 799-802.

Andersson, G., Kyrre Svalastog, O., Kaldo, V. \& Sarkohi, A. (2007). Future thinking in tinnitus patients. J Psychosom Res, 63(2), 191-194.

Aritake-Okada, S., Uchiyama, M., Suzuki, H., Tagaya, H., Kuriyama, K., Matsuura, M., et al. (2009). Time estimation during sleep relates to the amount of slow wave sleep in humans. Neurosci Res, 63(2), 115-121.

Aritake, S., Uchiyama, M., Tagaya, H., Suzuki, H., Kuriyama, K., Ozaki, A., et al. (2004). Time estimation during nocturnal sleep in human subjects. Neurosci Res, 49(4), 387-393.

Ariznavarreta, C., Cardinali, D. P., Villanua, M. A., Granados, B., Martin, M., Chiesa, J. J., et al. (2002). Circadian rhythms in airline pilots submitted to long-haul transmeridian flights. Aviat Space Environ Med, 73(5), 445-455.

Arlin, M. (1986). The effects of physical work, mental work and quantity on children's time perception. Journal of experimental child psychology, 42, 84-98.

Arushanian, E. B., Baida, O. A. \& Mastiagin, S. S. (2006). Effect of melatonin on memory, individual time perception, and anxiety in young people of different chronotype groups. Eksp Klin Farmakol, 69(1), 21-23. 
Asberg, M., Thoren, P., Traksman, L., Bertilsson, L. \& Ringerber, V. (1976). Serotonin depression: a biochemical subgroup within the affective disorders. Science, 191, 478-480.

Babcock, H. (1930). An experiment in the measurement of mental deterioration. Archieves of Psychology, 117, 105.

Babkoff, H., Zukerman, G., Fostick, L. \& Ben-Artzi, E. (2005). Effect of the diurnal rhythm and 24 $\mathrm{h}$ of sleep deprivation on dichotic temporal order judgment. J Sleep Res, 14(1), 7-15.

Bandura, A. (1977). Self-efficacy: Toward a unifying theory of behavioral change. Psychological Review, 84, 191-215.

Barkley, R. A., Murphy, K. R. \& Bush, T. (2001). Time perception and reproduction in young adults with attention deficit hyperactivity disorder. Neuropsychology, 15(3), 351-360.

Barnett, P. A. \& Gotlib, I. H. (1988). Psychosocial functioning and depression: Distinguishing among antecedents, concomitants and consequences. Psychological Bulletin, 104, 97 - 126.

Barrero, L. H., Katz, J. N., Perry, M. J., Krishnan, R., Ware, J. H. \& Dennerlein, J. T. (2009). Work pattern causes bias in self-reported activity duration: a randomised study of mechanisms and implications for exposure assessment and epidemiology. Occup Environ Med, 66(1), 38-44.

Beck, A. T. (1967). Depression: causes and treatment. Philadelphia: University of Pennsylvania Press.

Beck, A. T. (1976). Cognitive therapy and the emotional disorders. Nueva York: International University Press.

Beck, A. T. (1987). Cognitive models of depression. Journal of cognitive Psychotherapy, 1, 5-37.

Beck, A. T. \& Emery, G. (1985). Anxiety disorders and phobias: a cognitive perspective. Nueva York: Basic Books.

Beck, A. T., Jallon, S. D. \& Young, J. E. (1985). Treatment of depression with cognitive therapy and amitriptyline. Archives Gen Psychiatry 42, 142-148.

Beck, A. T., Rush, A. J., Shaw, B. F. \& Emery, G. (1983). Terapia cognitiva de la depresión. Bilbao, DDB.

Beck, A. T., Ward, C. H., Meldenson, M., Mock, J. \& Erbaugh, J. (1961). An inventory for measuring depression. Archives General Psychiatry, 4 (6), 561-571. 
Beck, C. T. (1988). Norm setting for the verbal estimation of a 40-second interval by women of childbearing age. Percept Mot Skills, 67(2), 577-578.

Beck, C. T., Reynolds, M. A., \& Rutowski, P. (1992). Women's verbal estimation of a 40-second interval during the first week postpartum: a replication. Percept Mot Skills, 74(1), 321-322.

Bernal, J. D. (1939). The Social Function of Science. London: Routledge.

Beugnet-Lambert, C., Lancry, A, \& Leconte, P. (1988). Chonopsychologie: rythmes et activités humaines. Presses Universitaires de Lille.

Bidzan, L. (1991). Time perception (chronognosis) in mental disorders. Psychiatr Pol, 25(6), 11-15.

Blewett, A. E. (1992). Abnormal subjective time experience in depression. Br J Psychiatry, 161, 195-200.

Block, R. A. (1978). Remembered duration : effects of event and sequence complexity. Memory and cognition, 6, 320-326.

Block, R. A., Hancock, P. A. \& Zakay, D. (2000). Sex differences in duration judgments: a metaanalytic review. Mem Cognit, 28(8), 1333-1346.

Bobes, J., González, M. P. \& Sáinz, P. A. (2000). Instrumentos básicos para la práctica de la psiquiatría clínica. Barcelona : Novertis, S. A.

Boland, R. J. \& Keller, M. B. (2002). Course and outcome of depression. En I. Gotlib y C. Hammen (eds). Handbook of Depression (pp 43-60). NY: Guilford Press.

Boudreau, E. A., Johnson, K. P., Jackman, A. R., Blancato, J., Huizing, M., Bendavid, C., Jones, M. P., Chandrasekharappa, S. C., Lewy, A. J., Smith, A. C. \& Magenis, R. E. (2009). Review of disrupted sleep patterns in Smith-Magenis syndrome and normal melatonin secretion in a patient with an atypical interstitial 17p11.2 deletion. Am J Med Genet, 149A, 1382-1391.

Bórbely, A. A. \& Wirz-Justice, A. (1982). Sleep, sleep deprivation and depression. A hypothesis derived form a model of sleep regulation. Human Neurobiology, 1, 205-210.

Bower, G. H. (1981). Mood and memory. American Psychologist, 36, 129-148.

Bower, G. H. (1987). Commentary on mood and memory. Behavior research and therapy, 25, 443455. 
Bowlby, J. (1980). Loss : Sadness and depression. New York: Basic Books.

Brackbill, Y. \& Fitzgerald, H. E. (1972). Stereotype temporal conditioning in infants. Psychophisiology, 9, 659-677.

Bremmer, J.D., Innis, R.B., White, T., Fujita, M., Silbersweig, D., Goddard, A. W., et al. (2000). SPECT [I-123]iomazenil measurement of the benzodiazepine receptor in panic disorder. Biological Psychiatry 47(2), 96-106.

Briales, C. \& Grzib, G. (1999). Psicología general. Madrid: Ramón Areces.

Bschor, T., Ising, M., Bauer, M., Lewitzka, U., Skerstupeit, M., Muller-Oerlinghausen, B., et al. (2004). Time experience and time judgment in major depression, mania and healthy subjects. A controlled study of 93 subjects. Acta Psychiatr Scand, 109(3), 222-229.

Buela-Casal, G. \& Sierra, J. C. (1995). Los trastornos del sueño. En A. Belloch, B. Sandín y F. Ramos (eds.), Manual de Psicopatología, Vol. 1. (pp. 381-402) Madrid: McGraw-Hill.

Buela-Casal, G. \& Sierra, J. C. (2008). Los trastornos del sueño. En A. Belloch, B. Sandín y F. Ramos (eds.), Manual de Psicopatología, Vol. 1. (pp. 381-402) Madrid: McGraw-Hill.

Bueno, J. L., Firmino, E. A. \& Engelman, A. (2002). Influence of generalized complexity of a musical event on subjective time estimation. Percept Mot Skills, 94(2), 541-547.

Bueno, J. L. O. \& Ramos, D. (2007). Musical mode and estimation of time. Perceptual and Motor Skills, 105(3, Pt 2), 1087-1092.

Bueno, M. B. (1993). El desarrollo del conocimiento humano sobre el tiempo. Infancia $y$ Aprendizaje, 61, 29-54.

Bumke, O. (1926). Tratado de las enfermedades mentales. Barcelona: Seix Ed.

Butler, A. C., Chapman, J. E., Forman, E. M. \& Beck, A. T. (2006). The empirical status of cognitive-behavioral therapy: A review of meta-analyses. Clinical Psychology Review, 26, $17-31$.

Butcher, J. N., Mikeka, S. \& Hooley, J. M. (2007). Psicología clínica. Madrid: Pearson. 
Buysse, D. J., Reynolds, C. F. \& Kupfer, D. J. (1994). Clinical diagnoses in 216 insomnia patients using the International Classification of Sleep Disorders (ICSD), DSM - IV and ICD - 10 categories: a report from the APA/NIMH DSM - IV field trial. Sleep, 17, 630-637.

Bünning, E. (1958/1977). El relof fisiológico. Berlin: Springer.

Cambras Riu, T. (2006). Propiedades fundamentales de los ritmos circadianos. En J. A. Madrid y A. Rol de Lama (eds.), Cronobiología básica y clínica. (pp. 151-189). Madrid: Editec.

Campbell, L. A. \& Bryant, R. A. (2007). How time flies: a study of novice skydivers. Behav Res Ther, 45(6), 1389-1392.

Campbell, S. S., Murphy, P. J. \& Boothroyd, C. E. (2001). Long-term time estimation is influenced by circadian phase. Physiol Behav, 72(4), 589-593.

Campos, M.S. \& Martínez Larrea, J. A. (2002). Trastornos afectivos: análisis de su comorbilidad en los trastornos psiquiátricos más frecuentes. Anales del Sistema Sanitario de Navarra. Suplementos, 25 (Supl.3), 117-136.

Camps, D., Recuero, Y., Samar, M. E. \& Ávila, R. (2005). Análisis bibliométrico de tesis de doctorado del área de las ciencias de la salud: Primera parte, Odontología. Rev Fac Cienc Med Univ Nac Córdoba, 62, 53-56.

Cardinali, D. P. \& Golombek, D. A. (1994). Naturaleza y propiedades de los ritmos biológicos. Análisis de los ritmos circadianos. En D. P. Cardinali, J. J. Jordá \& E. J. Sánchez (Eds.), Introducción a la cronobiología. Fisiología de los ritmos biológicos. (pp. 15-26). Santander: Universidad de Cantabria.

Carmeci, F., Misuraca, R. \& Cardaci, M. (2009). A study of temporal estimation from the perspective of the Mental Clock Model. J Gen Psychol, 136(2), 117-128.

Carrasco, M. C., Bernal, M. C. \& Redolat, R. (2001). Time estimation and aging: a comparison between young and elderly adults. Int J Aging Hum Dev, 52(2), 91-101.

Carstensen, L. L. \& Turk-Charles, S. (1994). The salience of emotion across the adult life course. Psychology and Aging, 9, 259-264.

Carstensen, L. L. \& Fredrickson, B. F. (1998). Socioemotional selectivity in healthy older people and younger people living with the human immunodeficiency virus: The centrality of emotion when the future is constrained. Health Psychology, 17, 1-10. 
Carstensen, L. L., Isaacowitz, D. M. \& Charles, S. T. (1999). Taking time seriously: A theory of socioemotional selectivity. American Psychologist, 54, 165-181.

Cassem, E. H. (1995). Depressive disorders in the medically ill: an overview. Psychosomatics 36, 2-10.

Chambon, M., Droit-Volet, S. \& Niedenthal, P. M. (2008). The effect of embodying the elderly on time perception. Journal of Experimental Social Psychology, 44(3), 672-678.

Charney, D. S., Heninger, G. R. \& Jatlow, P. I. (1986). Increased anxiogenic effects of caffeine in panic disorders. Archieves of general psychiatry, 42, 233-243.

Charney, D. S. \& Heninger, G. R. (1986). Abnormal regulation of noradrenergic funtion in panic disorders:effects of clinidine in healthy subjects and patients with agoraphobia and panic disorder. Archieves of general psychiatry, 43, 1042-1054.

Chaston, A., \& Kingstone, A. (2004). Time estimation: the effect of cortically mediated attention. Brain Cogn, 55(2), 286-289.

Coccaro, E. F. (1989). Central sorotonin and impulsive aggression. British journal of psychiatry, 155 (suppl 8), 52-62.

Costello, C. G. (1972). Depression: Loos of reinforcers or loos of reinforcer effectiveness? Behavior therapy, 3, 340-347.

Conde, V. \& Useros, E. (1975). Adaptación castellana de la Escala de Evaluación Conductual para la Depresión de Beck. Revista de Psiquiatría y Psicología Médica de Europa y América Latina, 12, 217-236.

Conti, R. (2001). Time flies: investigating the connection between intrinsic motivation and the experience of time. J Pers, 69(1), 1-26.

Côté, S. M., Boivin, M., Liu, X., Nagin, D. S. Zoccolillo, M. \& Tremblay, R. E. (2009). Depression and anxiety symptoms: onset, developmental course and risk factors during early childhood. Journal of Child Psychology and Psychiatry, and allied disciplines, Vol. 50 (10), 1201-8

Coull, J. T., Vidal, F., Nazarian, B. \& Macar, F. (2004). Functional anatomy of the attentional modulation of time estimation. Science, 303(5663), 1506-1508.

Coyne, J. C. (1976). Toward an interactional description of depression. Psychiatry, 39, 28-40. 
Crane, D. (1972). Invisible college: diffusion of knowledge in scientific communities. Chicago, IL: University of Chicago Press.

Cuijpers, P., Van Lier, P. A., Van Straten, A. \& Donker, M. (2005). Examining differential effects of psychological treatment of depressive disorder: an application of trajectory analyses. Journal of Affectives Disorders, 89, 137-146.

D'Argembeau, A. \& Van der Linden, M. (2004). Phenomenal characteristics associated with projecting oneself back into the past and forward into the future: influence of valence and temporal distance. Conscious Cogn, 13(4), 844-858.

Danckert, J. A. \& Allman, A. A. (2005). Time flies when you're having fun: temporal estimation and the experience of boredom. Brain Cogn, 59(3), 236-245.

Davies, F. C. (1981). Ontogeny of circadian rhythms. En J. Aschoff (Ed.), Handbook of behavioral neurobiology, vol. 4, (pp. 257-274). Nueva York: Plenum Press.

De la Iglesia, H. (2006). Relojes Moleculares. En J. A. Madrid y A. Rol de Lama (eds.), Cronobiología básica y clínica. (pp. 241-268). Madrid: Editec.

Delay, E. R. \& Mathey, M. E. (1985). Effects of ambient noise on time estimation by humans. Perceptual and motor Skills, 61,415-419.

Delvenne, V., Kekhofs, M., Apelboom-Fondu, J., Lucas, F. \& Mendlewickz, J. (1992). Sleep polygraphic variables in anorexia nervosa and depression: a comparative study in adolescents. Journal of affective disorders, 25, 167-172.

DeRubeis, R. J., Evans, M. D., Hollon, S. D., Garvey, M. J., Grove, W. M. \& Tuason, V. B. (1990). How does cognitive therapy work? Cognitive change and symptom change in cognitive therapy and pharmacotherapy for depression. Journal of Consulting and Clinical Psychology, 58, 862-69.

DeRubeis, R. J., Gelfand, L. A., Tang, T. Z. \& Simons, A. D. (1999). Medications versus cognitive behavior therapy for severely depressed outpatients: mega-analysis of four randomized comparisons. American Journal of Psychiatry 156(7), 1007-1013.

Díaz Morales J. F. \& Aparicio, M. (2003). Relaciones entre matutinidad-vespertinidad y estilos de personalidad. Anales de psicología, (19), 2, 247-256. 
Díaz Morales, J. F., Ferrari, J. R. \& Cohen, J. R. (2008). Indecision and avoidant procrastination: the role of morningness-eveningness and time perspective in chronic delay lifestyles. $J$ Gen Psychol, 135(3), 228-240.

Díez, M. A. (1994). Depresión y anticipación en la menopausia. Tesis doctoral. Departamento de Psicología Básica, Psicobiología y Metodología. Facultad de Psicología. Universidad de Salamanca.

Dimsdale, J. E. \& Moss, J. (1980). Plasma catecholamines in stress and exercise. JAMA, 243, 340342.

Doleys, D. M. \& Doherty, D. C. (2002). Evaluación psicológica y conductual. En P. Prithvi Raj (ed), Tratamiento práctico del dolor (pp. 429-448). Madrid: EDIDE, S. L.

Dougherty, D. M., Dew, R. E., Mathias, C. W., Marsh, D. M., Addicott, M. A. \& Barratt, E. S. (2007). Impulsive and premeditated subtypes of aggression in conduct disorder: differences in time estimation. Aggress Behav, 33(6), 574-582.

Droit-Volet, S., Clement, A. \& Fayol, M. (2008). Time, number and length: Similarities and differences in bisection behavior in children and adults. The Quarterly Journal of Experimental Psychology, 1-20.

Dubovsky, S. L., Davies, R. \& Dubovsky, A. N. (2006). Trastornos del estado de ánimo. En R. E. Hales \& S. C. Yodofsky (Eds.), Fundamentos de Psiquiatría Clínica. (pp. 259-360). Barcelona: Masson.

Duncan, W. C. Jr. (1996). Circadian rhythms and the pharmacology of affective illnes. Pharmacology \& therapeutics, 71, 253-312.

Effron, D. A., Niedenthal, P. M., Gil, S. \& Droit-Volet, S. (2006). Embodied temporal perception of emotion. Emotion, 6(1), 1-9.

Ellenberger, H. F. (1970/1976). El descubrimiento del inconsciente. Madrid: Gredos.

Esposito, M. J., Natale, V., Martoni, M., Occhionero, M., Fabbri, M. \& Cicogna, P. (2007). Prospective time estimation over a night without sleep. Biological Rhythm Research, 38(6), 443-450.

Esqueda, L. \& Linares, F. (2007). Metodología para evaluar los rasgos suicidas. Aportes a la psicología social de la salud. Venezuela: Universidad de los Andes. 
Estaun-Ferrer, S. (1985). Hacia una cronopsicología. Cuadernos de Psicología, 9, 201-207.

Ey, H. (1963). La conscience, Paris: P.U.F.

Ezrati-Vinacour, R. \& Levin, I. (2001). Time estimation by adults who stutter. J Speech Lang Hear Res, 44(1), 144-155.

Fava, M. \& Davidson, K. G. (1996). Definition and epidemiology of treatment-resistant depression. Psychiatric Clinics of North America, 19(2), 179-200.

Feixas, G. \& Villegas, M. (1990). Constructivismo y psicoterapia. Bilbao: DDB.

Fernández, R. \& Carpizo, R. (1994). El reloj circadiano humano (2). El ritmo vigilia-sueño: Alteraciones circadianas. Depresión. En D. P. Cardinali, J. J. Jordá \& E. J. Sánchez (Eds.), Introducción a la cronobiología. Fisiología de los ritmos biológicos. (pp. 129-140). Santander: Universidad de Cantabria.

Ferrari, J. R. (1991a). Compulsive procrastination: some self-reported characteristics. Psychol Rep, $68(2), 455-458$.

Ferrari, J. R. (1991b). Procrastination and project creation: Chossing easy, nondiagnostic item to avoid self-relevant information. Journal of social behaviour and personality, 6 (3), 619-628.

Ferster, C. B. (1973). A functional analysis of depression. American Psychologist, 28, 857-870.

Figiel, G. S., Epstein, C. \& McDonald, W. M. (1998). The use of rapid-rate transcranial magnetic stimulation (rTMS) in refractory depressed patients. Journal of neuropsychiatry clinical neuroscience, 10, 20-25.

Fischer, R. (ed.) (1967). Interdisciplinary perspectives of time. Annual New York Academy of Science, 138,2 .

Fitzgerald, T. E., Tennen, H., Affleck, G. \& Pransky, G. S. (1993). The relative importance of dispositional optimism and control appraisals in quality of life after coronary artery bypass surgery. Journal of Behavioral Medicine, 16:25-43.

Flett, G. L., Blankstein, K. R. \& Martin, T. R. (1995). Procrastination, negative self-evaluation and stress in depression and anxiety: a review and preliminary model. En J. R. Ferrari, J. L. Johnson y W. G. McCown (eds.). Procrastination and task avoidance: Theory, research and treatmen. (pp. 137-167). New York: Plemun Press. 
Font, A. (1991). Relaciones entre expectativas de resultado teórico, expectativas de resultado autorreferencial y expectativas de autoeficacia. Revista latinoamericana de psicologia, Vol $23(1), 53-69$.

Folkard, S. \& Monk, T. H. (Eds). (1985). Hours of work: Temporal factors in work scheduling. New York: Wiley.

Fong, G. T. \& Hall, P. A. (2003). The importance of time perspective in predicting, understanding, and reducing health risk behaviors among adolescents. In D. Romer (Ed.), Reducing adolescent risk: Toward an integrated approach (pp. 106-112). Newbury Park, CA: Sage.

Fraisse, P. (1963). The psychology of time. Nueva York: Harper \& Row. (Original de 1957. Psychologie du temps. Paris: Presses universitaires de France).

Fraisse, P. (1957/1982). The adaptation of the child to time. En W. J. Freidman (Ed.), The developmental psychology of time (pp. 113-139). Nueva York: Academic Press.

Fraisse, P. (1985). El porvenir de la psicología. Madrid: Morata.

Frankanhauser, M. (1959). Estimation of time: an experimental study. Stockholm: Almqvist \& Wiksell.

Frankl, V. E. (1946). El hombre en busca de sentido. Barcelona: Herder.

Frazer, A., Brown, R., Kocsis, J. Caroff, S., Amsterdam, J., Winokur, A. et al. (1986). Patterns of melatonin rhythms in depression. Journal of neural transmission, 21, 269-290.

Fredrickson, B. L. \& Carstensen, L. L. (1990). Choosing social partners: How old age and anticipated endings make us more selective. Psychology and Aging, 5, 335-347.

Furham, A. \& Hughes, K. (1999). Individual difference of nightwork and shift-work rotation. Personality and Individual Differences, 26, 941-959.

Galindo, A. (1995). El tiempo en la física. En A. Dou (ed.), El Tiempo. Tiempo, relatividad y saberes. Madrid: UPCO.

Garber, J. \& Flynn, C. A. (2001). Predictors of depressive cognitions in young adolescents. Cognitive. Therapy and Research, 25, 353-376. 
García Callado, M $\mathrm{M}^{\mathrm{a}}$ J. (1995). Las vivencias del Tiempo. El diálogo psicoanalítico y la restauración del sentido del ser. En A. Dou (ed.), El Tiempo. Tiempo, relatividad y saberes. (pp. 61-67) Madrid: UPCO.

Gil, S. \& Droit-Volet, S. (2007). Angen and time perception in children. Emotion, 7, 219-225.

Gil, S. \& Droit-Volet, S. (2009). Time perception, depression and sadness. Behav Processes, 80(2), 169-176.

Gilbert, P. (1992). Depression: The evolution of powerlessness. Hillsdale, Nueva York: LEA.

Gilbert, P., McEwan, K., Mitra, R., Franks, L., Richter, A. \& Rockliff, H. (2008). Feeling safe and content: A specific affect regulation system? Relationship to depression, anxiety, stress, and self-criticism. The Journal of Positive Psychology, 3(3), 182-191.

Glass, D. R., Pilkonis, P. A. \& Leber, W. R. (1989). National Institute of Mental Health treatment of depression collaborative research program. Archives Generals of psychiatry 46, 971-982.

Goddard, A. W., Mason, G. F., Almai, A., Rothman, D. L., Behar, K. L., Petroff, O. A. C. et al. (2001). Reductions in cortical GABA levels in panic disorder detected with 1H-magnetic resonance spectroscopy. Archieves of General Psychiatry 58, 556-561.

Goddard, J. (2000). Perceived passage of time: its possible relationship to attention-deficit hyperactivity disorder. Med Hypotheses, 55(4), 351-352.

González-Tablas, M. M., Díez, M. A. \& Llorca, G. (1996). Fiabilidad y validez del Cuestionario de Cogniciones Anticipatorias (QCA) de Légeron, Rivière y Marboutin (1991): Estudio de una muestra de mujeres españolas. Actas Luso-Españolas de Neurología y Psiquiatría, 24 (3), 125-128.

Goodwin, F. K., Wirz-Justice, A. \& Wehr, T.A. (1982). Evidence that the pathophysiology of depression and the mechanism of antidepressant drugs both involve alterations in circadian rhythms. Adv. Biochem Psychopharmacology. 32, 1-11.

Gordjin, M.C., Beersma, D. G., Bouhuys, A. L., Korte, H. J. \& Van den Hoofdakker, R. H. (1995). A longitudinal study of diurnal mood variation in depression: Characteristics and significance. Journal of affective disorders, 31, 261-273.

Gorman, J. M. \& Coplan, J. D. (1996). Comorbidity of drepression and panic disorder. Comprehensive Psychiatry, 57 (suppl 10), 34-41. 
Gorman, J. M., Kent, J. M., Sullivan, G. M. \& Coplan, J. D. (2000). Neuroanatomical hypothesis of panic disorder, revised. Americal journal of psychiatry, 157, 493-505.

Gotlib, I. H. \& Hammen, C. (1992). Psychological aspects of depression. Toward a cognitiveinterpersonal integration. Chichester, Jonh Wiley \& Sons.

Gotlib, I. \& Hammen, C. (2002). (Eds). Handbook of Depression. NY: Guilford Press.

Grahame-Smith, D. G. (1992). Serotonin in affective disorders. International Clinical Psychopharmacology, 6 (suppl 4), 5-13.

Gross, P. L. K. \& Gross, E. M. (1927). College libraries and chemical education. Science, 66, 385389.

Grondin, S., \& Plourde, M. (2007). Judging multi-minute intervals retrospectively. Q J Exp Psychol (Colchester), 60(9), 1303-1312.

Gruber, R. P. \& Block, R. A. (2003). Effect of caffeine on prospective and retrospective duration judgements. Hum Psychopharmacol, 18(5), 351-359.

Gruber, R. P., \& Block, R. A. (2005). Effects of caffeine on prospective duration judgements of various intervals depend on task difficulty. Hum Psychopharmacol, 20(4), 275-285.

Halberg, F. (1969). Chronobiology. Annual Review of Psychology, 31, 675-725.

Halvari, H. (1991). Perception of goal proximity, latency and duration of action plans, and worry in relation to goal distance in time and personality characteristics. Percept Mot Skills, 72(3 Pt 1), 707-741.

Harrow, M., Hansford, B. G. \& Astrachan-Fletcher, E. B. (2009). Locus of control: relation to schizophrenia, to recovery, and to depression and psychosis: A 15-year longitudinal study. Psychiatry Research, 15 Vol. 168 (3), 186-92.

Hawking, S. (1988/2005). Historia del tiempo: del Big Bang a los agujeros negros. Madrid: Crítica.

Healy, D. \& Waterhouse, J. M. (1990). The circadian system and affective disorders: clocks or rhythms? Chronobiologyl International, 7, 5-10.

Heatherton, T. F. \& Weinberger, J. L. (eds.) (1994). Can personality change? Washington DC: APA. 
Heidegger, M. (1927/1963). El ser y el tiempo. México: Fondo de Cultura Económica.

Hertzog, C., Touron, D. R. \& Hines, J. C. (2007). Does a time-monitoring deficit influence older adults' delayed retrieval shift during skill acquisition? Psychol Aging, 22(3), 607-624.

Hiks, R. E., Millaer, G. W. \& Kinsbourne, M. (1976). Prospective and retrospective judgments of time as a function of amount of information processed. American journal of psychology, 89, 719-730.

Hilsman, R. \& Garber, J. (1995). A test of the cognitive diathesis-stress model of depression in children: academic stressors, attributional style, perceived competence, and control. Journal of Personality and Social Psychology, 69(2), 370-380.

Hino-Fukuyo, N., Haginoya, K., Uematsu, M., Nakayama, T., Kikuchi, A., Kure, S., Kamada, F., Abe, Y., Arai, N., Togashi, N., Onuma, A. \& Tsuchiya, S. (2008). Smith-Magenis syndrome with West syndrome in a 5-year-old girl: a long-term follow-up study. Journal Of Child Neurology, Vol. 24 (7), pp. 868-873.

Hodgins, D. C., \& Engel, A. (2002). Future time perspective in pathological gamblers. J Nerv Ment Dis, 190(11), 775-780.

Hollander, E., Liebowitz, M. R., Gorman, J. M., Cohen, B,, Fyer, A. \& Klein, D.F. (1989). Cortisol and sodium lactate induced panic. Archieves of General Psychiatry 46,135-40.

Hollander, E. \& Simeon, D. (2006). Trastornos de ansiedad. En R. E. Hales \& S. C. Yudofsky (eds.). Fundamentos de Psiquiatría Clínica. (pp.361-452). Barcelona: Masson.

Hollon, S. D., DeRubeis, R. J., Shelton, R. C., Amsterdam, J. D., Salomon, R.M., O'Reardon, J. P. et al. (2005). Prevention of relapse following cognitive therapy versus medications in moderate to severe depression. Archives of General Psychiatry, 62, 417-422.

Hollon, S. D., Stewart, M. O., \& Strunk, D. (2006). Enduring effects for cognitive behavior therapy in the treatment of depression and anxiety. Annual Review of Psychology, 57, 285-315.

Horesh, N., Amir, M., Kedem, P., Goldberger, Y. \& Kotler, M. (1997). Life events in childhood, adolescence and adulthood and the relationship to panic disorder. Acta psychiatrica Scandinavica 96(5),373-378.

Horstmanshof, L., \& Zimitat, C. (2007). Future time orientation predicts academic engagement among first-year university students. Br J Educ Psychol, 77(Pt 3), 703-718. 
Iarovitskii, V. B., \& Baturin, V. A. (1991). Reproduction of the minute time interval in depression in patients with schizophrenia and manic-depressive psychosis. Zh Nevropatol Psikhiatr Im S S Korsakova, 91(1), 112-114.

Jaim-Etcheverry, G. \& Ziehar, L. M. (1982). Coexistence of monoamies in perepheral adrenergic neurones. En A. C. Cuello (ed.). Co-Transmission (pp 189-207).London : Macmillan.

Jasnow, M. \& Feldstein, S. (1986). Adult-like temporal characteristics of mother-infant vocal interactions. Child development, 57, 754-761.

Jaspers, K. (1973). Psicopatología General. Buenos Aires: Beta. (Trabajo original de 1965).

Joubert, C. E. (1992). Happiness, time consciousness, and subjective life expectancy. Percept Mot Skills, 74(2), 649-650.

Kallert, T. W. (1994). Changed perception in depressive diseases--an overview. Schweiz Arch Neurol Psychiatr, 145(6), 5-13.

Kant, I. (2005). Crítica de la razón pura. Madrid : Taurus (Obra original 1781).

Kaplan, H. I. \& Sadock, B. J. (1999). Sinopsis de Psiquiatría.8a edición. Madrid: Editorial Médica Panamericana, S.A.

Keck, P. E., Merikangas, K. R. \& McElroy, S. L. (1994). Diagnostic and treatment implications of psychiatric comorbidity with migraine. Annual Clinical Psychiatry, 6, 165-171.

Kelly, C., Shulman, V., Khine, H. \& Avner, J. R. (2007). Parental perception of the passage of time during a stressful event. Pediatr Emerg Care, 23(6), 376-379.

Keough, K. A., Zimbardo, P. G. \& Boyd, J. N. (1999). Who's smoking, drinking and using drugs? Time perspective as a predictor of substance use. Basic and Applied Social Psychology, 21(2), 149-164.

Kivimaäki, M., Vahtera, J., Elovainio, M., Helenius, H., Singh-Manoux, A. \& Pentti, J. (2005) Optimism and pessimism as predictors of change in health after death or onset of severe illness in family, Health Psychology, 24 (4), pp. 413-421.

Klapproth, F. (2007). Time perception, estimation paradigm, and temporal relevance. Percept Mot Skills, 104(3 Pt 1), 749-757. 
Klein, N. D. \& Miller, G. A. (1993). Depressive personality in nonclinical subjects. American journal of psychiatry, 150 1718-1724.

Klerman, G. L. (1987). Cognitive disfunction, vulnerability and integrating theories of depression. Integrative psychiatry, 5, 32-35.

Klerman, G. L., Weissman, M. M., Rounsaville, B. J. \& Chevron, E. (1984). Interpersonal psychotherapy of depression. New York: Basic Books.

Kowalska, J., \& Szelag, E. (2006). The effect of congenital deafness on duration judgment. J Child Psychol Psychiatry, 47(9), 946-953.

Kraepelin, E. (1896). Compendium der Psychiatrie zum Gebrauche für Studirende und Aerzte. (5 ed.). Leipzig: Abel Verlag.

Kragh, H. (1987). Introducción a la historia de la ciencia. Barcelona: Cincel.

Kruse, A. (2000). Time, biography and life course. Z Gerontol Geriatr, 33 Suppl 1, 90-97.

Kubovy, M. (1981). Concurrent-pitch segregation and the theory of indispensable attributes. En M. Kubovy \& J. R. Pomerantz (Eds.), Perceptual organization (pp. 55-98). Hillsdale, NJ: Lawrence Erlbaum Associates.

Kuhn, T. S. (1991). The natural and the human sciences; en David R. Hiley, James F. Bohman and Richard Shusterman (eds.). The interpretive turn. Philosophy, science, culture (p. 17-24). Ithaca, New York: Cornell University Press.

Kuhs, H. (1991). Time experience in melancholia: a comparison between findings based on phenomenology and experimental psychology. Compr Psychiatry, 32(4), 324-329.

Kuhs, H., Hermann, W., Kammer, K. \& Tolle, R. (1991). Time estimation and the experience of time in endogenous depression (Melancholia): an experimental investigation. Psychopathology, 24(1), 7-11.

Kuriyama, K., Uchiyama, M., Suzuki, H., Tagaya, H., Ozaki, A., Aritake, S., et al. (2003). Circadian fluctuation of time perception in healthy human subjects. Neurosci Res, 46(1), 2331. 
Kuyken, W., Watkins, E.R. \& Beck, A.T. (2005). Cognitive-behavioural therapy for mood disorders. En G. Gabbard, J. Beck, \& J. Holmes. (Eds). Concise Oxford Textbook of Psychotherapy. Oxford: Oxford University Press.

Kuyken, W., Watkins, E., \& Holden, E. R. \& Cook, W. (2006). Rumination in adolescents at risk for depression. Journal of Affective Disorders, 96, 39-47.

Kuyken, W., Dalgleish, T. \& Holden, E. (2007). Advances in cognitive-behaviour therapy for unipolar depression. Canadian Journal of Psychiatry, 51, 805-813.

Lang, P. J. (1985). The cognitive psychophysiology of emotion: fear and anxiety. En A. H. Tuma \& J. D. Maser (eds.). Anxiety and the anxiety disorders (pp. 131-170). Hillsdale, N.J.: Erlbaum.

Lange, K. W., Tucha, O., Steup, A., Gsell, W. \& Naumann, M. (1995). Subjective time estimation in Parkinson's disease. J Neural Transm Suppl, 46, 433-438.

Larsen, R. J. (1985). Individual differences in circadian activity rhythm and personality. Personality and Individual Differences, 6, 305-311.

Lauver, D. \& Tak, Y. (1995). Optimism and coping with a breast cancer symptom. Nursing research, 44(4):202-207.

Lay, C. H. \& Brokenshire, R. (1997). Conscientiousness, procrastination and person-task characteristics in job searching by unemployed adults. Current Psychology : Developmental, learning, personality, social, 16 (1), 83-96.

Légeron, P., Rivière, B. \& Marboutin, J. P. (1991). L’echelle des cognitions anticipatoires. L'Encéphale, 19, 11-16.

Lehofer, M. \& Retzer, A. (2005). A systemic view on psychosis. Fortschr Neurol Psychiatr, 73 Suppl 1, S88-91.

Lens, W. (1986). Future Time Perspective: A cognitive-motivational concept. In D. R. Brown, \& J. Veroff (eds.), Frontiers of Motivational Psychology (pp. 173-190). New York: SpringerVerlag.

Lens, W., Simons, J. \& Dewitte, S. (2001). Student motivation and self-regulation as a function of future time perspective and perceived instrumentality. In S. Volet \& S. Järvelä (Eds.). 
Motivation in learning contexts: theoretical advances and methological implications (pp. 233-248). New York: Pergamon.

Lennings, C. J., Burns, A. M. \& Cooney, G. (1998). Profiles of time perspective and personality: Developmental considerations. Journal of Psychology, 132, 629-643.

Leonard, B. E. (1992). Sub-types of serotonin receptors : biochemical changes and pharmacological consecuences. International Clinical Psychopharmacology, 7, 13-21.

Levine, R. V. (1997). The geography of time: The temporal misadventures of a social psychologist. New York: Basic Books.

Levine, R. V., West, L. J. \& Reis, H. T. (1980). Perceptions of Time and Punctuality in the United States and Brazil. Journal of Personality and Social Psychology, Vol. 38, No. 4, 541-550.

Lewin, K. (1942). Time perspective and morale. En G. Watson (ed.), Civilian morale. Boston: Houghton Mifflin.

Lewinsohn, P.M. (1974). A behavioral approach to depresión. En R.J. Friedman y M.M. Katz (Eds.), The psychology of depression: Contemporary theory and research (pp.157-185). Nueva York: Wiley.

Lewinsohn, P. M. (1976). Activity schedules in the treatment of depression. En C.E. Thoresen y J.D. Krumboltz (Eds.), Counselling methods (págs. 74-83). NuevaYork: Holt, Rinehart y Winston.

Lewinsohn, P. M., Hoberman, H., Teri, L. \& Hautzinger, M. (1985). An integrative theory of depression. En S. Reiss \& R. R. Bootzin (Eds.), Theoretical issues in behaviour therapy (pp. 331-359). Orlando, FL: Academic Press.

Lewis, A. (1980). Problems presented by the ambiguous word "anxiety» as used in psychopathology. En G. D. Burrows \& B. Davies (Eds.), Studies on anxiety (pp. 1-15). Amsterdam: Elsevier/North-Holand.

Lewkowicz, D. J. (1989). The role of temporal factors in infant behavior and development. En I. Lewin \& D. Zakay (Eds.), Time and human cognition: A life-span perspective (pp. 9-62). North-Holland: Elsevier Science Publishers B. V.

Lewy, A. (2003). Clinical applications of melatonin in circadian disorders. Dialogues in clinicla neurosciences, 5, 399-413. 
Lewy, A., Sack, R. L., Singer, C. M., White, D. M. \& Hoban, T. M. (1988). Winter depression and the phase shift hypothesis for bright light's therapeutic effects: history, theory and experimental evidence. Journal of biological rhythms, 3, 121-134.

Lieving, L. M., Lane, S. D., Cherek, D. R., \& Tcheremissine, O. V. (2006). Effects of marijuana on temporal discriminations in humans. Behav Pharmacol, 17(2), 173-183.

Livneh, H. \& Martz, E. (2007). Reactions to diabetes and their relationship to time orientation. International Journal of Rehabilitation Research, Vol. 30 (2), 127-36.

López, P. (1996). Introducción a la bibliometría. Valencia: Promolibro.

López Piñero, J. M. \& Terrada, M. L. (1992). Los indicadores bibliométricos y la evaluación de la actividad médicocientífica. Usos y abusos de la bibliometría. Medicina Clínica (Barc), 98, 64-68.

López-Roig S., Neipp, M. C., Pastor, M. A., Perol, M. C. \& Massutí, B. (2004). Creencias de autoeficacia y conducta de autoexploración en mujeres con cáncer de mama. En: M. Salanova, R. Grau, I. M. Martínez, E. Cifre, S. Llorens y M. García-Renedo (eds.): Nuevos Horizontes en la Investigación sobre Autoeficacia (pp. 142-148). Castellón: Universidad Jaume I, Servicio de comunicación y publicaciones.

López Sánchez, J. M. \& Higueras Aranda, A. (1996). Compendio de Psicopatología. Granada: Círculo de Estudios Psicopatológicos.

López Piñero, J. M. (1972). El análisis estadístico y sociométrico de la literatura científica. Valencia: Centro de Documentación e informática médica. Facultad de medicina. Universidad de Valencia.

Lotka, A. J. (1926). The frequency distribution of scientific productivity. J Washington Acad Sci, $16: 317-324$.

Lustig, C. \& Meck, W. H. (2001). Paying attention to time as one gets older. Psychol Sci, 12(6), 478-484.

Mach, E. (1987). Análisis de las sensaciones. Barcelona, Alta Fulla (Original de 1986).

Madrid, J. A. (2006). Los relojes de la vida. Una introducción a la cronobiología. En J. A. Madrid y A. Rol de Lama (eds.), Cronobiología básica y clínica. (pp. 39-81). Madrid: Editec. 
Madrid, J. A., Martínez-Nicolas, A. \& Sánchez-Gálvez, R. Mª (2006). Cronotoxicología y cronofarmacología. En J. A. Madrid y A. Rol de Lama (eds.), Cronobiología básica y clínica. Madrid: Editec

Mahlberg, R. \& Bschor, T. (2007). Alterations of time judgement with age. Psychiatr Prax, 34(3), 117-121.

Mahlberg, R., Kienast, T., Bschor, T. \& Adli, M. (2008). Evaluation of time memory in acutely depressed patients, manic patients, and healthy controls using a time reproduction task. European Psychiatry, 23(6), 430-433.

Mahon, N. E., Yarcheski, T. J. \& Yarcheski, A. (2000). Future time perspective and positive health practices among young adolescents: a further extension. Percept Mot Skills, 90(1), 166-168.

Mangan, P. A., Bolinskey, P. K., Rutherford, A. \& Wolfe, C. (1996). Why time flies in old age. The New Scientist, November 23.

Martin, M., Figiel, G. S. \& Mattingly, G. (1992). ECT-induced interictal delirium in patients with a history of a CVA. Journal geriatric psychiatry neurology 5, 149-155.

Martz, E. (2004). Do Reactions of Adaptation to Disability Influence the Fluctuation of Future Time Orientation Among Individuals with Spinal Cord Injuries? Rehabilitation Counseling Bulletin. Vol.47(2), pp. 86-95.

Martz, E., \& Livneh, H. (2003). Death anxiety as a predictor of future time orientation among individuals with spinal cord injuries. Disabil Rehabil, 25(18), 1024-1032.

Masiá, J. (1995). Preguntas antropológicas sobre el tiempo. En A. Dou (ed.), El Tiempo. Tiempo, relatividad y saberes. (pp. 77-99). Madrid: UPCO.

Mathey, P. (1992). Time and the depressive subject. Encephale, 18 Spec No 4, 491-496.

Matthews, G. (1988). Morningness-eveningness as a dimension of personality: Trait, state and psychopshysiological correlates. European Journal of Personality, 2, 277-293.

McClelland, D. C. (1981). Is personality consistent? En A. I. Rabin, J. Aronoff, A. M. Barclay \& R. A. Zucker (eds.). Further explorations in personality. (pp. 87-113). Nueva York: Wiley. 
McCormick, D. A. \& Williamson, A. (1989). Convergence and divergence of neurotransmitter action in human cerebral cortex. Proceedings of the national academy of sciences of the USA, 86, 8098-8102.

McDermott, O. D., Prigerson, H. G. \& Reynolds C. F. (1997). Sleep in the wake of complicated grief symptoms: an exploratory study. Biological psychiatry 41, 710-716.

McGrath, J. E. \& Kelly, J. R. (1986). Time and human interaction: Toward a social psychology of time. New York: Guilford Press.

Mecacci, L. \& Rochetti, G. (1998). Morning and evening types: stress-related personality aspects. Personality and Individual Differences, 25, 537-542.

Meck, W. H. (2005). Neuropsychology of timing and time perception. Brain and Cognition, 58, 18.

Melges, F. T. (1982). Time and the inner future: A temporal approach to psychiatric disorders. New York: Wiley.

Meluzzi, A., Gasco, A., Francesetti, G. \& Gecele, M. (1991). Time in depression. Minerva Psichiatr, 32(3), 179-188.

Merrill, K. A., Tolbert, V. E. \& Wade, W. A. (2003). Effectiveness of cognitive therapy for depression in a community mental health center: a benchmarking study. Journal of Consulting and Clinical Psychology, 71(2), 404-409.

Mezey, A. G. \& Cohen, S. I. (1961). The effect of depressive illness on time judgment and time experience. Journal of Neurology, neurosurgery and Psychiatry, 24, 269-270.

Michon, J. (1967). Tapping regularity as a measure of perceptual motor load. Ergonomics, 9, 401412.

Millar-Craig, M. W., Bishop, C. N. \& Raftery, E. B. (1978). Circadian variation of blood-pressure. Lancet, 1, 795-797.

Miller, N. E. (1951). Learnable drives and rewards. En S.S. Stevens (ed.), Handbook of experimental psychology (pp. 435-472). Nueva York: Wiley.

Mimura, M., Kinsbourne, M. \& O'Connor, M. (2000). Time estimation by patients with frontal lesions and by Korsakoff amnesics. J Int Neuropsychol Soc, 6(5), 517-528. 
Minkowski, E. (1973). El tiempo vivido. México D. F.: Fondo de Cultura Económica. (Original de 1968).

Miró, E., Cano, M. C., Espinosa-Fernandez, L., \& Buela-Casal, G. (2003). Time estimation during prolonged sleep deprivation and its relation to activation measures. Hum Factors, 45(1), 148-159.

Molero, J. (1979). Tiempo y temporalidad. Córdoba: Publicaciones del Monte de Piedad y Caja de ahorros de Córdoba.

Montangero, J. (1984). Perspectivas actuelles sur la psychogenèse du temps. L'Année Psychologique, 84, 433-460.

Montgomery S. A. \& Fineberg, N. (1989). Is there a relationship between serotonin receptor subtypes and selectivity of response in specific psychiatry illnesses? British journal of psychiatry, 155(suppl 8), 63-70.

Moore, M., Höfer, S., McGee1, H. \& Ring, L. (2005). Can the concepts of depression and quality of life be integrated using a time perspective? Health and Quality of Life Outcomes, 3,1.

Moore, R. Y. (1983). The suprachiasmatic nucleus and the organization of CNS circadian rhythm. Trends Neurosci, 5,404-407.

Morin, L. P. (1999). Serotonin and the regulation of mammalian circadian rhythmicity. Annals of medicine, 31, 12-33.

Morita, T., Fukui, T., Morofushi, M. \& Tokura, H. (2007). Subjective time runs faster under the influence of bright rather than dim light conditions during the forenoon. Physiol Behav, 91(1), 42-45.

Morita, T., Nishijima, T. \& Tokura, H. (2005). Time sense for short intervals during the follicular and luteal phases of the menstrual cycle in humans. Physiol Behav, 85(2), 93-98.

Morofushi, M., Shinohara, K. \& Kimura, F. (2001). Menstrual and circadian variations in time perception in healthy women and women with premenstrual syndrome. Neurosci Res, 41(4), 339-344.

Mueller, T. I., Leon, A. C., Keller, M. B., Solomon, D. A., Endicott, J., Coryell, W. et al. (1999). Recurrence after recovery from major depressive disorder during 15 years of observational follow-up. American Journal of Psychiatry, 156, 1000-1006. 
Mundt, C., Richter, P., van Hees, H. \& Stumpf, T. (1998). Time-experience and time-estimation in depressive patients. Nervenarzt, 69(1), 38-45.

Munzel, K., Gendner, G., Steinberg, R. \& Raith, L. (1988). Time estimation of depressive patients: The influence of interval content. European Archives of Psychiatry and Clinical Neuroscience, 237, 171-178.

Murphy, D. L., Zohar, J., Benkelfat, C. Pato, M. T., Pigott, T. A. \& Insel, T.R. (1989). Obsessivecompulsive disorder as a 5-HT subsystem-related behavioural disorder. British journal of psychiatry, 155 (8), 15-24.

Murray, G., Allen, N. B. \& Trinder, J. (2002). Mood and the circadian system: investigation of a circadian component in positive affect. Chronobiol Int, 19(6), 1151-1169.

Nakajima, T., Uchiyama, M., Enomoto, T., Shibui, K., Ishibashi, K., Kanno, O., et al. (1998). Human time production under constant routine. Psychiatry Clin Neurosci, 52(2), 240-241.

Nebel, L. E., Howell, R. H., Krantz, D. S., Falconer, J. J., Gottdiener, J. S. \& Gabbay, F. S. (1996). The circadian variation of cardiovascular stress levels and reactivity: Relationship to individual differences in morningness/ eveningness. Psychophysiology, 33, 273-281.

Neubauer, A. C. (1992). Psychometric comparison of two circadian rhythm questionnaires and their relationship with personality. Personality and Individual Differences, 13 (2), 125-131.

Noguer-Carmona S., Gallo, P., Parada, A., García-Duran, Huet M., Méndez-Vásquez, R. I. \& Suñén-Pinyol, E. (2006). Estudio bibliométrico sobre esquizofrenia en España (1999-2004): productividad, impacto y colaboración (2a Edición). Barcelona: SENYFundació.

Nordfjäll, K., Svenson, U., Norrback, K. F., Adolfsson, R., Lenner, P., et al. (2009). The individual blood cell telomere attrition rate is telomere length dependent. PLoS Genet, 5(2): e1000375. doi:10.1371/journal.pgen.1000375.

Nosachev, G. N. (1992). Perception and experience of time by patients with depression in manicdepressive psychosis and attack-like schizophrenia. Neurosci Behav Physiol, 22(2), 175178.

Noulhiane, M., Mella, N., Samson, S., Ragot, R. \& Pouthas, V. (2007). How emotional auditory stimuli modulate time perception. Emotion, 7(4), 697-704. 
Núñez, I. (1995). El desvelo de la Temporalidad. En A. Dou (ed.), El Tiempo. Tiempo, relatividady saberes. (pp. 123-126). Madrid: UPCO.

Nurnberger, J. I., Adkins, S. Lahiri, D. K., Mayeda, A., Hu, K., Lewy, A. et al. (2000).Melatonin suppresionn by light in euthymic bipolar and unipolar patients. Archives of general psychiatry, 57, 572-579.

Organización Mundial de la Salud (OMS) (1948). Clasificación internacional de las enfermedades (6 $6^{\mathrm{a}}$ edición) (CIE-10). Madrid, OMS.

Organización Mundial de la Salud (OMS) (1955). Clasificación internacional de las enfermedades (7 $7^{\mathrm{a}}$ edición) (CIE-10). Madrid, OMS

Organización Mundial de la Salud (OMS) (1965). Clasificación internacional de las enfermedades ( $8^{\mathrm{a}}$ edición) (CIE-10). Madrid, OMS

Organización Mundial de la Salud (OMS) (1978). Clasificación internacional de las enfermedades (9a edición) (CIE-10). Madrid, OMS

Organización Mundial de la Salud (OMS) (1992). Clasificación internacional de las enfermedades (10 a edición) (CIE-10). Madrid, OMS.

Ornstein, R. (1969). On the experience of time. Baltimore: Penguin.

Ornstein, R. (1977): The psychology of consciousness. N. Y: Marcout Braco Jovanovich

Ornstein, R. E. (1997). On the experience of time. Boulder: Westview Press.

Ortega y Gasset, J. (1986). Obras completas. Tomo 5. Madrid, Alianza editorial.

Owen, A. L. \& Wilson, R. R. (2006). Unlocking the riddle of time in learning disability. J Intellect Disabil, 10(1), 9-17.

Palenzuela, D. L., Prieto, G., Da Silva, L. \& De Olivera, A. (1992). Estudio transcultural de la Escala de Expectativas de Control Percibido (ECP). Proyecto de investigación. Ministerios de Asuntos Exteriores e Investigación y Ciencia. Universidad de Salamanca.

Palenzuela, D. L. (1993). Personal control: An integrative-multidimensional approach. En D. L. Palenzuela y A. M. Barrios (Eds.). Modern treds in personality theory and research. Porto: Apport. 
Palenzuela, D. L. \& Rodríguez Morejón, A. (1994). Depressogenic cognitive styles. En B. De Rad, W.K.B. Hofstee, y G.L. Van Heck (eds.), Personality Psychology in Europe (Vol. 5, pp. 274-279). Tilburg, The Netherlands: Tilburg University Press.

Partridge, B. C. \& Fox, S. H. (2000). Juvenile offenders and accurate perception of time. Percept Mot Skills, 91(3 Pt 1), 1011-1019.

Paykel, E. S. (1982). Handbook of affective disorders. New York: Guilford.

Paykel, E. S. (2007). Cognitive therapy in relapse prevention in depression. International Journal of Neuropsychopharmacology, 10, 131-136.

Pedri, S. \& Hesketh, B. (1993). Time perception: effects of task speed and delay. Percept Mot Skills, 76(2), 599-608.

Perris, C. (1987). Towards an integrating theory of depression focusing on the concept of vulnerability. Integrative psychiatry, 5, 27-32.

Pelechano, V. (2000). Psicología sistemática de la personalidad. Barcelona: Ariel.

Peters, H. P. F. (1991) Structuring scientific activities by co-author analysis. Scientometrics, 20(1), 235-255.

Pérez, A. (1995). Cronobiología. En A. Dou (ed.), El Tiempo. Tiempo, relatividad y saberes. (pp. 119-122). Madrid: UPCO.

Piaget, J. (1954). The construction of reality in the child. Nueva York: Basic Books.

Piaget, J. (1971). La epistemología del tiempo. Buenos aires: El Ateneo.

Piaget, J. (1978). El desarrollo de la noción de tiempo en el niño. México: Fondo de cultura económica.

Pittendrigh, C. (1960). Circadian rhythms and the circadian organization of living systems. Cold Spring Harbor Simposia on Quantitative Biology, 25, 159-182.

Pluck, G., Kwang-Hyuk, L., Lauder, H., Fox, J., Spence, S. \& Parks, R. (2008). Time Perspective, Depression, and Substance Misuse Among the Homeless. Journal of Psychology, Vol. 142, 159-168. 
Poland, R. E., McCracken, J. T. \& Lutchmansingh, P. (1997). Differential response of rapid eye movement sleep to cholinergic blockade by scopolamine in currently depressed, remitted and normal control subjects. Biol Psychiatry 41, 929 - 938.

Polyukhov, A. M. (1989). Subjective time estimation in relation to age, health, and interhemispheric brain asymmetry. Z Gerontol, 22(2), 79-84.

Portilla, M. P. G., Sáiz, P. A., Jiménez, L. \& Fernández, C. (2002). Epidemiología. En J. Bobes, M. Bousoño, M. P.G. Portilla \& P. A. Sáiz (eds.), Trastorno de ansiedad generaliza. (pp. 9-16). Barcelona: Ars Médica.

Pouthas, V. (1985). Timing behavior in young children: A developmental approach to conditioned spaced responding. En J. A. Michon \& J. L. Jackson (Eds.), Time, mind and bahavior (pp. 100-109). Heidelberg: Springer-Verlag.

Prabhu, G.G., Agrawal, A.K. \& Teja, J.S. (1969). Effect of anxiety and depression on time estimation and judgment. Indian Psychological Review, 6, pp. 16-21.

Predebon, J. (1995). Prospective and retrospective time estimates as a function of clock duration. Percept Mot Skills, 80(3 Pt 1), 941-942.

Pritchard, A. (1969). Statistical bibliography on bibliometrics? Journal of Documentation, Vol.1.

Putilov, A. A., Russkikh, G. S. \& Danilenko, K. V. (2000). Phese of melatonin rhythm in winter depression. En J. Olcese (ed.), Melatonin after four decades (441-458). Nueva York: Plenum Publishers.

Rammsayer, T. (1990). Temporal discrimination in schizophrenic and affective disorders: evidence for a dopamine-dependent internal clock. Int J Neurosci, 53(2-4), 111-120.

Real Academia Española (2003). Diccionario de la lengua española. Edición electrónica. Versión 1.0. Espasa Calpe, S.A.

Rehm, L. P. (1977). A self-control model of depression. Behavior Therapy, 8, 787-804.

Reifler, B. V. (2006). Play it again, Sam-Depression is recurring. New England Journal of Medicine, 354(11), 1189-1190.

Reinberg, A. E., Lewy, H. \& Smolensky, M. (2001). The birth of Chronobiology: Julien Joseph Virey 1814. Chronobiology international, 18 (2), 173-186. 
Reynolds, C. F., Shaw, D. H., Newton, T. F., Coble, P. A. \& Kupfer, D. J. (1983). EEG sleep in outpatients with generalited anxiety: a preliminary comparision with depressed outpatients. Psychiatry Research, 8, 81-90.

Rial, R., Garau, C., Aparicio, S. \& Esteban, S. (2006). Evolución, significado biológico y alteraciones del sueño. En J. A. Madrid y A. Rol de Lama (eds.), Cronobiología básica y clínica. (pp. 365-398). Madrid: Editec.

Riesen, J. M. \& Schnider, A. (2001). Time estimation in Parkinson's disease: normal long duration estimation despite impaired short duration discrimination. $J$ Neurol, 248(1), 27-35.

Rijken, M., Komproe, I. H., Ros, W. J. G., Winnubst, J. A. M. \& van Heesch, N. C. A. (1995). Subjective well-being of elderly women: Conceptual differences between cancer patients, women suffering from chronic ailments and healthy women. British Journal of Clinical Psychology, 34, 289-300.

Rioux, I., Tremblay, S., \& Bastien, C. H. (2006). Time estimation in chronic insomnia sufferers. Sleep, 29(4), 486-493.

Roca, M. (2004). Trastornos de la personalidad. Barcelona: Wyeth.

Romera Iruela, M. J. (1992). Potencialidad de la bibliometría para el estudio de la ciencia: aplicación a la educación especial. Revista de educación, 297, pp. 459-478.

Rosa, A. \& Travieso, D. (2002). El tiempo del reloj y el tiempo de la acción. Introducción al número monográfico sobre Tiempo y Explicación Psicológica. Estudios de Psicología, 23 (1), 7-15.

Rosenbaum, J. F., Fava, M. \& Nierenberg, A. A. (1995). Treatment-resistant mood disorders. En Gabbard, G. O. (ed.) Treatment of psychiatric disorders (1275-1328), Washington DC, American Psychiatric Press.

Rosenthal, N. E., Sack, D. A., Gillin, J. C., Lewy, A. J., Goodwin, F. K., Davenport, Y. N. et al. (1984). Seasonal affective disorder. Archives of general psychiatry, 41, 72-80.

Rothspan, S. \& Read, S. J. (1996). Present versus future time perspective and HIV risk among heterosexual college students. Health Psychol, 15(2), 131-134.

Roy, M. \& Christenfeld, N. J. (2007). Bias in memory predicts bias in estimation of future task duration. Mem Cognit, 35(3), 557-564. 
Roy, M., Christenfeld, N. J. \& McKenzie, C. R. (2005). Underestimating the duration of future events: memory incorrectly used or memory bias? Psychol Bull, 131(5), 738-756.

Roy, M., Mitten, S. T. \& Christenfeld, N. J. S. (2008). Correcting memory improves accuracy of predicted task duration. Journal of Experimental Psychology: Applied, 14(3), 266-275.

Roy-Byrne, P. P., Cowley, D. S., Greenblatt, D. J., Shader, R. I. \& Hommer, D. (1990) Reduced benzodiazepine sensitivity in panic disorder. Archives of general psychiatry, 47(6),534-538.

Rueda, A. D. \& Schmitter-Edgecombe, M. (2009). Time estimation abilities in mild cognitive impairment and Alzheimer's disease. Neuropsychology, 23(2), 178-188.

Rudd, M. D., Dahm, P. F. \& Rajab, M. H. (1993).Diagnostic comorbidity in persons with suicidal and behavior. American Journal of Psychiatry, 150, 928-934.

Rustig, C. L. \& Larsen, R. J. (1998). Diurnal patterns of unpleasant mood: associations with neuroticism, depression and anxiety. Journal of personality, 66, 85-103.

San Agustín, (1968). Las confesiones. Barcelona: Editorial Juventud (Obra original del año 397400 d. C.).

Sandín, B. (1995). Teorías sobre los trastornos de ansiedad. En A. Belloch, B. Sandín y F. Ramos (eds.), Manual de Psicopatología, Vol. 2. (pp. 113-169) Madrid: McGraw-Hill.

Sandín, B. (2008). Teorías sobre los trastornos de ansiedad. En A. Belloch, B. Sandín y F. Ramos (eds.), Manual de Psicopatología, Vol. 2. (pp. 113-169) Madrid: McGraw-Hill.

Sandín, B. \& Chorot, P. (1991). Psicopatología de la ansiedad. En A. Belloch y E. Ibáñez (eds.), Manual de Psicopatología (pp. 605-668). Valencia: Promolibro.

Sandín, B. \& Chorot, P. (1995). Síndromes clínicos de la ansiedad. En A. Belloch, B. Sandín y F. Ramos (eds.), Manual de Psicopatología, Vol. 2. (pp.81-112), Madrid: McGraw-Hill.

Sandín, B. \& Chorot, P. (2008). Síndromes clínicos de la ansiedad. En A. Belloch, B. Sandín y F. Ramos (eds.), Manual de Psicopatología, Vol. 2. (pp.81-112), Madrid: McGraw-Hill.

Sánchez, Ma P. (1999). Temporalidad, cronopsicología y diferencias individuales. Madrid: Centro de Estudios Ramón Areces. 
Sancho, R. (1990). Indicadores bibliométricos utilizados en la evolución de la ciencia y la tecnología. Revista Española de Documentación Científica, 3-4, 842-865.

Santo-Domingo, J., Baca, E., Carrasco, J. L. \& García-Camba, E. (2002). Manual de psiquiatría. Barcelona: Ars Médica.

Sanz, J. \& Vázquez, C. (1995). Trastornos del estado de ánimo: Teorías psicológicas. En A. Belloch, B. Sandín y F. Ramos (eds.), Manual de Psicopatología, Vol. 2. (pp. 341-378), Madrid: McGraw-Hill.

Sanz, J. \& Vázquez, C. (1998). Fiabilidad, validez y datos normativos del Inventario para la Depresión de Beck. Psicothema, 10 (2), 303-318.

Sanz, J. \& Vázquez, C. (2008). Trastornos del estado de ánimo: Teorías psicológicas. En A. Belloch, B. Sandín y F. Ramos (eds.), Manual de Psicopatología, Vol. 2. (pp. 341-378), Madrid: McGraw-Hill.

Schildkraut, J. J. (1965). The catecholamine hipotesis of affective disorders: a review of supporting evidence. American Journal of Psychiatry, 122, 509-514.

Schmitter-Edgecombe, M. \& Rueda, A. D. (2008). Time estimation and episodic memory following traumatic brain injury. Journal of Clinical and Experimental Neuropsychology, 30(2), 1-12.

Seligman, M. E. P. (1975). Indefensión. Madrid: Debate.

Seligman, M. E. P. (1989). Explanatory style: Predicting depression, achievement, and health. En M.D. Yapko (ed.). Brief Therapy Approaches to Treating Anxiety and Depression (pp. 532). NewYork: Brunner/Mazel.

Seligman, M. E. P. \& Jonhnston, J. C. (1973). A cognitive theory of avoidance learning. En F. J. McGuigan \& Lumsden (eds.). Contemporary approaches to condictioning and learning (pp. 60-110). Washington, DC: Winston.

Seri, Y., Kofman, O. \& Shay, L. (2002). Time estimation could be impaired in male, but not female adults with attention deficits. Brain Cogn, 48(2-3), 553-558.

Severino, S. K., Wagner, D. R., Moline, M. L. Hurt, S. W., Pollack, C. P. \& Zendell, S. (1991). High nocturnal body temperature in premenstrual syndrome and late luteal phase dysphoric disorder. American journal of psychiatry, 148, 1329-1335. 
Sevigny, M. C., Everett, J. \& Grondin, S. (2003). Depression, attention, and time estimation. Brain Cogn, 53(2), 351-353.

Shea, M. T. \& Hirschfeld, R. M. A. (1996). Chronic mood disorder and depressive personality. Psychiatric Clinics of North America, 19, 103-119.

Shmotkin, D. (1991). The role of time orientation in life satisfaction across the life-span. Journal of Gerontology: Psychological Sciences, 46, 243-250.

Siever, L. J. \& Davis, K. L. (1985). Overview: toward a dysregulation hypothesis of depression. American Journal of Psychiatry, 142, 1017-1025.

Skinner, B. F. (1953). Science and human behaviour. Nueva York, MacMillan. Edición en castellano: Ciencia y Conducta humana. Barcelona: Martinez-Roca, 1970.

Skinner, B. (1979). Contingencias de Reforzamiento: Un Análisis Teórico. México: Editorial Trillas.

Smith, A. C., McGavran, L., Robinson, J., Waldstein, G., Macfarlane, J., Zonana, J., Reiss, J., Lahr M., Allen, L. \& Magenis E. (1986). Interstitial deletion of (17)(p11.2p11.2) in nine patients. Am J Med Genet, 24, 393-414.

Smith, C., Reilly, C. \& Midkiff, K. (1989). Evaluation of three circadian rhytm questionnaires with suggestions for an improved of morningness. Journal of Aplied Psychology, 74, 728-738.

Smith, R. S., Guilleminault, C. \& Efron, B. (1997). Circadian rhythms and enhanced athletic performance in the national football league. Sleep, 20 (5), 362-365.

Smoski, M. J., Felder, J., Bizzell, J., Green, S. R., Ernst, M., Lynch, T. R \& Dichter, G. S. (2009). fMRI of alterations in reward selection, anticipation, and feedback in major depressive disorder. Journal Of Affective Disorders, Vol. 118 (1-3), 69-78.

Sokolow, M., Werdegar, D., Kaim, H. K. \& Hinman, A. T. (1996). Relationship between level of blood pressure measured casually and by portable recorders and severity of complications in essential hypertension. Circulation, 34, 279-298.

Spielberger, C. D. (1966). Anxiety and behavior. New York, Academic Press.

Speilberger, C. D. (1972). Anxiety as an emotional state. En C. D. Spielberger (Ed.), Anxiety current trends in theory and research. New York, Academic Press. 
Spielberger, C. D., Gorsuch, R. T. \& Lushene, R. E. (1994). Cuestionario de Ansiedad EstadoRasgo. Madrid: TEA (Obra original de 1968).

Spielberger, C. D. Jacobs, G. Russell, S. \& Crane, R. (1983). Assessment of anger: The StateTrait Anger Scale. En J. N. Butcher \& C. D. Spielberger (Eds.), Advances in personality assessment (Vol. 2, pp. 159-187) Hillsdale, NJ: Lawrence Erlbaum Associates.

Spielberger, C. D., Pollans, C. H. \& Worden, T. J. (1984). Anxiety disorders. En S. M. Turner \& M. Hersen (Eds.), Adult psychopathology and diagnosis, pp 262-303. New York: Wiley.

Stern, D. N. \& Gibbon, J. (1979). Temporal expectations of social behavior in mother-infant play. En E. B. Thoman (Ed.), Origins of the infant's social responsiveness. Hillsdale, N. Y.: Erlbaum.

Stine, M. M., O'Connor, R. J., Yatko, B. R., Grunberg, N. E. \& Klein, L. C. (2002). Evidence for a relationship between daily caffeine consumption and accuracy of time estimation. Hum Psychopharmacol, 17(7), 361-367.

Suomi, S. J., Seaman, S. F. \& Lewis, J. K. (1978). Effects on imipramine treatment of separationinduced social disorders in rhesus monkeys. Archives Gen Psychiatry 35, 321-325.

Tang, N. K. \& Harvey, A. G. (2005). Time estimation ability and distorted perception of sleep in insomnia. Behav Sleep Med, 3(3), 134-150.

Tankova, I., Adan, A. \& Buela-Casal, G. (1994). Circadian typology and individual differences. A review. Personality an Individual Differences, 16 (5), 671-684.

Taylor, L. \& Ingram, R. E. (1999). Cognitive reactivity and depressotypic information processing in children of depressed mothers. Journal of Abnormal Psychology, 108(2), 202-210.

Teasdale, J. D. (1988). Cognitive vulnerability to persistent depression. Cognition and Emotion, 2, 247-274.

Teicher, M. H., Glod, C. A. \& Magnus, E. (1997). Circadian rest-activity disturbances in seasonal affective disorder. Archives Generals of Psychiatry, 54, 124-130.

Terrada, M. L. (1973). La literatura médica española contemporánea. Estudio estadístico y sociométrico. Valencia: Centro de Documentación e Información Médica.

Testu, F. (1989). Cronopsychologie et rytmes scolaires. París : Masson. 
Thase, M. E. \& Kupfer D. J. (1996). Recent developments in the pharmacotherapy of mood disorders. Journal Consultant of Clinical Psychology 64, 646-659.

Thelen, E. (1979). Rhythmical stereotypies in normal human infants. Animal behavior, 27, 699-715.

Thelen, E. (1981). Rhythmical behavior in infancy: An ethological perspective. Developmental Psychology, 17, 237-257.

Thomas, E. A. C. \& Weaver, W. B. (1975). Cognitive processing and time perception. Perception and Psychophysics, 17, 363-367.

Thompson, S. C. \& Collins, M. A. (1995). Applications of perceived control to cancer: an overview of therory and measurement. Journal of Psychosocial oncology, 13, 2, 11-26.

Thorne, F. C. (1966). Theory of the psychological state. Journal of clinical psychology, 22, 127135.

Tice, D. M. \& Baumeister, R. F. (1997). Longitudinal study of procrastination, performance, stress and health: the costs and benefits of dawdling. Psychological Science, 8 (6), 454-458.

Tipples, J. (2008). Negative emotionality influences the effects of emotion on time perception. Emotion, 8(1), 127-131.

Tobin, S., \& Grondin, S. (2009). Video games and the perception of very long durations by adolescents. Computers in Human Behavior, 25(2), 554-559.

Triesman, M. (1963). Temporal discrimination and the indifference interval: Implications for a model of the internal clock. Psychological monograph, 77, 576, número entero.

Tse, P. U., Intriligator, J., Rivest, J. \& Cavanagh, P. (2004). Attention and the subjective expansion of time. Percept Psychophys, 66(7), 1171-1189.

Turco, T. L. \& Stamps, L. E. (1980). Heart rate conditioning in young infants using a visual conditional stimulus. Journal of experimental child psychology, 29, 117-125.

Twenge, J. M., Catanese, K. R. \& Baumeister, R. F. (2003). Social exclusion and the deconstructed state: time perception, meaninglessness, lethargy, lack of emotion, and self-awareness. $J$ Pers Soc Psychol, 85(3), 409-423. 
Uhde, T. W., Roy-Byrne, P., Gillin, J. C., Mendelson, W. B., Boulenger, J. P., Vittone, B. J. et al. (1984). The sleep of patients with panic disorder: a preliminary report. Psychiatry Research, 12(3):251-259.

Unrug-Neervoort, A., Kaiser, J. \& Coenen, A. (1992). Influence of diazepam on prospective time estimation. Percept Mot Skills, 75(3 Pt 1), 993-994.

Urretavizcaya, M., Soria, V. \& Cambras, T. (2006). Ritmos biológicos y enfermedad mental. En J. A. Madrid y A. Rol de Lama (eds.), Cronobiología básica y clínica. (pp. 777-807). Madrid: Editec.

Vallejo, J. (2006). Introducción a la psicopatología y la psiquiatría. Barcelona, Masson, SA.

Vallejo, J. \& Crespo, J. M. (1999). Afrontar la depresión. Barcelona, J\&C.

Vallejo Pareja, M., Comeche Moreno, Mª. I., Ortega Pardo, J., Rodríguez Muñoz, Mª \& Díaz García, M. (2009). Las expectativas de autoeficacia y el ajuste emocional en el afrontamiento de la fibromialgia. Escritos de psicología, Vol. 2 (2), 28-34.

Van Cauter, E., Linkowski, P., Kerkhofs, M., Hubain, P., L'Hermite Baleriaux, M., Leclerqc, R. et al. (1991). Circadian and sleep-related endocrine rhythms in schizophrenia. Archives of general psychiatry, 48, 348-356.

Van Cauter, E. \& Turek, F. (1986). Depresión: a disorder of timekeeping? Perspectives in biology and medicine, 29, 510-519.

Van den Hoofdakker, R. H. (1994). Chronobiological theories of nonseasonal affective disorders and their implitacions for treatment. Journal of biological rhythms, 9, 157-183.

Vázquez, C., Nieto, M., Hernangómez, L. \& Hervás, G. (2005). Tratamiento psicológico en un caso de depresión mayor. En J. P. Espada, J. Olivares, J. y F. X. Méndez (eds.). Terapia psicológica: Casos prácticos (pp. 201-231). Madrid: Pirámide.

Vázquez C. \& Sanz, J. (1995). Trastornos del estado de ánimo: Aspectos clínicos. En A. Belloch, B. Sandín y F. Ramos (eds.), Manual de Psicopatología, Vol. 2. (pp. 299-340) Madrid: McGraw-Hill.

Vázquez C. \& Sanz, J. (2008). Trastornos del estado de ánimo: Aspectos clínicos. En A. Belloch, B. Sandín y F. Ramos (eds.), Manual de Psicopatología, Vol. 2. (pp. 299-340) Madrid: McGraw-Hill. 
Vázquez, C. \& Siles, S. (1999). Depresión parental y filial: Factores de riesgo, efectos mutuos, y una propuesta explicativa. En J. Buendía (Ed.). Familia y psicología de la salud (pp. 203236). Madrid: Pirámide.

Venneri, A., Pestell, S. \& Nichelli, P. (2003). A preliminary study of the cognitive mechanisms supporting time estimation. Perceptual and Motor Skills, 96(3,Pt2), 1093-1106.

Villapecellín, A. (1995). Percepción del tiempo. En A. Dou (ed.), El Tiempo. Tiempo, relatividad y saberes. (pp. 127-132). Madrid: UPCO.

Vohs, K. D. \& Schmeichel, B. J. (2003). Self-regulation and the extended now: controlling the self alters the subjective experience of time. J Pers Soc Psychol, 85(2), 217-230.

Von Kirchenheim, C. \& Persinger, M. A. (1991). Time distortion: A comparison of hypnotic induction and progressive relaxation procedures: A brief communication. International Journal of Clinical and Experimental Hypnosis, Vol, 39(2), 63-66.

Watt, J. D. (1991). Effect of boredom proneness on time perception. Psychol Rep, 69(1), 323-327.

Wearden, J. H., Edwards, H., Fakhri, M. \& Percival, A. (1998). Why "sounds are judged longer than lights": Application of a model of the internal clock in humans. Quarterly Journal of Experimental Psychology Section B-Comparative and Physiological Psychology, 51(2), 97120.

Wearden, J. H., Norton, R., Martin, S. \& Montford-Bebb, O. (2007). Internal clock processes and the filled-duration illusion. J Exp Psychol Hum Percept Perform, 33(3), 716-729.

Wearden, J. H., Todd, N. P. \& Jones, L. A. (2006). When do auditory/visual differences in duration judgements occur? Q J Exp Psychol (Colchester), 59(10), 1709-1724.

Wehr, T. A. \& Wirz-Justice, A. (1982). Circadian mechanisms in affective illnes and in antidepressant drug action. Pharmacopsychiatry, 15, 317-326.

Weissman, M. M., Bland, R. C. \& Camino, G, J. (1996). Cross-national epidemiology of major depression and bipolar disorder. JAMA, 276, 293-299.

Weitzman, E. D., Zimmerman, J. C. \& Czeisler, C. A. (1983). Cortisol secretion is inhibited during sleep in normal man. Journal Clinical Endocrinology Metabolism, 56, 352-358. 
Wever, R. A. (1985). Internal interactions within the human circadian system: the másking effect. Experientia, 41, 332-342.

Whybrow, P. C. (1996). The Hatherleigh guide to managing depression. Nueva York: Hatherleigh Press.

Whybrow, P. C., Akiskal, H. S. \& McKinney, W. T. (1984). Mood disorder: Toward a new psychobiology. Nueva York: Plenum.

Wilson, G.D. (1990). Personality, time of day and visual perception: preferences and selective attention. Personality and Individual Differences, 9, 345-352.

Wirz-Justice, A. (2003). Chronobiology and mood disorders. Dialogues in clinical neurosciences, $5,351-325$.

Wittmann, M. \& Paulus, M. P. (2008). Decision making, impulsivity and time perception. Trends in Cognitive Sciences, 12(1), 7-12.

Wittmann, M., Vollmer, T., Schweiger, C. \& Hiddemann, W. (2006). The relation between the experience of time and psychological distress in patients with hematological malignancies. Palliat Support Care, 4(4), 357-363.

Wolpe, J. (1972/1979). Neurosis. En W. Arnold, H. J. Eysenck \& R. Meili (Eds.), Diccionario de psicología. (pp 404-408). Madrid: Ediciones Rioduero.

Woodward, A. M. (1977). The roles of reviews in information transfer. Journal of the American Society of Information Science, 28(3), 175-180.

Yannielli, P. C. (2007). Cronobiología de la ansiedad y de la depresión. En D. A. Golombek (Ed.). Cronobiología humana. Ritmos y relojes biológicos en la salud y en la enfermedad (pp. 251-275). Bernal, Buenos Aires: Universidad Nacional de Quilmes.

Yarcheski, A., Mahon, N. E., Yarcheski, T. J. \& Cannella, B. L. (2004). A meta-analysis of predictors of positive health practices. Journal of Nursing Scholarship, Vol. 36 (2), 102-8.

Yerkes, R. M. \& Dobson, J.D. (1908). The relation of strength of stimulus to rapidity oh habit formation. Journal of comparative Neurology of Psychology, 18, 459-482.

Ziman, J. (1980). Teaching and learning about science and society. Cambridge: Cambridge University Press. 
Zimbardo, P. G. \& Boyd, N. (1999). Putting time in perspective: a valid, reliable, individualdifferences metric. Journal of Personality and Social Psychology, 17(6), 1.271-1.288.

Zimbardo, P. G., Keough, K. A. \& Boyd, J. N. (1997). Present time perspective as a predictor of risky driving. Personality Individual Differences, 23, 1007-1023.

Zimbardo, P. G., Marshall, G., White, G. \& Maslach, C. (1973). Objective assessments of hyponotically induced time distorsion. Science, 181, 282-284.

Zinbarg, R. E., Barlow, D. H. \& Liebowitz, M. (1994). The DSM-IV field trial for mixed anxietydepression. American Journal of Psychiatry, 151, 1153-1162. 